DOC.20041020.0015

QA: QA

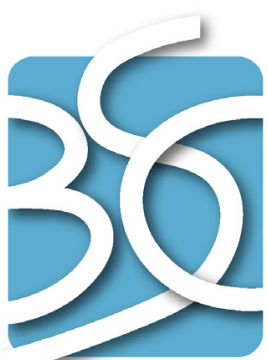

BECHTEL

SAIC COMPANYLC

ANL-EBS-MD-000016 REV 02

October 2004

\title{
Defense HLW Glass Degradation Model
}

Prepared for:

U.S. Department of Energy

Office of Civilian Radioactive Waste Management

Office of Repository Development

1551 Hillshire Drive

Las Vegas, Nevada 89134-6321

Prepared by:

Bechtel SAIC Company, LLC

1180 Town Center Drive

Las Vegas, Nevada 89144

Under Contract Number

DE-AC28-01RW12101 


\section{DISCLAIMER}

This report was prepared as an account of work sponsored by an agency of the United States Government. Neither the United States Government nor any agency thereof, nor any of their employees, nor any of their contractors, subcontractors or their employees, makes any warranty, express or implied, or assumes any legal liability or responsibility for the accuracy, completeness, or any third party's use or the results of such use of any information, apparatus, product, or process disclosed, or represents that its use would not infringe privately owned rights. Reference herein to any specific commercial product, process, or service by trade name, trademark, manufacturer, or otherwise, does not necessarily constitute or imply its endorsement, recommendation, or favoring by the United States Government or any agency thereof or its contractors or subcontractors. The views and opinions of authors expressed herein do not necessarily state or reflect those of the United States Government or any agency thereof. 
QA: QA

\section{Defense HLW Glass Degradation Model ANL-EBS-MD-000016 REV 02 \\ October 2004}




\section{OCRWM}

\section{Model Signature Page/Change History}

2. Type of Mathematical Model

$\triangle$ Process Model

Abstraction Model

System Model

Describe Intended Use of Model

Calculate the release rate of radionuclides from defense high-level waste glass following breach of the canister in the repository.

3. Title

Defense HLW Glass Degradation Model

4. DI (including Rev. No., if applicable):

ANL-EBS-MD-000016 REV 02

\section{Total Appendices}

Five (5)

\begin{tabular}{|l|l|l|}
\hline 7. Originator & Printed Name & Denis Strachan \\
\hline $\begin{array}{l}\text { 8. Independent Technical } \\
\text { Reviewer }\end{array}$ & Pasu Pasupathi \\
\hline 9. Checker & Jim Cunnane \\
\hline 10. QER & Darrell Svalstad \\
\hline 11. Responsible Manager/Lead & Dennis Thomas \\
\hline 12. Responsible Manager & Neil Brown
\end{tabular}

13. Remarks

\section{Change History}

\begin{tabular}{|c|l}
\hline 14. Revision No. & 15. Description of Change \\
\hline 00 & Initial Issue
\end{tabular}

Provide a graphical comparison in section 6.4 of degradation rates calculated from the derived model with experimental values to show that the model is conservative. Replace Table 6 with a graphical representation of degradation rate of glass as a function of temperature and $\mathrm{pH}$ calculated from the recommended correlations.

$00 / 01$ Discuss the validity of the Knauss et al. 1990 data for model development in section 4. Make some needed editorial corrections and change the specific surface area units in Table 6 column 6 from $\mathrm{m}^{2} / \mathrm{g}$ to $\mathrm{m}^{2} / \mathrm{kg}$. Address NRC comments regarding use of boron for degradation in acidic solutions instead of silicon and selection of $\log$ keff $=9$ instead of 10 for acidic solutions

$00 / 02$

Change the use of the two DTNs involving the glass degradation data, obtained from the Knauss et al. (1990) reference, from Input Data and Parameters (Section 4.1) to Assumptions (Section 5, Assumption 5.) and change its classification in the DIRS to Corroborating Information. Justify the Assumption through reference to 


\begin{tabular}{|l|l|l|}
\hline \multirow{2}{*}{ OCRWM } & Model Change History (ContinUed) & Page iv \\
\cline { 3 - 3 } & 1. Total Pages: 206 \\
\hline
\end{tabular}

\section{Title \\ Defense HLW Glass Degradation Model}

4. DI (including Rev. No., if applicable):

ANL-EBS-MD-000016 REV 02

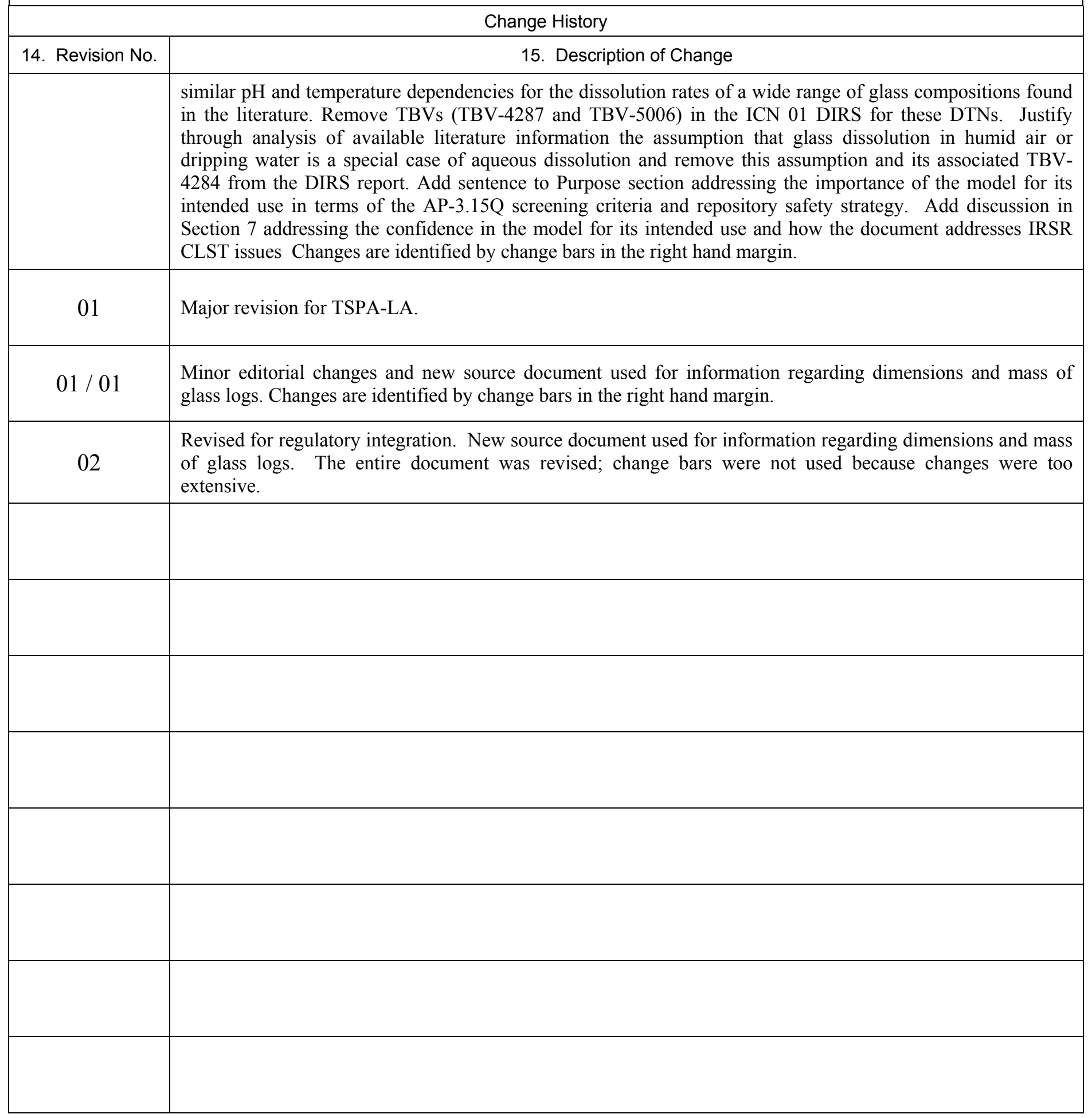




\section{CONTENTS}

Page

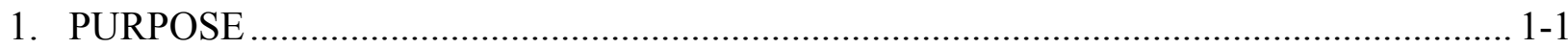

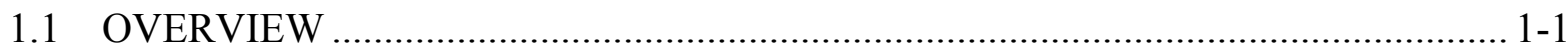

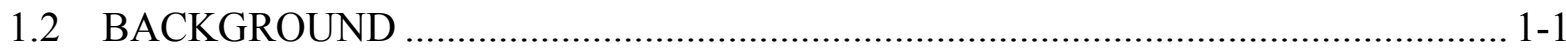

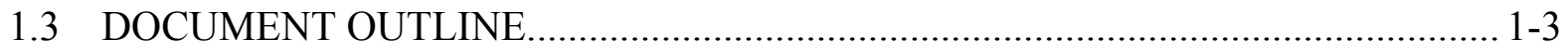

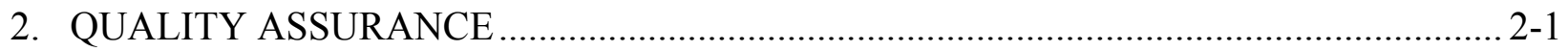

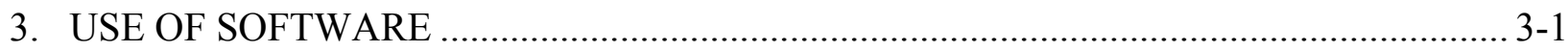

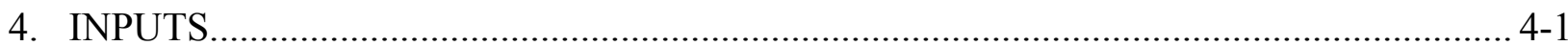

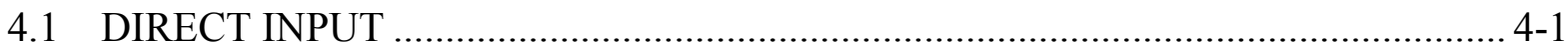

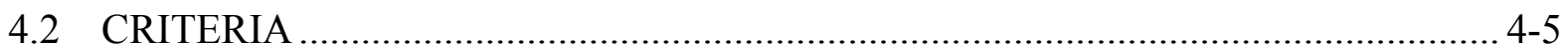

4.3 CODES, STANDARDS, AND REGULATIONS .................................................. 4-6

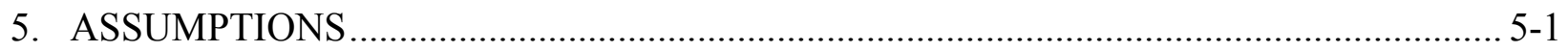

5.1 WATER HAS ACCESS TO SOME OF THE CRACK SURFACES ......................... 5-1

5.2 A PH VALUE FOR CONDENSED WATER ON GLASS OF 10 IS USED

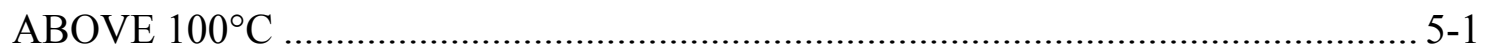

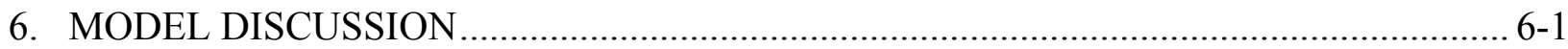

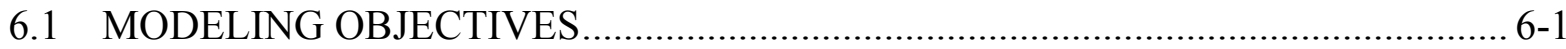

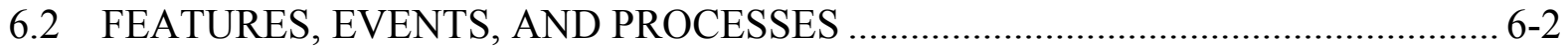

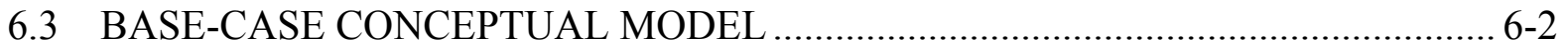

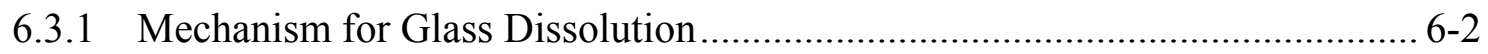

6.3.2 Simplifications Used in the Glass Degradation Model..................................... 6-7

6.3.3 Uncertainties in the Subsystem and Environment ......................................... 6-8

6.4 CONSIDERATION OF ALTERNATIVE CONCEPTUAL MODELS …….............. 6-8

6.4.1 Diffusion-Controlled Release ................................................................. 6-8

6.4.2 Composition-Independent Effective Rate Constant......................................... 6-10

6.5 BASE-CASE GLASS DISSOLUTION MODEL ……….................................... 6-11

6.5.1 Mechanistic Rate Expression for Aqueous Dissolution.................................. 6-12

6.5.2 Determination of Model Parameter Values for TSPA-LA ............................. 6-15

6.5.3 Dissolution of Glass Exposed to Humid Air or Dripping Water .................... 6-28

6.5.4 Calculation of the Exposed Surface Area of Waste Glass ............................... 6-44

6.5.5 Application of Base Case Model to Heterogeneous Glasses and GlassCrystalline Composites ............................................................................. 6-48

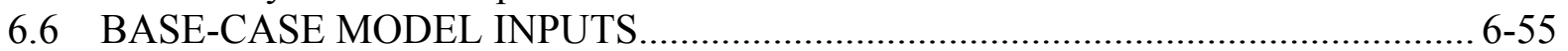

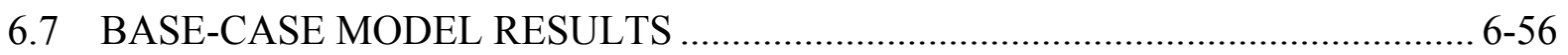

6.8 UNCERTAINTY AND VARIABILITY ......................................................... 6-58

6.8.1 Uncertainty in Surface Area of Glass Contacted by Water ............................ 6-58

6.8.2 Uncertainty in the Glass Degradation Model.............................................. 6-60

6.8.3 Uncertainty in Stoichiometric Releases of Radionuclides.............................. 6-61

6.8.4 Impact of Input Variable Uncertainty ........................................................... 6-61 


\section{CONTENTS (Continued)}

Page

6.8.5 Impacts of Uncertainty on Scientific Analysis Output ................................... 6-61

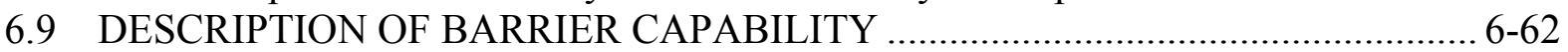

6.9.1 Analysis of DHLW Glass Barrier Capability ............................................... 6-62

6.9.2 Summary of Barrier Capability of DHLW Glass .......................................... 6-66

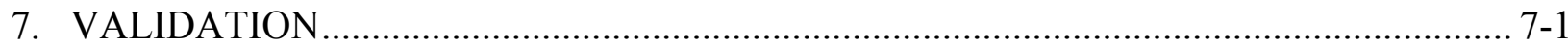

7.1 VALIDATION OF THE FORM OF THE GENERAL GLASS DEGRADATION

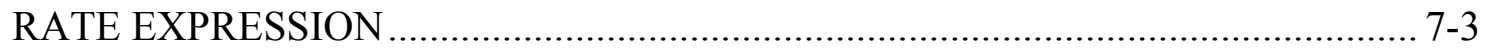

7.2 VALIDATION OF THE FINAL DEGRADATION RATE EXPRESSION ............... 7-4

7.3 COMPARISON OF PARAMETER VALUES FOR DEGRADATION MODEL WITH VALUES FOR OTHER GLASSES ........................................................ 7-6

7.3.1 Dependence on $\mathrm{pH}$ and Temperature....................................................... 7-6

7.3.2 Tests with CSG Glass ……………………............................................ 7-7

7.3.3 Tests with LD6-5412 Glass ……………….............................................. 7-8

7.3.4 Tests with R7T7 Glass ......................................................................... 7-9

7.3.5 Tests with Magnox Glass ....................................................................... 7-11

7.3.6 Tests with Binder Glass ............................................................................ 7-12

7.4 COMPARISON OF THE EXPOSED SURFACE AREA PARAMETER RANGE TO LITERATURE DATA …………………….......................................

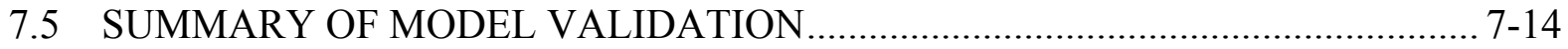

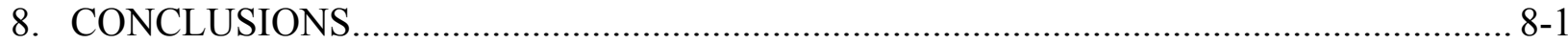

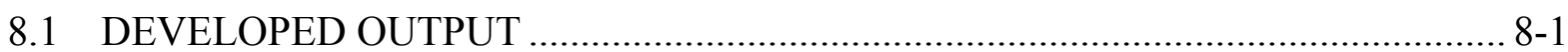

8.2 OUTPUT UNCERTAINTY AND DISTRIBUTIONS ………….......................... 8-5

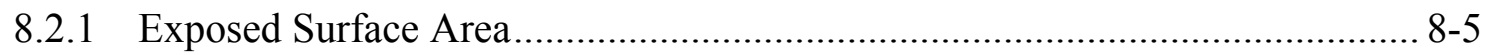

8.2.2 Glass Degradation Rate....................................................................... 8-5

8.2.3 Radionuclide Release Rates...................................................................... 8-6

8.2.4 Impact of Input Uncertainties on Output ..................................................... 8-6

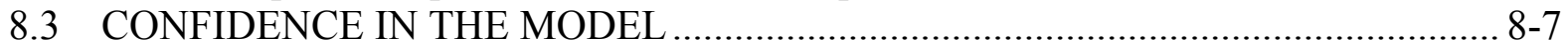

8.4 NRC ACCEPTANCE CRITERIA...................................................................... 8-7

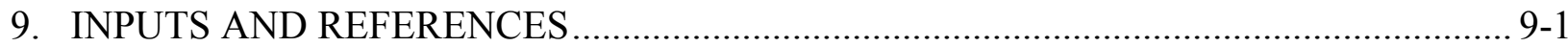

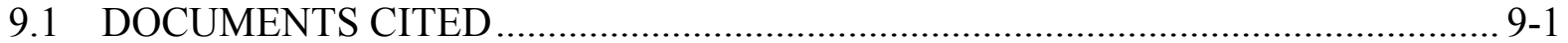

9.2 CODES, STANDARDS, REGULATIONS, AND PROCEDURES ……................. 9-14

9.3 SOURCE DATA, LISTED BY DATA TRACKING NUMBER …………............... 9-15

9.4 OUTPUT DATA, LISTED BY DATA TRACKING NUMBER …………….......... 9-16

APPENDIX A PH AND TEMPERATURE DEPENDENCE OF THE FORWARD DISSOLUTION RATE OF SRL 202G GLASS......................................... A-1

APPENDIX B EXTRACTION OF $\log _{10}\left(\mathrm{k}_{\mathrm{E}}\right)$ FROM MEASURED DISSOLUTION RATES AND CALCULATION OF RATES 


\section{CONTENTS (Continued)}

Page

APPENDIX C VAPOR HYDRATION TESTS …………………………………...............

APPENDIX D HIGH-LEVEL RADIOACTIVE WASTE GLASS ALTERATION

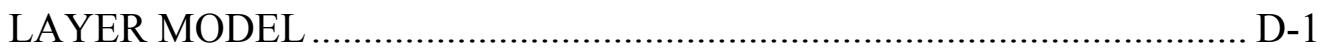

APPENDIX E EVALUATION OF DATA IN KNAUSS ET AL. 1990 [DIRS

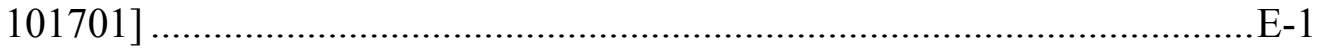

APPENDIX F DATA QUALIFICATION REPORT FOR DTN: MO0408ANLGNN01.527 ...................................................................

APPENDIX G DATA QUALIFACTION PLAN ……………………………………....... G-1 


\section{INTENTIONALLY LEFT BLANK}




\section{FIGURES}

Page

6-1. Linear Regression of Test Results at $70^{\circ} \mathrm{C}$ and Combined Results for Tests With and Without Added Iron at $90^{\circ} \mathrm{C}$ in (a) Acidic Solutions and (b) Alkaline Solutions... 6-18

6-2. Plot of Measured Rates and Regressed Lines Against $\mathrm{pH}$ Measured at Room Temperature

6-3. Sorption Isotherm for Water on SRL 165 Glass at Room Temperature...................... 6-28

6-4. Typical Cross Section of Vapor-Hydrated Glass................................................... 6-33

6-5. $\quad$ Layer Thicknesses in VHTs with SRL 131-TDS Glass at $200^{\circ} \mathrm{C}$ with Various Amounts of Demineralized Water

6-6. Measured Layer Thickness and Corrosion Rates in Standard VHTs with (a) SRL 51S Glass and (b) SRL 131-TDS and SRL 165 Glasses

6-7. Arrhenius Plot for Measured Rates for Glasses in Standard VHTs.......................... 6-38

6-8. Cumulative Boron Release in Tests with (a) SRL 165 Glass and (b) ATM-10 Glass... 6-41

6-9. Forward Dissolution Rate [NR(Si)] versus $\mathrm{pH}$ for Sodalite, Binder Glass, and CWF at $90^{\circ} \mathrm{C}$

6-10. Results of PCT Conducted with As-Received Binder Glass, PC Binder Glass, and PC CWF Composite at (a) $\mathrm{S} / \mathrm{V}=2,300 \mathrm{~m}^{-1}$ and (b) $\mathrm{S} / \mathrm{V}=23,000 \mathrm{~m}^{-1}$....

6-11. Comparison of Releases of $(\bullet) \mathrm{B},(\diamond) \mathrm{Na},(\square) \mathrm{Tc},(\diamond) \mathrm{Np},(\nabla) \mathrm{Pu}$, and $(\Delta) \mathrm{Am}$ in Immersion Tests with (a) ATM-8 Glass, (b) an SRP Glass, (c) SRL 131A Glass, and (d) SRL 202A Glass

6-12. Normalized Mass Losses for (a) Tc and $\mathrm{Np}$ and (b) Pu and Am versus Normalized Mass Loss of Boron for Each Sample in Tests N2-9, N2-10, and N2-12 with SRL 165 Glass.

7-1. Measured NR(Si) from Single-Pass Flow-Through Tests with CSG Glass ................. 7-8

7-2. Results of Single-Pass Flow-Through Tests with LD6-5412 Glass ............................ 7-9

7-3. Arrhenius Plot for Dissolution of R7T7 Glass........................................................ 7-10

7-4. Results of MCC-1 Tests with R7T7 Glass for $(\diamond) \mathrm{B},(\boldsymbol{\square}) \mathrm{Na}$, and $(\bullet) \mathrm{Si} \ldots \ldots \ldots \ldots \ldots \ldots . . . . . . .11$

7-5. Results of Tests with MW Glass at $60^{\circ} \mathrm{C}$ and $90^{\circ} \mathrm{C}$................................................ 7-12

7-6. Results of MCC-1 Tests with Binder Glass ............................................................. 7-13 


\section{TABLES}

Page

1-1. Document Outline ............................................................................................... 1-3

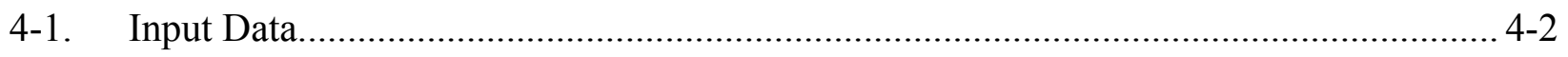

4-2. Input Parameters ………………………….................................................. 4-3

4-3. YMRP Acceptance Criteria Applicable to This Report................................................ 4-5

6-1. Features, Events, and Processes (FEPs) Included in this Report................................... 6-2

6-2. Alternative Conceptual Models Considered ............................................................ 6-8

6-3. Corroborative/Supporting Information Used to Develop Models ................................. 6-12

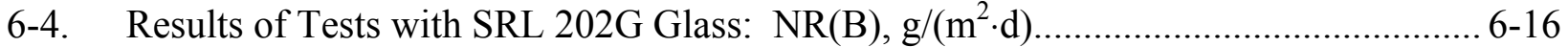

6-5. Compositions and Dissolution Rates of Glasses Used in MCC-1 Tests......................... 6-21

6-6. Values of $\mathrm{k}_{\mathrm{PCT}}$ Extracted from 7-day PCTs ........................................................... 6-23

6-7. Values of $\mathrm{k}_{\max \text {, alkaline }}$ Calculated Using Different Options........................................... 6-27

6-8. Corrosion Rates Measured in Standard VHTs ........................................................ 6-38

6-9. Effects of Devitrification on Glass Durability ............................................................. 6-49

6-10. Effect of Nepheline on Glass Durability ............................................................. 6-50

6-11. Forward Dissolution Rates for Sodalite, Binder Glass, and CWF at $90^{\circ} \mathrm{C} \mathrm{..................} \mathrm{6-52}$

6-12. Data for PCTs with CWF and Binder Glass …….................................................... 6-53

6-13. Results of 7-day PCT with CWF Composite.......................................................... 6-54

6-14. Model Inputs Used in HLW Glass Degradation Model.............................................. 6-56

6-15. Cumulative Releases of $\mathrm{B}, \mathrm{Np}, \mathrm{Pu}$, and $\mathrm{Am}$ in N2 Tests........................................... 6-66

7-1. Information Used to Validate the Model and Provide Confidence in the Parameters..... 7-3

7-2. Comparison of Measured and Calculated Corrosion Rates of Various Glasses ............... 7-4

7-3. Values of $\eta$ and $E_{a}$ Extracted from Literature Data ................................................... 7-7

7-4. $\quad$ Measured Surface Areas for Full-Scale Glass of R7T7 Glass ....................................... 7-14

8-1. Computational Model Parameter Values Developed in This Report ${ }^{\mathrm{a}}$............................ 8-3 


\section{ACRONYMS}

ANL

ASTM

C1220

C1285

CCC

CEA

CSG

CSNF

CWF

DOE

DSNF

DWPF

EA

HLW

LA

MCC-1

MW

NL

NR

PCT

PCT-A

SPFT

$\mathrm{S} / \mathrm{V}$

TAPA-LA

TSPA-SR

TSPA-VA

VHT

WVDP
Argonne National Laboratory

American Society for Testing and Materials

ASTM International test method C1220 (also referred to as MCC-1)

ASTM International test method C1285 (also referred to as PCT)

Canister Centerline Cooling

Commissariat à l'Énergie Atomique

Celia's Simple Glass

Commercial Spent Nuclear Fuel

ceramic waste form

U.S. Department of Energy

DOE Spent Nuclear Fuel

Defense Waste Processing Facility

Environmental Assessment (glass)

high-level radioactive waste

License Application

Material Characterization Center - Test Method 1

Magnox Waste

Normalized Elemental Mass Loss

Normalized Elemental Release Rate

product consistency test

product consistency test - Method A

Single-Pass Flow-Through

glass surface area to solution volume ratio

Total System Performance Assessment -License Application

Total System Performance Assessment - Site Recommendation

Total System Performance Assessment - Viability Assessment

vapor hydration test

West Valley Demonstration Project 


\section{INTENTIONALLY LEFT BLANK}




\section{PURPOSE}

The purpose of this report is to document the development of a model for calculating the release rate for radionuclides and other key elements from high-level radioactive waste (HLW) glasses under exposure conditions relevant to the performance of the repository. Several glass compositions are planned for the repository, some of which have yet to be identified (i.e., glasses from Hanford and Idaho National Engineering and Environmental Laboratory). The mechanism for glass dissolution is the same for these glasses and the glasses yet to be developed for the disposal of DOE wastes. All of these glasses will be of a quality consistent with the glasses used to develop this report.

\subsection{OVERVIEW}

One of the waste forms to be placed in the repository is HLW glass. For the most part, this consists of a borosilicate glass containing approximately 25 mass \% high-level waste oxides from the DOE inventory of waste from the processing of nuclear weapons. The dissolution mechanism for these glasses has been studied since the 1950s, but more intensely since about 1980. While the details of the kinetic mechanism are well known, only a few of the parameters are of interest for the model that will be used in the performance assessment of the Yucca Mountain repository. These parameters are the temperature and the $\mathrm{pH}$ of the solution that will contact the glass. Since the release of elements from the glass depends only on the temperature and the composition of the contacting solution, the same model can be used for glass dissolution in packages containing only HLW glass and those containing HLW glass codisposed with spent fuel (CSNF or DSNF).

This report was developed in accordance with Technical Work Plan for: Regulatory Integration Modeling and Analysis of the Waste Form and Waste Package (BSC 2004 [DIRS 171583]). It specifically addresses the item "Defense High-Level Waste Glass Degradation" of the product development plan, and is in compliance with AP-SIII.10Q, Models.

\subsection{BACKGROUND}

In this section, a concise overview of the mechanism by which glasses interact with water is provided so that the reader has a basic understanding of the important aspects of the kinetic mechanism. From this, the reader is in a better position to understand how the dissolution of glass affects the overall performance of the repository.

How glasses interact with water has been the subject of many studies dating back to the 1950s and 1960s (Doremus 1975 [DIRS 170920]; Goldman et al. 1957 [DIRS 171003]; Durham 1957 [DIRS 171004]; Schneider 1971 [DIRS 170919]; Thomas and Christenson 1957 [DIRS 171005]).

Mostly industrial needs drove these studies, such as the leaching of container and window glasses. These uses required a predictive capability on the order of tens of years. In the 1970s, the use of glass, in particular borosilicate glass, for nuclear waste applications was investigated. By the late 1970s, it was obvious that the existing state of knowledge about the glass-water interaction was insufficient to qualitatively calculate how a glass might behave over a period of tens of years, much less the 10,000 years needed for the nuclear waste repositories. In the early 
1980s, Grambow developed what was to become the best mechanism for the glass-water interaction. This mechanism is used today as the basis for the assessment of the performance of nuclear waste glass to be disposed in Europe, Japan, and the U.S.

A glass containing 40 components has a chemical mechanism that has up to 39 chemical reactions that are needed to accurately describe its dissolution. In alkaline solutions, the mechanism is dominated by one reaction that is rate limiting. This one reaction so dominates the overall kinetics that it alone need be considered to explain the dissolution rate. It is important at this point to make the clear distinction between 'kinetics' and 'thermodynamics.' Kinetics is path dependent. Thermodynamics is a state function; the properties depend only on the beginning and end states, not which steps were taken to get from the beginning to the end. The two can only be combined when the thermodynamics of each step are known and each of the chemical reactions in the kinetic mechanism is known. It is fortuitous that the thermodynamics of the dominating reaction are simple and known. This has allowed thermodynamics to be applied to an otherwise incomplete kinetic mechanism. For borosilicate glasses, the dominant reaction in the chemical mechanism is the reaction involving orthosilicic acid, $\mathrm{H}_{4} \mathrm{SiO}_{4}$. Although thermodynamics is applied to this process, there is an implicit understanding that the system of glass plus water can never come to equilibrium. It is impossible to mix the components of glass together in an aqueous solution and expect glass to precipitate; there are too many other phases that are thermodynamically stable or metastable with respect to glass for glass to form from solution. Because only a single reaction must be considered in the overall kinetic mechanism, there are some shortcomings that result. For example, although reference may be made to the glass being in equilibrium with solution, what is really meant is an apparent equilibrium for the rate-limiting step in the reaction. Because glass dissolution depends on only one step in the kinetic mechanism, the mechanism can be simplified to that single step so that the kinetic rate can be calculated while relegating the remaining reactions to thermodynamic equilibrium.

Thus, from a simplified mechanistic point of view, glass dissolves congruently (i.e., dissolves completely into solution). When the concentration of dissolved glass is very small, say $10^{-8} \mathrm{~g} / \mathrm{L}$, all the constituents stay in solution. However, it does not require a much higher concentration of glass before the solution becomes saturated with respect to some mineral phases, usually those containing elements like $\mathrm{Fe}$ or $\mathrm{Zr}$. These elements then precipitate as minerals that achieve thermodynamic equilibrium with the contacting solution. While these minerals (some of which may contain silica) continue to form and precipitate, $\mathrm{H}_{4} \mathrm{SiO}_{4}$ continues to build in solution as long as the mass of $\mathrm{Si}$ in the mineral phases is less than that supplied by the dissolving glass. As the $\mathrm{H}_{4} \mathrm{SiO}_{4}$ concentration increases in solution, the dissolution rate of the glass decreases.

Because many elements from the glass are involved in the formulation of mineral phases, it is not easy experimentally to follow the reaction of glass with water. Fortunately, for borosilicate glasses, B-bearing minerals are very soluble. Also, B usually forms anionic species in aqueous solution and they, for the most part, do not sorb on most surfaces. Therefore, experimentally the progress of the reaction (i.e., the amount of glass reacted with solution) is followed by determining the concentration of $\mathrm{B}$ in solution and knowing the $\mathrm{B}$ concentration in the glass.

The model presented in this report is based on this fundamental knowledge of the glass dissolution mechanism. This mechanism is the basis for other performance assessments in Sweden (SKB 1999 [DIRS 171283]) and the United States (McGrail et al. 1998 [DIRS 153974). 
However, because of the required input parameters to TSPA-LA, the kinetic rate equation for the HLW glass is modified to give the model developed in this report.

This model is valid over the relative humidity range of $0 \%$ to $100 \%$, the temperature range of $20^{\circ} \mathrm{C}$ to $300^{\circ} \mathrm{C}$, the $\mathrm{pH}$ range 1 to 14 and for glasses with compositions similar to those shown in Table 6-5. For example, the glass degradation model developed in this report is intended to be representative of all HLW glasses that meet the chemical durability requirement in the current versions of Waste Acceptance System Requirements Document (DOE 2002 [DIRS 158873]) and Waste Acceptance Product Specifications for Vitrified High-Level Waste Forms (DOE 1996 [DIRS 102589]). Application of the glass model to HLW forms other than compliant borosilicate glasses must be determined separately.

This model receives input from in-package chemistry and provides output directly to TSPA-LA.

\subsection{DOCUMENT OUTLINE}

The document outline is contained in Table 1-1.

Table 1-1. Document Outline

\begin{tabular}{|l|l|}
\hline \multicolumn{1}{|c|}{ Section } & \multicolumn{1}{c|}{ Description } \\
\hline 1. Purpose & A description of the purpose of the report with a brief overview, background, and roadmap. \\
\hline 2. Quality Assurance & A brief discussion of the QA applicability. \\
\hline 3. Use of Software & Covers the use of any software other than commercial software. \\
\hline 4. Inputs & Necessary information or data from other parts of the project. \\
\hline 5. Assumptions & Assumptions used in the model discussed in this report. \\
\hline 6. Model Discussion & $\begin{array}{l}\text { A discussion in which the technical basis for the model is given, including the in-depth } \\
\text { discussion of the mathematical model and scientific aspects. }\end{array}$ \\
\hline 7. Validation & This section contains the discussion of model validation. \\
\hline 8. Conclusions & A conclusion concerning the model presented in this report. \\
\hline $\begin{array}{l}\text { 9. Inputs and } \\
\text { References }\end{array}$ & $\begin{array}{l}\text { A bibliography and listing of any model inputs and outputs, including those that support the } \\
\text { graphs shown in this report. }\end{array}$ \\
\hline Appendix A & $\begin{array}{l}\text { The pH and temperature dependence of the forward dissolution rate is described. } \\
\text { Measured and calculated HLW glass dissolution rates are used to extract values for the } \\
\text { effective rate constant. }\end{array}$ \\
\hline Appendix B & $\begin{array}{l}\text { Results from vapor hydration tests are used to determine the alteration rate of the HLW } \\
\text { glass in water vapor. }\end{array}$ \\
\hline Appendix C & $\begin{array}{l}\text { The gel layer that develops on a glass during alteration contains some condensed water. } \\
\text { The porosity of this layer is calculated in this appendix and used to determine the amount } \\
\text { of water in this layer. }\end{array}$ \\
\hline Appendix D & $\begin{array}{l}\text { Knauss and coworkers at Lawrence Livermore National Laboratory performed single-pass } \\
\text { flow-through tests over a wide pH range. These data are evaluated in this appendix. }\end{array}$ \\
\hline
\end{tabular}




\section{INTENTIONALLY LEFT BLANK}




\section{QUALITY ASSURANCE}

This document was developed in accordance with Technical Work Plan for: Regulatory Integration Modeling and Analysis of the Waste Form and Waste Package (BSC 2004 [DIRS 171583]). From Section 8 in this plan, it was determined that this report is subject to Quality Assurance Requirements and Description (DOE 2004 [DIRS 171539]) because it will be used to support performance assessments. No item or barrier on the Q-List (BSC 2004 [DIRS 168361]) is investigated as part of the output from this model or the development of this model. The primary procedure followed in developing this document was AP-SIII.10Q, Models.

Technical Work Plan for: Regulatory Integration Modeling and Analysis of the Waste Form and Waste Package (BSC 2004 [DIRS 171583]) contains the process control evaluation used to evaluate the control of electronic management of data during the modeling and documentation activities. The evaluation determined that the methods in the implementing procedures are adequate. No deviations from these methods were used. 


\section{INTENTIONALLY LEFT BLANK}




\section{USE OF SOFTWARE}

Microsoft Excel:mac 2001 was used to compile test data and perform simple arithmetic calculations, such as calculating the mean and standard deviation values that are used in this report. No developed applications such as macros were used with the software; only user-defined formulas, mathematical functions and statistical routines provided with the commercially available version were used. No external models were used in the development of this report.

Microsoft KaleidaGraph Version 3.0.5 was used to plot the data within this report. No developed applications, software routines, or macros were used with the software; only plotting functions provided with the commercially available version were used. The originator and checker have verified the plots against the original data.

The Microsoft Excel:mac 2001 and Microsoft KaleidaGraph Version 3.0.5 software applications are both commercial off-the-shelf software and are not required to be qualified, per Section 2.1.6 of LP-SI.11Q-BSC, Software Management. 


\section{INTENTIONALLY LEFT BLANK}




\section{INPUTS}

This section discusses the inputs used in this report.

\subsection{DIRECT INPUT}

All of the data directly used to develop the glass degradation model in this report were acquired as quality data at ANL. Some of the data used to corroborate parameter values used in the model were measured in tasks conducted at ANL under other quality assurance plans compliant with Quality Assurance Requirements and Description (DOE 2004 [DIRS 171539]) and Integrated Safety Management Quality Assurance Program (DOE 2001 [DIRS 155622]). Other corroborative data used in the analyses were taken from the open literature; those references are listed in Section 9. Information used to develop the model for calculating the exposed glass surface area was obtained from controlled sources. Per AP-3.15Q, Managing Technical Product Inputs, the input status of these references is reflected in the Document Input Reference System entries associated with this report. These data are appropriate for use in this report because they provide quantified measures of the dissolution behavior of relevant borosilicate glasses under documented test conditions. The data used in this report are the best available data for determining a rate expression and parameter values for waste glass degradation. The results taken from some literature sources were further analyzed to extract information from the data that was not directly provided by the authors or to convert the measured values to different units.

Data used to model the surface area of glass available for reaction was taken from DOE documents providing specifications for canisters and potential waste glasses. Information regarding the HLW glasses to be produced at DOE facilities and the nominal dimensions of the standard (short) canister used at DWPF and WVDP is obtained from Integrated Interface Control Document (DOE 2002 [DIRS 158398], Figure C-20). ${ }^{1}$ The nominal dimensions of the long canister from Hanford are based on the maximum dimensions specified for the long canister (DOE 2002 [DIRS 158398], Figure C-21). The nominal dimensions were used because other uncertainties, such as fill height (Appendix D, Section D.3) and weighted average glass specific surface area (Section 6.5.4), compensate for the small difference if the maximum dimensions were used. This information is used to calculate the mass and specific surface area of the glass in a canister that is a weighted average based on the projected amount and characteristics of glass from different production sites. The impact of the uncertainty in each value, that is, how representative the value is for waste forms made at that facility, is captured by the range of possible surface areas of the representative glass product that may be contacted by water as quantified by the exposure factor ( $\left.f_{\text {exposure }}\right)$.

Other input parameters include handbook values of the gas constant and specific volume of saturated steam at $200^{\circ} \mathrm{C}$ (Weast 1977 [DIRS 106266]). Data from three literature sources are used in calculations. The best available data for the extent of cracking in DOE HLW glass from the thermal stress during cooling was measured by Smith and Baxter (1981 [DIRS 102089]) and from impact was measured by Smith and Ross (1975 [DIRS 102088]). These are used to

\footnotetext{
1 For a further discussion on the size of the glass waste form, see Appendix D, Section D.3.
} 
calculate the maximum value for the available surface area for use in the degradation model. These results are suitable for the intended use in the glass surface area model because they are the result of a well-planned and executed testing method, and the measurements were carried out in a systematic and controlled manner by qualified personnel working for U.S. national laboratories. The amount of water measured by Aines et al. (1987 [DIRS 104318]) in a vaporhydrated reference waste glass is used to calculate the porosity of alteration rind. This is the best available measurement of the water content of a degraded waste glass and was published in a peer-reviewed publication. The infrared spectroscopy method used by Aines et al. (1987 [DIRS 104318]) is based on direct measurement of distinct O-H vibrations in molecular water and silanol groups. This method has been used by others to determine the amount of water in glasses that have been altered (Zoitos et al. 1989 [DIRS 163351]). The work was conducted as part of the glass waste form-testing program for the Nevada Nuclear Waste Storage Investigations project under DOE-accepted quality assurance controls. The results are suitable for the intended use in the glass surface area model because measurements were carried out in a well thought out, systematic, and quality-controlled manner.

Characteristics of Potential Repository Wastes (DOE 1992 [DIRS 102812]) is used as a direct input to this report. This document was produced in 1992 by the Office of Civilian Radioactive Waste Management, and contains information on the waste forms expected to be contained in the Yucca Mountain Repository. A limited number of technical errors have been found in the radionuclide inventories contained in Characteristics of Potential Repository Wastes (DOE 1992 [DIRS 102812]), which as a result is no longer considered qualified data. However, the radionuclide inventory data are not used in this report. Instead, this report uses the dimensions of the glass waste canister and the characteristics of the HLW glass. As a result, per Section 5.2.1(k) of AP-SIII.10Q, this data may be considered qualified for its intended use because the reliability of the data source is not in question for the relevant data. This data source demonstrates the properties of interest (i.e., the canister dimensions and waste form characteristics) because it is the best available source of the relevant data. Furthermore, the dimension data are corroborated in a more recent document (DOE 2002 [DIRS 158398]).

The input data used in the development of the glass degradation model and the determination of model parameter values are summarized in Table 4-1 and described below. Table 4-2 lists the input parameters used to develop the model. The uncertainties in the input data are discussed in Section 6.8.

Table 4-1. Input Data

\begin{tabular}{|l|l|}
\hline \multicolumn{1}{|c|}{ Data Name } & \multicolumn{1}{c|}{ Data Source } \\
\hline Glass immersion test results: concentrations and pH & MO0306ANLGIM01.525 [DIRS 164329] \\
\hline Glass immersion test results: normalized mass losses & MO0306ANLGIM02.525 [DIRS 164330] \\
\hline Glass vapor hydration test results: layer thickness & MO0306ANLGVH01.526 [DIRS 164331] \\
\hline Glass unsaturated (drip) test results: boron mass and pH & MO0408ANLGNN01.527 [DIRS 171574] \\
\hline Glass compositions and MCC-1 and PCT results & MO0308ANLGPC01.528 [DIRS 164790] \\
\hline & DOE 1992 [DIRS 102812], Tables 3.1.1, 3.2.1, and \\
Characteristics of HLW glasses for canister dimensions & 3.3 .1 and Sections 3.1.1, 3.2.3, and 3.4.3 \\
& DOE 2002 [DIRS 158398] (Figures C-20 and C-21) \\
\hline
\end{tabular}


Table 4-2. Input Parameters

\begin{tabular}{|l|l|c|c|c|}
\hline \multicolumn{1}{|c|}{ Parameter Name } & \multicolumn{1}{|c|}{ Parameter Source } & $\begin{array}{c}\text { Parameter } \\
\text { Value(s) }\end{array}$ & Units & Distribution \\
\hline Gas Constant, R & $\begin{array}{l}\text { Weast 1977 } \\
\text { [DIRS 106266], p. F-241 }\end{array}$ & 8.314 & $\mathrm{~J} / \mathrm{mol} \cdot \mathrm{K}$ & constant \\
\hline $\begin{array}{l}\text { Specific volume of Saturated Steam at } \\
200^{\circ} \mathrm{C}\end{array}$ & $\begin{array}{l}\text { Weast 1977 } \\
\text { [DIRS 106266], p. E-20 }\end{array}$ & 0.12716 & $\mathrm{~m}{ }^{3} / \mathrm{kg}$ & constant \\
\hline Thermal Cracking of HLW Glass & $\begin{array}{l}\text { Smith and Baxter 1981 } \\
\text { [DIRS 102089] }\end{array}$ & $12 \times$ & (no units) & constant \\
\hline Impact Cracking of HLW Glass & $\begin{array}{l}\text { Smith and Ross 1975 } \\
\text { [DIRS 102088] }\end{array}$ & $40 \times$ & (no units) & constant \\
\hline $\begin{array}{l}\text { Pore Water Content of Glass Alteration } \\
\text { Rind Layer }\end{array}$ & $\begin{array}{l}\text { Aines et al. 1987 } \\
\text { [DIRS 104318], Abstract }\end{array}$ & 7 & mass \% & constant \\
\hline
\end{tabular}

- DTN: MO0306ANLGIM01.525 [DIRS 164329] (Tables 1, 2, 3, and 4)

This DTN includes qualified data from the ANL Task "Q-Data Immersion Tests" that was completed as a part of Test Plan for Long-Term Studies of the Degradation and Radionuclide Release from Defense High-Level Waste (DHLW) Glass (BSC 2002 [DIRS 164401]). The data in Tables 1-4 of the DTN are the measured solution concentrations and solution $\mathrm{pH}$ values (measured on solution aliquots at room temperature) for tests conducted at $70^{\circ} \mathrm{C}, 90^{\circ} \mathrm{C}$, and $90^{\circ} \mathrm{C}$ with added iron compounds (used in Appendix A). These data are appropriate for use in this report because they were collected specifically to provide a measure of the effect of $\mathrm{pH}$ and the presence of iron oxides, which represent thermodynamically stable iron corrosion products, and dissolved iron on the glass corrosion rate under controlled laboratory conditions for development of the glass degradation model and determination of parameter values in this report. The data provide a measure of the corrosion rates of a glass in solutions preset to specific $\mathrm{pH}$ values. The solution concentrations are used in Appendix A of this report.

\section{- DTN: MO0306ANLGIM02.525 [DIRS 164330] (Tables 1, 2, 3, 4, and 5)}

This DTN includes qualified data from the ANL Task "Q-Data Immersion Tests" that was completed as a part of Test Plan for Long-Term Studies of the Degradation and Radionuclide Release from Defense High-Level Waste (DHLW) Glass (BSC 2002 [DIRS 164401]). The data in Table 1 of the DTN give the measured compositions of the SRL 202G glass (used in Appendix A and Section 6.5.2.2). These data are appropriate for use in this report because they were collected specifically to provide the composition of the glass used in the tests to calculate the glass degradation rate based on the measured concentrations of particular elements. The data in Tables 2-4 of the DTN are normalized mass loss values of boron and other major glass components for tests conducted at $70^{\circ} \mathrm{C}, 90^{\circ} \mathrm{C}$, and $90^{\circ} \mathrm{C}$ with added iron compounds (used in Appendix A of the DTN). Table 5 gives the results for Product Consistency Tests conducted at $90^{\circ} \mathrm{C}$ in demineralized water. These data are appropriate for use in this report because they were collected specifically to provide a measure of the effect of $\mathrm{pH}$ and the presence of iron oxides (i.e., iron corrosion products) and dissolved iron on the corrosion rate of glass 
under controlled laboratory conditions for development of the glass degradation model and determination of parameter values in this report. The data provide a measure of the corrosion rates of a glass in solutions preset to specific $\mathrm{pH}$ values.

\section{- DTN: MO0306ANLGVH01.526 [DIRS 164331] (Tables 1, 2, and 3)}

This DTN identifies qualified data from the ANL Task "Vapor Hydration Testing of Glass" that was completed as a part of Test Plan for Long-Term Studies of the Degradation and Radionuclide Release from Defense High-Level Waste (DHLW) Glass (BSC 2002 [DIRS 164401]). Table 1 of the DTN summarizes the test conditions and results in terms of measured layer thickness. Table 2 of the DTN provides the measured densities of the SRL 51S, SRL 131, and SRL 165S glasses used in the tests. Table 3 of the DTN provides the measured glass compositions. These data are appropriate for use in this report because they were collected on glasses with compositions similar to those that will be made under controlled laboratory conditions for development of the glass degradation model and determination of parameter values in this report. The data provide a measure of the overall corrosion rate of glass when exposed to humid air, which includes the rate of water sorption and condensation onto the glass and glass corrosion. The data provide a measure of the effect of the relative humidity and temperature on the glass corrosion rate that can be used to extract model parameter values for exposure of waste glass to humid air. These data will be used to determine the range and distribution of dissolution rates to be used for performance assessment calculations. These results are used in Section 6.5.3.3 of this report.

\section{- DTN: MO0408ANLGNN01.527 [DIRS 171574] (Tables 1, 2, 3, 4, 5, and 6)}

This DTN identifies qualified data from the ANL Task "Unsaturated (Drip) Tests with Glass" that was completed as a part of Test Plan for Long-Term Studies of the Degradation and Radionuclide Release from Defense High-Level Waste (DHLW) Glass (BSC 2002 [DIRS 164401]). Table 1 of the DTN gives the measured boron concentration and normalized mass loss for each sampling and Table 2 of the DTN gives the cumulative boron concentration and normalized mass loss for the N2 test series (conducted with SRL 165 glass). Table 3 of the DTN gives the measured boron concentration and normalized mass loss for each sampling and Table 4 of the DTN gives the cumulative boron concentration and normalized mass loss for the N3 test series (conducted with ATM-10 glass). Tables 5 and 6 of the DTN give the measured solution $\mathrm{pH}$ values for the $\mathrm{N} 2$ and $\mathrm{N} 3$ test series, respectively. These data are appropriate for use in this report because they were collected specifically to provide a measure of the corrosion rates of two relevant glass compositions under controlled laboratory conditions for development of the glass degradation model and determination of parameter values in this report. The data are used in this report to determine the corrosion rates of two glasses that are periodically contacted by small amounts of a tuff groundwater solution. The data provide a measure of the combined effects of water dripping onto the glass, glass corrosion, and water dripping off the glass on the glass degradation rates. The overall corrosion rate is used to determine the range and distribution of glass dissolution rates. These results are used in Section 6.5.3.5 of this report. 


\section{- DTN: MO0308ANLGPC01.528 [DIRS 164790] (Tables 1, 2, and 3)}

This DTN provides MCC-1 and PCT-A results from the ANL Task "Evaluating the Relationship Between PCT-A and Long-Term Behavior." Table 1 of the DTN gives the compositions of nine glasses used to determine the effect of glass composition on the dissolution rate. Table 2 of the DTN gives the results for MCC-1 leach tests with the nine glasses. These data are used in Section 6.5.2.1 of this report to determine the effect of glass composition when solution feedback effects are negligible. Table 3 of the DTN gives the results of 7-day PCT conducted with the nine glasses. These data are used in Section 6.5.2.2 to determine the effect of glass composition on the dissolution rate when solution feedback effects dominate the test response. These data are appropriate for use in this report because they were collected specifically to provide measured dissolution rates for relevant glass compositions under controlled laboratory conditions for development of the glass degradation model and determination of parameter values in this report.

\subsection{CRITERIA}

Projects Requirements Document (Canori and Leitner 2003 [DIRS 166275]) identifies the high-level requirements for the Project and the U.S. Nuclear Regulatory Commission (NRC) acceptance criteria for these requirements are listed in Yucca Mountain Review Plan, Final Report (NRC 2003 [DIRS 163274]). The NRC acceptance criterion that is applicable to this report and the links to 10 CFR Part 63 [DIRS 156605] are listed in Table 4-3.

Table 4-3. YMRP Acceptance Criteria Applicable to This Report

\begin{tabular}{|l|l|l|}
\hline \multicolumn{1}{|c|}{ Title } & \multicolumn{1}{|c|}{$\begin{array}{c}\text { 10 CFR Part 63 } \\
\text { Reference }\end{array}$} & \multicolumn{1}{c|}{$\begin{array}{c}\text { YMRP Acceptance } \\
\text { Criteria }\end{array}$} \\
\hline Degradation of Engineered Barriers & $\begin{array}{l}\text { 10 CFR 63.114 } \\
{[\mathrm{DIRS} 156605]} \\
{[(\mathrm{a})-(\mathrm{c}) \text { and }(\mathrm{e})-(\mathrm{g})]}\end{array}$ & $\begin{array}{l}\text { NRC 2004 [DIRS 163274], } \\
\text { Section 2.2.1.3.1.3 }\end{array}$ \\
\hline Radionuclide Release Rates [and Solubility Limits] $]$ & $\begin{array}{l}10 \text { CFR 63.114 } \\
{[\mathrm{DIRS} 156605]} \\
{[(\mathrm{a})-(\mathrm{c}) \text { and }(\mathrm{e})-(\mathrm{g})]}\end{array}$ & $\begin{array}{l}\text { NRC 2004 [DIRS 163274], } \\
\text { Section 2.2.1.3.4.3 }\end{array}$ \\
\hline
\end{tabular}

The NRC YMRP acceptance criteria are based on meeting the requirements in 10 CFR 63.114 [DIRS 156605] as they relate to the degradation of engineered barriers and radionuclide release rates. Pertinent criteria (BSC 2004 [DIRS 171583], Table 3-1) in Sections 2.2.1.3.1.3 and 2.2.1.3.4.3 of Yucca Mountain Review Plan, Final Report (NRC 2004 [DIRS 163274]) include Acceptance Criterion 1 (System Description and Model Integration are Adequate), Acceptance Criterion 2 (Data are Sufficient for Model Justification), Acceptance Criterion 3 (Data Uncertainty is Characterized and Propagated Through the Model Abstraction), Acceptance Criterion 4 (Model Uncertainty is Characterized and Propagated Through the Model Abstraction), and Acceptance Criterion 5 (Model Abstraction Output is Supported by Objective Comparisons). These criteria and how they are addressed in the model developed in this report are discussed in Section 8.4. The technical work plan (BSC 2004 [DIRS 171583], Section 3) includes validation criteria. These are discussed in Section 7. 
Waste Acceptance System Requirements Document (DOE 2002 [DIRS 158873]) and Waste Acceptance Product Specifications for Vitrified High-Level Waste Forms (DOE 1996 [DIRS 102589]) provide acceptance criteria for standard borosilicate waste glasses and glass canisters. The models developed in this report are intended to represent the full range of borosilicate waste glass that meet the specifications in these documents and are acceptable for disposal.

\subsection{CODES, STANDARDS, AND REGULATIONS}

The work associated with this report was performed in accordance with the following regulations, codes, and standards:

- 10 CFR Part 63 [DIRS 156605]. Energy: Disposal of High-Level Radioactive Wastes in a Geologic Repository at Yucca Mountain, Nevada. Readily available.

- ASTM C 1174-97 [DIRS 105725], Standard Practice for Prediction of the Long-Term Behavior of Materials, Including Waste Forms, Used in Engineered Barrier Systems (EBS) for Geological Disposal of High-Level Radioactive Waste.

- ASTM C1285-02 [DIRS 163205], Standard Test Methods for Determining Chemical Durability of Nuclear, Hazardous, and Mixed Waste Glasses and Multiphase Glass Ceramics: The Product Consistency Test (PCT).

- ASTM C1220-98 [DIRS 119321], Standard Test Method for Static Leaching of Monolithic Waste Forms for Disposal of Radioactive Waste. 


\section{ASSUMPTIONS}

Several assumptions were made in the development of this model.

\subsection{WATER HAS ACCESS TO SOME OF THE CRACK SURFACES}

Assumption: It is assumed that water has free access to some of the crack surfaces of the glass and that the reaction rate in the cracks is less than for a free glass surface.

Rationale: As a glass cools in the canister, the combination of thermal and hoop stresses causes the glass to crack. The assumption is made in this model that not all the crack surfaces are accessible by water. While the data with artificial cracks suggest that the water access is limited (Perez and Westsik 1981 [DIRS 111044]), data from basaltic glasses at the ocean trenches suggests that the surfaces of bubbles in the glass, including the cracks that connect them to the surface, are accessed by water. Reaction rates within the cracks were lower than those at a free surface. Sené et al. (1999 [DIRS 163283]) established that the expected surface area contacted by water is less than the calculated surface area including the contribution from cracks. The reaction rate between water in the cracks and glass is reduced relative to the free surface because $\left[\mathrm{H}_{4} \mathrm{SiO}_{4}\right]$ is higher in the crack due to the low transport of dissolved material from the crack. Thus, in the model, the high exposed surface area factor assumes free access of water to all cracks and the low value assumes $50 \%$ of the crack surfaces are contacted with a reaction rate that is $50 \%$ of the rate at the free surface of the glass.

\subsection{A pH VALUE FOR CONDENSED WATER ON GLASS OF 10 IS USED ABOVE $100^{\circ} \mathrm{C}$}

Assumption: It is assumed that condensed water on the surface of glass will have a $\mathrm{pH}$ of 10 for temperatures above $100^{\circ} \mathrm{C}$.

Rationale: When the temperature rises above $100^{\circ} \mathrm{C}$, most of the liquid phase is converted to water vapor and the limit for $\mathrm{pH}$ from In-Package Chemistry Abstraction (BSC 2004 [DIRS 167621] is reached. At these temperatures and humidities, the glass reacts with the water vapor to form a thin layer of water on the surface of the glass. Because the ratio of surface area to volume is very high (about 4,000 $\mathrm{m}^{-1}$ ), the $\mathrm{pH}$ can be very high. As the temperature increases in the repository at constant pressure, the relative humidity decreases. The functional dependence on the relative humidity is not known, but alteration rate is known to decrease to zero at $44 \%$. Both the effect of $\mathrm{CO}_{2}$ and the relative humidity cannot be accurately calculated as a function of temperature. However, conservatively assuming that only $\mathrm{Na}^{+}$is released from the glass, the condensed water would become a $\mathrm{NaOH}$ solution. Reacting this solution with $\mathrm{CO}_{2}$ gas from a reservoir of unlimited volume at constant $p \mathrm{CO}_{2}=10^{-1.5} \mathrm{kPa}\left(10^{-3.5} \mathrm{~atm}\right)$ converts the solution to one containing $\mathrm{NaCO}_{3}$, which, under these conditions, has a $\mathrm{pH}$ of about 10.2 to 10.3 $\left(\mathrm{pK}_{\mathrm{a}}\right.$ for $\mathrm{HCO}_{3}{ }^{-}+\mathrm{H}_{2} \mathrm{O}=\mathrm{CO}_{3}{ }^{2-}+\mathrm{H}_{3} \mathrm{O}^{+}$(Stumm and Morgan 1981 [DIRS 100829], pp. 204 to 206). Therefore, the rate of glass alteration increases as the temperature increases as calculated from the activation energy and the $\mathrm{pH}$ is fixed at the high value of 10 for the purposes of calculating an alteration rate. Using a fixed $\mathrm{pH}$ is conservative because the calculated rate increases with temperature (activation energy), the actual $\mathrm{pH}$ of the solution on the glass is lower than 10 because of $\mathrm{CO}_{2}$ availability, and the equilibrium constant for water shifts to lower values 
with increasing temperature. Implicit in this model is that, other than increases in the rate from the temperature contribution, the rate remains constant until $44 \%$ relative humidity at which point it falls to zero. For pure water at a total pressure of $0.101 \mathrm{MPa}$, this occurs at $125^{\circ} \mathrm{C}$. For cases where saline solutions from In-Package Chemistry Abstraction (BSC 2004 [DIRS 167621]) dictate the vapor pressure of water is less than that of pure water. 


\section{MODEL DISCUSSION}

\subsection{MODELING OBJECTIVES}

The models described in this report were developed to calculate corrosion rates of waste glasses that are immersed in water or contacted by humid air or dripping water in the event that the waste package and glass canister are breached. Degradation of defense HLW glass is not identified as a principal factor in the calculated dose. Therefore, only the lowest acceptable level of confidence (Level 1) in the results from this model is required (BSC 2004 [DIRS 171583], Section 2.2), the validations of which are discussed in Sections 6.8, 6.9, and 7. The glass dissolution rate is used as an upper limit to the release rates of radionuclides from the glass as it corrodes. That is, the solubility of phases containing radionuclides is not taken into account in this model. The radionuclide release rate (Curies/time) is calculated as the product of three terms: the alteration rate of the glass, the exposed surface area of glass, and the inventory of radionuclides in the glass. Contained in this report are models for (1) calculating the glass alteration rate at a given solution $\mathrm{pH}$ and temperature when contacted by humid air or water (dripping or static) and (2) calculating the glass surface area available for corrosion. The release rate of a particular radionuclide can be calculated by multiplying the glass dissolution rate by the total surface area of glass that can be contacted by water and by the inventory of that radionuclide in the glass (e.g., Curies per g glass). The radionuclide inventory must be obtained from Initial Radionuclide Inventories (BSC 2004 [DIRS 170022]).

The terms "alteration" and "dissolution" require some definition within the context of this report. "Alteration" refers to the process by which glass is converted to more stable minerals in the presence of water or water vapor. "Dissolution" refers to alteration of the glass but also the release of constituents to solution. In the case of dripping or bulk water, both "alteration" and "dissolution" may be used without confusion. In the case of water vapor, the glass is altered to more stable mineral phases, but the components can only migrate away if there is some transport mechanism such as dripping water or diffusion. At some time after alteration in water vapor, contact with dripping or bulk water would result in release of the soluble components in the alteration products on the surface of the glass. Overall, the glass is degraded by these processes from its as-produced state, hence, the word "degradation" appears in the title of this report.

The glass alteration model is intended to represent the full range of disposed glasses based on the current waste form acceptance requirements in Waste Acceptance System Requirements Document (DOE 2002 [DIRS 158873]) and because within the range of HLW glasses, the dissolution of borosilicate glasses is the same. The effects of $\mathrm{pH}$ and temperature are explicitly calculated with the model. The effects of glass composition, solution composition, and water contact mode are taken into account with a parameter whose range of values provides modeled rates that span the range measured in laboratory experiments with various glass compositions under a range of water contact conditions. Although the modeled rate is not an explicit function of time, the rate that is used for each time step in TSPA-LA calculations is calculated as a function of the solution $\mathrm{pH}$ and temperature, both of which are expected to change over time. 


\subsection{FEATURES, EVENTS, AND PROCESSES}

This model includes consideration of features of the HLW glass, its disposal environment, and the events and processes that are expected to influence the rate of readionuclide release (DTN: MO0407SEPFEPLA.000 [DIRS 170760]). These FEPs, along with their disposition into the TSPA-LA model, are summarized in Table 6-1. Other screened out HLW glass FEPs and the bases for their screening decisions are described in Waste-Form Features, Events, and Processes (BSC 2004 [DIRS 170020]).

Table 6-1. Features, Events, and Processes (FEPs) Included in this Report

\begin{tabular}{|c|l|l|}
\hline $\begin{array}{c}\text { FEP } \\
\text { Number }\end{array}$ & \multicolumn{1}{c|}{ FEP Name } & \multicolumn{1}{c|}{ Section(s) Where Disposition is Described } \\
\hline $2.1 .01 .02 .0 \mathrm{~B}$ & Interactions between codisposed waste & 6.7 \\
\hline $2.1 .01 .03 .0 \mathrm{~A}$ & Heterogeneity of waste inventory & 6.5 .2 and 6.5.2.2 \\
\hline $2.1 .02 .03 .0 \mathrm{~A}$ & $\begin{array}{l}\text { HLW glass degradation (alteration, } \\
\text { dissolution, and radionuclide release) }\end{array}$ & 6.5 \\
\hline $2.1 .02 .05 .0 \mathrm{~A}$ & HLW glass cracking & 6.5 .4 \\
\hline $2.1 .09 .02 .0 \mathrm{~A}$ & Chemical interaction with corrosion products & $6.5 .2 .1,6.5 .2 .3$, and Appendix A \\
\hline
\end{tabular}

\subsection{BASE-CASE CONCEPTUAL MODEL}

The model for DHLW glass degradation developed in this report provides the source term for radionuclides released as glass degrades in a breached waste package after being contacted by humid air or dripping water, or when glass becomes immersed in water. The model is applicable to the full range of disposed glasses with compositions that meet the DOE acceptance criteria. Model parameter values were developed from the results of tests conducted on glasses with compositions that span the range of $\mathrm{Al}, \mathrm{Na}$, and $\mathrm{Si}$ contents that have the greatest effect on chemical durability. The model is also applicable to the possible water-contact scenarios, including contact by humid air, contact by dripping water, and immersion. The upper limit value of the glass degradation rate coefficient is determined for degradation of immersed glass and the lower limit value is determined for degradation under dripping water and humid air conditions.

The FEPs that are included in the model for DHLW glass degradation and how they are addressed are summarized in Table 6-1.

\subsubsection{Mechanism for Glass Dissolution}

The dissolution of glass into water has been studied extensively for many years, resulting in an extensive database of test results. Several models have been developed to interpret various subsets of these data. Competing models based on diffusion-control and on dissolution control have been proposed, usually to describe the results under specific test conditions and for specific glass compositions (Doremus 1975 [DIRS 170920]; Wallace and Wicks 1983 [DIRS 171276]).

The processes that contribute to the degradation of nuclear waste glasses include water diffusion in the glass and through alteration layers, ion exchange between the alkali in the glass and hydronium $\left(\mathrm{H}^{+}\right)$ion in water, alkali metal diffusion through alteration layers, water-alkali metal interdiffusion, hydrolysis reactions to release boron, silicon, and other components, diffusion of 
hydrolyzed species through alteration layers, reformation of hydrolyzed bonds, in situ crystallization of hydrolyzed glass (gel), and the formation of alteration phases (Grambow 1984 [DIRS 118987]; and McGrail et al. 2002 [DIRS 163272]). Different processes may predominate under different test conditions. However, most researchers now agree that, after or at the same time as ion exchange occurs, the dissolution rate of a borosilicate glass in alkaline solutions is controlled by the solution concentration of orthosilicic acid (Advocat et al. 1999 [DIRS 163199]; Bourcier 1994 [DIRS 101563]; Grambow et al. 1986 [DIRS 163258]; Knauss et al. 1990 [DIRS 101701]; McGrail et al. 1998 [DIRS 153974]). As glass reacts with water, the Si-O-Si network is hydrolyzed. The rate-limiting step involves the hydrolysis of the last Si-O-Si bond to release a unit of orthosilicic acid, $\mathrm{H}_{4} \mathrm{SiO}_{4}$, to the bulk solution.

The dissolution reaction can be written as in Equation 1a, and the reverse (condensation) reaction as Equation 1b:

$$
\begin{aligned}
& \text { glass } \equiv \mathrm{Si}-\mathrm{O}-\mathrm{Si}(\mathrm{OH})_{3}+\mathrm{H}_{2} \mathrm{O} \rightarrow \text { glass } \equiv \mathrm{Si}-\mathrm{OH}+\mathrm{H}_{4} \mathrm{SiO}_{4}(\mathrm{aq}) \\
& \text { glass } \equiv \mathrm{Si}-\mathrm{OH}+\mathrm{H}_{4} \mathrm{SiO}_{4}(\mathrm{aq}) \rightarrow \text { glass } \equiv \mathrm{Si}-\mathrm{O}-\mathrm{Si}(\mathrm{OH})_{3}+\mathrm{H}_{2} \mathrm{O}
\end{aligned}
$$

The atomic processes that occur during the hydrolysis of $\mathrm{Si}-\mathrm{O}-\mathrm{Si}$ groups by water have been investigated in ab-initio quantum mechanical studies (Lasaga and Gibbs 1990 [DIRS 163265]). The net dissolution rate is the difference between the rates expressed in Equations 1a and $1 \mathrm{~b}$. Clearly, the net rate will depend on the activity of orthosilicic acid (the activity of $\mathrm{Si}-\mathrm{O}-\mathrm{Si}$ bonds on the glass surface is defined to be 1). The net rate can be expressed in terms of the $\mathrm{H}_{4} \mathrm{SiO}_{4}$ activity in solution and in a "saturated" solution (Lasaga 1983 [DIRS 141616]; Aagaard and Helgeson 1982 [DIRS 101530]). Glass cannot reach true equilibrium with solution because it is thermodynamically unstable with respect to more stable minerals made up from the constituents of the glass. To put it differently, it is not possible to dissolve all the constituents of a glass in solution and have a glass precipitate. Thus, in reality, the rate for the dissolution reaction (Equation 1a) will always be higher than the reverse or condensation reaction (Equation 1b). In the context of the model for glass dissolution, the solution is considered to attain an "apparent" saturation limit when the net dissolution rate becomes immeasurably low (Grambow 1985 [DIRS 163257]). This means that there is a hypothetical equilibrium constant for the reaction sequence expressed in Equations 1a and 1b. It must be emphasized that the reactions shown in Equations $1 \mathrm{a}$ and $1 \mathrm{~b}$ are for the one reaction that determines the overall glass dissolution rate in alkaline solutions. The dissolution mechanism contains many such reactions involving other components of the glass that do not affect the overall dissolution rate. In acid solutions, the reactions that determine the overall glass dissolution rate have not been fully identified, but appear to be associated with reactions to release glass network formers other than $\mathrm{Si}$ (Abraitis et al. 2000 [DIRS 163195]).

The model for glass dissolution developed by Grambow is described succinctly by Werme et al. (1990 [DIRS 163346]), and that description is reproduced here. 
The rate expression for surface reaction-controlled dissolution can be written as:

$$
r_{m}=k_{+}\left(1-\frac{a_{S i}}{a_{s a t}}\right)
$$

where $\mathrm{k}_{+}$is the forward rate, $\mathrm{a}_{\mathrm{Si}}$ is the activity of orthosilicic acid in the bulk solution, and $\mathrm{a}_{\text {sat }}$ is the activity of $\mathrm{H}_{4} \mathrm{SiO}_{4}$ at saturation. In the Grambow model, diffusion of $\mathrm{H}_{4} \mathrm{SiO}_{4}$ through a chemically and physically altered layer of glass (alteration layer or rind) may affect or control the release under certain conditions. In the alteration layer, there are many sorption sites for $\mathrm{H}_{4} \mathrm{SiO}_{4}$. Thus, as the alteration layer thickens, transport of $\mathrm{H}_{4} \mathrm{SiO}_{4}$ through the layer results in the bulk solution having one concentration of $\mathrm{H}_{4} \mathrm{SiO}_{4}$ and a higher concentration in the aqueous phase near the glass-layer interface. The transport-limited rate is expressed as a diffusion equation:

$$
r_{t}=\left(\frac{D}{L}\right)\left(a_{S i, s}-a_{S i}\right)+r_{l t}
$$

where $\mathrm{D}$ is the diffusion constant for silica, $\mathrm{L}$ is the alteration layer thickness, $a_{S i, s}$ and $a_{S i}$ are the orthosilicic acid activities at the glass surface and bulk solution, respectively. The term $r_{l t}$ is an ad hoc term included in the rate expression to account for the residual dissolution rate that is the result of a constant driving force to convert glass to alteration products in the presence of water. The term $r_{l t}$ is often assigned an empirical value determined from laboratory tests. The term $\left(a_{S i, s^{-}} a_{S i}\right)$ gives the gradient of the silica activity across the layer. The Grambow model provides an expression for the dissolution rate that includes the effects of both dissolution and diffusion by combining Equations 2 and 3:

$$
\mathrm{r}_{m}=k_{+} \frac{(D / L)\left(a_{s a t}{ }^{-a_{S i}}\right)+r_{l t}}{a_{s a t}(D / L)+k_{+}}
$$

The minimum concentration gradient occurs across the layer when $a_{S i}$ is equal to the saturation concentration $a_{s a t}$ and the diffusion rate is $r_{l t}$. The term $a_{s a t}(\mathrm{D} / \mathrm{L})$ gives the maximum transport rate through a layer with thickness $\mathrm{L}$. The measured dissolution rate will be transport-limited when $a_{s a t}(\mathrm{D} / \mathrm{L})<<\mathrm{k}_{+}$, and Equation 4 reduces to Equation 3. Under conditions where $a_{s a t}(\mathrm{D} / \mathrm{L})>>k_{+}$, Equation 4 reduces to Equation 2 and dissolution is reaction-limited.

The degradation of borosilicate glasses contacted by water is usually modeled to be the result of three main processes: water diffusion into the glass, ion exchange between water and the glass, and hydrolysis reactions (Bourcier 1994 [DIRS 101563]; McGrail et al. 2001 [DIRS 171165]; Grambow and Muller 2001 [DIRS 171412]). The effects of water diffusion and ion exchange discussed above are important early in the reaction. Ion exchange reactions occur to replace alkali metal and alkaline earth ions in the glass with protons from solution giving rise to the hydroxyl groups in the reactant "glass $\equiv \mathrm{Si}-\mathrm{O}-\mathrm{Si}(\mathrm{OH})_{3}$ " shown in Equation 1a. The alkali metal and alkaline earth ions are released from the glass as ions (e.g., $\mathrm{Na}^{+}$and $\mathrm{Ca}^{2+}$ ). Hydrolysis reactions occur to break the covalent bonds that form the glass network. Many elements are released from the glass as polyatomic species, such as $\mathrm{B}(\mathrm{OH})_{4}{ }^{-}$and $\mathrm{Si}(\mathrm{OH})_{4}$. While ion 
exchange and hydrolysis reactions can occur at sites on the surface of the glass, water also diffuses into the glass and reacts at interior sites (Grambow and Muller 2001 [DIRS 171412]). Alkali metals, alkaline earth metals, and boron are initially released from the glass preferentially to silicon and aluminum in acidic and neutral solutions (Abraitis et al. 2000 [DIRS 163195]). Ion exchange appears to take place independent of matrix dissolution in alkaline solutions (McGrail et al. 2001 [DIRS 171165]). The rates of ion exchange and water diffusion decrease with time and the dissolution becomes controlled by matrix dissolution. Solubility limits with respect to several minerals are quickly reached and they precipitate. The ion exchange and the precipitation of minerals leads to a solution that is incongruent with respect to the glass composition. Because the precipitating minerals remove less alkali, the solution in contact with most nuclear waste glasses becomes alkaline. Although experimentally the glass dominates the solution in contact with glass, the corrosion of the package components will dictate the composition of the solutions that will come in contact with the glass. Thus, implementation of the glass degradation model will utilize the solution $\mathrm{pH}$ that is calculated in In-Package Chemistry Abstraction (BSC 2004 [DIRS 167621]). ${ }^{2}$

Because boron is not incorporated into alteration phases, whereas most of the other elements are, the extent of glass dissolution in most laboratory tests is provided by the boron solution concentration. The boron concentration is used to determine the parameter values in the glass degradation model, which is then used to calculate the release rates of radionuclides from the glass. An exception is the use of the vapor hydration test results, which are discussed in Section 6.5.3.3. In these tests, a thin film of water, the thickness of which has only been estimated, contacts glass. The small volume of water promotes the formation of alteration phases. These alteration products are the same as those that are formed in tests in which bulk water is in contact with the test specimen and are formed in the long-term on natural materials (Bates and Steindler 1983 [DIRS 104261]). The extent of glass corrosion is measured using the thickness of an alteration layer (Ebert 2003 [DIRS 164518]) or the thickness of the unreacted glass (Jiřička et al. 2001 [DIRS 163262]). With either of these methods, the extent of reaction is determined from the amount of glass converted to alteration phases.

As a result of the mechanistic studies, the glass dissolution rate can generally be expressed with the formula given by Aagaard and Helgeson (1982 [DIRS 101530]):

$$
r_{\text {glass }}=k_{r} \times\left[\prod_{i} a_{i}^{-v_{i}}\right] \times\left[1-\exp \left(\frac{A_{r}}{\sigma R T}\right)\right]
$$

where

$$
\begin{aligned}
r_{\text {glass }} & =\text { glass dissolution rate } \\
k_{r} & =\text { rate constant that carries the units of rate } \\
a_{i} & =\text { the chemical activity of the species } \mathrm{i} \\
v_{i} & =\text { the stoichiometric coefficient for species } \mathrm{i} \text { in the mechanistic step }
\end{aligned}
$$

2 Although the $\mathrm{pH}$ is passed from In-Package Chemistry Abstraction (BSC 2004 [DIRS 167621]), there is no continuous water when the temperature is above $100^{\circ} \mathrm{C}$. In this case, Assumption 5.2, in which the $\mathrm{pH}$ is assumed to be 10 , is used. 
$\sigma=$ related to the stoichiometry of the rate limiting step relative to the dissolving solid

$A_{r}=$ reaction affinity; a measure of the driving force for the reaction to occur

$R=$ the gas constant

$T=$ absolute temperature.

For glass, Equation 5 can be simplified to:

$$
r_{\text {glass }}=\overrightarrow{k_{0}} \times 10^{\eta \cdot p H} \times\left[\exp \left(\frac{-E_{a}}{R T}\right)\right] \times\left[1-\frac{Q}{K}\right]
$$

where the parameters have the same meaning as in Equation 5 and where the rate limiting step involves only silica (Equations 1a,b):

$\overrightarrow{k_{0}} \quad=$ intrinsic rate constant that depends only on glass composition and carries units of rate

$\eta=$ order of the rate limiting step with respect to the activity of hydronium ion, $a_{H^{+}}$

$\mathrm{E}_{a}=$ activation energy for the rate limiting step

$\mathrm{Q}=$ ion activity product; in this case, the activity of $\mathrm{H}_{4} \mathrm{SiO}_{4}$

$\mathrm{K}=$ equilibrium constant for the rate limiting step, in this case the activity of $\mathrm{H}_{4} \mathrm{SiO}_{4}$ at saturation.

Since all waste glasses have the reactions shown in Equation $1 \mathrm{a}, \mathrm{b}$, then the values for $\mathrm{E}_{\mathrm{a}}$, $\eta$, and $\mathrm{K}$ are the same for these glasses. The only composition dependence is in the intrinsic rate constant. This simplifies the discussion of glass dissolution and, in the model presented here, allows Equation 6 to be simplified further.

The final term in Equation 6 is known as the affinity term. This term is responsible for rate decreasing as the reaction proceeds or as the $\mathrm{H}_{4} \mathrm{SiO}_{4}$ concentration increases either from internal (glass) or external sources. Recent work indicates that the final rate of dissolution (that dictated by the approach of $\mathrm{Q} / \mathrm{K}$ to 1 ) is on the order of $10^{4}$ lower than the initial dissolution rate at $90^{\circ} \mathrm{C}$ and a $\mathrm{pH}$ value of 10 (Gin and Mestre 2001 [DIRS 171170]). This means that final dissolution rates under static conditions are on the order of $10^{-4} \mathrm{~g} /\left(\mathrm{m}^{2} \cdot \mathrm{d}\right)$. In an open system, the actual dissolution rate depends on the flow rate through the value of Q (Equation 6).

Whereas laboratory tests have contributed the most insight to determining the glass corrosion mechanism, the results of field tests and the study of natural analogs have provided confidence in that understanding. In most cases, the study of glass corrosion in the field is restricted to examination of the reacted glass itself. Solution data are rarely available and the reaction conditions are often poorly constrained, especially in the case of natural analogs. Changes in the chemical compositions of reacted surface layers can provide evidence of leaching soluble glass components or the ingression of solutes from water in contact with the glass (Wicks 1992 [DIRS 163349], Chapter 7). Field and laboratory studies comparisons generally show that higher corrosion rates are measured in laboratory studies than occur in the field (Zoitos et al. 1989 [DIRS 163351]). 


\subsubsection{Simplifications Used in the Glass Degradation Model}

The glass degradation model is simplified for implementation in TSPA-LA calculations. The key simplifications and their impact are discussed below.

\subsubsection{Constant Value Used for the Activity of Orthosilicic Acid}

As mentioned in the discussion with respect to Equation 6, the dissolution rate decreases as the concentration of $\mathrm{H}_{4} \mathrm{SiO}_{4}$ increases at constant $\mathrm{pH}$ and $\mathrm{T}$, whether the increase is from glass dissolution or external sources. For ease of implementation, the model developed in this report includes explicit terms for the temperature and $\mathrm{pH}$ and an implicit term containing a constant value for the activity of $\mathrm{H}_{4} \mathrm{SiO}_{4}$ for each TSPA-LA time step. The value of (1-Q/K) (Equation 6) can vary from $1\left(\mathrm{Q}=0\right.$ or no $\left.\mathrm{H}_{4} \mathrm{SiO}_{4}\right)$ to less than $10^{-4}(\mathrm{Q} \approx \mathrm{K}$ or the saturation value for $\mathrm{H}_{4} \mathrm{SiO}_{4}$ ); neither of which represent open repository conditions. To account for the low drip rate that is expected in the repository and for the very slow dissolution rate if the aqueous phase was static, a maximum value of $(1-\mathrm{Q} / \mathrm{K})$ was selected for both acid and alkaline solutions. To bound the minimum, a value based on the vapor hydration test results was used for alkaline solutions and a value based on unsaturated (drip) test results was used for acidic solutions. This is discussed in Section 6.5.3.3.4.

\subsubsection{Glass Dissolution Dependence on pH}

Results from tests on several waste glasses have shown the dissolution rate to pass through a minimum at a $\mathrm{pH}$ value of approximately 7 as the test solutions change from acid to alkaline. Although it is likely that the differences in the behaviors of different glasses in acidic solutions is due to their composition, and particularly the relative amounts of aluminum and silicon, the rate limiting step appears to be different (Abraitis et al. 2000 [DIRS 163195]). In this report, degradation rates of all waste glasses are modeled to increase as $\mathrm{pH}$ decreases from neutral to lower $\mathrm{pH}$ values and as $\mathrm{pH}$ increases from neutral to higher $\mathrm{pH}$ values. This is discussed in Sections 6.5.2 and 7.4. In this report, equations are developed to calculate the rates for both the acidic and alkaline solutions over the entire $\mathrm{pH}$ range (0 to 14$)$.

\subsubsection{The Same Dependence on $\mathrm{pH}$ and Temperature is Used for All Waste Glass Compositions}

Since the rate-limiting step in the dissolution mechanism is the same for all waste glasses, the $\mathrm{pH}$ and temperature dependence is the same for all waste glasses (Section 7.4.6).

\subsubsection{The Glass is Unaltered in Water Vapor Below $100^{\circ} \mathrm{C}$}

The alteration of glasses in water vapor as a function of the water vapor pressure is not completely understood. Water vapor enters the glass matrix in many natural and manmade glasses. Obsidian artifacts are often dated by determining the extent to which water has diffused into the glass artifact (Friedman and Long 1976 [DIRS 163253]). However, at low temperatures, these artifacts are not altered even though water has diffused into the glass. Manmade artifacts with much less durability than nuclear waste glasses have existed for up to 3,500 years without significant alteration (Cunnane et al. 1994 [DIRS 101589]). 


\subsubsection{Uncertainties in the Subsystem and Environment}

Except in the case where the relative humidity is less than $44 \%$, the amount of water contacting the exposed glass is not specified directly in the model. Rather, it is treated as an uncertainty that is taken into account through the range and distribution of the effective rate constant. The lower end of the range of values of the effective rate constant is selected to yield a calculated value that matches the rate measured in tests with glass contacted by dripping water (when the solution is acidic) or by humid air (when the solution is alkaline) at the $\mathrm{pH}$ and temperatures of those tests. The $\mathrm{pH}$ of the solution accumulated in a breached waste package is provided by In-Package Chemistry Abstraction (BSC 2004 [DIRS 167621]). The upper end of the range of values of the effective rate constant is selected to yield a calculated rate that matches the rate measured for immersed glass. The most likely value of the effective rate constant is selected to be the lower limit. This is because the environment within a breached waste package is anticipated to be hydrologically unsaturated for most of the service life.

The composition of the waste glass in a breached container is also treated as an uncertainty. The radionuclide inventory is averaged over all HLW glass packages. However, an average glass composition is not used in this report. Instead, the results of tests conducted with glasses having a range of compositions are used to provide a corresponding range of degradation rates, and the upper range for immersion conditions and lower range for dripping water conditions is used to determine model parameter values.

\subsection{CONSIDERATION OF ALTERNATIVE CONCEPTUAL MODELS}

A summary of the alternative conceptual models considered is provided in Table 6-2.

Table 6-2. Alternative Conceptual Models Considered

\begin{tabular}{|l|l|l|}
\hline Alternative Conceptual Models & \multicolumn{1}{|c|}{ Key Concepts } & \multicolumn{1}{|c|}{ Screening Assessment and Basis } \\
\hline Diffusion-controlled release & $\begin{array}{l}\text { Release rate of radionuclides } \\
\text { determined by solid-state diffusion } \\
\text { rates. }\end{array}$ & $\begin{array}{l}\text { Not incorporated into TSPA-LA model } \\
\text { Not supported by data for waste glasses }\end{array}$ \\
\hline $\begin{array}{l}\text { Composition independent } \\
\text { effective rate constant }\end{array}$ & $\begin{array}{l}\text { Intrinsic rate constants vary over } \\
\text { a small interval for different } \\
\text { compositions and the very low } \\
\text { flow rates in the repository } \\
\text { compared to those used in the } \\
\text { laboratory mean that the affinity } \\
\text { term will be low. }\end{array}$ & $\begin{array}{l}\text { Not incorporated into TSPA-LA model } \\
\text { Current approach provides a much more } \\
\text { robust range of values for use in the } \\
\text { TSPA-LA }\end{array}$ \\
\hline
\end{tabular}

\subsubsection{Diffusion-Controlled Release}

An alternative conceptual model that is considered for the process controlling glass degradation was developed for HLW glass in France. Researchers at the Commissariat à l'Énergie Atomique (CEA) in France attribute the residual dissolution rate to diffusion-controlled release of silica (Jégou et al. 2000 [DIRS 163260]; Vernaz et al. 2001 [DIRS 163328]; Gin, Jollivet et al. 2001 [DIRS 163256]; Gin, Ribet, and Couillard 2001 [DIRS 163255]). They have concluded that the reaction-control model in Equation 5 is inconsistent with the results of various tests they have conducted with the reference glass R7T7 and simple analog glasses, and that the results are better described with a diffusion-based model. They point to the fact that a range of saturation 
concentration values are measured under different test conditions (primarily in tests at different $\mathrm{S} / \mathrm{V}$ ratios) and that $\mathrm{a}_{\mathrm{sat}}$ is not an intrinsic value of a glass. Rather, it is simply a fitting parameter that is sensitive to the test conditions. Vernaz et al. (2001 [DIRS 163328], pp. 31 and 32) state:

For most glasses, the dissolution rate is not controlled primarily by the chemical affinity of the hydrolysis reaction, but rather by the transport properties of the reacting species through the gel layer, which evolve significantly during glass leaching...

A current shortcoming of the French approach is the inability to identify the diffusion layer. It may be composed of the entire alteration layer or only a very thin layer at the layer-glass interface. The effects of the diffusion layer are simply regressed from test data. Careful examinations of reacted glass surfaces with transmission electron microscopy have not detected the presence of such a layer. The CEA researchers admit to the present uncertainty of whether the entire gel layer or only a small fraction of the gel layer near the alteration front serves as the diffusion layer that controls the glass dissolution rate in concentrated solutions.

The rate expression used at CEA (Vernaz et al. 2001 [DIRS 163328], p. 34) is given in Equation 7 with the following correspondences: $r_{m} \equiv R_{\text {dissolution }} ; D \equiv D_{g e l} ; L \equiv x ; a_{s} \equiv C_{s l b} ; a_{b s} \equiv$ $C_{S i} ; a_{s a t} \equiv C^{*} ; k_{f} \equiv r_{0}$.

$$
R_{\text {dissolution }}=\frac{r_{0}\left[\left(\frac{D_{\text {gel }}}{x}\right) \times\left(C_{\text {slb }}-C_{S i}\right)+r_{\text {residual }}\right]}{\left(\frac{D_{\text {gel }}}{x}\right) \times C^{*}+r_{0}}
$$

The silicon concentration at the glass/gel interface $\left(C_{s l b}\right)$ is expressed as a function of the Si concentration in solution $\left(C_{S i}\right)$ and the degree of dissociation $(\alpha)$ as:

$$
C_{s l b}=C_{\text {glass }}\left\{1-\left[1-\exp \left(-\alpha C_{S i}\right)\right]\right\}
$$

Values of the parameters $D_{\text {gel }}, C^{*}$ (or $a_{\text {sat }}$ ), and $\alpha$ are obtained from a fit to the experimental data collected under specific test conditions (temperature, $\mathrm{pH}, \mathrm{S} / \mathrm{V}$ ) to match anticipated disposal environments. The ability of the CEA model to predict glass degradation behavior depends on how well the tests conducted to determine these parameter values represent conditions in a breached waste package. The dependence of the forward rate, $\mathrm{r}_{0}$, by Vernaz et al. (2001 [DIRS 163328]) on the temperature and $\mathrm{pH}$ must also be determined to implement Equation 7. The dependence of the dissolution rate on $\mathrm{pH}$ and temperature are not stated explicitly by Vernaz et al. (2001 [DIRS 163328]), except for determination of the parameters $D_{g e l}, C^{*}$, and $\alpha$.

Many of the tests conducted at CEA that led them to use a diffusion-controlled model have been summarized by Jégou et al. (2000 [DIRS 163260]) and by Vernaz et al. (2001 [DIRS 163328]). As part of the screening exercise, the evaluation of those test data was reviewed to confirm that they support rejection of the dissolution-control model in Equation 6. The tests described by Jégou et al. (2000 [DIRS 163260]) were conducted with the simple, three component glass 
$14.21 \mathrm{Na}_{2} \mathrm{O}-20.23 \mathrm{~B}_{2} \mathrm{O}_{3}-65.56 \mathrm{SiO}_{2}$ at $90^{\circ} \mathrm{C}$ at an $\mathrm{S} / \mathrm{V}$ of $400 \mathrm{~m}^{-1}$ for up to only 14 days. The data in Figure 4 of the report by Jégou et al. (2000 [DIRS 163260]) do not indicate that a constant silica concentration has been attained within 14 days, even though the Si saturation concentration is exceeded. Results from these tests showed that $\mathrm{B}$ and $\mathrm{Na}$ continued to release even after the saturation concentration of $\mathrm{H}_{4} \mathrm{SiO}_{4}$ had been reached.

Diffusion is an important process in the glass dissolution mechanism. Diffusion of water into the glass and alkali metals out of the glass are initial steps in glass degradation and in the long-term, although the latter is still under discussion. In the long-term, ion exchange and the small but constant precipitation of alteration products may also control the rate in silica-saturated solutions (McGrail et al. 2001 [DIRS 171165]). In the case of nuclear waste glasses at the beginning of the glass-water reaction, ion exchange quickly attains steady-state rates and can be included in the rate constant value.

Accounting for diffusion-control of glass dissolution under near-saturation conditions is not addressed in the TSPA-LA model developed in this report for several reasons, including unconvincing arguments regarding the importance of diffusion-control in the gel layer during glass dissolution, the inability to identify the diffusion barrier, the need for additional fitting parameters in the model, the negligible impact on the calculated rates, and the literature that shows the same results are consistent with Equation 6.

\subsubsection{Composition-Independent Effective Rate Constant}

In the model developed herein, the affinity term, the $(1-\mathrm{Q} / \mathrm{K})$ term from Equation 6 , and the intrinsic rate constant, $\overrightarrow{k_{0}}$ (Equation 6 ), are combined into an effective rate constant that has variability based on the results from many experiments. This approach is taken because the concentration of $\mathrm{H}_{4} \mathrm{SiO}_{4}$ is not tracked in the TSPA-LA. Thus, the variability in the intrinsic rate constant from the different glass compositions is combined with the natural variation in the affinity term because of the changes in solution concentration.

A composition independent intrinsic rate constant is a fairly close approximation to the experimental results from experiments in which this quantity has been measured. The value for the $\overrightarrow{k_{0}}$ in alkaline solutions that can be extracted from the data $\left(\mathrm{pH}=9.9, \mathrm{~T}=18^{\circ} \mathrm{C}\right.$, $\mathrm{r}_{\mathrm{B}}=0.0122 \mathrm{~g} /\left(\mathrm{m}^{2} \cdot \mathrm{d}\right)$ reported by Abraitis et al. (2000 [DIRS 163195]) on a glass with significantly different composition is $4.5 \times 10^{5} \mathrm{~g} /\left(\mathrm{m}^{2} \cdot \mathrm{d}\right)$. When compared to the

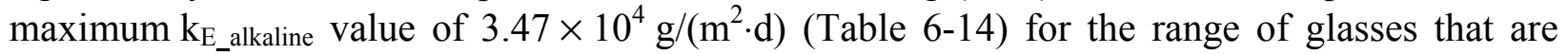
expected at Yucca Mountain, the agreement is good considering that the tests that were used to obtain the dissolution rates were different; both tests yield a rate that is biased low because neither is a single-pass flow-through test. Thus, the case can be made that the variation in the intrinsic rate constant is small and the use of a constant value would result in an insignificant bias when calculating the rates.

The range of values for the affinity term, $(1-\mathrm{Q} / \mathrm{K})$, is from 1 to $10^{-4}$, with the latter value coming from the work of Gin and Mestre (2001 [DIRS 171170]). The long-term dissolution rate is expected to be quite low and has been measured at values of less than $10^{-4}$ that of the forward 
rate (Grambow et al. 1992 [DIRS 119131]; Gin and Frugier 2003 [DIRS 171328]; Ebert and Mazer 1994 [DIRS 171327]; and Lemens et al. 2003 [DIRS 171169]). The flow rates at Yucca Mountain are very low (BSC 2004 [DIRS 169860]). The high flow rate (15 L/y, BSC 2004 [DIRS 167621]) at the repository divided by the surface area of the glass in a waste package (Equation 48 with $\mathrm{f}_{\text {exposure }}=4$ ) is $4.1 \times 10^{-5} \mathrm{~m}^{3} / \mathrm{d} / 7.3 \mathrm{~m}^{2}=1.4 \times 10^{-6} \mathrm{~m} / \mathrm{d}$, or $1.8 \times 10^{-11} \mathrm{~m} / \mathrm{s}$. This value is several orders of magnitude lower than the fast flow rates used to determine forward dissolution rates with single-pass flow-through experiments (McGrail et al. 1997 [DIRS 111039]). At these flow rates, the dissolution rate of the glass is not expected to be at either the forward or the final rate. At the lower flow rate of $0.15 \mathrm{~L} / \mathrm{y}$ expected at the repository (BSC 2004 [DIRS 167621]), the dissolution rate of the glass would be much lower. These considerations suggest that the affinity term can be combined with the intrinsic rate constant to give an effective rate constant, $\mathrm{k}_{\mathrm{E}}$.

\subsection{BASE-CASE GLASS DISSOLUTION MODEL}

As HLW glass dissolves, congruent release of radionuclides is assumed. This is calculated as the product of three terms:

$$
R_{R N}=\text { rate }_{G} \times S \times I_{R N}
$$

where

$R_{R N}=$ the release rate of radionuclide, $\mathrm{RN}$ (g/day)

rate $_{G}=$ the dissolution rate of the glass $\left(\mathrm{g} /\left(\mathrm{m}^{2} \cdot \mathrm{d}\right)\right)$

$S \quad=$ the surface area of glass contacted by water $\left(\mathrm{m}^{2}\right)$

$I_{R N}=$ the inventory of radionuclide $\mathrm{RN}$ in the glass (g RN/g glass).

Mathematical expressions are developed in this report for the degradation rate of the glass and the glass surface area contacted by water. The input data and the information used to develop each model are described in Section 4.1 and the sources of corroborating/supporting information are summarized in Table 6-3. The development of these models is described below. The inventory is obtained from Initial Radionuclide Inventories (BSC 2004 [DIRS 170022]). 
Table 6-3. Corroborative/Supporting Information Used to Develop Models

\begin{tabular}{|c|c|c|}
\hline Issue & Information & Sources \\
\hline \multirow{5}{*}{$\begin{array}{l}\text { Form of glass dissolution rate } \\
\text { expression }\end{array}$} & $\begin{array}{l}\text { Mechanistic model for dissolution } \\
\text { of aluminosilicate minerals and } \\
\text { application to borosilicate waste } \\
\text { glass }\end{array}$ & $\begin{array}{l}\text { CRWMS M\&O } 1998 \text { [DIRS 100362] } \\
\text { Ebert } 2000 \text { [DIRS 145944] } \\
\text { Lasaga and Gibbs } 1990 \text { [DIRS 163265] } \\
\text { Lasaga } 1983 \text { [DIRS 141616] } \\
\text { Aagaard and Helgeson 1982 [DIRS 101530] } \\
\text { Grambow } 1985 \text { [DIRS 163257] } \\
\text { Jégou et al. } 2000 \text { [DIRS 163260] } \\
\text { Vernaz et al. } 2001 \text { [DIRS 163328] } \\
\text { Gin, Jollivet et al. } 2001 \text { [DIRS 163256] } \\
\text { Gin, Ribet, and Couillard } 2001 \text { [DIRS 163255] }\end{array}$ \\
\hline & $\begin{array}{l}\text { Effect of glass composition on } \\
\text { forward rate }\end{array}$ & $\begin{array}{l}\text { Ellison et al. } 1994 \text { [DIRS 111030] } \\
\text { Van Iseghem and Grambow 1988 [DIRS 111048] } \\
\text { Strachan and Croak } 2000 \text { [DIRS 163327] }\end{array}$ \\
\hline & $\begin{array}{l}\text { Effect of affinity term and } \\
\text { alteration phases on glass } \\
\text { degradation rate }\end{array}$ & $\begin{array}{l}\text { Bourcier 1991 [DIRS 119110] } \\
\text { Advocat et al. } 1990 \text { [DIRS 110996] } \\
\text { Patyn et al. } 1990 \text { [DIRS 111042] } \\
\text { Van Iseghem and Grambow 1988 [DIRS 111048] } \\
\text { Fortner and Bates } 1996 \text { [DIRS 111033] } \\
\text { Ebert et al. } 1993 \text { [DIRS 111052] } \\
\text { Feng et al. } 1993 \text { [DIRS 111031] } \\
\text { Bates and Steindler } 1983 \text { [DIRS 104261] } \\
\text { Abrajano et al. } 1986 \text { [DIRS 110990] } \\
\text { Ebert, Bakel, and Brown 1996 [DIRS 111023] } \\
\text { Ebert and Tam 1997 [DIRS 111029] } \\
\text { Ebert and Bates } 1993 \text { [DIRS 113264] }\end{array}$ \\
\hline & Range of parameter values $\mathrm{k}_{\mathrm{E}}$ & $\begin{array}{l}\text { Ebert et al. } 1998 \text { [DIRS 111027] } \\
\text { Ebert et al. } 1987 \text { [DIRS 163248] } \\
\text { Wronkiewicz et al. } 1997 \text { [DIRS 163350] } \\
\text { Brady and Walther 1989 [DIRS 110748] } \\
\text { Carroll et al. } 1994 \text { [DIRS 111011] }\end{array}$ \\
\hline & $\begin{array}{l}\text { Glass degradation in humid air } \\
\text { and dripping water }\end{array}$ & $\begin{array}{l}\text { Ebert, Hoburg, and Bates } 1991 \text { [DIRS 111028] } \\
\text { Hagymassy et al. } 1969 \text { [DIRS 111034] } \\
\text { Bates et al. } 1990 \text { [DIRS 111002] } \\
\text { Friedman and Long } 1976 \text { [DIRS 163253] } \\
\text { Bates and Steindler } 1983 \text { [DIRS 104261] } \\
\text { Byers et al. } 1985 \text { [DIRS 163209] } \\
\text { Luo et al. } 1997 \text { [DIRS 163271] } \\
\text { Greenspan } 1977 \text { [DIRS 104945] }\end{array}$ \\
\hline Exposed glass surface area & Model parameter values & $\begin{array}{l}\text { Bickford and Pellarin } 1987 \text { [DIRS 163207] } \\
\text { Perez and Westsik } 1981 \text { [DIRS 111044] } \\
\text { Pederson et al. } 1983 \text { [DIRS 118927] } \\
\text { Jiřička et al. } 2001 \text { [DIRS 163262] }\end{array}$ \\
\hline
\end{tabular}

\subsubsection{Mechanistic Rate Expression for Aqueous Dissolution}

The same rate expression is used to calculate the degradation rate of glass exposed to humid air, dripping water, or immersed in water. This is because the same processes are operative under those conditions. The primary difference is how much glass must dissolve before solubility limits affect the degradation rate. The rate expression used in this report was developed originally for the dissolution of aluminosilicate minerals and later adapted for dissolution of borosilicate glass in aqueous solutions (Bourcier 1994 [DIRS 101563], pp. 17 to 22). The same rate expression that was documented in Chapter 6 of Total System Performance Assessment- 
Viability Assessment (TSPA-VA) Analyses Technical Basis Document (CRWMS M\&O 1998 [DIRS 100362], p. 6-77, Equation 6-37) is used in the analyses described in this report. These models for aluminosilicate minerals and glass were developed for reaction conditions in which the amount of water was not restrictive to dissolution. Extension of the rate expression to the degradation of glass contacted by small volumes of water is part of this report. The rate expression includes parameters for the effects of glass composition, $\mathrm{pH}$, temperature, and dissolved silica on the dissolution rate. The simplification of that rate expression for use in TSPA-LA calculations and the determination of parameter values that represent the degradation of a range of waste glass compositions in different water contact scenarios are described in this report. The analysis of the rate expression is summarized below. The rate expression for the dissolution of glass in an aqueous solution is:

$$
\text { rate }_{G}=k_{f}\left(1-\frac{Q}{K}\right)+k_{\text {long }}
$$

where

rate $_{G}=$ the dissolution rate of the glass, mass/(area $\cdot$ time)

$k_{f} \quad=$ the forward glass dissolution rate, which is a function of the glass composition, temperature, and solution $\mathrm{pH}$, mass/(area·time)

$Q=$ the $\mathrm{H}_{4} \mathrm{SiO}_{4}$ concentration in the solution, mass/volume

$K=$ the apparent $\mathrm{H}_{4} \mathrm{SiO}_{4}$ saturation concentration for the glass, mass/volume

$k_{\text {long }}=$ long-term dissolution rate, mass/(area-time).

Equation 10 is used to simplify application to experimental data, where concentrations rather than activities are provided and the degradation (or dissolution) rates are given on a per area basis. The rate expression contains two main parts: the forward rate, $\mathrm{k}_{\mathrm{f}}$, which represents the dissolution rate in the absence of feedback effects of dissolved silica, and the reaction affinity term, $(1-\mathrm{Q} / \mathrm{K})($ Eq. 6). The value of the affinity term is determined based on how far the silica concentration $(\mathrm{Q})$ is from the apparent saturation concentration $(\mathrm{K})$. The value of $\mathrm{K}$ depends on the reaction conditions (experiment or repository). Because the value of $\mathrm{Q}$ can range between zero and $\mathrm{K}$, the value of the affinity term is mathematically constrained to values between one and zero. A glass will dissolve at the highest rate possible at a given temperature and $\mathrm{pH}$ value when the value of the affinity term is one (i.e., when $\mathrm{Q}=0$ ). The dissolution rate will decrease as the value of the affinity term decreases (i.e., as the value of Q approaches $\mathrm{K}$ ) until a minimum is reached. The constant term $k_{\text {long }}$ was included in the rate expression to prevent the calculated rate from becoming zero if the value of $\mathrm{Q}$ became equal to (or greater than) $\mathrm{K}$ in simulations over long durations (Grambow 1985 [DIRS 163257]). The $k_{f}$ and, perhaps, $k_{\text {long }}$ are characteristics of the glass while $\mathrm{Q}$ depends on the contact conditions.

The forward glass dissolution rate depends on the glass composition, solution $\mathrm{pH}$, and temperature (first three terms in Equation 6). 
These dependencies can be expressed explicitly as (Ebert 2000 [DIRS 145944]):

$$
k_{f}=\overrightarrow{k_{0}} \times 10^{\eta \cdot p H} \times \exp \left(\frac{-E_{a}}{R T}\right)
$$

where

$$
\begin{aligned}
k_{f}= & \text { forward glass dissolution rate, mass } /(\text { area } \cdot \text { time }) \\
\vec{k}_{0}= & \text { intrinsic rate constant, which depends only on glass composition, in units of } \\
& \text { mass } /(\text { area } \cdot \text { time }) \\
\eta= & \text { order of the reaction with respect to } \mathrm{H}^{+}, \text {dimensionless } \\
E_{a}= & \text { activation energy for the rate limiting step Equation } 1 \mathrm{a}, \mathrm{b}, \mathrm{kJ} / \mathrm{mol} \\
R= & \text { gas constant, } 8.314 \times 10^{-3} \mathrm{~kJ} /(\mathrm{mol} \cdot \mathrm{K}) \\
T \quad= & \text { temperature, Kelvin. }
\end{aligned}
$$

This expression is applied to all borosilicate waste glass compositions. The full rate expression is obtained by combining Equations 10 and 11, which yields Equation 12:

$$
\text { rate }_{G}=\overrightarrow{k_{0}} \times 10^{\eta \cdot p H} \times\left[\exp \left(\frac{-E_{a}}{R T}\right)\right] \times\left[1-\frac{Q}{K}\right]+k_{\text {long }}
$$

The rate expression in Equation 12 can be used for different water contact modes because the dissolution rate does not depend directly on the volume of water that is in contact with the glass or whether the contact is static or dynamic. Instead, the rate depends on the chemistry of the water through the $\mathrm{pH}$ and the concentration of dissolved silica (the latter dependence is expressed through the affinity term). The rate does not have an explicit time dependence because the rate of dissolution is a function of the solution concentrations and the temperature. The effect of the exposure mode (i.e., whether glass is contacted by humid air, dripping water, or is immersed) will be accounted for by the range of model parameter values.

The rate expression can be further simplified to a rate expression that can be used in TSPA-LA. Because the dissolution rate under repository conditions will never become zero and for ease of implementation, the variation in the $\mathrm{k}_{\text {long }}$ and the affinity term can be combined into an effective rate constant. This effective rate constant, then, also carries with it the variability from the different glass compositions that will be disposed in the repository. Equation 12 becomes:

$$
\text { rate }_{\text {glass }}=k_{E} \times 10^{\eta \cdot p H} \times \exp \left(\frac{-E_{a}}{R T}\right)
$$

The value of $k_{E}$ takes into account the effects of the glass composition, including the heterogeneity of the waste inventory, as well as the effects of the solution composition. The model for glass degradation requires specification of three parameter values: $k_{E}, \eta$, and $E_{a}$, and two variables: $\mathrm{T}$ and $\mathrm{pH}$. Values of the parameters for use in the glass degradation model are determined in this report. The approach taken is to use the same values of $\eta$ and $E_{a}$ for all glass compositions and define the range and distribution of $\mathrm{k}_{\mathrm{E}}$ values so that the range of calculated 
degradation rates spans the range of rates measured in laboratory tests. There are different values for both of these parameters for acid and alkaline solutions.

\subsubsection{Determination of Model Parameter Values for TSPA-LA}

\subsubsection{Dependence on $\mathrm{pH}$ and Temperature}

Tests were conducted specifically to measure the effect of $\mathrm{pH}$ and temperature on the forward dissolution rate of a glass (SRL 202G) having a composition representative of DWPF glasses. The tests are described in detail in Appendix A. Briefly, tests were conducted following the MCC-1 static leach test procedure (ASTM C 1220-98 [DIRS 119321]). Monolithic glass specimens were immersed in test solutions having various buffered $\mathrm{pH}$ values for various durations at either $70^{\circ} \mathrm{C}$ or $90^{\circ} \mathrm{C}$. At the end of the test duration, the solution was analyzed for boron to determine the extent of dissolution. In some tests, $\mathrm{FeCl}_{3}, \mathrm{FeOOH}, \mathrm{Fe}_{2} \mathrm{O}_{3}$, or $\mathrm{Fe}_{3} \mathrm{O}_{4}$ was added to measure the effect of dissolved iron and the presence of iron corrosion products on the glass dissolution rate. Negligible amounts of iron dissolved except in the $\mathrm{pH} 1.2$ and 3.7 solutions. The normalized boron mass loss, NL(B), was calculated from the measured concentrations with Equation 14:

$$
N L(B)=\frac{C(B)-C^{\circ}(B)}{f(B) \times\left(\frac{S}{V}\right)}
$$

where $\mathrm{C}(\mathrm{B})$ is the boron concentration measured in the test solution, $\mathrm{C}^{\circ}(\mathrm{B})$ is the boron concentration measured in a blank test solution at the same temperature, $\mathrm{S} / \mathrm{V}$ is the glass surface area/solution volume ratio, and $\mathrm{f}(\mathrm{B})$ is the mass fraction of boron in the glass. This normalizes the mass of boron released from the glass in the test to the surface area of the sample and the mass fraction of boron in the glass. The units for $\mathrm{NL}(\mathrm{B})$ are mass glass per unit area. The values of NL(B) were plotted against the test duration and lines fit to short-term results to estimate the forward dissolution rate at each $\mathrm{pH}$ for tests at $70^{\circ} \mathrm{C}$ and $90^{\circ} \mathrm{C}$ and at $90^{\circ} \mathrm{C}$ with added iron. For each set of $\mathrm{pH}$ and temperature, the slope of the fit line gives the forward dissolution rate, which is expressed as the normalized boron release rate, NR(B). The data and analyses are given in Appendix A. The rates determined from the plots are summarized in Appendix A, Table A-8 and reproduced in Table 6-4. The dissolution rate at $70^{\circ} \mathrm{C}$ and $\mathrm{pH} 11.9$ was determined both with and without the result of the test run for the shortest duration (GB6-70-1). The $\mathrm{pH}$ dependence was determined from the rate with that point included and the temperature dependence was determined from the rate with that point excluded. The impact of the point on the parameter values is negligible relative to experimental and modeling uncertainties. 
Table 6-4. Results of Tests with SRL 202G Glass: NR(B), $g /\left(m^{2} \cdot d\right)$

\begin{tabular}{|c|c|c|c|}
\hline Nominal $\mathrm{pH}^{\mathrm{a}}$ & Tests at $70^{\circ} \mathrm{C}$ & Tests at $90^{\circ} \mathrm{C}$ & $\begin{array}{c}\text { Tests at } 90^{\circ} \mathrm{C} \\
\text { (With Added Iron) }\end{array}$ \\
\hline 1.0 & - & - & 133 \\
\hline 1.3 & 55.5 & 79.1 & - \\
\hline 3.7 & 2.26 & 6.47 & 7.17 \\
\hline 5.0 & 1.03 & 1.27 & - \\
\hline 8.5 & 0.139 & 0.410 & 0.543 \\
\hline 9.3 & 0.197 & 0.522 & 0.816 \\
\hline 9.8 & - & 3.38 & - \\
\hline 10.2 & 0.646 & - & 5.17 \\
\hline 11.9 & $8.33^{b}$ & 15.4 & 15.6 \\
\hline
\end{tabular}

The rates measured at each temperature are used to determine the $\mathrm{pH}$ dependence for acidic and alkaline solutions. These values are plotted against the nominal solution $\mathrm{pH}$ in Figure 6-1 for acidic and alkaline solutions, respectively. The rates in acidic solution decrease as the $\mathrm{pH}$ increases, whereas the rates in alkaline solutions increase as the $\mathrm{pH}$ increases.

The results of the $70^{\circ} \mathrm{C}$ tests were fit with regression (KaleidaGraph) lines having the equations:

$$
\log _{10}\left(\operatorname{rate}_{\mathrm{G}}\right)=-0.482 \times \mathrm{pH}+2.31
$$

for acidic solutions and

$$
\log _{10}\left(\text { rate }_{\mathrm{G}}\right)=0.543 \times \mathrm{pH}-5.63
$$

for alkaline solutions. These fits are shown in Figure 6-1 by dashed lines. The results of tests conducted at $90^{\circ} \mathrm{C}$ with and without added iron are experimentally indistinguishable at all $\mathrm{pH}$ values, and the combined results of tests at $90^{\circ} \mathrm{C}$ with and without added iron were fit with regression lines. This result is significant because an abundance of iron corrosion products are expected to be present in a breached waste package due to corrosion of iron-containing structural components, including the waste package itself. These results show significant concentrations of dissolved iron will only occur when the solution $\mathrm{pH}$ is very low (near 3.7), and that the chemical effects of dissolved iron will not impact the glass degradation rate at any $\mathrm{pH}$ value. Iron corrosion products may affect the glass degradation rate indirectly through sorption of dissolved silica.

Data for tests at $90^{\circ} \mathrm{C}$ in acidic and alkaline solutions were fit separately with lines having the equations:

$$
\log _{10}\left(\operatorname{rate}_{\mathrm{G}}\right)=-0.485 \times \mathrm{pH}+2.59
$$

in acidic solutions and:

$$
\log _{10}\left(\operatorname{rate}_{\mathrm{G}}\right)=0.471 \times \mathrm{pH}-4.35
$$


in alkaline solutions. These fits are shown as dotted lines in Figure 6-1. Because results are only available for two temperatures, the results in acidic solution at both temperatures and the results in alkaline solutions at both temperatures were combined to determine the average slopes. Regressions to results at both temperatures are shown as solid lines in Figure 6-1 for acidic and alkaline solutions. The equations of the regressed lines are:

$$
\log _{10}\left(\operatorname{rate}_{\mathrm{G}}\right)=-0.494 \times \mathrm{pH}+2.51
$$

for acidic solutions and:

$$
\log _{10}\left(\operatorname{rate}_{\mathrm{G}}\right)=0.491 \times \mathrm{pH}-4.73
$$

for alkaline solutions. The average slopes are -0.49 for acidic solutions and 0.49 for alkaline solutions. These values are used as the values for the $\mathrm{pH}$ dependence in the TSPA-LA glass model. Only the slope of these lines is used. Separate lines having this slope are fit to the $70^{\circ} \mathrm{C}$ and the $90^{\circ} \mathrm{C}$ rates in the next step.

The $\mathrm{pH}$ dependencies determined for dissolution in acidic and alkaline solutions were regressed to the measured rates to determine the temperature dependence. Lines having slope -0.49 were regressed to the data for tests at $70^{\circ} \mathrm{C}$ and $90^{\circ} \mathrm{C}$ in acidic solutions, and lines having slope 0.49 were regressed to the data for tests at $70^{\circ} \mathrm{C}$ and $90^{\circ} \mathrm{C}$ in alkaline solutions. Terms for the effects of temperature and $\mathrm{k}_{\mathrm{E}}$ were expressed as $\mathrm{A}_{\text {acid }}$ for tests in acidic solutions and $\mathrm{A}_{\text {alkaline }}$ for tests in alkaline solutions so that the test results could be regressed. The effects of temperature are distinguished in a subsequent step. The sum of the residuals between the measured rates (Table 6-4) and the rates calculated with Equation 21:

$$
\log _{10}\left(\operatorname{rate}_{\mathrm{G}}\right)=\mathrm{A}_{\mathrm{acid}}-0.49 \times \mathrm{pH}
$$

were minimized to determine the value of $\mathrm{A}_{\text {acid }}$ for acidic solutions, and the residuals between the measured rates (from Table 6-4) and the rates calculated with Equation 22:

$$
\log _{10}\left(\text { rate }_{\mathrm{G}}\right)=\mathrm{A}_{\text {alkaline }}+0.49 \times \mathrm{pH}
$$

were minimized to determine the value of $\mathrm{A}_{\text {alkaline }}$ for alkaline solutions. Calculation of the rates and minimization of the residuals was done using a Microsoft Excel spreadsheet (Appendix A, Table A-9). The resulting equations for the regressed fit lines are:

$$
\begin{gathered}
\log _{10}\left(\text { rate }_{\mathrm{G}}\right)=2.34-0.49 \times \mathrm{pH} \text { for acidic solutions at } 70^{\circ} \mathrm{C} \\
\log _{10}\left(\text { rate }_{\mathrm{G}}\right)=2.60-0.49 \times \mathrm{pH} \text { for acidic solutions at } 90^{\circ} \mathrm{C} \\
\log _{10}\left(\text { rate }_{\mathrm{G}}\right)=-5.12+0.49 \times \mathrm{pH} \text { for alkaline solutions at } 70^{\circ} \mathrm{C} \\
\log _{10}\left(\text { rate }_{\mathrm{G}}\right)=-4.54+0.49 \times \mathrm{pH} \text { for alkaline solutions at } 90^{\circ} \mathrm{C}
\end{gathered}
$$

These best fit lines are plotted along with the measured rates in Figure 6-2.

The Arrhenius relationship was used to calculate the activation energy from the rates at $70^{\circ} \mathrm{C}$ and $90^{\circ} \mathrm{C}$ at the same solution $\mathrm{pH}$. This approach is valid even with only two temperatures, since 
many previous studies have shown that the rate has Arrhenius temperature dependence as seen in Equation 5. The rate is expressed as a function of temperature as:

$$
\operatorname{rate}_{\mathrm{G}}=\mathrm{B} \cdot \exp \left(-\mathrm{E}_{\mathrm{a}} / \mathrm{RT}\right)
$$

where $\mathrm{B}$ is a constant and $\mathrm{R}$ is the ideal gas constant $\left(8.314 \times 10^{-3} \mathrm{~kJ} /(\mathrm{mol} \cdot \mathrm{K})\right)$. The ratio of the rates at $90^{\circ} \mathrm{C}$ and $70^{\circ} \mathrm{C}$ is:

$$
\frac{\text { rate }_{G}\left(T_{2}\right)}{\text { rate }_{G}\left(T_{1}\right)}=\exp \left\{\frac{E_{a}}{R}\left[\frac{1}{T_{1}}-\frac{1}{T_{2}}\right]\right\}
$$

Inserting $\mathrm{T}_{1}=70^{\circ} \mathrm{C}(=343 \mathrm{~K})$ and $\mathrm{T}_{2}=90^{\circ} \mathrm{C}(=363 \mathrm{~K})$ and $\mathrm{R}=0.008314 \mathrm{~kJ} /(\mathrm{mol} \mathrm{K})$ gives

$$
\frac{\text { rate }_{G}\left(90^{\circ} \mathrm{C}\right)}{\text { rate }_{G}\left(70^{\circ} \mathrm{C}\right)}=\exp \left\{1.932 \times 10^{-2} \times E_{a}\right\}
$$

(a)

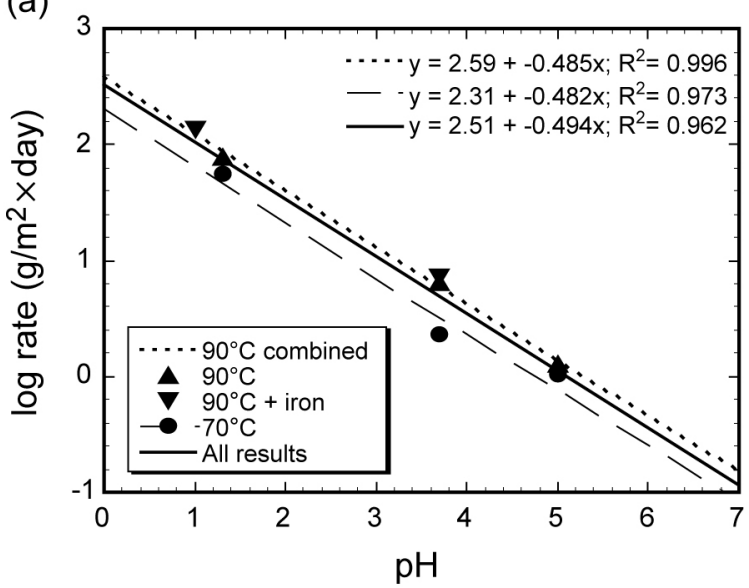

(b)

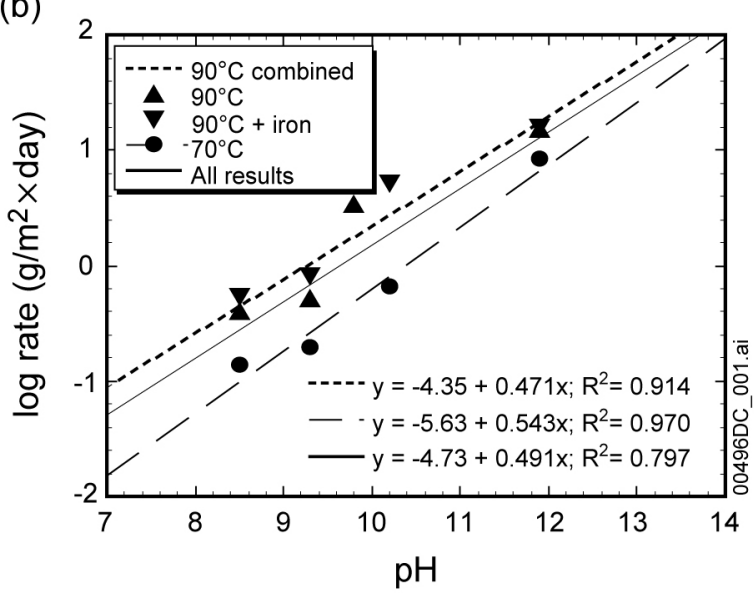

Source: Table 6-4.

Figure 6-1. Linear Regression of Test Results at $70^{\circ} \mathrm{C}$ and Combined Results for Tests With and Without Added Iron at $90^{\circ} \mathrm{C}$ in (a) Acidic Solutions and (b) Alkaline Solutions

Equations 23 and 24 were used to calculate the activation energy in acidic solutions, and Equations 25 and 26 were used to calculate the activation energy in alkaline solutions. For acidic solutions, the rates calculated at a $\mathrm{pH}$ value of 0 are $219 \mathrm{~g} /\left(\mathrm{m}^{2} \cdot \mathrm{d}\right)$ and $398 \mathrm{~g} /\left(\mathrm{m}^{2} \cdot \mathrm{d}\right)$ at $70^{\circ} \mathrm{C}$ and $90^{\circ} \mathrm{C}$, respectively. The ratio rate $\left(90^{\circ} \mathrm{C}\right) / \operatorname{rate}\left(70^{\circ} \mathrm{C}\right)$ is $398 / 219=1.820$. Solving Equation 29 with this ratio gives a value for the acid side activation energy of $\mathrm{E}_{\mathrm{a}}=\ln (1.820) / 0.01932=31.0 \mathrm{~kJ} / \mathrm{mol}$.

Similarly, the alkaline side activation energy used in the model is $\mathrm{E}_{\mathrm{a}}=69 \mathrm{~kJ} / \mathrm{mol}$. 


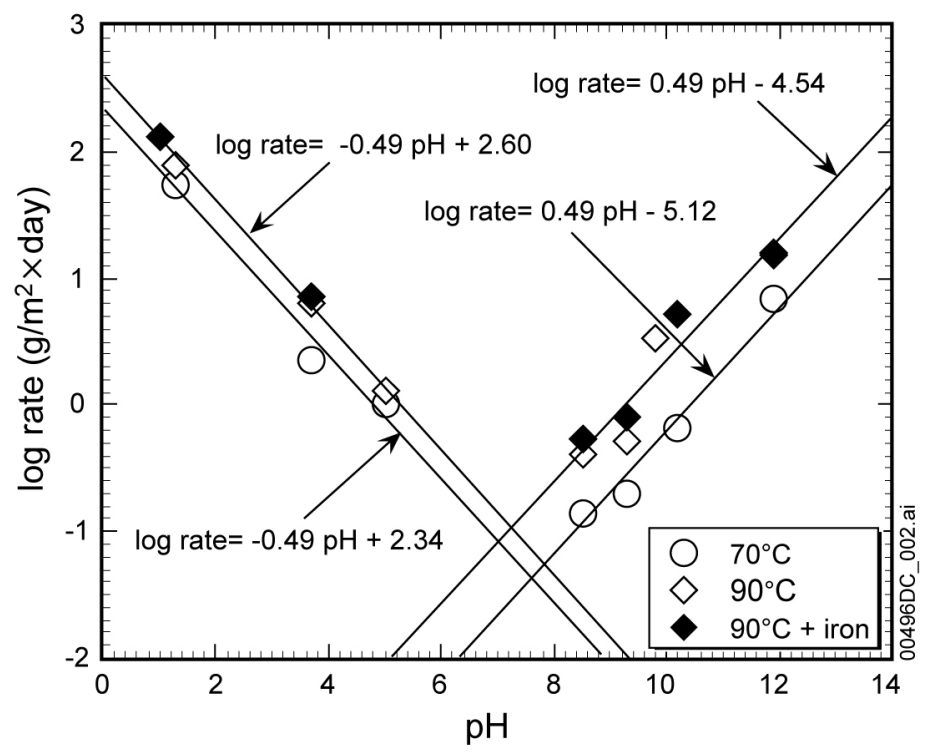

Source: Appendix A, Table A-9.

Figure 6-2. Plot of Measured Rates and Regressed Lines Against pH Measured at Room Temperature

Different steps in the reaction mechanism for the dissolution of borosilicate glasses dominate in acidic and alkaline solutions. These reactions have different $\mathrm{pH}$ dependencies, as shown in Figure 6-1 for SRL 202G glass, and intersection of the lines in near-neutral solutions gives rise to the overall $\mathrm{V}$-shaped $\mathrm{pH}$ dependence seen in Figure 6-2.

\subsubsection{Dependence on Glass Composition}

The glass degradation model developed in this report is representative of the range of acceptable waste glass compositions for disposal. The effect of the glass composition on the glass dissolution rate is represented in Equation 6 by the intrinsic dissolution rate constant $\left(\overrightarrow{k_{0}}\right)$. The value of $\overrightarrow{k_{0}}$ is determined by separating the contributions of the $\mathrm{pH}$ and temperature terms from the measured forward rate. The value of $\overrightarrow{k_{0}}$ that is extracted from the measured forward rate will depend on the values used for the $\mathrm{pH}(\eta)$ and temperature $\left(\mathrm{E}_{\mathrm{a}}\right)$ dependencies. Tests were conducted to estimate the forward dissolution rates of 9 glasses having compositions spanning the likely composition ranges of waste forms for DWPF, WVDP, and Hanford wastes (DTN: MO0308ANLGPC01.528 [DIRS 164790], Table 1). Glasses having concentrations of glass-forming components (e.g., $\mathrm{Al}, \mathrm{B}, \mathrm{Fe}$, and $\mathrm{Si}$ ) that are representative of concentrations expected in HLW glasses are referred to as "reference high-level glasses" in this report to distinguish them from other glass compositions that were tested to provide extreme compositions, for example, a glass without aluminum. Glass durability will not be significantly affected by the different radionuclide contents of different wastes because of the relatively low concentrations in the glass. However, differences in the amounts of other components in different wastes, such as aluminum and iron, will influence the glass composition and may affect glass durability. 
The suite of glasses used in the study was selected to study the sensitivity of $\vec{k}_{0}$ and the dissolution rate with respect to major components. Glasses were selected specifically to span the range of possible aluminum contents because the aluminum content is known to affect the durability of waste glasses in short-term tests (Ellison et al. 1994 [DIRS 111030], pp. 35, 39, 42, and 47). The aluminum content is also suspected to affect the propensity for the formation of zeolite-alteration phases (Van Iseghem and Grambow 1988 [DIRS 111048], pp. 631 and 639; Ellison et al. 1994 [DIRS 111030], p. 46; Strachan and Croak 2000 [DIRS 163327]). The compositions of the glasses that were tested are listed in Table 6-5. The PNL 76-68 glass was included in the study as a glass with no aluminum. The LD6-5412 and Hanford L compositions were developed for low-activity wastes and have higher sodium contents than are anticipated for HLW glasses. While these glass compositions may be outside the range of likely HLW glasses, they provide useful measures of the sensitivity of $\vec{k}_{0}$ at or near the lower bound of aluminum content and upper bound of sodium content of waste glasses. This set of glasses also provides a wide composition range: $\mathrm{B}$ (5.34 to 12.9 mass $\left.\% \mathrm{~B}_{2} \mathrm{O}_{3}\right), \mathrm{Fe}\left(0.12\right.$ to 22.9 mass $\left.\% \mathrm{Fe}_{2} \mathrm{O}_{3}\right), \mathrm{Na}$ (8.00 to 20.2 mass $\% \mathrm{Na}_{2} \mathrm{O}$ ), and $\mathrm{Si}\left(30.2\right.$ to 58.9 mass $\% \mathrm{SiO}_{2}$ ) contents.

Test specimens were subjected to MCC- 1 tests at $90^{\circ} \mathrm{C}$ for durations between 1 and 15 days to measure the forward dissolution rates. These tests were conducted with demineralized water and the solution $\mathrm{pH}$ was allowed to drift as the glasses dissolved. The $\mathrm{pH}$ values attained in the tests were all greater than 9 , so the results were analyzed with the parameters for alkaline solutions. The $\mathrm{pH}$ values were measured at room temperature. The glass dissolution rate concentration was determined from the boron concentrations. Test results are given in DTN: MO0308ANLGPC01.528 [DIRS 164790], Table 2. Values of $\log _{10}\left(\vec{k}_{0}\right)$ were extracted from the measured rates by separating the effects of the $\mathrm{pH}$ and temperature using Equation 13 with parameter values $\eta=0.49$ and $\mathrm{E}_{\mathrm{a}}=69 \mathrm{~kJ} / \mathrm{mol}$ (Section 6.5.2.1 and Appendix B, Table B-1). The mean \pm one standard deviation of the values of $\log _{10}\left(\vec{k}_{0}\right)$ calculated for the nine glasses is $\log _{10}\left(\vec{k}_{0}\right)\left[\mathrm{g} /\left(\mathrm{m}^{2} \cdot \mathrm{d}\right)\right]=5.14 \pm 0.17$ (Appendix B, Table B-1). The mean and standard deviation for the subset of reference HLW glasses (Hanford-D, WV ref 6, SRL 51S, SRL 165U, SRL 202U, and SRL 131U) is $\log _{10}\left(\vec{k}_{0}\right)\left[\mathrm{g} /\left(\mathrm{m}^{2} \cdot \mathrm{d}\right)\right]=5.07 \pm 0.13$. The percent relative standard deviation is small in both cases $(100 \times 0.17 / 5.14=3.31 \%$ and $100 \times 0.13 / 5.07=2.56 \%$, respectively for the $\log _{10}$ values; $100(2.042-1.380) 10^{5} / 1.380 \times 10^{5}=+48 \%, 100(0.9333-$ $1.380) 10^{5} / 1.380 \times 10^{5}=-32 \%, 100(1.585-1.175) 10^{5} / 1.175 \times 10^{5}=+35 \%, 100(0.8710-$ $1.175) 10^{5} / 1.175 \times 10^{5}=-26 \%$, for the values of $\overrightarrow{k_{0}}$ ). This indicates that the glass composition has only a small effect on the value of $\log _{10}\left(\overrightarrow{k_{0}}\right)$ or $\vec{k}_{0}$. A single value of $\vec{k}_{0}$ can be used to represent the range of HLW glass compositions. 
Table 6-5. Compositions and Dissolution Rates of Glasses Used in MCC-1 Tests

\begin{tabular}{|c|c|c|c|c|c|c|c|c|}
\hline \multirow{2}{*}{ Glass } & \multicolumn{5}{|c|}{ Elemental Mass \% } & \multirow{2}{*}{$\begin{array}{l}N R(B)^{a} \\
g /\left(m^{2} \cdot d\right)\end{array}$} & \multirow{2}{*}{$\mathrm{pH}$} & \multirow{2}{*}{$\begin{array}{l}\log _{10}\left(k_{0}\right) \\
{\left[g /\left(m^{2} \cdot d\right)\right]}\end{array}$} \\
\hline & Al & B & $\mathrm{Fe}$ & $\mathrm{Na}$ & Si & & & \\
\hline LD6-5412 & 6.82 & 1.66 & 0.09 & 15.0 & 27.5 & 0.47 & 9.3 & 5.04 \\
\hline Hanford-L & 6.33 & 2.75 & 4.03 & 14.8 & 17.9 & 0.97 & 9.5 & 5.26 \\
\hline Hanford-D* ${ }^{*}$ & 5.36 & 2.17 & 16.1 & 11.7 & 14.1 & 1.8 & 10.5 & 5.04 \\
\hline WV ref $6^{*}$ & 3.17 & 4.00 & 8.41 & 5.93 & 19.2 & 0.69 & 9.5 & 5.11 \\
\hline SRL 51S* & 2.79 & 2.30 & 8.53 & 7.11 & 26.3 & 0.66 & 9.9 & 4.90 \\
\hline SRL $165 U^{*}$ & 2.16 & 2.10 & 8.21 & 8.04 & 24.7 & 1.0 & 9.6 & 5.23 \\
\hline SRL 202U* & 2.03 & 2.48 & 7.97 & 6.61 & 22.9 & 0.69 & 9.8 & 4.97 \\
\hline SRL 131U* & 1.73 & 3.00 & 8.85 & 8.95 & 20.4 & 1.2 & 9.8 & 5.21 \\
\hline PNL 76-68 & 0 & 2.79 & 6.41 & 10.5 & 19.8 & 1.1 & 9.2 & 5.46 \\
\hline
\end{tabular}

Source: DTN: MO0308ANLGPC01.528 [DIRS 164790].

NOTES: ${ }^{a}$ Rate measured at $90^{\circ} \mathrm{C}$.

${ }^{\mathrm{b}}$ Glasses with asterisks are reference HLW glasses.

\subsubsection{Effects of the Affinity Term on the Glass Degradation Rate}

The affinity term $(1-\mathrm{Q} / \mathrm{K})$, in Equations 6 and 12, provides a measure of the feedback effects of solutes that are reactants in the reverse of the rate-determining step for glass dissolution (Bourcier 1991 [DIRS 119110], p. 13). The rate when the value of the affinity term is one provides the most conservative upper bound for the dissolution rate. This is the forward glass dissolution rate. This is an overly conservative bound to use in TSPA-LA calculations, because the value of the affinity term cannot remain at a value of one after water contacts the glass and the glass begins to dissolve. The amount of dissolved silica present in tuff groundwater is itself high enough to give a value of the affinity term that is significantly less than one when it contacts waste glass. If a thin film of water forms on the glass, for example, by condensation of water vapor, the value of the affinity term will decrease significantly after a small amount of glass has dissolved because the release of even a little silica into solution will generate high silica concentrations in the small volume of water. The analyses in this section were done to identify a defensible upper bound to the dissolution rate that is less conservative than the forward rate.

It is useful to remember that the affinity term is a thermodynamic term even though it is used in a kinetic equation and it is an approximation for the complete dissolution mechanism. From a calculation point of view, Q takes on values that depend on the amount of glass dissolved and the silica-bearing phases that precipitate. However, in the long term, Q takes on a steady state value that depends on the rates of precipitation of phases containing $\mathrm{SiO}_{2}$ and the dissolution of the glass. At high amounts of glass dissolved in a static solution, the dissolution rate of some glasses has been observed to increase after a long period of nearly constant dissolution rate. van Iseghem and Grambow (1988 [DIRS 111048]) first noticed this effect and determined that it was the result of the precipitation of analcime (a zeolite). Since 1988, several authors have noticed the same phenomenon under a variety of different test conditions (Ebert et al. 1993 [DIRS 111052], pp. 573 and 575; Patyn et al. 1990 [DIRS 111042], p. 301, Figure 1; Feng et al. 1993 [DIRS 111031], pp. 195 and 200, Figure 3; Bates and Steindler 1983 [DIRS 104261], p. 85; Abrajano et al. 1986 [DIRS 110990], pp. 254 and 255, Figure 1; Bourcier 1991 [DIRS 119110], p. 211, Figure 2; Ebert, Bakel, and Brown 1996 [DIRS 111023], 
p. 573; McGrail, Martin, and Lindenmeier 1997 [DIRS 111040], p. 257). Other processes that remove dissolved silica from solution can impact the glass degradation rate in the same way. This has been observed in tests conducted in the presence of various clays (Gin, Jollivet et al. 2001 [DIRS 163256]). Tests in the presence of ductile iron and various iron oxides have shown a similar effect (McVay and Buckwalter 1983 [DIRS 101728]; Werme et al. 1990 [DIRS 163346]). The removal of silica from solution due to sequestration in glass alteration phases or sorption to other phases has the same effect on the glass degradation rate. The long-term impact of these processes in the repository will depend on the precipitation rates of the alteration phases and sorption capacities of iron corrosion products. The possibility that the precipitation rate or sorption capacity will limit the glass degradation rate is not included in the model, thereby making the model conservative.

Phases like analcime that can cause enhanced dissolution through consumption of silica are unlikely to form under most repository conditions. One exception is the case where the relative humidity is greater than $44 \%$ and the temperature of the glass is greater than $99^{\circ} \mathrm{C}$. Under these conditions, similar to those of a vapor hydration test, a thin layer of water can form on the surface of the glass because the reaction kinetics are high enough and the initial solution that forms has a water vapor pressure less than the surrounding atmosphere. Unlike the vapor hydration test, however, the repository provides essentially an infinite amount of $\mathrm{CO}_{2}$ gas at constant $p \mathrm{CO}_{2}=10^{1.5} \mathrm{kPa}\left(10^{-3.5}\right.$ atm). It will react with the solution as it forms initially and limit the rise in $\mathrm{pH}$. Because these conditions have not been investigated (i.e., VHTs with constant partial pressure of $\mathrm{CO}_{2}$ ), a limit based on other information is used in this model.

A measure of the $\mathrm{pH}$ of the solution that forms on the test specimen in a vapor hydration test is given by Vienna et al. (2001 [DIRS 163331]), Jiřička et al. (2001 [DIRS 163262]) and Ebert et al. (1991 [DIRS 111026]), where the $\mathrm{pH}\left(25^{\circ} \mathrm{C}\right)$ either measured on the test specimen or in the solution that dripped from the test specimen can be as high as 12 . The high $\mathrm{pH}\left(25^{\circ} \mathrm{C}\right)$ of the solution that is calculated in In-Package Chemistry Abstraction (BSC 2004 [DIRS 167621]) is 8.5. The $\mathrm{pH}$ at elevated temperature is lower than at $25^{\circ} \mathrm{C}$ because of the shift of the water dissociation constant to lower values with increasing temperature. The $\mathrm{pH}$ shift is about 0.8 at $90^{\circ} \mathrm{C}$ and 0.6 at $70^{\circ} \mathrm{C}$. Therefore, above $99^{\circ} \mathrm{C}$, it is assumed that the $\mathrm{pH}$ in this model is fixed at 10 and the increase in the rate is calculated with Equation 13. In practical terms, alteration of the glass in humid air is limited to the temperature range $100^{\circ} \mathrm{C}$ to $125^{\circ} \mathrm{C}$ because for pure water, the relative humidity at 1 atmosphere total pressure falls below $44 \%$ at $125^{\circ} \mathrm{C}$. If salt solutions from the evaporation of groundwater elsewhere in the drift or waste package control the relative humidity, then the upper temperature at which vapor phase alteration would occur is less than $125^{\circ} \mathrm{C}$. Both $125^{\circ} \mathrm{C}$ and a $\mathrm{pH}$ value of 10 represent conservative values.

\subsubsection{Maximum Value of $\mathbf{k}_{\mathrm{E}}$ for Glass Degradation in Alkaline Solutions}

Triplicate 7-day PCTs were conducted with the nine glasses used to evaluate the effect of glass

composition on the value of $\vec{k}_{0}$ (Section 6.5.2.2) (DTN: MO0308ANLGPC01.528 [DIRS 164790]). The 7-day PCTs were conducted at $90^{\circ} \mathrm{C}$. The averages of tests with each glass were used to extract values of $\mathrm{k}_{\mathrm{PCT}}$ using Equation 13 with parameter values $\eta=0.49$ and $\mathrm{E}_{\mathrm{a}}=69 \mathrm{~kJ} / \mathrm{mol}$ (Appendix B, Table B-3). The averages of the measured 7-day PCT rates (based on the release of boron), the measured final $\mathrm{pH}$, and the extracted value of $\log _{10}\left(\mathrm{k}_{\mathrm{PCT}}\right)$ are 
summarized in Table 6-6. The mean and standard deviation for glasses in Table 6-6, except for EA glass, is $\log _{10}\left(\mathrm{k}_{\mathrm{PCT}}\right)\left[\mathrm{g} /\left(\mathrm{m}^{2} \cdot \mathrm{d}\right)\right]=3.574 \pm 0.485$ (the average of the two sets of analyses of SRL 51S glass was used to calculate the mean and standard deviation). The value of the mean plus two standard deviations (rounded to three significant figures) is $\log _{10}\left(\mathrm{k}_{\mathrm{PCT}}\right)\left[\mathrm{g} /\left(\mathrm{m}^{2} \cdot \mathrm{d}\right)\right]=4.54$. This value is used as the maximum value for the parameter $\log _{10}\left(\mathrm{k}_{\mathrm{E}}\right)$ in the base model. This value bounds the values for the "other glasses" in Table B-2 (Appendix B) that were excluded from the determination of $\mathrm{k}_{\mathrm{E}}$. The fact that the maximum value of $\mathrm{k}_{\mathrm{E}}$ is greater than the value of $\mathrm{k}_{\mathrm{E}}$ calculated from the 7-day PCT response of the EA glass implies that the upper limit rate used in the TSPA-LA calculations will bound the dissolution rates of all waste glasses that meet the DOE acceptance criterion that the response (i.e., the average dissolution rate) of a waste glass must be lower than the response of the EA glass in PCT-A (DOE 2002 [DIRS 158873], Section 4.8.1). The maximum value of $\log _{10}\left(\mathrm{k}_{\mathrm{E}}\right)$ in

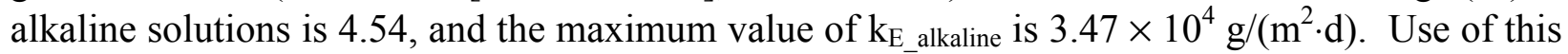
value in Equation 13 gives the maximum dissolution rate for all HLW glasses. This value is used to calculate the maximum dissolution rate for alkaline solutions. The expression in terms of $\log _{10}\left(\right.$ rate $\left._{\mathrm{G}}\right)$ is:

$$
\log _{10}\left(\text { rate }_{\mathrm{G}}\right)=4.54+0.49 \times \mathrm{pH}+\log _{10}\left[\exp \left(\frac{-69 \mathrm{~kJ} / \mathrm{mol}}{\mathrm{RT}}\right)\right]
$$

Table 6-6. Values of $\mathrm{k}_{\mathrm{PCT}}$ Extracted from 7-day PCTs

\begin{tabular}{|c|c|c|c|c|}
\hline Glass & $N R(B)\left(g /\left(m^{2} \cdot d\right)\right)$ & $\mathrm{pH}$ & $\begin{array}{c}\log _{10}\left(k_{P C T}\right) \\
{\left[g /\left(m^{2} \cdot d\right)\right]}\end{array}$ & Reference \\
\hline SRL 51S & 0.0381 & 10.66 & 3.29 & $\begin{array}{l}\text { MO0308ANLGPC01.528 } \\
\text { [DIRS 164790] }\end{array}$ \\
\hline SRL 51S & 0.0353 & 10.33 & 3.42 & $\begin{array}{l}\text { MO0308ANLGPC01.528 } \\
\text { [DIRS 164790] }\end{array}$ \\
\hline SRL 165U & 0.0440 & 10.31 & 3.52 & $\begin{array}{l}\text { MO0308ANLGPC01.528 } \\
\text { [DIRS 164790] }\end{array}$ \\
\hline SRL 202U & 0.0426 & 10.42 & 3.45 & $\begin{array}{l}\text { MO0308ANLGPC01.528 } \\
\text { [DIRS 164790] }\end{array}$ \\
\hline SRL 131U & 0.687 & 11.63 & 4.07 & $\begin{array}{l}\text { MO0308ANLGPC01.528 } \\
\text { [DIRS 164790] }\end{array}$ \\
\hline WV ref 6 & 0.0386 & 9.98 & 3.63 & $\begin{array}{l}\text { MO0308ANLGPC01.528 } \\
\text { [DIRS 164790] }\end{array}$ \\
\hline Hanford-D & 0.0516 & 10.67 & 3.41 & $\begin{array}{l}\text { MO0308ANLGPC01.528 } \\
\text { [DIRS 164790] }\end{array}$ \\
\hline SRL202G & 0.0869 & 11.11 & 3.42 & $\begin{array}{l}\text { MO0306ANLGIM02.525 } \\
\text { [DIRS 164330] }\end{array}$ \\
\hline Hanford-L & 0.0679 & 10.96 & 3.39 & $\begin{array}{l}\text { MO0308ANLGPC01.528 } \\
\text { [DIRS 164790] }\end{array}$ \\
\hline PNL 76-68 & 0.171 & 9.43 & 4.54 & $\begin{array}{l}\text { MO0308ANLGPC01.528 } \\
\text { [DIRS 164790] }\end{array}$ \\
\hline LD6-5412 & 0.0117 & 11.20 & 2.51 & $\begin{array}{l}\text { MO0308ANLGPC01.528 } \\
\text { [DIRS 164790] }\end{array}$ \\
\hline EA & 1.17 & 11.87 & 4.18 & $\begin{array}{l}\text { Ebert et al. } 1998 \\
\text { [DIRS 111027] }\end{array}$ \\
\hline
\end{tabular}




\subsubsection{Maximum Value of $k_{E}$ for Glass Degradation in Acidic Solutions}

The dissolution of borosilicate waste glasses causes the solution to become alkaline because of the ion exchange reactions that occur and because mineral precipitation leaves alkali ions in solution. Acidic solutions arise from other sources such as by radiolysis of the solution in contact with the glass or the corrosion of steel in the waste package. Fairly high radiation fields are needed to generate enough acid to overcome the hydroxide generated by glass dissolution under test conditions relevant to disposal conditions. For example, in tests conducted at an S/V of about $30 \mathrm{~m}^{-1}$, gamma radiation exposures of about $10 \mathrm{~Gy} / \mathrm{h}\left(1 \times 10^{3} \mathrm{R} / \mathrm{h}\right)$ were required to maintain $\mathrm{pH}$ values below 7 during the dissolution of a DWPF glass (Ebert et al. 1987 [DIRS 163248]). At the much higher $\mathrm{S} / \mathrm{V}$ relevant to the disposal system, glass dissolution will have a much stronger impact on the solution $\mathrm{pH}$ than radiolysis. For example, dissolution of an actinide-doped DWPF glass at $90^{\circ} \mathrm{C}$ and an $\mathrm{S} / \mathrm{V}$ of $340 \mathrm{~m}^{-1}$ in a $35 \mathrm{~Gy} / \mathrm{h}\left(3.5 \times 10^{3} \mathrm{R} / \mathrm{h}\right)$ gamma radiation field resulted in alkaline $\mathrm{pH}$ values for tests conducted up to two years (Wronkiewicz et al. 1997 [DIRS 163350], p. 48).

While there have been experiments with glasses under acidic conditions, the rate controlling steps in the reaction have not been fully investigated. The approach taken in this report is to use the same form as the rate expression for degradation in alkaline solutions and extract model parameters from test data for dissolution in acidic solutions. Degradation in acidic solutions is probably dominated by the hydrolysis of Al-O bonds rather than $\mathrm{Si}-\mathrm{O}$ bonds (Abraitis et al. 2000 [DIRS 163195]; Brady and Walther 1989 [DIRS 110748], p. 2,828; Carroll et al. 1994 [DIRS 111011], p. 535) that results in a V-shaped $\mathrm{pH}$ dependence observed for many borosilicate glasses. Some evidence for the lack of significant feedback in acidic solutions is given by the results of the MCC-1 tests discussed in Appendix A, where less negative deviation from the linear rate observed in the short-term tests (roll over) is seen at $\mathrm{pH} 3.7$ and $\mathrm{pH} 5.0$ than in tests in alkaline solutions. The roll over seen in tests at $\mathrm{pH} 1.3$ occurs because the glass is almost completely dissolved at longer durations. That is, the roll over is due to the decrease in the amount of glass (the source of boron) available to react rather than to feedback effects of dissolved silica.

No credit is taken in the TSPA-LA glass degradation model for feedback effects slowing glass dissolution in acidic solutions. The upper limit for the dissolution rate in acidic solutions is determined directly from the results of the $\mathrm{pH}$ buffer tests discussed in Section 6.5.2.1. The value of $\mathrm{k}_{\mathrm{E}}$ for acidic solutions is calculated by combining Equation 24 and the $\log _{10}$ of Equation 13 (with $\eta=0.49, \mathrm{E}_{\mathrm{a}}=31 \mathrm{~kJ} / \mathrm{mol}$, and $\mathrm{R}=0.008314 \mathrm{~kJ} / \mathrm{mol} \mathrm{K}$ ) for dissolution at $90^{\circ} \mathrm{C}$ (363 K):

$$
2.60-0.49 \times p H=\log _{10}\left(k_{E}\right)-0.49 \times p H+\log _{10}\left[\exp \left(\frac{-31}{\mathrm{R} \times 363}\right)\right]
$$


Canceling the $\mathrm{pH}$ terms and solving for $\log _{10}\left(\mathrm{k}_{\mathrm{E}}\right)$ gives:

$$
\log _{10}\left(\mathrm{k}_{\mathrm{E}}\right)=2.60 \frac{\mathrm{g}}{\left(\mathrm{m}^{2} \cdot \mathrm{d}\right)}-\log _{10}\left[\exp \left(\frac{-31 \mathrm{~kJ} / \mathrm{mol}}{(0.008314 \mathrm{~kJ} /(\mathrm{mol} \cdot \mathrm{K})) \times(363 \mathrm{~K})}\right)\right]
$$

from which the value of $\log _{10}\left(\mathrm{k}_{\mathrm{E}_{-} \text {acid }}\right)=7.06 \mathrm{~g} /\left(\mathrm{m}^{2} \cdot \mathrm{d}\right)$ and $\mathrm{k}_{\mathrm{E}_{-} \text {acid }}=1.15 \times 10^{7} \mathrm{~g} /\left(\mathrm{m}^{2} \cdot \mathrm{d}\right)$. This is the maximum value of $\mathrm{k}_{\mathrm{E}}$ in acidic solutions.

The upper bound glass degradation rate for the acidic $\mathrm{pH}$ values expressed in terms of $\log _{10}\left(\right.$ rate $\left._{\mathrm{G}}\right)$ is:

$$
\log _{10}\left(\text { rate }_{G}\right)=7.06-0.49 \times p H+\left[\exp \left(\frac{-31}{\mathrm{R} \times 363}\right)\right]
$$

This is checked by comparing the rate calculated at $\mathrm{pH} 5.0$ and $90^{\circ} \mathrm{C}$ with the rate that was measured experimentally:

$$
\begin{gathered}
\log _{10}\left(\text { rate }_{\mathrm{G}}\right)=7.06-0.49(5.0)+\log _{10}\left[\exp \left(\frac{-31 \mathrm{~kJ} / \mathrm{mol}}{(0.008314 \mathrm{~kJ} /(\mathrm{mol} \cdot \mathrm{K})) \times(363 \mathrm{~K})}\right)\right] \\
\log _{10}\left(\text { rate }_{\mathrm{G}}\right)=0.149 \mathrm{~g} /\left(\mathrm{m}^{2} \cdot \mathrm{d}\right) \\
\operatorname{rate}_{\mathrm{G}}=1.41 \mathrm{~g} /\left(\mathrm{m}^{2} \cdot \mathrm{d}\right)
\end{gathered}
$$

The measured rate at $\mathrm{pH} 5.0$ and $90^{\circ} \mathrm{C}$ is $1.27 \mathrm{~g} /\left(\mathrm{m}^{2} \cdot \mathrm{d}\right)($ Table 6-4). The two values are in good agreement.

\subsubsection{Support for the Selection of $k_{E}$}

In this section, the methodology for the selection of $\mathrm{k}_{\mathrm{E}}$ is discussed by selecting a base case and several other options to obtain values for $\mathrm{k}_{\mathrm{E}}$. The maximum value for $\log _{10}\left(\mathrm{k}_{\mathrm{E}}\right)$ used in the model for TSPA-LA for dissolution in the high $\mathrm{pH}$ solutions is based on the values determined from 7-day PCT results for glasses in Table 6-6 except EA glass. The upper bound to the value of $\log _{10}\left(\mathrm{k}_{\mathrm{E}}\right)$ for the alkaline $\mathrm{pH}$ values is taken as the mean value for $\log _{10}\left(\mathrm{k}_{\mathrm{PCT}, \mathrm{ref}}\right)\left[\mathrm{g} /\left(\mathrm{m}^{2} \cdot \mathrm{d}\right)\right]$ plus two standard deviations (which is 4.54). Several alternatives to the base case were considered for selecting the maximum value of $\mathrm{k}_{\mathrm{E}}$ to bound the range of potential waste glasses in alkaline solutions (values summarized here were calculated in Appendix B, Table B-3). These are summarized below in the order of increasing level of conservatism.

Base Case-Use the average 7-day PCT rate for glasses in Table 6-6 except EA: $\mathrm{k}_{\max \text {, alkaline }}=$ kPCT.

The selected approach uses the average value of the dissolution rates of glasses determined from 7-day PCT results $\left(\right.$ at $90^{\circ} \mathrm{C}$ ) to determine the value of the effective rate constant. The glass compositions that were tested span the expected composition range for waste glasses with regard 
to the $\mathrm{Al}, \mathrm{Na}$, and Si contents. The mean $\log _{10}\left(\mathrm{k}_{\mathrm{PCT}}\right.$, ref $)\left[\mathrm{g} /\left(\mathrm{m}^{2} \cdot \mathrm{d}\right)\right]$ for all glasses in Table $6-6$, except EA glass, is $3.57 \pm 0.48$.

Option 1a-Use the average 7-day PCT rate for all glasses in Table 6-6: $\mathrm{k}_{\mathrm{max}}$, alkaline $=\mathrm{k}_{\mathrm{PCT}}$.

The mean value of $\log \left(\mathrm{k}_{\mathrm{E}}\right)$ for the all the glasses is $\log _{10}\left(\mathrm{k}_{\mathrm{PCT}}\right.$, ref $)\left[\mathrm{g} /\left(\mathrm{m}^{2} \cdot \mathrm{d}\right)\right]=3.58 \pm 0.47$.

Option 1b-Use the average 7-day PCT rate for only the HLW glasses in Table 6-6: $\mathrm{k}_{\max \text {, alkaline }}=$ kPCT.

The mean $\log _{10}\left(\mathrm{k}_{\mathrm{PCT}}\right.$, ref $)\left[\mathrm{g} /\left(\mathrm{m}^{2} \cdot \mathrm{d}\right)\right]$ for the seven reference HLW glasses in Table 6-6, namely, SRL 51S (average), SRL 165U, SRL 202U, SRL 131U, WV ref 6, Hanford-D, and SRL 202G, is 3.57 and the standard deviation is $0.23 \mathrm{~g} /\left(\mathrm{m}^{2} \cdot \mathrm{d}\right)$.

Option 2-Use the average dissolution rate of EA glass in 7-day PCT conducted in tuff

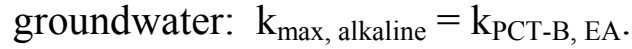

The dissolution rate in tuff groundwater is more repository-relevant than the rate measured in demineralized water with 7-day PCT because the composition of the leachant is similar to that of groundwater likely to first contact the waste glass. The average dissolution rate of EA glass in a tuff groundwater under these conditions (at $\left.90^{\circ} \mathrm{C}\right)$ is $0.64 \mathrm{~g} /\left(\mathrm{m}^{2} \cdot \mathrm{d}\right)$ with a $\mathrm{pH}$ of 11.61 at the end of 7 days. The value of $\log _{10}\left(\mathrm{k}_{\mathrm{PCT}-\mathrm{B}, \mathrm{EA}}\right)\left[\mathrm{g} /\left(\mathrm{m}^{2} \cdot \mathrm{d}\right)\right]$ extracted from these results with Equation 51 is 4.05. The dissolution rate in tests with tuff groundwater based on the release of boron is about one-half of the rate measured with 7-day PCT in demineralized water (Option 3). This is because the dissolved silicon already present in the groundwater solution used in the tests (approximately $46 \mathrm{mg} / \mathrm{L}$; Ebert et al. 1998 [DIRS 111027], p. 29, Table 2) has a significant effect on the dissolution rate as measured by the release of boron. The uncertainty in $\log _{10}\left(\mathrm{k}_{\mathrm{E}}\right)$ for tests with EA glass in demineralized water (Option 3) is also used as the uncertainty for tests with EA glass in tuff groundwater, namely, \pm 0.23 .

Option 3-Use the average dissolution rate of EA glass in 7-day PCT: $\mathrm{k}_{\mathrm{max} \text {, alkaline }}=\mathrm{k}_{\mathrm{PCT} \text {, EA }}$.

The average dissolution rate in a 7-day PCT is calculated by dividing the normalized mass loss by the test duration, which is 7 days. The 7-day PCT rate includes the effect of the buildup of dissolved glass components during the test. The average boron concentration for a 7-day PCT conducted with the EA glass at three different laboratories is $553 \pm 30 \mathrm{mg} / \mathrm{L}$ and the average $\mathrm{pH}$ is 11.87 (Ebert 2000 [DIRS 145950]). The average normalized dissolution rate is calculated by dividing the concentration by the mass fraction of boron in the EA glass, which is 0.0347 , by the $\mathrm{S} / \mathrm{V}$ of the test, which is $2,000 \mathrm{~m}^{-1}$, and by the test duration, which is 7 days. The average dissolution rate in 7 -day PCT (at $90^{\circ} \mathrm{C}$ ) is calculated to be about $1.17 \mathrm{~g} /\left(\mathrm{m}^{2} \cdot \mathrm{d}\right.$ ) at $\mathrm{pH} 11.87$. The value of $\log _{10}\left(\mathrm{k}_{\mathrm{E}}\right)$ calculated with Equation 51 is $4.18 \mathrm{~g} /\left(\mathrm{m}^{2} \cdot \mathrm{d}\right)$. The standard deviation of the measured boron concentration is $5.4 \%$. This is used as the relative uncertainty in the value of $\log _{10}\left(\mathrm{k}_{\mathrm{E}}\right)$, so that the value of $\log _{10}\left(\mathrm{k}_{\mathrm{E}}\right)\left[\mathrm{g} /\left(\mathrm{m}^{2} \cdot \mathrm{d}\right)\right]$ is $4.18 \pm 0.23$.

This option empirically relates the bounding dissolution rate to the product acceptance requirement for vitrified waste forms (DOE 2002 [DIRS 158873], Section 4.8.1) requires vitrified waste forms to have lower releases of $\mathrm{B}, \mathrm{Li}$, and $\mathrm{Na}$ than the EA glass in the PCT-A 
(DOE 1996 [DIRS 102589], Section 3.1). This is tantamount to requiring the PCT-A rates of accepted waste glasses to be less than the PCT-A rate of the EA glass. However, because different $\mathrm{pH}$ values will likely be attained in tests with different glasses, the values of $\mathrm{k}_{\mathrm{E}}$ for all waste glasses accepted for disposal will not necessarily be less than $\mathrm{k}_{\mathrm{E}}$ for the EA glass. Since the values of $\mathrm{k}_{\mathrm{E}}$ for future waste glass compositions can be calculated and compared with $\mathrm{k}_{\mathrm{E}}$ for the EA glass, this option provides a useful upper bound.

Option 4-Use the intrinsic dissolution rate measured for reference glasses: $\mathrm{k}_{\max \text {, alkaline }}=\mathrm{k}_{0 \text {, ref }}$.

This option uses the intrinsic dissolution rates that have been measured for reference waste glasses to determine the effective rate constant. Forward dissolution rates measured with shortterm MCC-1 tests (at $90^{\circ} \mathrm{C}$ ) for the six reference glasses likely to bound the compositions of waste forms for DWPF, WVDP, and Hanford were presented earlier in this report (glasses SRL 51S, SRL 165U, SRL 202U, SRL 131U, WV6, and Hanford-D in Table 6-5). The mean and standard deviation for the intrinsic dissolution rates of those $6 \mathrm{HLW}$ glasses is $\log _{10}\left(\mathrm{k}_{0}\right.$, ref $)$ $\left[\mathrm{g} /\left(\mathrm{m}^{2} \cdot \mathrm{d}\right)\right]=5.07 \pm 0.13($ Appendix B, Table B-1).

The values of $\mathrm{k}_{\mathrm{E}}$ extracted from these tests are summarized in Table 6-7 for values calculated based on the releases of boron. Bounding values are calculated as the mean plus two standard deviations in order to directly compare the values of $\log _{10}\left(\mathrm{k}_{\mathrm{E}}\right)$. The highest bounding value of $\log _{10}\left(\mathrm{k}_{\mathrm{E}}\right)$ is that calculated from the forward rates of the tests with reference glasses (Option 4, $\mathrm{k}_{\mathrm{E}}=\mathrm{k}_{0 \mathrm{ref}}$ ); these provide the most conservative estimates that have been measured. However, this bound is overly conservative because it neglects the slowing effect of the affinity term on the dissolution rate. The lowest bounding value of $\log _{10}\left(\mathrm{k}_{\mathrm{E}}\right)$ is that calculated from the 7-day PCT rates for tests with HLW reference glasses ( $\mathrm{k}_{\mathrm{PCT}}$, ref). Use of an upper bound value of $\log _{10}\left(\mathrm{k}_{\mathrm{E}}\right)$ that is higher than the value for EA glass takes into account the possibility that a waste glass could be less reactive than the EA glass in PCT-A, but still have a higher long-term dissolution rate than the EA glass.

Based upon this discussion, it is concluded that the $\mathrm{k}_{\mathrm{E}}$ determined for the model use is appropriate.

Table 6-7. Values of $k_{\max }$, alkaline Calculated Using Different Options

\begin{tabular}{|l|c|c|c|}
\hline \multirow{2}{*}{ Option } & & \multicolumn{2}{c|}{$\log _{10}\left(\mathrm{k}_{\mathrm{E}}\right)\left[\mathbf{g} /\left(\mathbf{m}^{\mathbf{2}} \cdot \mathbf{d}\right)\right]^{\mathbf{a}}$} \\
\cline { 3 - 4 } & Measured Value & Mean $\pm \mathbf{s}^{\mathbf{b}}$ & Bounding Value $^{\mathbf{c}}$ \\
\hline Base Case (all glasses except EA) & $\mathrm{k}_{\mathrm{E}}=\mathrm{k}_{\mathrm{PCT}, \text { ref }}$ & $3.57 \pm 0.48$ & 4.54 \\
\hline 1a (all glasses) & $\mathrm{k}_{\mathrm{E}}=\mathrm{k}_{\mathrm{PCT}, \text { ref }}$ & $3.58 \pm 0.47$ & 4.52 \\
\hline 1b (HLW reference glasses) & $\mathrm{k}_{\mathrm{E}}=\mathrm{k}_{\mathrm{PCT}, \text { ref }}$ & $3.57 \pm 0.23$ & 4.05 \\
\hline 2 (EA in tuff groundwater) & $\mathrm{k}_{\mathrm{E}}=\mathrm{k}_{\mathrm{PCT}-\mathrm{B}, \mathrm{EA}}$ & $4.05 \pm 0.23$ & 4.51 \\
\hline 3 (EA in demineralized water) & $\mathrm{k}_{\mathrm{E}}=\mathrm{k}_{\mathrm{PCT}, \mathrm{EA}}$ & $4.18 \pm 0.23$ & 4.64 \\
\hline 4 (forward rates) & $\mathrm{k}_{\mathrm{E}}=\mathrm{k}_{0, \mathrm{ref}}$ & $5.07 \pm 0.13$ & 5.33 \\
\hline
\end{tabular}

NOTES: ${ }^{a}$ Effective rate constant based on release of boron.

b Mean \pm one standard deviation.

c Upper bound to value of $\log _{10}\left(k_{E}\right)\left(k_{\max }\right.$, alkaline $)$ is calculated as the mean plus two standard deviations. 


\subsubsection{Dissolution of Glass Exposed to Humid Air or Dripping Water}

\subsubsection{Interaction of Humid Air with Waste Glass}

In the unsaturated environment of the Yucca Mountain site, it is likely that waste glass will be contacted initially by humid air after failure of the waste package and canister. When glass is exposed to humid air, water molecules will sorb onto specific sites on the glass surface, primarily silanol and alkali metal sites. The amount of water that sorbs on the glass will depend on the relative humidity of the air, the temperature of the glass surface, and how fast the water reacts with the glass. The sorption isotherm for water on a reference waste glass made with SRL 165 frit has been measured at room temperature (Ebert, Hoburg, and Bates 1991 [DIRS 111028], p. 134, Figure 1b) (Figure 6-3). The measured isotherm was fit using the following equation:

$$
\theta=[-\mathrm{b} / \ln (\mathrm{RH} / 100)]^{1 / \mathrm{r}}
$$

where $\theta$ is the number of statistical monolayers of sorbed water, $\mathrm{RH}$ is the relative humidity, $\mathrm{b}$ and $r$ are constants with values of $b=3.2$ and $r=1.5$ for SRL $165 \mathrm{U}$ glass.

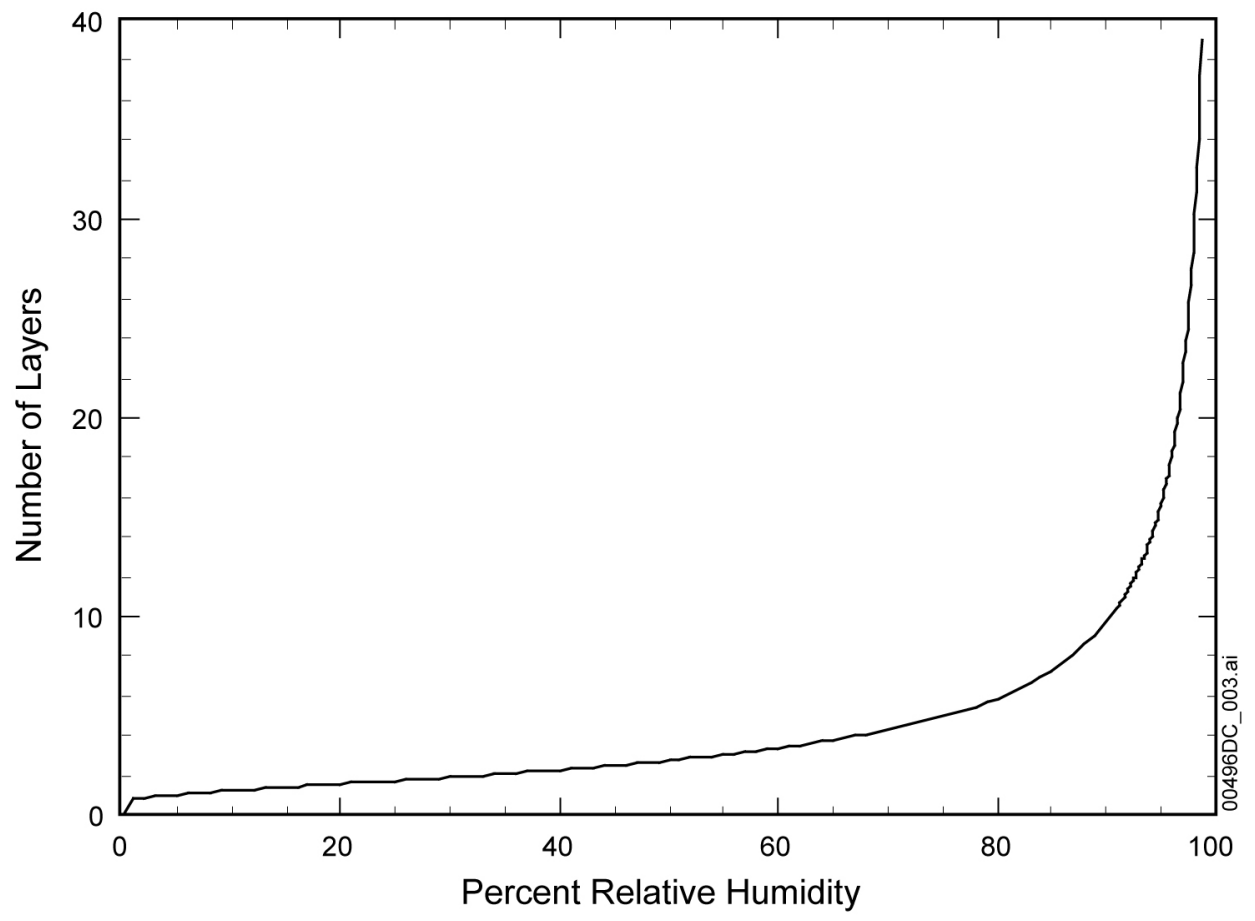

Source: Ebert, Hoburg, and Bates 1991 [DIRS 111028], p. 134, Figure 1b.

Figure 6-3. Sorption Isotherm for Water on SRL 165 Glass at Room Temperature

The shape of the isotherm is similar to isotherms for water on silica and quartz (Hagymassy et al. 1969 [DIRS 111034], p. 489). The first layer forms at a relative humidity of about 4\%. This corresponds to sorption at the primary silanol sites (chemisorption). Subsequent layers form as water vapor bonds with chemisorbed water to form beads of water on the glass surface. The amount of sorbed water increases to about 3 layers when the relative humidity is $54 \%$ and six layers when the relative humidity is $80 \%$. At relative humidities above about $80 \%$, a sufficient amount of water has condensed to coalesce into a film of water approximately $20-\mathrm{nm}$ to 
30-nm thick covering the entire surface. Isotherms have not been measured for the sorption of water on waste glass at higher temperatures. A similar relationship between the amount of water that forms on the glass and the relative humidity is expected at higher temperatures.

No hysteresis was observed in the isotherm collected for the waste glass, which indicates that the sorbed water did not react with the glass at this temperature and did not condense in tight pores during the several days required to measure the isotherm. The absence of hysteresis indicates that dealkalization reactions did not occur to a significant extent under these conditions. However, sorbed and condensed water will react with the glass at higher temperatures (discussion of vapor hydration tests in Section 6.5.3.3). The interaction between glass and water vapor at temperatures below $100^{\circ} \mathrm{C}$ has not been adequately investigated. However, as the temperature decreases from $125^{\circ} \mathrm{C}$ in the repository, the relative humidity increases and the reaction rates decrease. Rates as a function of temperature have been investigated and are discussed later in this section. However, these rates were obtained at $100 \%$ relative humidity and limited amounts of $\mathrm{CO}_{2}$ at temperatures greater than $125^{\circ} \mathrm{C}$. At temperatures above $125^{\circ} \mathrm{C}$ in the repository ( 1 atmosphere total pressure), the relative humidity will be below $44 \%$ where experimental evidence shows that there is no alteration of the glass. This is consistent with the observations by Vernon (1933 [DIRS 100942]) who found no water on iron below $65 \%$ relative humidity.

In the various configurations in which fractured glass may be contacted by humid air or dripping water, water may drip or flow away from the glass or may accumulate over time while contacting the glass. As glass dissolves in the adsorbed water, the ionic strength increases causing the water vapor pressure to drop. While the vapor pressure changes little at the beginning, the ionic strength of the solution can be quite high at long contact times. Hence, the water vapor pressure of any solution on the surface of the glass at long time would be expected to be lower than the water in the repository. To be conservative, the case could be made that continuous exposure to water-saturated air will result in a process of vapor condensation, flow across the glass, and dripping wherein dissolved species can be transported away from the glass and fresh water vapor continually condenses. The corrosion rate of the glass under these conditions will be affected by the rates at which water vapor condenses in the film of water on the surface and solution drips from the glass. These processes will affect the glass dissolution rate through their effects on the solution chemistry of the film. How this process starts has not been adequately investigated, however, the rate at which the glass reacts with the water, either vapor or condensed film, depends on the temperature - faster at higher temperatures. Slowing the process is the fact that at a fixed total pressure of $0.1 \mathrm{MPa}(1$ atmosphere), the relative humidity of pure water drops below $44 \%$ at $125^{\circ} \mathrm{C}$, meaning at temperatures above that no reaction occurs. The effects of the condensation, flow, and drip rates on the glass dissolution rate are taken into account in the TSPA-LA glass degradation model empirically with experimentally measured rates to determine model parameter values. That is, even though water condensation and transport processes are not modeled explicitly, the fact that rates measured in tests in which these processes are operative are used to determine parameter values means the effects of that process on the rate are accounted for in the model.

Two modes of corrosion in humid air are thought to occur in the repository depending on the availability of water vapor. If the relative humidity is greater than $44 \%$ and the temperature is greater than $100^{\circ} \mathrm{C}$, a film of water will form on the glass. Corrosion products will form as the 
glass is altered, but these alteration products will remain on the glass surface until contacted and transported by liquid water. If the relative humidity approaches $100 \%$ from readily available water vapor and the temperature approaches $100^{\circ} \mathrm{C}$, enough water can condense on the glass to flow or drip from the glass thereby making dissolved glass components available for transport. Extremes for both of these cases have been examined experimentally and are analyzed in this report to model glass degradation by humid air or dripping water. In tests representing the first case, the amount of water available to form the film on the glass was limited so that the film remained static for long times and water did not drip from the glass during the test. Vapor hydration tests have been used to promote the formation of alteration phases to identify the phases that form, determine if they contain radionuclides, and determine if their formation increases the glass alteration rate. Tests have shown that radionuclides become incorporated into alteration phases that form on the specimen surface (Ebert et al. 1991 [DIRS 111026], p. 212). Subsequent exposure of vapor-hydrated glass to liquid water results in a rapid release of soluble components, including some radionuclides, from the alteration layer into solution as dissolved and colloidal species (Bates et al. 1990 [DIRS 111002], p. 1,100, Table 5). Radionuclides that are retained in soluble phases during vapor hydration (e.g., Tc, Np, U, etc.) will be released quickly when those phases are contacted by water. Radionuclides that are retained in sparingly soluble phases during vapor hydration will have concentrations controlled by the solubility of the alteration phase in which they are sequestered or can be released as radiocolloids if the alteration layer spalls from the glass surface. This could occur if there are mechanical strains that exceed the strength of the layer, such as those induced by wet-dry cycling.

Two test methods were used to study corrosion in dripping water conditions. One method was modified vapor hydration tests conducted with enough water in the vessels that dripping occurred in a condensation-dripping reflux cycle. The solution at the bottom of the vessel and the reacted samples were analyzed. The other method was unsaturated (drip) tests conducted by periodically injecting groundwater into the test vessel so that water collected on and then dripped off the sample. The solution that accumulated in the bottom of the vessel was periodically recovered and analyzed. The results of these tests are used to model corrosion in dripping water.

The glass degradation rates measured under humid air and dripping groundwater conditions are used to establish the lower bound to the effective rate constant, $\mathrm{k}_{\mathrm{E}}$. The following analysis describes how the rate expression in Equation 13 is applied to corrosion in humid air and in dripping water.

\subsubsection{Modeling Glass Degradation by a Thin Film of Water}

The corrosion behavior of glass contacted by a thin film of static water is treated as a special case of aqueous corrosion that is described using the same rate expression used for aqueous dissolution. Glass degradation in humid air cannot occur until a film of water forms on the glass. The sorption of one or two monolayers of water is not sufficient to corrode the glass. Enough water must be available to hydrolyze species released from the glass. Tests show that, even at elevated temperatures, a relative humidity greater than $44 \%$ is required to corrode waste glass (Abrajano et al. 1986 [DIRS 110990]). Water consumed by glass reaction or diffusion into the glass must be replaced for corrosion to continue. Ion exchange is the first process to take place when water contacts glass. Thus, the first reaction between water vapor or condensed water and glass would result in a solution with lower water vapor pressure than the surroundings that 
provides the chemical potential for the sorption of additional water. If water vapor is not available, then glass degradation would cease. If water vapor is available, water would absorb into the film for as long as the vapor pressure of the film on the glass remains lower than that of the water source. The initial dealkalization of glass will result in high concentrations of alkali metals and hydroxide (i.e., high $\mathrm{pH}$ values) that will provide a large potential for continuous condensation of water vapor.

Several processes take place when glass and water vapor interact at high temperature. The net result of these interactions depends on which of these dominates the kinetics. Water diffuses into the glass. Water condenses on the surface of the glass or in the alteration layer. Mediated by water, the glass is altered to thermodynamically stable alteration minerals. Clearly at temperatures in excess of $150^{\circ} \mathrm{C}$, the alteration process dominates because little if any diffusion zone is found at the gel-glass interface. The rate of this process decreases with temperature much more rapidly than does diffusion. The dependence of alteration on the relative humidity is not well understood; very few tests have been done. In addition, the tests that have been done to date were not performed at constant $\mathrm{CO}_{2}$ fugacity. At constant $\mathrm{CO}_{2}$ fugacity, the $\mathrm{pH}$ values are expected to be limited to values of about 10. Because the $\mathrm{pH}$ increase is limited, the increase in the reaction rate is limited (Equation 13).

Since the relative humidity for pure water at $0.1 \mathrm{MPa}$ total pressure falls below $44 \%$ at $125^{\circ} \mathrm{C}$, no glass alteration occurs above $125^{\circ} \mathrm{C}$. Between $100^{\circ} \mathrm{C}$ and $125^{\circ} \mathrm{C}$, a film of water forms on the surface of the glasses based on the analyses shown below. However, because the $\mathrm{CO}_{2}$ fugacity is constant and there is an unlimited amount of $\mathrm{CO}_{2}$, the $\mathrm{pH}$ of this water is limited to 10 .

\subsubsection{Using Vapor Hydration Tests to Model Degradation in Humid Air}

This section describes how the results of vapor hydration tests (VHTs) are used to model the corrosion of waste glasses exposed to humid air. The vapor hydration test method was initially developed to reproduce the hydration of obsidian artifacts in the laboratory. The hydration rinds (a layer of different refractive index from the parent glass caused by the presence of water) formed on obsidian artifacts are used by archaeologists as a dating method (Friedman and Long 1976 [DIRS 163253]). The weathering of obsidian results in water diffusing through the surface with little chemical interaction. The hydration rind can be measured with a polarizing light microscope. Friedman and Long (1976 [DIRS 163253]) used vapor hydration tests on obsidians with different compositions to develop a model for dating obsidian artifacts. Water was determined to diffuse into the glass with a rate that depended on the square root of time. The VHT was initially applied to nuclear waste glasses by Bates and Steindler (1983 [DIRS 104261]), who found complex kinetics and the formation of a complex set of alteration phases. It was found that weathering of basaltic glass and nuclear waste glasses resulted in the formation of altered material rather than the simple physically strained layer seen on obsidians. Thus, alteration of the glass happened much more quickly than or simultaneous to the diffusion of the water into the glass. In bulk water, however, the dissolution of obsidian is the same as that for nuclear waste glasses (McGrail et al. 1988 [DIRS 171174]). Vapor hydration tests have also been used to demonstrate the usefulness of natural analog glasses, such as obsidian and basaltic glass, for predicting the long-term corrosion behavior of waste glasses weathered under terrestrial conditions (Byers et al. 1985 [DIRS 163209]). Tests have shown the same phase assemblages that form during natural weathering of basaltic glass over thousands to 
millions of years at ambient temperatures also form in short-term VHTs conducted at elevated temperatures (Luo et al. 1997 [DIRS 163271]).

The VHT has also been used to measure the degradation rates of natural glasses and nuclear waste glasses at elevated temperatures for extrapolation to lower temperatures of interest. As in the case of obsidian, the extent of waste glass degradation in VHTs is measured using the thickness of an alteration layer that formed on the surface. Figure 6-4 shows a cross-section image of a typical VHT sample. The alteration layer overlays the remaining unreacted glass and is itself overlain by discrete precipitated phases (secondary phases). Precipitated phases are usually observed on the outer surface of the alteration layer, which indicates nucleation occurs preferentially at the outer surface of the alteration layer. The reaction between the glass and water proceeds as water diffuses into the glass and alteration and diffusion is mediated by the presence of water. The actual process by which the glass is altered in the presence of water vapor or a thin layer of water is largely uncertain. However, because the structure is similar to that seen in glasses altered in the presence of liquid water, similar mechanisms are likely operating.

The alteration layer does not inhibit glass dissolution at the alteration layer-glass interface. This is because water can rapidly diffuse through the porous layer to attack the glass and soluble elements released from the glass can diffuse through the layer into the water film where they may become incorporated into existing or newly precipitated phases. Release of a specific element into solution at the surface will depend on its solubility and diffusion through the alteration layer. Sparingly soluble components, which are not incorporated into the clay, precipitate where the local chemistry allows precipitation to occur. The role of the alteration layer as a diffusion barrier is discussed in Appendix D.

There are two methods for measuring the extent of reaction from the samples from the VHT. One is based on the remaining glass in the specimen (Jiřička et al. 2001 [DIRS 163262]). In the second, the thickness of the clay alteration layer is used to measure the extent of glass degradation. The layer thickness is proportional to the volume of glass that has reacted, since the layer is fairly uniform across the glass surface. The precipitated phases at the outer surface are excluded from the measurement because most of the material in the precipitated phases was leached from the underlying layer. The precipitate phases are excluded to avoid double counting the volume of glass that has been altered. The degradation rate is determined as the slope of a plot of the layer thickness versus the test duration. The rate as thickness/time is converted to the mass of glass dissolved per unit area per unit time by multiplying that rate by the density of the glass. In this way, the entire volume of the alteration layer is modeled as being freed from the glass. Release of a specific element into solution must be determined based on its solubility and diffusion through the alteration layer (rind) using other models. 


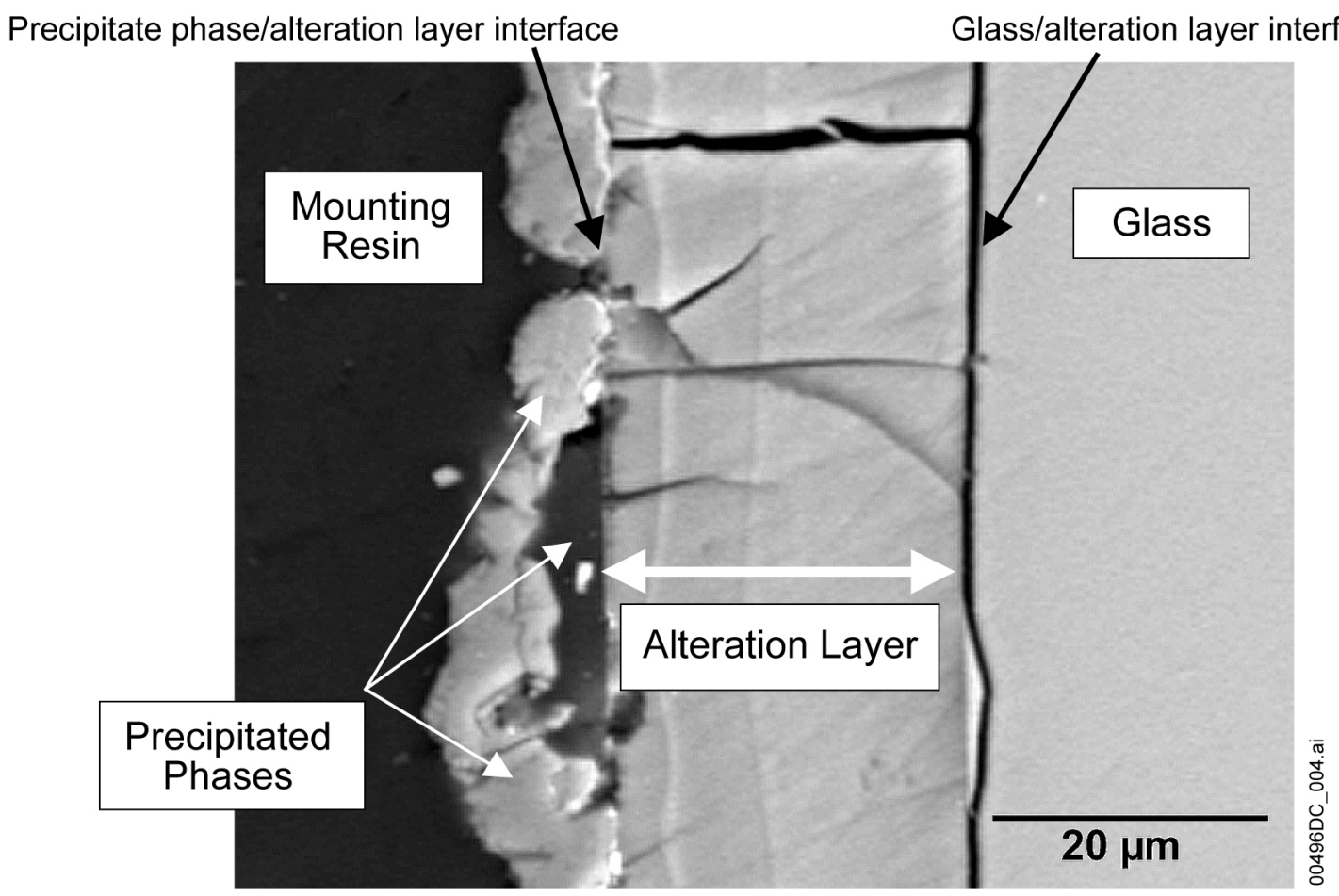

Source: Ebert 2003 [DIRS 164518].

Figure 6-4. Typical Cross Section of Vapor-Hydrated Glass

\subsection{ANL Vapor Hydration Tests}

Several series of VHTs were conducted specifically to measure the corrosion rates of three glasses at various temperatures and with various amounts of added water: SRL 51S, SRL 131-TDS, and SRL 165S. These test results are used to determine parameter values for the TSPA-LA glass degradation model that are applicable to glass degradation in humid air. The test results and analysis are described in Appendix C.

\subsection{Effect of Relative Humidity}

The VHT results used in the following analyses are taken from Tables C-2, C-3, and C-4 in Appendix C (DTN: MO0306ANLGVH01.526 [DIRS 164331]) for tests with SRL 51S, SRL 131-TDS, and SRL 165S glass, respectively. The effect of relative humidity was studied by varying the amount of water added to the test vessel. The relative humidity was not measured directly. Instead, the initial relative humidity was estimated from the volume of the test vessel, the mass of water in saturated steam at the test temperature, and the mass of water used in the test. The specific volume of steam is $2.0369 \mathrm{ft}^{3} / \mathrm{lb}$, which is used to calculate the density as:

$$
\left(1 \mathrm{lb} / 2.0369 \mathrm{ft}^{3}\right) \times(453.6 \mathrm{~g} / \mathrm{lb}) \times(1 \mathrm{ft} / 30.48 \mathrm{~cm})^{3}=0.00786 \mathrm{~g} / \mathrm{cm}^{3}
$$

At $200^{\circ} \mathrm{C}$, about $0.165 \mathrm{~g}$ of water is needed to provide $100 \% \mathrm{RH}$ in the approximately $21 \mathrm{~mL}$ free volume of the test vessel. 
Figure 6-5 shows the thicknesses of layers generated in tests conducted with SRL 131-TDS glass at $200^{\circ} \mathrm{C}$ with various amounts of demineralized water (the plotted data are tabulated in Appendix C, Table C-5). The two samples in each $22 \mathrm{~mL}$ vessel are referred to as "Sample A" and "Sample B." Most of the results shown in Figure 6-5 are from tests conducted for 21 days. Measurable layers were not formed after 21 days in tests with less than $0.1 \mathrm{~g}$ of water, but were formed after longer test durations. The results for three tests conducted for 31 days and tests conducted for 87 and 90 days are included in the plot to better show the low extent of reaction in tests with small amounts of water.

The thickest alteration layers were formed in tests with about 0.20 to $0.25 \mathrm{~g}$ of added water. This was a sufficient amount of water to provide $100 \% \mathrm{RH}$ at $200^{\circ} \mathrm{C}$ plus form a film of condensed water on the glass that did not drip off. The samples in tests with 0.22 and $0.24 \mathrm{~g}$ of water were completely corroded within 21 days. Water in excess of that needed to saturate the void space was available to condense on and react with the two samples. The brine formed on the sample will have a significantly lower vapor pressure than pure water, so less than $0.18 \mathrm{~g}$ of water vapor will be present as the glass corrodes. The vapor pressure of a film of brine solution on a borosilicate waste glass due to dealkalization reactions can be approximated as a solution of $\mathrm{NaOH}$. The vapor pressure of a saturated $\mathrm{NaOH}$ solution is about $2 \% \mathrm{RH}$ at $75^{\circ} \mathrm{C}$ and about $9 \% \mathrm{RH}$ at $20^{\circ} \mathrm{C}$ (Greenspan 1977 [DIRS 104945]). Even dilute brines will provide an appreciable potential for condensation of water vapor in the disposal system.

Figure 6-5 shows that thinner alteration layers were formed when more than $0.25 \mathrm{~g}$ of water were added. The layer thickness was independent of the amount of excess water added to the vessel, but did increase with the test duration, as shown by the results of tests with $7.5 \mathrm{~g}$ of water reacted for 21,31 , and 87 days. Slightly thicker layers formed in tests with $0.12 \mathrm{~g}$ of water $(67 \% \mathrm{RH})$ than in tests with excess water after 31 days. The lower reactivity is attributed to the lower $\mathrm{pH}$ values that are attained due to the reflux cycling that occurs with excess water.

Given these results, it is modeled that the same processes occur when humid air contacts waste glass in the disposal system as in VHTs, although the conditions in the VHTs are more aggressive because of the higher temperatures and water vapor pressures. In the VHTs, humid air contacts a suspended glass monolith in a closed vessel, whereas in the disposal system, humid air will contact glass within a steel canister in an open system with unlimited amounts of water vapor and $\mathrm{CO}_{2}$ gas $\left(p \mathrm{CO}_{2}=10^{-1.5} \mathrm{kPa}\right)$. High water vapor pressures are attained in the VHTs (about $1.4 \mathrm{MPa}$ at $200^{\circ} \mathrm{C}$ ), whereas the maximum total pressure in the disposal system will be about $0.1 \mathrm{MPa}(1 \mathrm{~atm})$. Although the water vapor pressures differ significantly, condensation of water on glass is expected to be controlled primarily by the vapor pressures of films formed on the glass. The availability of water vapor is an important difference between VHTs and the disposal system as is the thermal gradient that will exist between the waste glass and the source of water vapor. The water source in the VHTs is contained within the vessel and is near the reacting glass. In the disposal system, the condensation of water onto glass in the disposal system will probably be limited by transport of humid air to the glass. The VHT results provide no insight regarding transport limitations. 


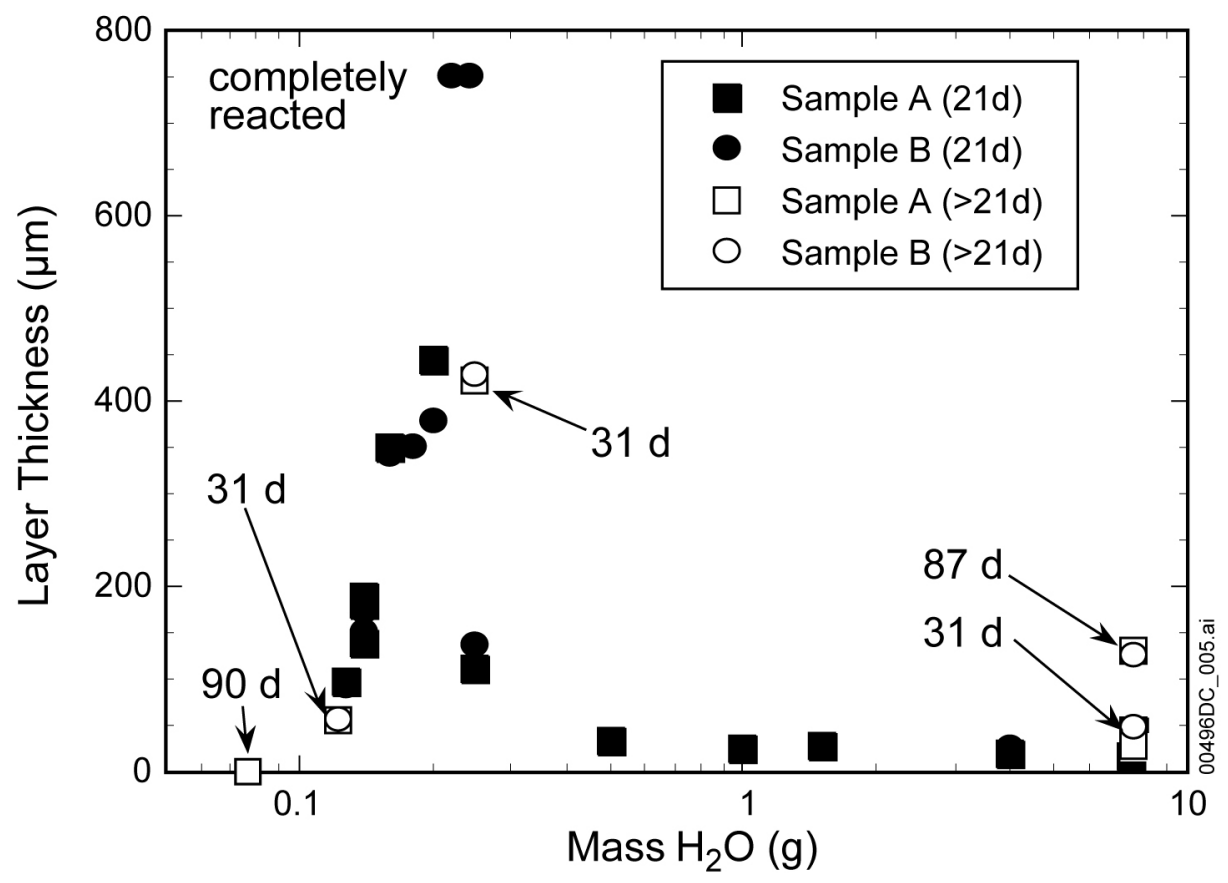

Source: Appendix C, Table C-5.

Figure 6-5. Layer Thicknesses in VHTs with SRL 131-TDS Glass at $200^{\circ} \mathrm{C}$ with Various Amounts of Demineralized Water

The observed effects of the amount of water added to the VHT vessel provide insight into the likely effects of relative humidity in the disposal system. Tests conducted at $200^{\circ} \mathrm{C}$ with less than about $0.18 \mathrm{~g}$ of water will result in less than $100 \% \mathrm{RH}$ in the test vessel, whereas tests with more than about $0.2 \mathrm{~g}$ of water will maintain $100 \% \mathrm{RH}$ after water condenses on the glass. About $0.05 \mathrm{~g}$ of water can condense on the VHT glass sample without dripping off (this is the mass of a typical drop of water), so that the addition of $0.25 \mathrm{~g}$ of water is enough to maintain a saturated vapor phase plus produce thin films on both samples that do not drip off. As the glass dissolves in the thin film of condensed water, the equilibrium water vapor pressure of the film of water on the sample will be lowered and cause additional water to condense until the film and water vapor equilibrate. The film may become heavy enough that some of the solution drips off the sample and into the bottom of the vessel. Fresh water vapor will continue to condense on the sample, and water at the bottom of the vessel will continue to evaporate in response to its vapor pressure, which will always be higher than the vapor pressure of the film on the samples. Therefore, water will continuously be transported from the source (i.e., the water at the vessel bottom) to the films on the samples and, when enough water condenses on the glass, solution will continue to drip from the samples. The importance of this dripping process is that dissolved glass components are transported away from the sample with every drop and the film is diluted by freshly condensed water vapor. Dilution of the film will lower the $\mathrm{pH}$ and consequently reduce the glass dissolution rate.

Figure 6-5 shows that the extent of reaction is much less in tests with less than about $0.2 \mathrm{~g}$ of water. From the density of steam calculated at $200^{\circ} \mathrm{C}$, tests with about 0.0764 and $0.0742 \mathrm{~g}$ of added water provide, at most, initial relative humidities of $0.0764 / 0.165=0.463(46.3 \% \mathrm{RH})$ and $0.0742 / 0.165=0.449(44.9 \% \mathrm{RH})$. Measurable layers formed in tests with SRL 131-TDS and 
SRL 51S glass reacted for 90 days in tests with 0.0764 and $0.0742 \mathrm{~g}$ of added water (tests 131-48RH-2 and 51S-48RH-2, see Appendix C, Tables C-2 and C-3). Because the relative humidity will decrease during the test when water condenses on the sample, and also as water is consumed during glass hydration, a relative humidity of $44 \%$ is taken as the minimum relative humidity required for corrosion to occur. The glass degradation rate expression is only applied when the relative humidity is above $44 \% \mathrm{RH}$. Both the effect of the relative humidity on the glass degradation rate at relative humidities above $44 \%$ and the effect of excess water are taken into account by the range of values used for $\mathrm{k}_{\mathrm{E}}$.

\subsection{Effect of Temperature in VHTs}

Standard VHTs were conducted at $70^{\circ} \mathrm{C}, 90^{\circ} \mathrm{C}, 125^{\circ} \mathrm{C}, 150^{\circ} \mathrm{C}, 175^{\circ} \mathrm{C}$, and $200^{\circ} \mathrm{C}$ to measure the effect of temperature on the degradation rate in humid air. The largest number of tests was conducted with SRL 51S glass; the results are summarized in Appendix C, Table C-2 (DTN: MO0306ANLGVH01.526 [DIRS 164331]). Figure 6-6a shows the results of tests conducted with SRL $51 \mathrm{~S}$ glass at $125^{\circ} \mathrm{C}, 150^{\circ} \mathrm{C}, 175^{\circ} \mathrm{C}$, and $200^{\circ} \mathrm{C}$, and Figure $6-6 \mathrm{~b}$ shows the results of tests with SRL 131 glass at $150^{\circ} \mathrm{C}$ and $200^{\circ} \mathrm{C}$ and the results of tests with SRL 165 glass at $125^{\circ} \mathrm{C}$ and $200^{\circ} \mathrm{C}$ against the test duration (the plotted data are tabulated in Appendix C, Tables C-6 and C-7). The thicker of the layers formed on the two samples in each test are plotted to determine the upper bound to the corrosion rates; the plotted layer thicknesses are tabulated in Table C-5. The results of tests VHT(150)-8, -9 , and -10 were excluded from Figure 6-6a because samples in those tests were significantly less reacted than samples in tests run for shorter durations under the same conditions. Measurable layers were not formed in tests with SRL $51 \mathrm{~S}$ at $70^{\circ} \mathrm{C}$ or $90^{\circ} \mathrm{C}$ through the longest durations tested (1,361 days). As expected, the layer growth rate increases with temperature. The rates determined from the regressions are included in the plots.

For comparison to rates to be calculated by using the TSPA-LA model, the rates were converted into units of $\mathrm{g}$ glass $/\left(\mathrm{m}^{2} \cdot \mathrm{d}\right)$ by multiplying the rate in $\mu \mathrm{m} /$ day by the density of the glass. The densities of the SRL 51S, SRL 131-TDS, and SRL 165S glasses were measured to be 2.67, 2.78, and $2.56 \mathrm{~g} / \mathrm{cm}^{3}$, respectively (DTN: MO0306ANLGVH01.526 [DIRS 164331], Table 2). The degradation rates measured in standard VHTs with the three glasses are summarized in Table 6-8 and shown in an Arrhenius plot in Figure 6-7. Linear regression to the standard VHT results for the three glasses gives a fit line with the equation $\ln ($ rate $)=33.1-118 / \mathrm{RT}$, from which the effective activation energy is $118 \mathrm{~kJ} / \mathrm{mol}$. 

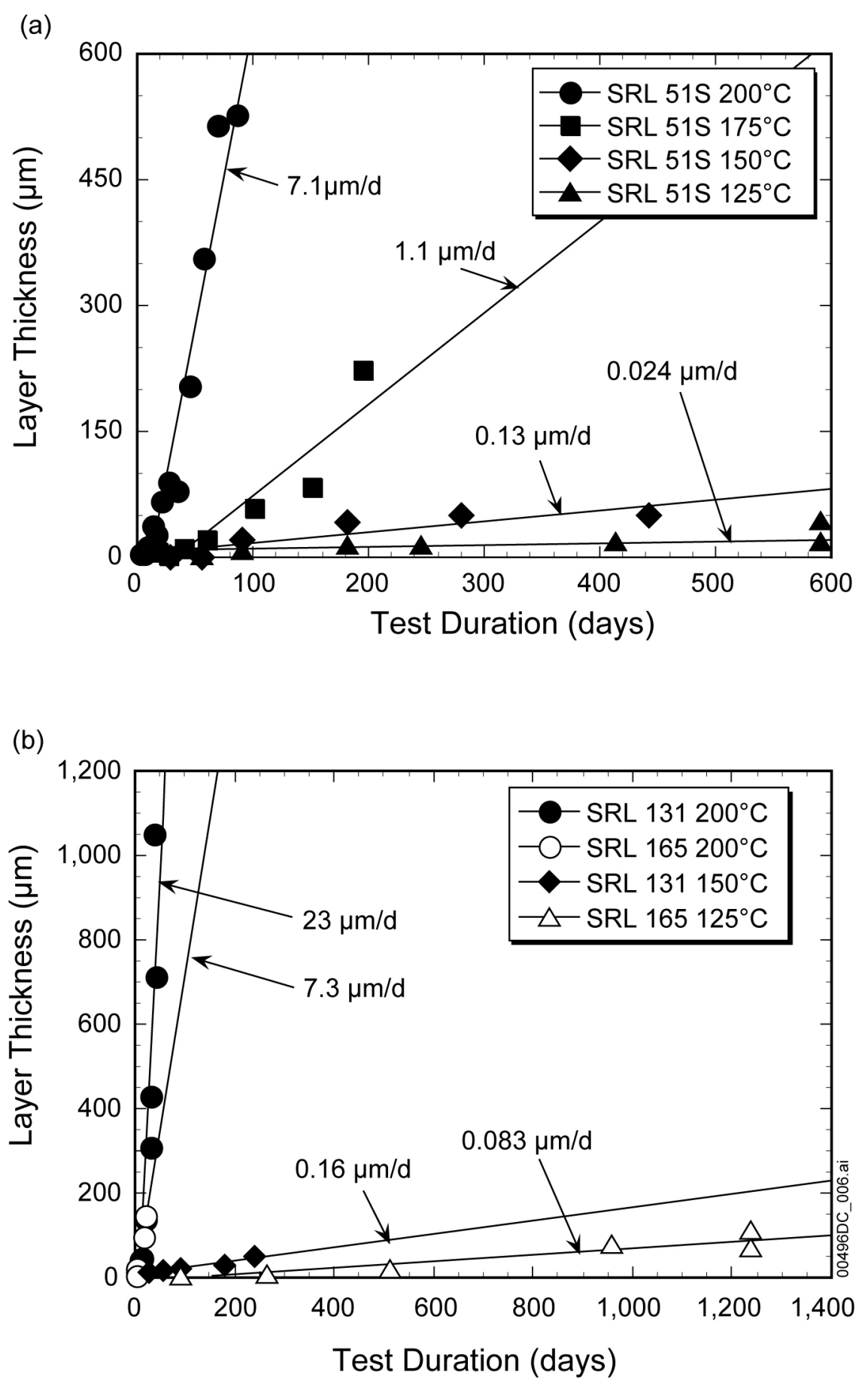

Source: Appendix C, Tables C-6 and C-7.

Figure 6-6. Measured Layer Thickness and Corrosion Rates in Standard VHTs with (a) SRL 51S Glass and (b) SRL 131-TDS and SRL 165 Glasses 
The effective activation energy extracted from the Arrhenius plot in Figure 6-7 represents the glass dissolution rates convoluted with the effects of other processes that occur in the test, such as water condensation. Differences in the $\mathrm{pH}$ and solution chemistries generated at different temperatures will affect the measured rates in addition to the differences in the temperature itself. A single effective activation energy is determined from results of VHTs with three different glasses so the effect of glass composition is also convoluted into the value of $118 \mathrm{~kJ} / \mathrm{mol}$ determined from regression.

Table 6-8. Corrosion Rates Measured in Standard VHTs

\begin{tabular}{|l|c|c|c|c|}
\hline & $125^{\circ} \mathbf{C}$ & $150^{\circ} \mathbf{C}$ & $175^{\circ} \mathbf{C}$ & $200^{\circ} \mathbf{C}$ \\
\hline \multicolumn{5}{|c|}{ Rate, $\mu \mathbf{m} / \mathbf{d}$} \\
\hline SRL 51S & 0.024 & 0.13 & 1.1 & 7.1 \\
\hline SRL 165 & 0.083 & not measured & not measured & 7.3 \\
\hline SRL 131-TDS & not measured & 0.16 & not measured & 23 \\
\hline \multicolumn{5}{|c|}{ In(Rate) $\left[\mathbf{g} /\left(\mathrm{m}^{2} \cdot \mathbf{d}\right)\right]$} \\
\hline SRL 51S & -2.75 & -1.06 & 1.08 & 2.94 \\
\hline SRL 165 & -1.55 & not measured & not measured & 2.93 \\
\hline SRL 131-TDS & not measured & -0.81 & not measured & 4.16 \\
\hline
\end{tabular}

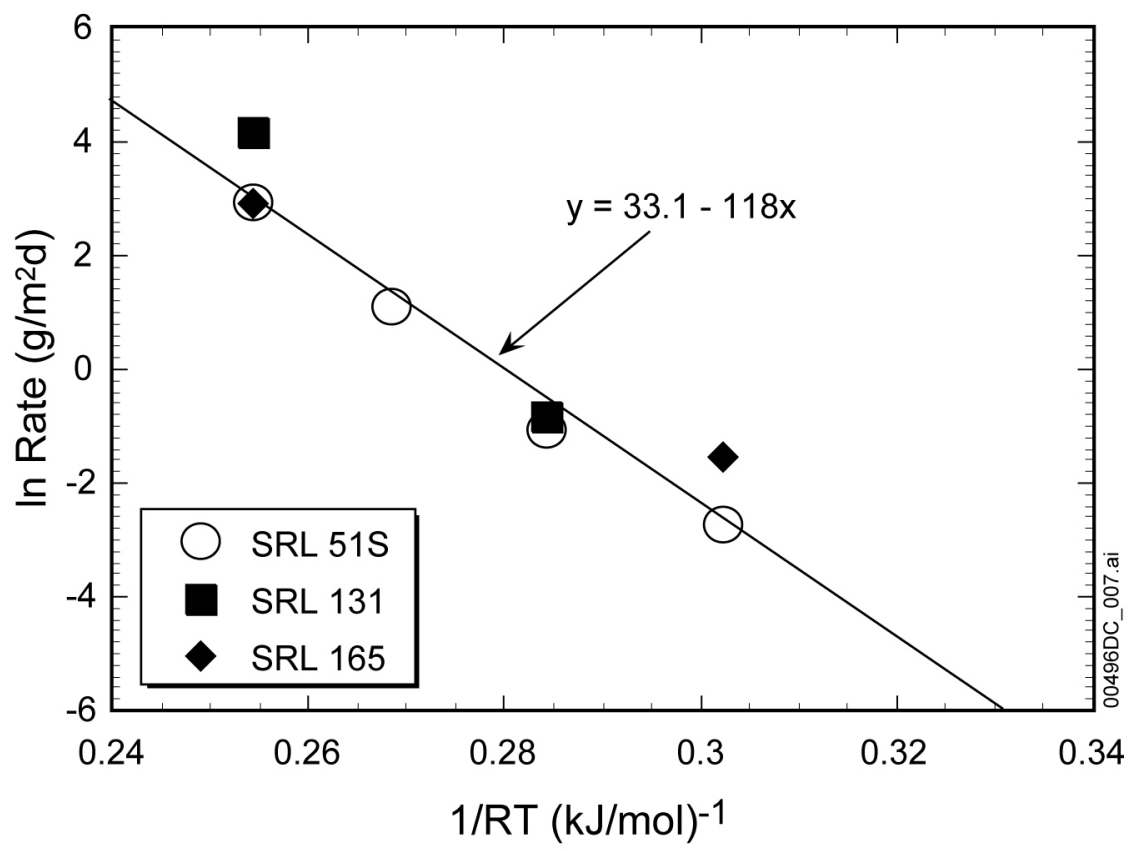

Source: Table 6-8.

Figure 6-7. Arrhenius Plot for Measured Rates for Glasses in Standard VHTs

\subsection{Extraction of Lower Bounding Rate Parameters}

The same rate equation (Equation 13) is used to calculate degradation rates for glass exposed to humid air, dripping water, and immersion environments. The range and distribution of parameter values are used to reflect the effects of the environment and glass composition on the dissolution rate. The effective activation energy determined from the standard VHTs is 
significantly different than the activation energies determined from immersion tests for alkaline solutions $(69 \mathrm{~kJ} / \mathrm{mol})$. This is because the activation energy determined from the VHTs includes the effects of other processes on the measured rates, including the effects of $\mathrm{pH}$ and chemical affinity. Both the $\mathrm{pH}$ and the chemical affinity may differ in the films formed in VHTs conducted at different temperatures. The $\mathrm{pH}$ of the film in which the glass degrades in the VHTs is not known and the effect of the $\mathrm{pH}$ cannot be separated from the effect of temperature in the activation energy determined in Figure 6-7. Therefore, the effective activation energy determined from the VHTs is only used to extrapolate the corrosion rate in humid air at $90^{\circ} \mathrm{C}$. This extrapolation accounts for the effects of temperature on the $\mathrm{pH}$ and chemical affinity as well as the reaction rate. The effective activation energy determined from the VHTs is not appropriate for use in the glass degradation rate expression (Equation 13). Instead, the activation energy measured from immersion tests is used in the glass degradation rate expression because it is independent of $\mathrm{pH}$ and chemical affinity affects. The rate for corrosion in humid air at $90^{\circ} \mathrm{C}$ is used with the $\mathrm{pH}$ and temperature parameters determined from the MCC-1 tests to extract the value of $\mathrm{k}_{\mathrm{E}}$ that can be used in Equation 13 to calculate dissolution rates for glass exposed to humid air.

Extrapolation of the solid line in Figure 6-7 gives a rate of $2.5 \times 10^{-3} \mathrm{~g} /\left(\mathrm{m}^{2} \cdot \mathrm{d}\right)$ at $90^{\circ} \mathrm{C}$. This rate is used as the minimum dissolution rate to be calculated with the degradation model at $90^{\circ} \mathrm{C}$. The extent of reaction predicted by a rate of $2.5 \times 10^{-3} \mathrm{~g} /\left(\mathrm{m}^{2} \cdot \mathrm{d}\right)$ after 1,362 days is $3.4 \mathrm{~g} / \mathrm{m}^{2}$, which corresponds to a layer thickness of $3.4 \mathrm{~g} / \mathrm{m}^{2} /\left(2.67 \mathrm{~g} / \mathrm{cm}^{3}\right)=1.3 \mu \mathrm{m}$. A layer this thick would be readily detectable with an SEM. The fact that no alteration was detected in the standard VHTs conducted at $90^{\circ} \mathrm{C}$ for as long as 1,362 days indicates that the extrapolated rate of $2.5 \times 10^{-3} \mathrm{~g} /\left(\mathrm{m}^{2} \cdot \mathrm{d}\right)$ at $90^{\circ} \mathrm{C}$ provides a conservative estimate of the lower bound for the range of degradation rates calculated by the model.

The lower limit value of $\mathrm{k}_{\mathrm{E}}$ is extracted from that rate by using the measured rate and the values of $\eta$ and $E_{a}$ that were determined using immersion tests (Section 6.5.3.5). This requires that the $\mathrm{pH}$ of the solution film on the VHT samples be specified. Because the solution is evaporated from the sample and recondensed in the bottom of the vessel when the standard VHT is terminated (i.e., for VHTs conducted without excess water), the $\mathrm{pH}$ of the sample film is not measured directly. Three sets of test data provide useful estimates of the $\mathrm{pH}$ of the water film:

1. The $\mathrm{pH}$ values of water that was recondensed on the vessel bottom at the end of the test were measured as a part of the test procedure. This was done to determine if solution dripped from the samples either during the test or during test termination. The results are in included in DTN: MO0306ANLGVH01.526 [DIRS 164331]. The $\mathrm{pH}$ of the condensates in most tests were measured to be 6 or 7 , which is interpreted in the test method as indicating solution did not drip from the samples. However, the condensates in some tests had $\mathrm{pH}$ values of 10 or 11 . This indicates that the $\mathrm{pH}$ values of the films on the samples were at least this high.

2. Small amounts of solution did remain on the samples in some of the standard VHTs. These solutions were sufficiently concentrated that they did not completely evaporate when the test was terminated. The $\mathrm{pH}$ values of these drops of solution were measured with $\mathrm{pH}$ paper, and the solutions were highly alkaline (e.g., $\mathrm{pH} 12$ ) in all cases. Neither the $\mathrm{pH}$ values of solution remaining on the sample nor that of the 
recondensate is considered quantitative, but both indicate that the film of water on the glass had a highly alkaline $\mathrm{pH}$.

3. The results of VHTs conducted with excess water provide a quantitative measure of the $\mathrm{pH}$ of the solution in the bottom of the test vessel at the end of the test. The results are included in DTN: MO0306ANLGVH01.526 [DIRS 164331]. The $\mathrm{pH}$ values of those solutions were measured with a combination electrode and $\mathrm{pH}$ meter. The $\mathrm{pH}$ values ranged from about 7 in short-term tests up to 12 . Because the $\mathrm{pH}$ rises due to glass dissolution (primarily due to dealkalization reactions), the $\mathrm{pH}$ of the solution contacting the glass must have been equal to or higher than that of the solution in the bottom of the vessel. The initial $\mathrm{pH}$ of the demineralized water was not measured, but is conservatively taken to be that of air-saturated water and near $\mathrm{pH}$ 5.7. The films on the samples in VHTs are modeled to have a value of $\mathrm{pH} 12$ due to glass degradation.

The value of $\mathrm{k}_{\mathrm{E}}$ is extracted from the VHT rate at $90^{\circ} \mathrm{C}$ using Equation 13 with the following values: $\operatorname{rate}_{\mathrm{G}}=2.5 \times 10^{-3} \mathrm{~g} /\left(\mathrm{m}^{2} \cdot \mathrm{d}\right)(\log ($ rate $)=-2.60) ; \eta=0.49 ; \mathrm{pH}=12 ; \mathrm{E}_{\mathrm{a}}=69 \mathrm{~kJ} / \mathrm{mol}$; and $\mathrm{T}=363 \mathrm{~K}$.

$$
\log _{10} \mathrm{k}_{\mathrm{E}}=-2.60 \mathrm{~g} /\left(\mathrm{m}^{2} \cdot \mathrm{d}\right)-0.49 \times 12-\log _{10}\left[\exp \left(\frac{-69 \mathrm{~kJ} / \mathrm{mol}}{0.008314 \mathrm{~kJ} / \mathrm{mol} \times \mathrm{K} \times 363 \mathrm{~K}}\right)\right]
$$

The extracted value of $\log _{10}\left(\mathrm{k}_{\mathrm{E}}\right)$ is $1.45 \mathrm{~g} /\left(\mathrm{m}^{2} \cdot \mathrm{d}\right) ; \mathrm{k}_{\mathrm{E}}=28.2 \mathrm{~g} /\left(\mathrm{m}^{2} \cdot \mathrm{d}\right)$.

The expression to calculate the minimum rate for alkaline solutions is:

$$
\log _{10}\left(\operatorname{rate}_{\mathrm{G}}\right)=1.45+0.49 \times \mathrm{pH}+\log _{10}\left[\exp \left(\frac{-69 \mathrm{~kJ} / \mathrm{mol}}{\mathrm{RT}}\right)\right]
$$

\subsubsection{Using Unsaturated Tests to Model Degradation in Dripping Water}

\subsection{ANL Unsaturated Tests}

The dissolution rates of reference HLW glasses SRL 165 and ATM-10 were measured in drip tests conducted at $90^{\circ} \mathrm{C}$. In these tests, $0.075 \mathrm{~mL}$ of tuff groundwater solution was injected into the test vessel and onto a monolithic glass sample every 3.5 days. The samples (N2-9, N2-10, and N2-12), which were accurately measured, were in the form of cylinders with average dimensions $(1.561 \pm 0.039) \times 10^{-2} \mathrm{~m}$ in diameter and $(2.028 \pm 0.026) \times 10^{-2} \mathrm{~m}$ in height; the total surface area of each sample, rounded to two significant figures was $1.4 \times 10^{-3} \mathrm{~m}^{2}$ (DTN: MO0408ANLGNN01.527 [DIRS 171574]). The samples were suspended in the test vessel on a perforated Stainless Steel Type 304L holder. Water collected on and corroded the sample. Excess water dripped from the specimen at each injection. At approximately 6-month intervals, the tests were interrupted and the solution that collected at the bottom of the vessel was removed for analysis. The sides and bottom of the test vessel were rinsed with demineralized water that was subsequently analyzed. The sides and bottom of the test vessel were then rinsed with a nitric acid solution to dissolve any material that had been released from the glass and fixed to the steel during the test interval. This acid strip solution was analyzed separately. The 
amount of boron released is used as a measure of the extent of glass dissolution. The amount of boron in the acid strip solution was generally only a few percent of the total boron. It was determined that including the fraction in the acid strip solution would add more uncertainty to the analysis, and because the release rate rather than the absolute mass of boron is desired, it was neglected. The amounts of actinides in the acid strip were included in the analyses to be discussed in Section 6.9.1.2.

Two blank tests were conducted identically to the other tests, but without a test specimen, one in parallel to the triplicate tests on each glass. The tuff groundwater solution contains a small amount of boron. The accumulation rate of boron in the blank drip tests were subtracted from the rates measured in the tests with glass, as mass B per day, to calculate the degradation rate.

Triplicate tests identified as N2-9, N2-10, and N2-12 were conducted with samples of SRL 165 glass and blank test N2-11 was run in parallel. Triplicate tests identified as N3-9, N3-10, and N3-12 were conducted with samples of ATM-10 glass and blank test, N3-11, was run in parallel. The test results are given in DTN: MO0408ANLGNN01.527 [DIRS 171574] as mass released over each test interval in Table 1 for the N2 series of tests and in Table 3 for the N3 series of tests. The cumulative masses at each sample date are given in Tables 2 and 4 for the N2 and N3 series, respectively. These data are shown in Figure 6-8. Solutions were not sampled from the N2 series between May 3, 1990 (day 1,550) and December 21, 1993 (day 2,878) and in the N3 series between September 10, 1990 (day 245) and January 12, 1994 (day 1,220), although the groundwater solution continued to be injected every 3.5 days over this period. Two data points were excluded from the plot: the boron concentrations measured in tests N3-10 and N3-11 (blank) were unusually high for the June 8, 2000 samplings. The B concentration in the N3-10 sample was about 30 times higher the expected value and in the N3-11 sample about 3 times higher. The B concentrations in the N3-9 and N3-12 solutions, which were analyzed at the same time as the N3-10 and N3-11, were within the expected range for the 686-day test interval and are included in Figure 6-8.

(a)

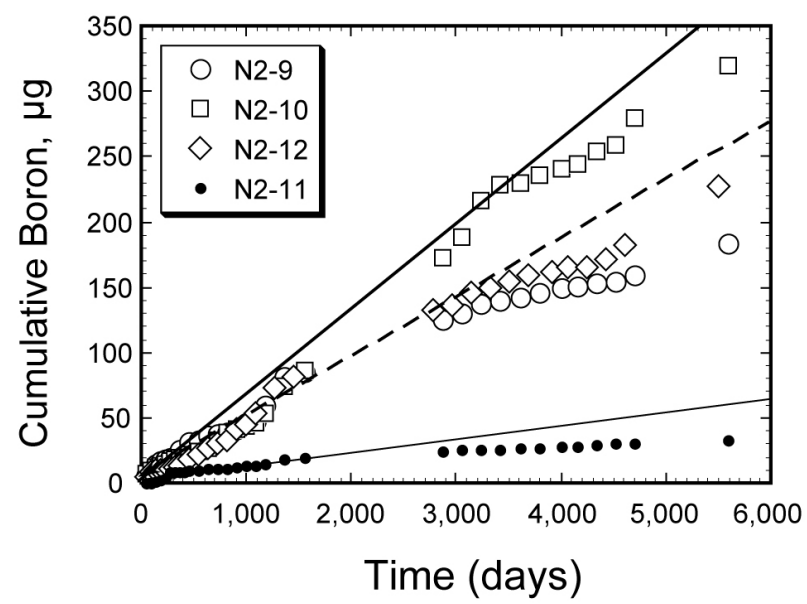

(b)

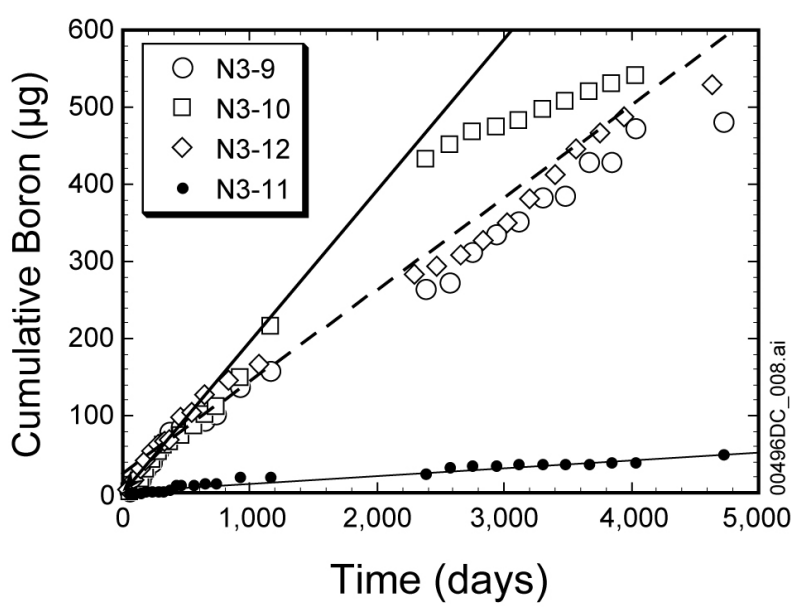

Source: DTN: MO0408ANLGNN01.527 [DIRS 171574], Tables 2 and 4.

Figure 6-8. Cumulative Boron Release in Tests with (a) SRL 165 Glass and (b) ATM-10 Glass 
The releases of boron from the test specimens in tests N2-9, -10, and -12 for SRL 165 glass and N3-9, -10, and -12 for ATM-10 glass overlap initially, but differ measurably beyond about 2,000 days. The heavy lines are drawn (empirically) in the figures to bound the boron release rates for each glass. The bounding rates from the solid lines are 0.066 and $0.20 \mu \mathrm{g} \mathrm{B} / \mathrm{d}$ for the N2 and N3 tests, respectively. The dashed lines give the average release rates from the three replicate tests, that is, by regression of the combined results for tests N2-9, N2-10, and N2-12 for SRL 165 glass and for tests N3-9, N3-10, and N3-12 for ATM-10 glass. The slopes of the dashed lines are $0.045 \mu \mathrm{g} \mathrm{B} / \mathrm{d}$ for the $\mathrm{N} 2$ tests $0.12 \mu \mathrm{g} \mathrm{B} / \mathrm{d}$ for the N3 tests. The thin lines are drawn through the results of the blank tests for each test series (N2-11 and N3-11). The boron release rates in the blank tests are $0.011 \mu \mathrm{g} \mathrm{B} / \mathrm{d}$. The mass fraction of boron in SRL 165 glass is about 0.021 and in ATM-10 glass is about 0.028 (DTN: MO0408ANLGNN01.527 [DIRS 171574]). The normalized glass dissolution rates are calculated using Equation 40 with both the bounding and the average release rates for rate $_{\mathrm{G}}$ :

$\left(\right.$ rate $\left._{\mathrm{G}} \mu \mathrm{g} \mathrm{B} / \mathrm{d}-\mathrm{Blank} \mu \mathrm{g} \mathrm{B} / \mathrm{d}\right) \times(1 /$ mass fraction B in glass $) \times(1 /$ surface area glass $)$

The upper bounding rate for SRL 165 glass in the N2 series is:

$$
\left(0.066-0.011 \frac{\mu g B}{d}\right) \times\left(1 \times 10^{-6} \frac{g}{\mu g}\right) \times\left(\frac{1 g \text { glass }}{0.021 g B}\right) \times\left(\frac{1}{1.4 \times 10^{-3} m^{2}}\right)=1.87 \times 10^{-3} \frac{g}{m^{2} d}
$$

The average rate for SRL 165 glass in the N2 series is:

$$
\left(0.045-0.011 \frac{\mu g B}{d}\right) \times\left(1 \times 10^{-6} \frac{g}{\mu g}\right) \times\left(\frac{1 g \text { glass }}{0.021 g B}\right) \times\left(\frac{1}{1.4 \times 10^{-3} m^{2}}\right)=1.16 \times 10^{-3} \frac{g}{m^{2} d}
$$

The upper bounding rate for ATM-10 glass in the N3 series is:

$$
\left(0.20-0.011 \frac{\mu g B}{d}\right) \times\left(1 \times 10^{-6} \frac{g}{\mu g}\right) \times\left(\frac{1 g \text { glass }}{0.028 g B}\right) \times\left(\frac{1}{1.4 \times 10^{-3} m^{2}}\right)=4.82 \times 10^{-3} \frac{g}{m^{2} d}
$$

The average rate for ATM-10 glass in the N3 series is:

$$
\left(0.12-0.011 \frac{\mu g B}{d}\right) \times\left(1 \times 10^{-6} \frac{g}{\mu g}\right) \times\left(\frac{1 g \text { glass }}{0.028 g B}\right) \times\left(\frac{1}{1.4 \times 10^{-3} m^{2}}\right)=2.78 \times 10^{-3} \frac{g}{m^{2} d}
$$

As was the case in the VHTs, the solution remaining in contact with the glass was not analyzed as a part of the unsaturated (drip) test procedure. In a few instances, the $\mathrm{pH}$ of a small drop of water that remained on the sample was measured with $\mathrm{pH}$ paper and found to have values of 4 to 5 . The $\mathrm{pH}$ values of the solutions collected in the bottom of the vessels of the later samplings were measured with a combination electrode and $\mathrm{pH}$ meter. These were also determined to be acidic: the average $\mathrm{pH}$ values for the $\mathrm{N} 2$ and $\mathrm{N} 3$ test series are 4.9 and 5.4, respectively (DTN: MO0408ANLGNN01.527 [DIRS 171574], Tables 5 and 6). The pH values of the solutions in the blank tests are also acidic. The solution $\mathrm{pH}$ values are affected by several competing factors. The tuff groundwater solution injected into the tests has a $\mathrm{pH}$ of about 8 . 
The solution $\mathrm{pH}$ increases as glass dissolves. It will decrease from radiolysis of the water by the radiation from the radionuclides in the glass and, potentially, from any corrosion of the stainless steel test vessel and sample support. However, corrosion of steels usually causes the solution to become more alkaline. The behavior of $\mathrm{CO}_{2}$ in this test is unclear. As the vessel is heated, the partial pressure of $\mathrm{CO}_{2}$ decreases as the water vapor pressure increases and the total pressure increases. At water injection, the pressure is relieved, but additional $\mathrm{CO}_{2}$ is introduced as dissolved carbonate in the water. Depending on the total pressure after each injection, some $\mathrm{CO}_{2}$ will exsolve from the solution or dissolve into solution. When the vessel is cooled to retrieve the accumulated solution from the bottom, $\mathrm{CO}_{2}$ will either dissolve or exsolve depending on the solution $\mathrm{pH}$ and the total and $\mathrm{CO}_{2}$ pressures. Any chemical effects that make the solution acidic must do so sufficiently to overcome the alkalinity imposed by the dissolution of the glass. Thus, the reason for the acidic $\mathrm{pH}$ values in these tests is not understood nor was it investigated.

\subsubsection{Extraction of Lower Bounding Rate Parameters}

The results of the ANL unsaturated tests are used to extract the lower bounding value of $\mathrm{k}_{\mathrm{E}}$ for degradation in acidic solutions. The value of $\mathrm{k}_{\mathrm{E}}$ was extracted from these results by using the same activation energy that is used for aqueous dissolution, namely, $31 \mathrm{~kJ} / \mathrm{mol}$. The same activation energy is used for the different exposure modes because hydrolysis of silicon-oxygen bonds is the rate-limiting step for glass dissolution under both conditions (Section 6.3.1). The value of $\mathrm{k}_{\mathrm{E}}$ is extracted from the rates measured in the unsaturated (drip) tests at $90^{\circ} \mathrm{C}$ using Equation 13 with the following values:

For SRL 165 glass in the N2 series: $\operatorname{rate}_{\mathrm{G}}=1.16 \times 10^{-3} \mathrm{~g} /\left(\mathrm{m}^{2} \cdot \mathrm{d}\right)\left[\log _{10}(\right.$ rate $\left.)=-2.94\right] ; \eta=-0.49$; $\mathrm{pH}=4.9 ; \mathrm{E}_{\mathrm{a}}=31 \mathrm{~kJ} / \mathrm{mol} ; \mathrm{R}=0.008314 \mathrm{~kJ} / \mathrm{mol} \mathrm{K}$; and $\mathrm{T}=363 \mathrm{~K}$.

$$
\log _{10} \mathrm{k}_{\mathrm{E}}=-2.937 \frac{\mathrm{g}}{\mathrm{m}^{2} d}-(-0.49 \cdot 4.9)-\log _{10}\left[\exp \left(\frac{-31 \mathrm{~kJ} / \mathrm{mol}}{0.008314 \mathrm{~kJ} / \mathrm{mol} \cdot \mathrm{K} \times 363 \mathrm{~K}}\right)\right]
$$

The extracted value of $\log _{10}\left(\mathrm{k}_{\mathrm{E}}\right)$ from the N2 series is $3.92 \mathrm{~g} /\left(\mathrm{m}^{2} \cdot \mathrm{d}\right)$ and $\mathrm{k}_{\mathrm{E}}=8.41 \times 10^{3} \mathrm{~g} /\left(\mathrm{m}^{2} \cdot \mathrm{d}\right)$.

For ATM-10 glass in the N3 series: rate $_{\mathrm{G}}=2.78 \times 10^{-3} \mathrm{~g} /\left(\mathrm{m}^{2} \cdot \mathrm{d}\right)\left[\log _{10}(\right.$ rate $\left.)=-2.56\right] ; \eta=-0.49$; $\mathrm{pH}=5.4 ; \mathrm{E}_{\mathrm{a}}=31 \mathrm{~kJ} / \mathrm{mol}$; and $\mathrm{T}=363 \mathrm{~K}$.

$$
\log _{10}\left(\mathrm{k}_{\mathrm{E}}\right)=-2.556 \frac{\mathrm{g}}{\mathrm{m}^{2} d}-(-0.49 \times 5.4)-\log _{10}\left[\exp \left(\frac{-31 \mathrm{~kJ} / \mathrm{mol}}{(0.008314 \mathrm{~kJ} /(\mathrm{mol} \times \mathrm{K})) \times(363 \mathrm{~K})}\right)\right]
$$

The extracted value of $\log _{10}\left(\mathrm{k}_{\mathrm{E}}\right)$ from the N3 series is $4.55 \mathrm{~g} /\left(\mathrm{m}^{2} \cdot \mathrm{d}\right)$ and $\mathrm{k}_{\mathrm{E}}=3.56 \times 10^{4} \mathrm{~g} /\left(\mathrm{m}^{2} \cdot \mathrm{d}\right)$.

The lower value of $\mathrm{k}_{\mathrm{E}}=8.41 \times 10^{3} \mathrm{~g} /\left(\mathrm{m}^{2} \cdot \mathrm{d}\right)$; $\log _{10}\left(\mathrm{k}_{\mathrm{E}}\right)=3.92$ is used as the lower bound of the degradation rates of waste glasses exposed to acidic waters. The expression for calculating the minimum degradation rate for acidic $\mathrm{pH}$ values (in terms of $\log _{10}\left(\right.$ rate $\left._{\mathrm{G}}\right)$ ) is:

$$
\log _{10}\left(\text { rate }_{\mathrm{G}}\right)=3.92+(-0.49 \times \mathrm{pH})+\log _{10}\left[\exp \left(\frac{-31 \mathrm{~kJ} / \mathrm{mol}}{\mathrm{RT}}\right)\right]
$$




\subsubsection{Calculation of the Exposed Surface Area of Waste Glass}

To calculate the release rate of radionuclides, the glass degradation rate is multiplied by the surface area that is contacted by water and the radionuclide inventory to calculate fraction release (Equation 9). The waste glass will crack in the pour canister from the thermal and mechanical stresses generated as the glass cools and as the waste form is handled (including accidental drops or other impact events). Cracking of the glass will result in surfaces deep within the glass that may be accessible to water or humid air. An important component of the TSPA-LA glass model is determination of the surface area that is contacted by water.

The surface area of glass that is exposed in a laboratory test is usually determined geometrically, if the specimens are large enough, or based on the sieve fraction when crushed samples are used. Some researchers have multiplied the geometric surface area by a roughness factor to take into account the fact that prepared surfaces are not smooth on a microscopic scale (Oversby 1982 [DIRS 163276]). A similar approach is taken to estimate the surface area of the waste glass, wherein the geometric surface area of the glass determined by the dimensions of the pour canister and the fill height are multiplied by a water exposure factor:

$$
\mathrm{S}_{0}=\mathrm{f}_{\text {exposure }} \times\left(2 \pi \mathrm{r}_{\mathrm{o}}^{2}+2 \pi \mathrm{r}_{\mathrm{o}} \times \mathrm{L}_{\mathrm{o}}\right)
$$

where

$\mathrm{S}_{0}$ is the initial exposed surface area of a glass including that due to fracturing

$r_{o}$ is the initial radius of a glass

$\mathrm{L}_{\mathrm{o}}$ is the initial length of a glass

$\mathrm{f}_{\text {exposure }}$ is the exposure factor.

The exposure factor is used to account for several uncertainties regarding the glass surface area that is used to calculate the glass degradation rate and, ultimately, the radionuclide release rate. These are:

- Thermal cracking

- Impact cracking

- Lower accessibility of water to tight cracks than at free surfaces

- Lower reactivity of glass in tight cracks than at free surfaces

- Lower transportability in tight cracks than at free surfaces.

The reactivity of surfaces in the tight fracture cracks that result from thermal and mechanical stresses depends on the glass composition, temperature, and the chemistry of the water that fills the crack in the same way these factors affect the dissolution rate at free surfaces. The key difference between the dissolution rates of the glass within cracks and at the outer surface is the transport rates of water and dissolved gases into the crack and reaction products out of the crack. Short-term dissolution tests showed that, while more glass dissolved in tests with samples that were fractured than not fractured, the difference was less than a factor of 3 (Bickford and Pellarin 1987 [DIRS 163207]). It had been concluded previously, from the results of tests in which various crack widths were simulated with platinum wire spacers, "the assumption that crack surfaces leach as readily as the external surface is unduly conservative" (Perez and Westsik 1981 [DIRS 111044], p. 168). The amounts of glass components released to solution 
from cracks and from free surfaces cannot be distinguished based on solution results alone. Analysis of test specimens reacted under test conditions similar to those used by Perez and Westsik (1981 [DIRS 111044]) indicated that the amount of altered glass in cracks near the surface (which were probably formed during preparation of specimens for use in the tests) was similar to the amount of altered glass that remained at free surfaces (Pederson et al. 1983 [DIRS 118927], p. 156, Figure 6). The cracks containing altered glass were observed only near the surface; it could not be determined if the cracks penetrated into the glass beyond what was altered.

Recent vapor hydration tests have shown that pressurized water can penetrate deep into cracked test samples (Jiřička et al. 2001 [DIRS 163262]). The small volumes of water that can accumulate within cracks will quickly become saturated as glass dissolves and a low dissolution rate will ensue. Observations of altered glass in cracks reveal that the glass on either side of the crack becomes either hydrated or transformed into clay (Jiřička et al. 2001 [DIRS 163262]; Crovisier et al. 1986 [DIRS 163211]). Cracks in waste glasses are not observed to open significantly because very little glass dissolves. Therefore, although water may penetrate through cracks well into the interior of glass, the amounts of radionuclides that can be released from cracks will be much smaller than from free surfaces.

Insufficient information is available to quantify either the fraction of cracks that are accessible to water or the difference between the corrosion rates in cracks and at a free surface. The approach taken in this report is to use a range of exposure factors to account for the uncertainty in the accessibility and reactivity of glass in cracks. The upper limit of the exposure factor is assigned to be 17. This value is based on reported values for the factors of 12 from thermal cracking when the canister is cooled in air (Smith and Baxter 1981 [DIRS 102089]), 40 from impacts during handling (Smith and Ross 1975 [DIRS 102088]), and on the accessibility of surfaces in cracks to water, and the same reactivity of glass within the crack as at a free surface. The lower limit of the exposure factor is assigned to be 4 . This accounts for thermal cracking $(12 \times)$ of glass in an air-cooled canister, impact cracking $(40 \times)$ applied to $1 \%$ of the glass, accessibility of water to half of the available surface within cracks, and the reactivity of glass within the crack being half the reactivity at a free surface. A maximum value of $\mathrm{f}_{\text {exposure }}=17$ is obtained when all glass surfaces formed by fractures are freely accessible to water and glass within cracks has the same reactivity as glass at free surfaces:

$$
\begin{aligned}
\mathrm{f}_{\text {exposure }} & =[40 \text { (impact cracking }) \times 12(\text { thermal cracking }) \times 0.01]+[12 \text { (thermal cracking }) \times 0.99] \\
& =16.68, \text { which is rounded up to } 17 .
\end{aligned}
$$

A minimum value of $f_{\text {exposure }}=4$ is obtained when one-half of the glass surfaces formed by fractures are freely accessible to water and glass within cracks has the one-half the reactivity of glass at free surfaces:

$$
\left.f_{\text {exposure }}=[17 \times 0.5 \text { (accessibility }) \times 0.5 \text { (reactivity) }\right]=4.25 \text {, which is rounded down to } 4 \text {. }
$$

The most probable value for the exposure factor is selected empirically at 4 because less than half of the crack surface area will be accessible to water. Data available in the literature indicate that the increase in release due to cracking is 3 times that based on the surface area of the for full-size samples; this is discussed in Section 7.2. 
The nominal dimensions of the standard (short) HLW canister that will be used for HLW glass produced at the DWPF and WVDP are: overall height $=3.0 \mathrm{~m}$; outside diameter $=0.61 \mathrm{~m}$ (DOE 1992 [DIRS 102812], Tables 3.1.1 and 3.3.1 and Sections 3.1.1 and 3.3.3; corroborated in DOE 2002 [DIRS 158398]). The nominal mass of an average glass produced at the DWPF is $1,682 \mathrm{~kg}$ and the nominal $85 \%$ fill volume is $0.626 \mathrm{~m}^{3}$ (DOE 1992 [DIRS 102812]; Tables 3.1.1 and 3.3.1 and Sections 3.1.1 and 3.3.3). The density ( $\rho$ ) of a DWPF glass is calculated from these values for the average mass and volume is $2.69 \mathrm{~g} / \mathrm{cm}^{3}$ (corresponding to $2,690 \mathrm{~kg} / \mathrm{m}^{3}$ ). Although the density is given as $2,730 \mathrm{~kg} / \mathrm{m}^{3}$ in Table 3.3 .1 of Characteristics of Potential Repository Wastes (DOE 1992 [DIRS 102812]), a density of 2,690 kg/m ${ }^{3}$ is used for DWPF glass in the calculations that follow. To be consistent with the calculation of the Hanford glass density, the value of $2,690 \mathrm{~kg} / \mathrm{m}^{3}$ was obtained from the average mass of glass per DWPF canister, the canister dimensions, and the fill height.

The nominal mass of an average WVDP glass is $1,900 \mathrm{~kg}$ and the density is about $2,700 \mathrm{~kg} / \mathrm{m}^{3}$ (DOE 1992 [DIRS 102812], Tables 3.1.1 and 3.2.1 and Sections 3.1.1 and 3.2.3). The volume of the glass calculated by dividing the mass by the density is $0.704 \mathrm{~m}^{3}$.

The geometric surface area is calculated from the volume of glass and dimensions of the canister. The initial radius of the glass, $r_{0}$, is simply one-half of the value of the outside diameter, which is $0.61 \mathrm{~m}$, minus the wall thickness, which is $9.5 \mathrm{~mm}$ for DWPF glass. The initial radius of the glass, $r_{o}$, is $(0.61 \mathrm{~m}-2 \times 0.0095 \mathrm{~m}) / 2=0.30 \mathrm{~m}$ (rounded to two significant figures). The length of the glass $\left(\mathrm{L}_{0}\right)$ is calculated by treating the canister as a right cylinder of radius $0.30 \mathrm{~m}$, equating the expression for the volume of a right cylinder (volume $=\pi \times \mathrm{r}_{0}{ }^{2} \times \mathrm{L}_{0}$ ) with the volume calculated from the total weight of the glass and the glass density (volume $=$ weight $/ \rho$ ), and solving the resulting expression for the length. The initial length of DWPF glass is estimated to be $\mathrm{L}_{\mathrm{o}}=2.2 \mathrm{~m}$ (expressed to the same accuracy as the radius). This value is based on the overall height of the canister subtracting the neck and the concave bottom, a fill height of $85 \%$, and the wall thickness. The geometric surface area of the glass is calculated using the formula for the surface area of a right cylinder $\left(2 \pi r_{o}{ }^{2}+2 \pi r_{o} \times L_{o}\right)$; the geometric surface area is $4.74 \mathrm{~m}^{2}$. The corresponding values for WVDP glass waste forms are: $r_{0}=0.30 \mathrm{~m}, \mathrm{~L}_{0}=2.49 \mathrm{~m}$, and the geometric surface area is $5.26 \mathrm{~m}^{2}$.

Hanford waste glass will be disposed in a "long" canister (about $4.5 \mathrm{~m}$ overall) (DOE 2002 [DIRS 158398], Figure C-21) instead of the "short" canisters used for DWPF and WVDP glasses. The diameter of the "long" canisters will be the same as the short canister. An estimated fill height for a Hanford canister is $4.2 \mathrm{~m}$ based on a fill neck that is about $0.2 \mathrm{~m}$ the bottom thickness, and the concave bottom. This fill height gives an estimated geometric surface area of $8.5 \mathrm{~m}^{2}$ to two significant figures. The density of the Hanford glass is estimated from the available data. In Table 3.4.2 of Characteristics of Potential Repository Wastes (DOE 1992 [DIRS 102812]), the mass of glass to be contained in a canister is $1,650 \mathrm{~kg}$ that would occupy a volume of $0.626 \mathrm{~m}^{3}$ at $825^{\circ} \mathrm{C}$. These data give a value for the density of the Hanford glass as $2,636 \mathrm{~kg} / \mathrm{m}^{3}$ at $825^{\circ} \mathrm{C}$. The density would increase with decreasing temperature. The density of the Hanford glass at $825^{\circ} \mathrm{C}$ is sufficiently close to the densities of the DWPF and WVDP glasses that a value of $2,700 \mathrm{~kg} / \mathrm{m}^{3}$ for the cooled Hanford glass is appropriate. The effect of uncertainty in the glass density on the surface area calculated for use in the TSPA-LA glass model is negligible compared with the uncertainties in the exposure factor. 
The specific surface area of a glass, $\mathrm{S}_{\mathrm{sp}}$, is calculated by dividing its geometric surface area by its mass. For the DWPF glass in a short canister, the specific surface area is $\left(4.7 \mathrm{~m}^{2}\right) \div(1,680 \mathrm{~kg})=$ $2.8 \times 10^{-3} \mathrm{~m}^{2} / \mathrm{kg}$. The specific surface area is $2.8 \times 10^{-3} \mathrm{~m}^{2} / \mathrm{kg}$ for a WVDP glass in a short canister. The specific surface area for a Hanford glass in a long canister is $\left(8.5 \mathrm{~m}^{2}\right) \div(3,210 \mathrm{~kg})$ $=2.6 \times 10^{-3} \mathrm{~m}^{2} / \mathrm{kg}$.

The surface area that remains as the glass degrades is calculated as the product of the specific surface area, the exposure factor, and the mass of glass that remains. The expression used to calculate the glass surface area as glass dissolves in a time step is:

$$
\mathrm{S}=\mathrm{f}_{\text {exposure }} \times \mathrm{S}_{\mathrm{sp}} \mathrm{m}^{2} / \mathrm{kg} \times\left(\mathrm{M}_{0} \mathrm{~kg}-\Sigma \mathrm{M} \mathrm{kg}\right)
$$

where $\mathrm{S}$ is the surface area available for reaction in the current time step, $\mathrm{M}_{0}$ is the initial mass of glass, and $\Sigma \mathrm{M}$ is the total mass of glass degraded in all previous time steps. The mass of glass degraded in a time step is calculated as the product of the glass degradation rate for that realization (see below) and the duration of the time step.

As listed in Waste Acceptance System Requirements Document (DOE 2002 [DIRS 158873], Table 7-1), it is currently expected that there will be about twice as many long canisters of HLW glass (14,500 canisters for Hanford) as short canisters (5,978 for the Savannah River Site, 1,190 for Idaho, 100 for ANL, and 300 for WVDP). The probability that a breached waste package contains long canisters is about two times the probability that it contains short canisters, and the ratio of short glass canisters from DWPF and WVDP is about 30:1. Therefore, weighted averages of $67 \%$ Hanford, $32 \%$ DWPF, and 1\% WVDP are used to calculate both the specific surface area and the mass of exposed glass:

$$
\begin{gathered}
\mathrm{S}_{\mathrm{sp}}=\left(0.67 \cdot 2.63 \cdot 10^{-3} \frac{\mathrm{m}^{2}}{\mathrm{~kg}}\right)+\left(0.32 \cdot 2.82 \cdot 10^{-3} \frac{\mathrm{m}^{2}}{\mathrm{~kg}}\right)+\left(0.01 \cdot 2.77 \cdot 10^{-3} \frac{\mathrm{m}^{2}}{\mathrm{~kg}}\right) \\
\mathrm{M}_{0}=\mathrm{M}_{0}=(0.67 \cdot 3210 \mathrm{~kg})+(0.32 \cdot 1682 \mathrm{~kg})+(0.01 \cdot 1900 \mathrm{~kg})
\end{gathered}
$$

The specific surface area from Equation 46 is $2.7 \times 10^{-3} \mathrm{~m}^{2} / \mathrm{kg}$, and the initial mass from Equation 47 is $2,710 \mathrm{~kg}$. Substituting the values calculated in Equations 46 and 47 into Equation 45 gives the expression used to calculate the surface area for the next time step using Equation 48:

$$
\mathrm{S}=\mathrm{f}_{\text {exposure }} \times 2.70 \times 10^{-3} \mathrm{~m}^{2} / \mathrm{kg} \times\left(2,710 \mathrm{~kg}-\Sigma \mathrm{M}_{\mathrm{t}} \mathrm{kg}\right)
$$

Calculation of the surface area for each realization requires selection of the cracking factor. The initial time step is conducted with $\Sigma \mathrm{M}=0$. The value of $\Sigma \mathrm{M}_{\mathrm{t}}$ is revised after each time step to reduce the remaining surface area. The value of $\Sigma \mathrm{M}_{\mathrm{t}}$ is calculated from the glass degradation rate and the duration of the time step. Inputs used to calculate the glass degradation rate are summarized in Table 4-2. 


\subsubsection{Application of Base Case Model to Heterogeneous Glasses and Glass-Crystalline Composites}

The applicability of the glass degradation model to devitrified glasses and glass-crystalline composites is evaluated for three reasons. First, almost all HLW glass will have small amounts (about $1 \mathrm{vol} \%$ ) of crystalline inclusion phases. Second, the CWF developed to immobilize salt waste from electrometallurgical treatment of spent sodium-bonded fuel is included in the government-managed nuclear waste to be accepted at the repository according to Waste Acceptance System Requirements Document (DOE 2002 [DIRS 158873], Table 7-1). Third, evaluation of the effects of devitrification phases is needed to address the effects of igneous intrusion events on HLW glass performance in the disposal system. Literature data are evaluated in this section to validate application of the TSPA-LA glass degradation model to devitrified and multiphase waste forms.

Borosilicate HLW glasses are currently formulated to minimize the formation of precipitates while it is molten in the melter (either when the melter is at the processing temperature, at lower temperatures when idling, or during a malfunction) and as it solidifies in the steel canister. The formation of precipitates in the glass melt is minimized because (1) they may form sludge at the bottom of the melter that obstructs glass flow and pouring, (2) electrically conductive phases can provide a short circuit in Joule-heated melters, and (3) the formation of some phases may lower the durability of the glass. The waste loading of most HLW streams processed with a Joule-heated melter are limited by formation of phases in the glass-melt such as spinel $(\mathrm{Ni}, \mathrm{Fe}, \mathrm{Mn})(\mathrm{Cr}, \mathrm{Fe})_{2} \mathrm{O}_{4}$ and acmite $\mathrm{NaFe}\left(\mathrm{Si}_{2} \mathrm{O}_{6}\right)$, particularly for Fe-rich waste streams. The formation of these phases does not have a significant impact on the glass durability because the silicate network is not significantly affected by the formation of these phases. The limitation on the formation of these phases is solely due to melter operation.

The formation of some phases reduces the chemical durability of the glass. Glasses are formulated to avoid formation of phases such as nepheline $\left(\mathrm{NaAlSiO}_{4}\right)$ because precipitation of these phases lead to a composition change in the glass (Li et al. 2003 [DIRS 171167]). Precipitation of crystalline phases that result in a higher proportion of alkali in the remaining glass usually reduce the glass durability. As these phases form, a higher proportion of components that form the silicate structure of the glass, such as $\mathrm{Al}$ and $\mathrm{Si}$, are removed from the glass melt than components that interrupt the glass structure, such as alkali metals. Likewise, glass additives are controlled to avoid both the formation of soluble inclusion phases, such as lithium metasilicate $\left(\mathrm{Li}_{2} \mathrm{SiO}_{3}\right)$, and glass-glass phase separation. The formation of less durable phases could impact the performance of waste glasses if those phases contain radionuclides, and may have an indirect effect if they do not contain radionuclides. For example, dissolution of soluble phases will increase the exposed surface area of glass, may provide percolation channels into the interior of glass that facilitate the release of soluble radionuclides such as technetium, and may affect the solution chemistry, such as increasing the $\mathrm{pH}$ and the solubility of radionuclides.

\subsubsection{Tests with Devitrified Glasses}

Bickford and Jantzen (Bickford and Jantzen 1984 [DIRS 163206]; Jantzen and Bickford 1985 [DIRS 163259]) studied the leach behaviors of DWPF reference glasses made with SRL 131 and 
SRL 165 frits under conditions to promote devitrification. In addition to nominal compositions, glasses having high $\mathrm{Al}$ or high Fe contents were tested to better understand the effects of devitrification phases on glass durability. The primary precipitated phases were spinel and acmite. These were also seen to be the primary devitrification phases in reference glasses for Hanford tank wastes (Vienna et al. 1997 [DIRS 163330]; Reynolds and Hrma 1997 [DIRS 163280]). The chemical durabilities of glasses made under oxidizing and reducing conditions, and glasses with different extents of devitrification were measured with the MCC-1 static leach test. Tests showed that the formation of acmite resulted in a slight decrease in the glass durability, whereas the formation of spinel had no effect. Glasses made with high Fe contents were more susceptible to devitrification and glasses made with high Al contents were less susceptible to devitrification than the composite glasses. The results of 28-day MCC-1 tests with composite SRL 165 glasses made using different cooling schedules to promote different extents of devitrification are summarized in Table 6-9.

Table 6-9. Effects of Devitrification on Glass Durability

\begin{tabular}{|l|c|c|c|}
\hline \multicolumn{1}{|c|}{ Conditions } & $\begin{array}{c}\text { vol \% } \\
\text { Crystalline }\end{array}$ & $\mathbf{N R}(\mathbf{S i}), \mathbf{g} /\left(\mathbf{m}^{2} \cdot \mathbf{d}\right)$ & $\mathbf{N R}(\mathbf{B}), \mathbf{g} /\left(\mathbf{m}^{2} \cdot \mathbf{d}\right)$ \\
\hline Quenched & 0 & 0.45 & 0.48 \\
\hline Simulated Centerline Cooling & $\begin{array}{c}5 \% \text { spinel } \\
20 \% \text { acmite }\end{array}$ & 0.63 & 0.75 \\
\hline Heat treated 24 hours at $700^{\circ} \mathrm{C}$ & $20 \%$ acmite & 0.79 & 1.25 \\
\hline
\end{tabular}

Source: Jantzen and Bickford 1985 [DIRS 163259], Table IV.

The heat-treated glass showed an increase of less than a factor of 3 in the degradation rate relative to the quenched glass based on 28-day MCC-1 tests. Jantzen and Bickford (1985 [DIRS 163259]) concluded that the nonuniform distribution of precipitates in devitrified glasses limited the precision that can be attained in tests with monolithic samples. They conducted a more extensive series of tests with crushed glass to expose a greater surface area and better represent the bulk glass. These test results corroborated the finding from the MCC-1 tests that devitrification resulted in a less than a factor of 3 increase in the dissolution rate. Those results also indicated that the release of boron was correlated with the extent of devitrification.

Li et al. (1997 [DIRS 163269]) and Li et al. (2003 [DIRS 171167]) studied the effects of nepheline formation on the chemical durability of a reference glass for the wastes in Hanford tanks. They found the amount of nepheline that formed increased with alumina and soda contents of the glass, but decreased with increasing silica content. Glasses of several compositions were cooled according to different canister centerline cooling (CCC) schedules, with CCC-I being cooled from the lowest peak temperature and CCC-VI being cooled from the highest peak temperature. The different cooling rates resulted in the formation of different amounts of nepheline. The relationship between glass composition, abundance of nepheline, and $\mathrm{NL}(\mathrm{B})$ and $\mathrm{NL}(\mathrm{Si})$ from 7-day PCTs (at $90^{\circ} \mathrm{C}$ ) are summarized in Table 6-10. In most cases, higher releases of both boron and silicon occur in glasses with nepheline. Since boron is present in the glass but not in nepheline, these results show a clear and significant impact of nepheline formation on the durability of all glasses except NP-Li-2. The negligible impact on glass NP-Li-2 indicates the impact of nepheline formation depends on the glass composition. 
Table 6-10. Effect of Nepheline on Glass Durability

\begin{tabular}{|c|c|c|c|c|}
\hline Glass & Treatment & $\begin{array}{c}\text { Mass \% } \\
\text { Nepheline }\end{array}$ & $\mathrm{NL}(\mathrm{B}), \mathrm{g} / \mathrm{m}^{2}$ & $N L(S i), g / m^{2}$ \\
\hline \multirow{3}{*}{$\begin{array}{l}\text { NP-BL } \\
\text { (baseline) }\end{array}$} & Quenched & 0.0 & 0.54 & 0.32 \\
\hline & CCC-V & 29.4 & 43.24 & 2.91 \\
\hline & CCC-III & 30.2 & 42.38 & 3.10 \\
\hline \multirow{2}{*}{$\begin{array}{l}\text { NP-Al-2 } \\
\text { (low Al) }\end{array}$} & CCC-V & 0.0 & 0.66 & 0.48 \\
\hline & CCC-I & 5.0 & 9.10 & 2.00 \\
\hline \multirow{3}{*}{$\begin{array}{l}\text { NP-AL-3 } \\
\text { (high Al) }\end{array}$} & Quenched & 0.0 & 0.38 & 0.27 \\
\hline & CCC-V & 37.9 & 44.73 & 0.59 \\
\hline & CCC-IV & 38.8 & 46.90 & 1.30 \\
\hline \multirow{2}{*}{$\begin{array}{l}\text { NP-Al-4 } \\
\text { (high Al) }\end{array}$} & Quenched & 0.0 & 0.37 & 0.26 \\
\hline & CCC-V & 40.2 & 44.94 & 0.93 \\
\hline \multirow{2}{*}{$\begin{array}{l}\text { NP-Li-1 } \\
\text { (low Li) }\end{array}$} & Quenched & 0.0 & 0.29 & 0.19 \\
\hline & CCC-VI & 1.0 & 0.76 & 0.20 \\
\hline \multirow{2}{*}{$\begin{array}{l}\text { NP-Li-2 } \\
\text { (high Li) }\end{array}$} & Quenched & 0.0 & 1.13 & 0.51 \\
\hline & CCC-I & 29.1 & 1.78 & 0.11 \\
\hline \multirow{2}{*}{$\begin{array}{l}\text { NP-B-1 } \\
\text { (low B) }\end{array}$} & Quenched & 0.0 & Not Analyzed & 0.47 \\
\hline & CCC-V & 32.8 & Not Analyzed & 1.04 \\
\hline \multirow{2}{*}{$\begin{array}{l}\text { NP-B-2 } \\
\text { (high B) }\end{array}$} & Quenched & 0.0 & 4.27 & 0.19 \\
\hline & CCC-I & 0.0 & 4.35 & 0.23 \\
\hline \multirow{2}{*}{$\begin{array}{l}\text { NP-K-1 } \\
\text { (high K) }\end{array}$} & Quenched & 0.0 & 1.06 & 0.45 \\
\hline & CCC-III & 29.3 & 48.19 & 3.56 \\
\hline \multirow{2}{*}{$\begin{array}{l}\text { NP-K-2 } \\
\text { (high K) }\end{array}$} & Quenched & 0.0 & 1.76 & 0.48 \\
\hline & CCC-III & 28.4 & 45.22 & 3.44 \\
\hline \multirow{2}{*}{$\begin{array}{l}\text { NP-Ca-1 } \\
\text { (low Ca) }\end{array}$} & Quenched & 0.0 & 0.81 & 0.39 \\
\hline & CCC-III & 30.5 & 46.68 & 3.02 \\
\hline \multirow{2}{*}{$\begin{array}{l}\text { NP-Ca-2 } \\
\text { (high Ca) }\end{array}$} & Quenched & 0.0 & 0.70 & 0.27 \\
\hline & CCC-II & 4.8 & 1.31 & 0.32 \\
\hline
\end{tabular}

Source: Li et al. 1997 [DIRS 163269], Table 2.

\subsubsection{Tests with Phase-Separated Glasses}

Nuclear waste glasses are formulated such that glass-in-glass phase separation does not occur. Glass-in-glass phase separation usually results in the formation of durable and not so durable phases. The compositions in the $\mathrm{M}_{2} \mathrm{O}-\mathrm{SiO}_{2}-\mathrm{Al}_{2} \mathrm{O}_{3}-\mathrm{B}_{2} \mathrm{O}_{3}$ (M represents an alkali metal) system that are prone to forming separate borate phases are well known to glass scientists and avoided during the formulation of waste glasses. The addition of alkali metals is required to stabilize the negative charge of 4-coordinated $\mathrm{BO}_{4}$ groups that fit in the silicate structure. Otherwise, an immiscible trigonally coordinated borate glass may form within the silicate glass. Glass-in-glass phase separation is sensitive to the thermal treatment of the glass. Vitrification can also result in the formation of sulfate and phosphate phases in borosilicate glasses that are less durable than the host phase. Consumption of alkali from the formation of these phases may affect the composition of the remaining glass (Li et al. 1996 [DIRS 163268]). Although glass-in-glass phase separation may add uncertainty to predictions of glass properties based on composition, including chemical durability, it does not necessarily impact the modeling of its performance or acceptability for disposal. That is, the response in tests such as the PCT will be dominated by the low durable phase(s), which ensures the glass durability will not be underestimated. 


\subsubsection{Tests With the Ceramic Waste Form}

The CWF was developed to immobilize high-level radioactive salts generated during treatment of spent sodium-bonded nuclear fuel (Ebert et al. 2002 [DIRS 163250]; Jeong et al. 2002 [DIRS 163261]; Lewis et al. 2002 [DIRS 163267]). Both the salt waste and the metallic wastes generated during the electrorefining treatment will be submitted for disposal as nonstandard HLW forms. Because of the low solubility of chloride in borosilicate glass, the salt waste is first occluded in zeolite 5A, then the salt-loaded zeolite is mixed with a borosilicate glass binder at a 3:1 zeolite-to-glass mass ratio and vitrified at $915^{\circ} \mathrm{C}$. During the melting operation, the saltloaded zeolite converts to the mineral sodalite $\left(\mathrm{Na}_{8} \mathrm{Al}_{6} \mathrm{Si}_{6} \mathrm{O}_{24} \mathrm{Cl}_{2}\right)$. Small amounts of halite $(\mathrm{NaCl})$ form as inclusions in the glass phase (1 to $4 \mathrm{vol} \%)$. Some of the radionuclides from the waste are partitioned between the sodalite, halite, and glass binder phases (e.g., iodine, alkali metals, and alkaline earth elements). Insoluble radionuclides form crystalline inclusion phases (primarily mixed lanthanide and actinide oxides and silicates) in the glass phase (typically $<1$ vol \%). The CWF has been tested and characterized to support qualification for disposal, including tests with the separate binder glass and sodalite phases.

The CWF provides an extreme example of waste glass with crystalline inclusion phases, including highly soluble halite inclusions, sodalite inclusions with similar solubility as the glass, and insoluble actinide oxide phases. Key test results are discussed below to evaluate the use of the TSPA-LA glass degradation model to glass-crystalline composite waste forms.

Degradation of the CWF is due to the simultaneous dissolution of the binder glass and sodalite phases. Inclusion phases within the glass will be exposed to water only as fast as the glass dissolves. The behaviors of the different inclusion phases when exposed to water will differ significantly. Halite inclusions will dissolve immediately whereas crystalline oxide phases will be mostly insoluble. The dissolution rates of both the binder glass and sodalite phases of the CWF are modeled with the same rate expression that is used for HLW glass (Equation 5) (Fanning et al. 2003 [DIRS 163252]). Tests have been conducted to measure separate parameter values for the dissolution of the binder glass, sodalite, and CWF (Fanning et al. 2003 [DIRS 163252]). The release of silicon was used to measure and compare the dissolution rates of the separate phases and the composite because B is not present in the sodalite phase. The forward dissolution rates of the sodalite, binder glass, and composite CWF measured in short-term MCC-1 tests at $90^{\circ} \mathrm{C}$ at several $\mathrm{pH}$ values are given in Table 6-11 and plotted (as $\mathrm{NR}(\mathrm{Si})$ versus $\mathrm{pH})$ in Figure 6-9. The dissolution rates of the three materials are the same in alkaline solutions, but the dissolution rate of sodalite is about a factor of 10 higher than that of the binder glass in acidic solutions. Dissolution of the CWF composite is dominated by dissolution of the sodalite phase in acidic solutions. Lines are drawn to show the $\mathrm{pH}$ dependence at $90^{\circ} \mathrm{C}$, which is based on the combined results of tests at $40^{\circ} \mathrm{C}, 70^{\circ} \mathrm{C}$, and $90^{\circ} \mathrm{C}$. The $\mathrm{pH}$ dependencies for CWF dissolution are $\eta=-0.40$ and $\eta=0.19$ for acidic and alkaline solutions, respectively (Fanning et al. 2003 [DIRS 163252], Table 6). These are bound by the values $\eta=-0.49$ and $\eta=0.49$ used in the glass degradation model. 
Table 6-11. Forward Dissolution Rates for Sodalite, Binder Glass, and CWF at $90^{\circ} \mathrm{C}$

\begin{tabular}{|c|c|c|c|}
\hline \multirow{2}{*}{$\mathbf{p H}$} & \multicolumn{3}{|c|}{$\mathbf{N R}(\mathbf{S i})\left(\mathbf{g} /\left(\mathbf{m}^{\mathbf{2}} \cdot \mathbf{d}\right)\right)$} \\
\cline { 2 - 4 } & Sodalite & Binder Glass & $\mathbf{C W F}$ \\
\hline 5.1 & 2.6 & 0.088 & 1.8 \\
\hline 6 & 0.64 & 0.056 & 0.67 \\
\hline 7 & 0.39 & 0.056 & 0.69 \\
\hline 8.1 & 0.99 & 0.93 & 1.3 \\
\hline 9.2 & 1.2 & 1.5 & 1.5 \\
\hline 10.2 & 2.5 & 5.3 & 3.3 \\
\hline
\end{tabular}

Source: Fanning et al. 2003 [DIRS 163252], Table 4.

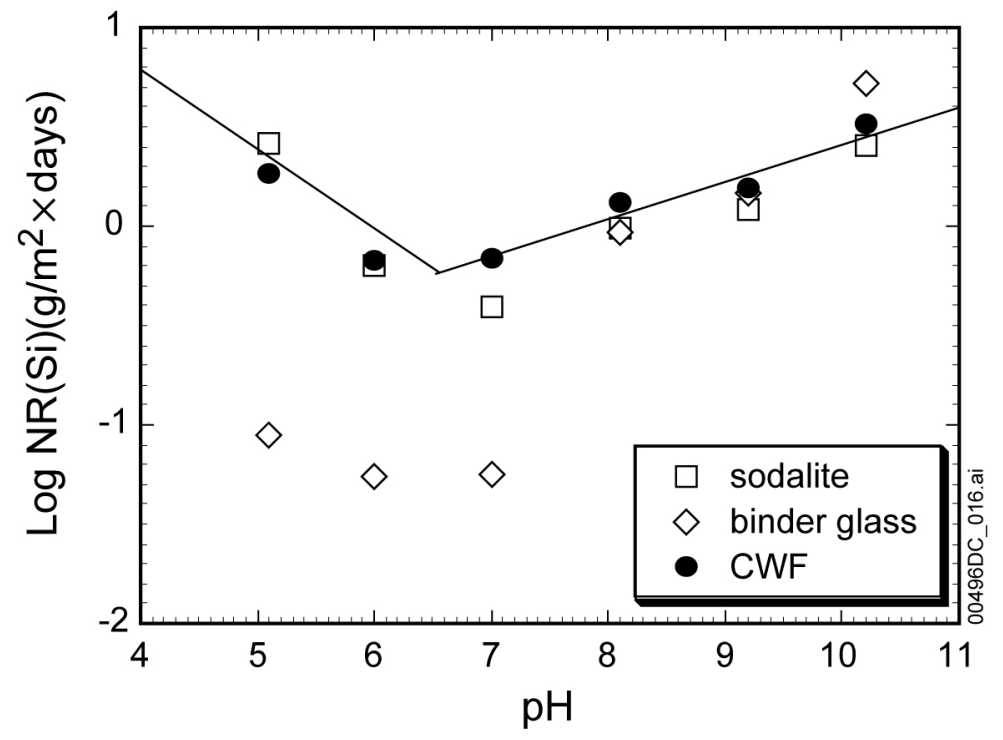

Source: Table 6-11.

NOTE: Lines show $\mathrm{pH}$ dependencies for acidic and alkaline solutions that were regressed from test results with CWF.

Figure 6-9. Forward Dissolution Rate $[\mathrm{NR}(\mathrm{Si})]$ versus $\mathrm{pH}$ for Sodalite, Binder Glass, and $\mathrm{CWF}$ at $90^{\circ} \mathrm{C}$

The activation energy measured for CWF composite is $65 \mathrm{~kJ} / \mathrm{mol}$ for acidic solutions and $84 \mathrm{~kJ} / \mathrm{mol}$ for alkaline solutions (Fanning et al. 2003 [DIRS 163252], Table 6). Both values are significantly higher than those used in the TSPA-LA glass degradation model $(31 \mathrm{~kJ} / \mathrm{mol}$ for acidic solutions and $69 \mathrm{~kJ} / \mathrm{mol}$ for alkaline solutions; see Section 6.7), but similar to the upper range measured for the binder glass and for other borosilicate glasses (Table 7-3).

The value of $\mathrm{k}_{\mathrm{E}}$ used in the TSPA-LA model is a function of the apparent solubility limit for the rate-limiting step in the kinetic mechanism ( $\mathrm{K}$ in Equations 10 and 12). The solubility of each phase in a multiphase waste form will be different; some crystalline phases may equilibrate with solution. The value of $\mathrm{k}_{\mathrm{E}}$ should represent the solubility of the phases containing radionuclides. The apparent solubility limit for the $\mathrm{CWF}$ composite at $90^{\circ} \mathrm{C}$ is about $174 \mathrm{mg} \mathrm{H}_{4} \mathrm{SiO}_{4} / \mathrm{L}$ (Fanning et al. 2003 [DIRS 163252], Figure 6). The apparent solubility limit is expressed by the parameter $\mathrm{K}$ in the mechanistic rate expression (Equations 10 and 12). The solubility limit of sodalite is about $55 \mathrm{mg} \mathrm{H}_{4} \mathrm{SiO}_{4} / \mathrm{L}$ and the apparent solubility limit of the binder glass is about 
$369 \mathrm{mg} \mathrm{H}_{4} \mathrm{SiO}_{4} / \mathrm{L}$ (Fanning et al. 2003 [DIRS 163252], Figure 6). The apparent solubility limit of the CWF is nearly proportional to the 3:1 mass ratio of the sodalite and binder glass. The impact of the differences in the solubility limits of the binder glass alone and a CWF composite are illustrated in the results of long-term PCT conducted at $90^{\circ} \mathrm{C}$. The average values of replicate tests with pressureless consolidated CWF and binder glass (Lewis et al. 2002 [DIRS 163267], Tables 25 and 28) are given in Table 6-12 and plotted in Figure 6-10. Tests were conducted with binder glass received from the vendor and with glass that was heated at $915^{\circ} \mathrm{C}$ for 16 hours, which is the condition used to make the pressureless consolidated CWF (referred to as PC glass). Both glasses were crushed and sieved to isolate the $-100+200$ mesh size fraction for testing. Tests were conducted at solid-to-water mass ratios of 1:10 ( $\mathrm{S} / \mathrm{V}$ ratio of about $2,300 \mathrm{~m}^{-1}$ ) and $1: 1\left(\mathrm{~S} / \mathrm{V}\right.$ ratio of about $\left.23,000 \mathrm{~m}^{-1}\right)$. There is a small difference in the reactivities of the as-received and PC-processed binder glass, but there is about a factor of 50 between the reactivities of the binder glass and the PC-processed CWF composite at all time periods. This is attributed to the difference in the solubility limits of the binder glass (either asreceived or PC-processed) and the CWF composite.

The value of $\mathrm{K}$ does not appear explicitly in the glass dissolution model. Instead, it is contained in the value of $\mathrm{k}_{\mathrm{E}}$. A bounding value of $10^{-2.26}$ molal $\left(528 \mathrm{mg} \mathrm{H}_{4} \mathrm{SiO}_{4} / \mathrm{L}\right)$ at $90^{\circ} \mathrm{C}$ for $\mathrm{K}$ was recommended by Stout and Leider (1998 [DIRS 111047], Table 3.5.1-2). The value measured for the binder glass is lower than that value, and the value measured for the CWF composite is lower still. Lower values of $\mathrm{K}$ in Equations 6, 10, and 12 mean the glass dissolution rate will slow more quickly as the amount of silica in solution increases.

Table 6-12. Data for PCTs with CWF and Binder Glass

\begin{tabular}{|c|c|c|c|}
\hline \multirow{2}{*}{$\begin{array}{c}\text { Test Duration } \\
\text { (days) }\end{array}$} & \multicolumn{3}{|c|}{$\mathrm{NL}(\mathrm{B})\left(\mathrm{g} / \mathrm{m}^{2}\right)$} \\
\hline & PC CWF & Binder Glass & PC Glass \\
\hline \multicolumn{4}{|c|}{ Tests at $\mathrm{S} / \mathrm{V}=2,300 \mathrm{~m}^{-1}$} \\
\hline 7 & 0.050 & 1.69 & 3.50 \\
\hline 28 & 0.096 & 2.79 & 5.70 \\
\hline 91 & 0.125 & 5.73 & 9.19 \\
\hline 182 & 0.187 & 6.90 & 9.82 \\
\hline 364 & 0.190 & 9.66 & 9.93 \\
\hline \multicolumn{4}{|c|}{ Tests at $\mathrm{S} / \mathrm{V}=23,000 \mathrm{~m}^{-1}$} \\
\hline 7 & $-^{a}$ & 1.09 & 1.87 \\
\hline 28 & 0.0390 & 1.93 & 3.00 \\
\hline 91 & 0.0501 & 4.55 & 4.85 \\
\hline 182 & 0.0879 & - & 5.44 \\
\hline 364 & 0.0925 & - & 5.53 \\
\hline
\end{tabular}

Source: Lewis et al. 2002 [DIRS 163267].

NOTE: ${ }^{\text {a }}$ Not measured. 
(a)

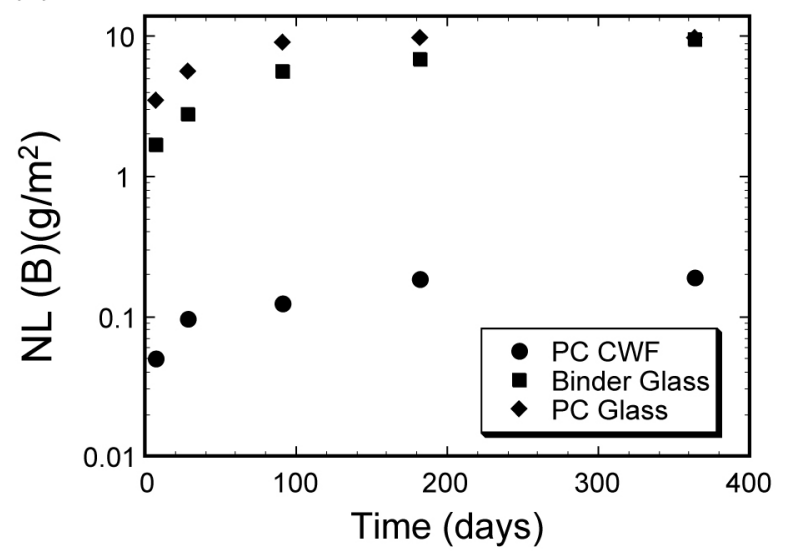

(b)

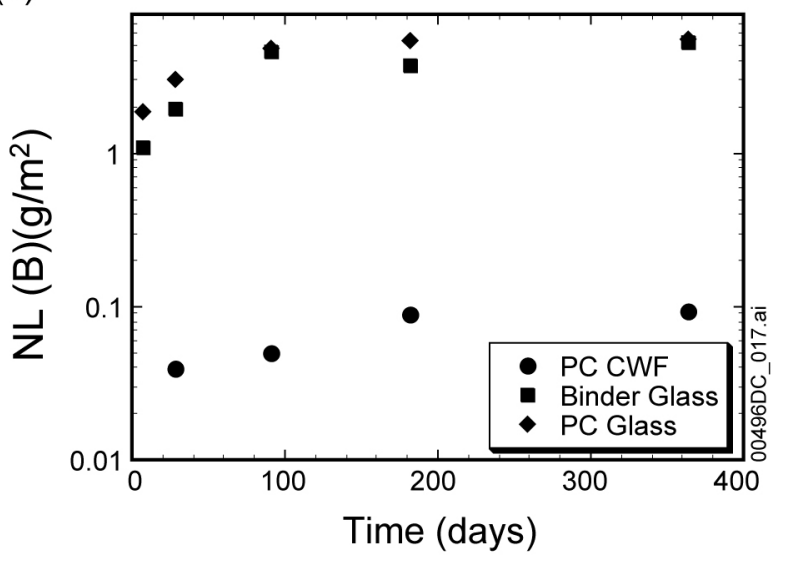

Source: Lewis et al. 2002 [DIRS 163267], Tables 25 and 28.

Figure 6-10. Results of PCT Conducted with As-Received Binder Glass, PC Binder Glass, and PC CWF Composite at (a) $S / V=2,300 \mathrm{~m}^{-1}$ and (b) $S / V=23,000 \mathrm{~m}^{-1}$

Many 7-day PCTs have been conducted with various CWF materials. An interlaboratory study was conducted to measure the precision with which the PCT could be conducted with CWF composite (Ebert et al. 2002 [DIRS 163250]). It was found that the precision of tests with CWF composite was as good as the precision for tests with borosilicate glasses (e.g., Smith and Marschman 1994 [DIRS 163284]). The results of the study are summarized in Table 6-13. Also included in Table 6-13 are the normalized mass losses calculated using the mean concentrations, an $\mathrm{S} / \mathrm{V}$ ratio of $2,300 \mathrm{~m}^{-1}$, and mass fractions of $\mathrm{B}=0.0145, \mathrm{Na}=0.0145$, and $\mathrm{Si}=0.201$. From the results $\mathrm{pH}=9.01$ and $\mathrm{NL}(\mathrm{B})=0.0675 \mathrm{~g} / \mathrm{m}^{2}$, and the values of $\eta=0.49$ and $\mathrm{E}_{\mathrm{a}}=69 \mathrm{~kJ} / \mathrm{mol}$ from the glass dissolution model, the value of $\log _{10}\left(\mathrm{k}_{\mathrm{E}}\right)$ is calculated to be 3.50 , $\mathrm{k}_{\mathrm{E}}=3.15 \times 10^{3} \mathrm{~g} /\left(\mathrm{m}^{2} \cdot \mathrm{d}\right)($ CWF entry in Appendix B, Table B-3). This is well within the range of values used in the glass degradation model (Section 6.7).

Table 6-13. Results of 7-day PCT with CWF Composite

\begin{tabular}{|l|c|c|c|c|}
\hline & $\mathbf{p H}$ & $\mathbf{B}$ & $\mathbf{N a}$ & $\mathbf{S i}$ \\
\hline mean concentration, $\mathrm{mg} / \mathrm{L}$ & 9.01 & 2.25 & 30.2 & 32.6 \\
\hline $\begin{array}{l}\text { pooled interlaboratory } \\
\text { standard deviation, } \mathrm{mg} / \mathrm{L}\end{array}$ & 0.124 & 0.347 & 3.40 & 2.97 \\
\hline $\begin{array}{l}\text { pooled intralaboratory } \\
\text { standard deviation, } \mathrm{mg} / \mathrm{L}\end{array}$ & 0.050 & 0.113 & 3.15 & 0.949 \\
\hline $\mathrm{NL}(\mathrm{i}), \mathrm{g} / \mathrm{m}^{2}$ & - & 0.0675 & 0.906 & 0.0705 \\
\hline $\left.\mathrm{NR}(\mathrm{i}), \mathrm{g} / \mathrm{m}^{2} \cdot \mathrm{d}\right)$ & - & 0.00964 & 0.129 & 0.0101 \\
\hline
\end{tabular}

Source: Ebert et al. 2002 [DIRS 163250], Table 4.

The release of boron is used to track the dissolution of HLW glasses because it has been shown to be representative of the glass matrix. Boron is only present in the binder glass phase of the CWF composite. Silicon is present in the binder glass and sodalite phases, and sodium is present in the binder glass, sodalite, and halite phases. The halite crystals exposed at the surface of crushed CWF are dissolved in the water wash step and are taken into account separately in the PCT conducted with CWF. Only halite that is exposed as glass dissolves during the test will 
contribute $\mathrm{Na}$ to the test solution. The amount of halite that dissolves during the PCT is tracked with the chloride concentration, since a negligible amount of chloride is released as the sodalite dissolves. The low solubility of sodalite means that the solution will quickly become saturated with respect to sodalite. Unlike the binder glass, sodalite can equilibrate with the test solution. Equilibration occurs quickly in the PCT, so that the PCT solution reflects primarily the dissolution of the glass binder phase. Silicon is released when either the glass or sodalite dissolve, but B is released only when the glass dissolves because only the glass contains boron. Dissolution of similar amounts of sodalite and binder glass would result in NL(Si) values being higher than NL(B). The similarity between the values of $\mathrm{NL}(\mathrm{B})$ and $\mathrm{NL}(\mathrm{Si})$ in Table 6-13 indicates that dissolution of binder glass dominates the PCT response. In contrast, NL(Si) values are significantly higher than $\mathrm{NL}(\mathrm{B})$ values for $\mathrm{CWF}$ reacted in $\mathrm{MCC}-1$ tests. For example, $\mathrm{NL}(\mathrm{B})=1.5 \mathrm{~g} / \mathrm{m}^{2}$ and $\mathrm{NL}(\mathrm{Si})=4.4 \mathrm{~g} / \mathrm{m}^{2}$ for PC CWF composite reacted in a 3-day MCC-1 test at $90^{\circ} \mathrm{C}$ and $\mathrm{NL}(\mathrm{B})=10.2 \mathrm{~g} / \mathrm{m}^{2}$ and $\mathrm{NL}(\mathrm{Si})=21.0 \mathrm{~g} / \mathrm{m}^{2}$ for 28 -day MCC-1 test at $125^{\circ} \mathrm{C}$ (Lewis et al. 2002 [DIRS 163267], Table 9). The solutions from the MCC-1 tests were not saturated with respect to sodalite, but the solutions in PCTs were. Degradation of CWF composites under disposal conditions will be dominated by dissolution of the binder glass, not sodalite. Therefore, it is appropriate to compare the release of boron and dissolution of the binder glass phase in laboratory tests with the TSPA-LA glass degradation model to determine if that model is representative of CWF performance.

\subsection{BASE-CASE MODEL INPUTS}

Inputs to the HLW glass degradation model developed in this report are summarized in Table 6-14. The sources for the input data and parameters for the glass degradation and exposed surface area models are summarized in Tables 4-1 and 4-2. Implementation of the glass degradation model in performance assessment calculations requires that values for the relative humidity, $\mathrm{pH}$, temperature, and average radionuclide inventory be obtained from other sources. The relative humidity, $\mathrm{pH}$, temperature, and average radionuclide inventory are variables in the model developed here. The values and ranges of the exposure factor ( $f_{\text {exposure }}$ ), the $\mathrm{pH}$ dependence $(\eta)$, temperature dependence $\left(\mathrm{E}_{a}\right)$, and rate coefficients $\left(\mathrm{k}_{\mathrm{E} \_ \text {acid }}\right.$ and $\left.\mathrm{k}_{\mathrm{E} \_ \text {alkaline}}\right)$ are selected from the ranges and distributions provided in this report. The glass degradation model is valid over the relative humidity range $0 \%$ to $100 \%$, the temperature range $20^{\circ} \mathrm{C}$ to $300^{\circ} \mathrm{C}$, and the $\mathrm{pH}$ range 1 to 13 and for glasses with compositions similar to those in Table 6-5. Although the maximum temperature at which the experiments have been performed with the glasses discussed in this report is $200^{\circ} \mathrm{C}$, the relative humidity at 1 atmosphere total pressure falls below $44 \%$ at $125^{\circ} \mathrm{C}$. Hence, glass does not react at temperatures exceeding $125^{\circ} \mathrm{C}$ at 1 atmosphere total pressure and the maximum range of applicability can be extended to $300^{\circ} \mathrm{C}$ without impact. This temperature is well below the glass transition temperature, which is in the range of $600^{\circ} \mathrm{C}$ to $700^{\circ} \mathrm{C}$ for proposed HLW glasses. At temperatures approaching or exceeding the glass transition temperature, glasses could crystallize with a possible impact on the degradation rate in water. 
Table 6-14. Model Inputs Used in HLW Glass Degradation Model

\begin{tabular}{|c|c|c|c|c|}
\hline Input Name & Input Description & Input Source & Value & $\begin{array}{c}\text { Type of } \\
\text { Uncertainty }\end{array}$ \\
\hline$f_{\text {exposure }}$ & $\begin{array}{l}\text { glass surface } \\
\text { exposure factor }\end{array}$ & Section 6.5.4 & 4 to 17 (no units) & Aleatory \\
\hline $\mathrm{S}_{\mathrm{sp}}$ & $\begin{array}{l}\text { glass geometric } \\
\text { specific surface area }\end{array}$ & Section 6.5.4 & $2.7 \times 10^{-3} \mathrm{~m}^{2} / \mathrm{kg}$ & Epistemic \\
\hline $\mathrm{M}_{0}$ & Average glass mass & Section 6.5.4 & $2,710 \mathrm{~kg}$ & Epistemic \\
\hline$\eta_{\text {acid }}$ & $\begin{array}{l}\mathrm{pH} \text { dependence for } \\
\text { dissolution in acidic } \\
\text { solutions }\end{array}$ & Section 6.5.2.5 & -0.49 (no units) & Epistemic \\
\hline$\eta_{\text {alkaline }}$ & $\begin{array}{l}\mathrm{pH} \text { dependence for } \\
\text { dissolution in } \\
\text { alkaline solutions }\end{array}$ & Section 6.5.2.4 & 0.49 (no units) & Epistemic \\
\hline$E_{a_{-} a \text { acidic }}$ & $\begin{array}{l}\text { Temperature } \\
\text { dependence for } \\
\text { dissolution in acidic } \\
\text { solutions }\end{array}$ & Section 6.5.2.5 & $31 \mathrm{~kJ} / \mathrm{mol}$ & Epistemic \\
\hline$E_{\text {a_alkaline }}$ & $\begin{array}{l}\text { Temperature } \\
\text { dependence for } \\
\text { dissolution in } \\
\text { alkaline solutions }\end{array}$ & Section 6.5.2.4 & $69 \mathrm{~kJ} / \mathrm{mol}$ & Epistemic \\
\hline $\mathrm{K}_{\mathrm{E} \_ \text {acidic }}$ & $\begin{array}{l}\text { Glass dissolution } \\
\text { coefficient for } \\
\text { dissolution in acidic } \\
\text { solutions }\end{array}$ & $\begin{array}{l}\text { Sections } 6.5 .2 .5 \\
\text { and } 6.5 .3 .5\end{array}$ & $\begin{array}{c}8.41 \times 10^{3}-1.15 \times 10^{7} \\
\mathrm{~g} /\left(\mathrm{m}^{2} \cdot \mathrm{d}\right)\end{array}$ & Epistemic \\
\hline $\mathrm{K}_{\mathrm{E} \_a l k a l i n e}$ & $\begin{array}{l}\text { Glass dissolution } \\
\text { coefficient for } \\
\text { dissolution in } \\
\text { alkaline solutions }\end{array}$ & $\begin{array}{l}\text { Sections } 6.5 .2 .4 \\
\text { and } 6.5 .3 .3 .4\end{array}$ & $28.2-3.47 \times 10^{4} \mathrm{~g} /\left(\mathrm{m}^{2} \cdot \mathrm{d}\right)$ & Epistemic \\
\hline
\end{tabular}

\subsection{BASE-CASE MODEL RESULTS}

The expression used to calculate the glass surface area as glass dissolves in each time step is:

$$
\mathrm{S}=\mathrm{f}_{\text {exposure }} \times 2.70 \times 10^{-3} \mathrm{~m}^{2} / \mathrm{kg} \times\left(2,710 \mathrm{~kg}-\Sigma \mathrm{M}_{\mathrm{t}} \mathrm{kg}\right)
$$

where $\mathrm{f}_{\text {exposure }}$ is the glass exposure factor and $\Sigma \mathrm{M}_{\mathrm{t}}$ is the total mass of glass degraded in all previous time steps. A single value of $f_{\text {exposure }}$ is selected for all time steps in a realization. The total mass of glass degraded in all previous time steps $\Sigma \mathrm{M}$ is calculated after each time step in a realization.

- The maximum value of the glass exposure factor is $\mathrm{f}_{\text {exposure, } \text { maximum }}=17$

- The minimum value of the glass exposure factor is $\mathrm{f}_{\text {exposure, }}$ minimum $=4$

- The range is assigned a triangular distribution with a most probable value of 4 .

No glass degradation occurs if the relative humidity is less than $44 \%$ and there is no dripping water. The rate $=0$ and $\mathrm{M}(\mathrm{t})=\mathrm{M}_{0}$. 
The rate expression developed for glass degradation is given by Equation 13 from Section 6.5.2:

$$
\text { rate }_{\mathrm{G}}=\mathrm{k}_{\mathrm{E}} \times 10^{\eta \cdot p H} \times \exp \left(-\mathrm{E}_{\mathrm{a}} / \mathrm{RT}\right)
$$

Separate sets of parameter values are used for degradation in acidic and alkaline solutions. Constant values of $\eta=-0.49$ and $E_{a}=31 \mathrm{~kJ} / \mathrm{mol}$ are used for acidic solutions, and constant values of $\eta=0.49$ and $E_{a}=69 \mathrm{~kJ} / \mathrm{mol}$ are used for alkaline solutions. Substituting these constant values into Equation 13, glass dissolution rates are calculated using Equations 50 and 51:

$$
\begin{aligned}
& \text { rate }_{\mathrm{G}}=\mathrm{k}_{\mathrm{E} \_ \text {acidic }} \times 10^{-0.49 \mathrm{pH}} \times \exp (-31 / \mathrm{RT}) \\
& \text { rate }_{\mathrm{G}}=\mathrm{k}_{\mathrm{E} \_ \text {alkaline }} \times 10^{0.49 \mathrm{pH}} \times \exp (-69 / \mathrm{RT})
\end{aligned}
$$

Values for $\mathrm{k}_{\mathrm{E}_{-} \text {acidic }}$ and $\mathrm{k}_{\mathrm{E} \_ \text {alkaline }}$ to be used in the current realization are selected from the following distributions:

- The maximum value of $\mathrm{k}_{\mathrm{E}_{-} \text {acidic }}$ is $1.15 \times 10^{7} \mathrm{~g} /\left(\mathrm{m}^{2} \cdot \mathrm{d}\right)($ Section 6.5.2.5)

- The minimum and most likely value of $\mathrm{k}_{\mathrm{E}_{-} \text {acidic }}$ is $8.41 \times 10^{3} \mathrm{~g} /\left(\mathrm{m}^{2} \cdot \mathrm{d}\right)($ Section 6.5 .3 .5$)$

- The maximum value of $\mathrm{k}_{\mathrm{E} \_ \text {alkaline }}$ is $3.47 \times 10^{4} \mathrm{~g} /\left(\mathrm{m}^{2} \cdot \mathrm{d}\right)($ Section 6.5 .2 .4$)$

- The minimum and most likely value of $\mathrm{k}_{\mathrm{E} \_ \text {alkaline }}$ is $28.2 \mathrm{~g} /\left(\mathrm{m}^{2} \cdot \mathrm{d}\right)$ (Section 6.5.3.3.4).

The sum of the rates from Equations 50 and 51 is used as the degradation rate the current model. Only $\mathrm{pH}$ and temperature appear in Equations 50 and 51. Therefore, no direct effect on the dissolution rate of the HLW glass from codisposed spent fuel occurs. The mass of glass degraded at the end of the current time step is calculated using Equation 52:

$$
\mathrm{M}(\mathrm{t})=\operatorname{rate}_{\mathrm{G}} \times \mathrm{t} \times \mathrm{S}
$$

where $\mathrm{M}(\mathrm{t})$ and $\mathrm{S}$ are the mass degraded and surface area available in the current time step, and $\mathrm{t}$ is the duration of the time step in the same time units as the rate.

The mass of glass remaining at the end of the current time step $\Sigma \mathrm{M}_{\mathrm{t}}$ is calculated using Equation 53:

$$
\Sigma \mathrm{M}_{\mathrm{t}}=\Sigma \mathrm{M}_{\mathrm{t}-1}-\mathrm{M}(\mathrm{t})
$$

where $\Sigma \mathrm{M}_{\mathrm{t}-1}$ is the mass of glass remaining prior to the current time step. The surface area available for the next time step is then calculated by using the value of $\Sigma \mathrm{M}_{\mathrm{t}}$ calculated in Equation 53 in Equation 49.

The release rate of radionuclides can be calculated from the values of rate ${ }_{\mathrm{G}}$ and $\mathrm{S}$ calculated in Equations 49, 50, and 51 in Equation 9 and the mass or Curie fraction of the radionuclide of interest $\left(\mathrm{I}_{\mathrm{RN}}\right)$ :

$$
R_{R N}=\operatorname{rate}_{G} \times S \times I_{R N}
$$


In this equation, $R_{R N}$ gives the release rate from each canister of HLW glass. An average waste package containing HLW glass or HLW glass codisposed with spent fuel will contain 4.87 canisters of HLW glass, on the average. Therefore, the total release rate from a breached waste package will be 4.87 times the value calculated from Equation 9.

The porosity, water content, volume, and thickness of the alteration layer that will form on the HLW glass are calculated in Appendix D. These values can be used to calculate the diffusion of elements through the layer. The volume of the alteration layer at the time of interest, $V_{R}$, is calculated from the mass of glass that has degraded up to that time (from Equation 53) and a typical density of HLW glass $\rho_{\mathrm{G}},=2,700 \mathrm{~kg} / \mathrm{m}^{3}$ as (Appendix D, Equation D-3c):

$$
\mathrm{V}_{\mathrm{R}}\left(\text { in } \mathrm{m}^{3}\right)=3.7 \times 10^{-4} \times \Sigma \mathrm{M}_{\mathrm{t}}(\text { in } \mathrm{kg})
$$

The volume of pore water in the alteration rind is also calculated using the mass of glass that has degraded (from Equation 53) and a constant that represents the porosity of the rind (Appendix D, Equation D-9):

$$
\mathrm{V}_{\mathrm{w}}\left(\text { in } \mathrm{m}^{3}\right)=6.3 \times 10^{-5} \times \Sigma \mathrm{M}_{\mathrm{t}}(\text { in } \mathrm{kg})
$$

The thickness of the rind layer, $T_{R}$, is calculated from the initial diameter of the glass and the amount of glass that has degraded (from Equation 53) (Appendix D, Equation D-17):

$$
\mathrm{T}_{\mathrm{R}}(\text { in meters })=0.30-\left[0.090-\left(3.0 \times 10^{-5}\right) \times \Sigma \mathrm{M}_{\mathrm{t}}\right]^{1 / 2}
$$

\subsection{UNCERTAINTY AND VARIABILITY}

The outputs of this report are expressions to calculate (1) the glass surface area that can be contacted by water in a breached waste package and (2) the glass dissolution rate as a function of temperature, $\mathrm{pH}$, and relative humidity. The glass degradation rate is first calculated in units of mass glass degraded per unit surface area per unit time then multiplied by the calculated glass surface area to calculate the glass degradation rate in units of mass per unit time. That product can be combined with the inventories of radionuclides of interest to calculate the release rate of those radionuclides (e.g., as curies/time). The uncertainties in the glass surface area and glass degradation rate are discussed separately in the following sections.

\subsubsection{Uncertainty in Surface Area of Glass Contacted by Water}

The area of glass that is accessible to water and the area that is contacted by water in a breached waste package are the most difficult model parameter values to measure and model. Uncertainty exists in the extent of fracturing in each glass, in the fraction of fractures that can be accessed by water, and in the fraction of the accessible surface area that is contacted by water vapor, dripping water, or bulk water. The uncertainty in the surface area available for reaction is addressed by multiplying the geometric surface area by an exposure factor $f_{\text {exposure. The range in values for the }}$ exposure factor represents uncertainty in the extent of cracking, the water diffusion into the cracks, radionuclide diffusion out, and the reactivity of the glass within a crack compared with the reactivity of glass at a free surface. It also accounts for variation in the glass densities and fill volumes of individual glass canisters. 
The extent of fracturing is modeled to be proportional to the geometric surface area of the glass. Waste glasses will fracture as they cool because of the thermal stresses in the glass and the hoop stresses from the difference in expansion between the glass and the pour canister. Additional fracturing may occur during handling. Although fractures at the surface can be measured and quantified, fractures in the bulk glass cannot. In addition, not all of the fractures that are formed may be accessible to water. The modeled surface area for a glass used in this report is an average value that accounts for the thermal cracking of all glass and cracking of a small percentage of the glass from handling. Data quantifying the effect of thermal cracking and impact cracking are combined with estimates of accessibility and reactivity of glass in tight cracks. A factor of 12 is used to account for thermal cracking in all canisters (Smith and Baxter 1981 [DIRS 102089]) and a factor of 40 is used to account for impact cracking of $1 \%$ of the canisters (Smith and Ross 1975 [DIRS 102088]). A maximum value of $\mathrm{f}_{\text {exposure }}=17$ is obtained by assuming that all glass surfaces formed by fractures are freely accessible to water and that glass within cracks has the same reactivity as glass at free surfaces (Section 6.5.4). A minimum value of $f_{\text {exposure }}=4$ is obtained by assuming that one-half of the glass surfaces formed by fractures are freely accessible to water and that glass within cracks has the one-half the reactivity of glass at free surfaces (Section 6.5.4).

The relative humidity and the range of values for the effective dissolution rate constant, $\mathrm{k}_{\mathrm{E}}$, are used to represent the uncertainty in the glass surface area in contact with water vapor, dripping water, and bulk water. If the relative humidity is less than or equal to $44 \%$, no glass degradation occurs. If the relative humidity is greater than $44 \%$, glass alteration occurs at a rate determined from the rate expression given in this report. The dependence of the rate on relative humidities above $44 \%$ and the presence of water (under either dripping or immersion conditions) is contained implicitly in $\mathrm{k}_{\mathrm{E}}$. Between $100^{\circ} \mathrm{C}$ and $125^{\circ} \mathrm{C}$, the $\mathrm{pH}$ of the water on the surface of the glass is assigned a value of 10 . This value is higher than the mildly acid values noted for the case where the layer drips from the surface of the glass and equal to the high value calculated in In-Package Chemistry Abstraction (BSC 2004 [DIRS 167621]). Practically, the lower limit to the relative humidity limits the temperature range over which glass is altered and, hence, the model applied. From the ambient temperatures prior to waste acceptance to the boiling point of water, the alteration rate is given by Equation 13 . From $100^{\circ} \mathrm{C}$ to $125^{\circ} \mathrm{C}$, the glass alteration rate is given by Equation 57.

$$
\log _{10}(\text { rate })=6.35+\log _{10}\left[\exp \left(\frac{-69 \mathrm{~kJ} / \mathrm{mol}}{(0.008314 \mathrm{~kJ} / \mathrm{mol} \times K) \times T}\right)\right]
$$

If salt solutions from the evaporation of groundwater elsewhere in the drift or waste package control the relative humidity, then the upper temperature at which vapor phase alteration would occur is less than $125^{\circ} \mathrm{C}$.

Another uncertainty related to the exposed glass surface area is the size of the breached canister. Both "short" canisters (about 3-m long) and "long" canisters (about 4.5-m long) will be used. The glasses in long and short canisters will provide different initial surface areas and initial masses. The initial surface area of glass in a long canister is about 1.5 times that in a short canister. It is anticipated that about two-thirds of the waste glass will be in long canisters and one-third in short canisters (DOE 2002 [DIRS 158873]). This is taken into account by assigning 
glass to have an initial mass of two-thirds of the mass of glass in a long canister plus one-third of the mass in a short canister.

The total surface area that is available to react in each time step is modeled to decrease in proportion to the mass of glass that has degraded in all previous time steps. The specific surface area remains constant to represent the balance between the increase in specific surface area as large pieces of glass shrink and the decrease as small pieces of glass completely dissolve.

\subsubsection{Uncertainty in the Glass Degradation Model}

How accurately the dissolution rates calculated with the base model represent the actual dissolution of glasses in the repository depends on the uncertainties with respect to: 1) the environmental conditions to which the glass is exposed, including temperature and water contact conditions (condensation of water vapor and the relative humidity, dripping water and the drip rate, immersion volume, $p \mathrm{CO}_{2}$, and $\left.\mathrm{pH}\right), 2$ ) the degree to which the model represents the glass alteration behavior, and (3) the degree to which model parameter values represent the range of waste glass compositions. These three sources of uncertainty are addressed in the TSPA-LA model through the range and distributions assigned to the model parameter values, primarily through the effective rate constant, $\mathrm{k}_{\mathrm{E}}$. Another important source of uncertainty is the relationship between the radionuclide release and boron release. These are discussed below.

\subsubsection{Uncertainty in the Form of the Model}

The uncertainty in how accurately the form of the model represents the glass alteration behavior is minimized by use of the same analytical expression to represent alteration rates measured for contact by humid air, dripping water, and immersion. This is because the model is directly tied to the degradation rates measured in laboratory tests under these conditions. The uncertainty in how well the model fits the degradation behavior under those conditions is captured by the value of the parameter(s) regressed from those test results.

The model is timeframe independent. That is, the calculated rate is not an explicit function of time. The model can be used to calculate the rate at different $\mathrm{pH}$ values and temperatures, both of which change over time. The rate reflects disposal time only through changes in those variables. This means that the rates, measured in laboratory tests under controlled conditions, are the same alteration rates for glass at the same conditions in the repository.

\subsubsection{Uncertainty in Parameter Values}

The uncertainty in how well the values for $\eta$ and $E_{a}$ represent the measured dissolution rates of SRL 202G glass at different $\mathrm{pH}$ values and temperature can be calculated from the uncertainties in the regression of results from the tests at different durations (Appendix A), from the values of $\eta$ (Figure 6-1), and from the values of $E_{a}$ extracted from the rates at two different temperatures (Equations 23 through 26, and Section 6.5.2.1).

The more important measure of uncertainty is how well these parameter values represent the range of glasses to be disposed. The range of parameter values is obtained by comparing the values for SRL $202 \mathrm{G}$ glass with those for other glass compositions. In the glass degradation model developed here, the uncertainties in the dependencies on the solution $\mathrm{pH}$, temperature, 
glass composition, solution composition, and water contact conditions are combined in the ranges of the effective rate constant, $\mathrm{k}_{\mathrm{E}}$, for dissolution in acidic and alkaline solutions. The bounding values are determined from experimentally measured dissolution rates under relevant conditions. The maximum values are determined from immersion tests in acidic or alkaline solutions and the minimum values are determined from tests in dripping water that resulted in acidic conditions and tests in humid air that resulted in alkaline conditions. Since the values of $\mathrm{k}_{\mathrm{E}}$ were extracted from the measured reaction rates with constant $\mathrm{pH}$ and temperature parameters, the effects of glass and solution composition and processes are not modeled explicitly. The uncertainties in these processes are captured in the range of values of $\mathrm{k}_{\mathrm{E}}$.

\subsubsection{Uncertainty in Stoichiometric Releases of Radionuclides}

In the model, glass dissolution is treated as a constant rate at a given temperature and $\mathrm{pH}$. The chemistry associated with the dissolution process and the variation with time even at fixed temperature and $\mathrm{pH}$ is not calculated. Hence, all radionuclides whether they are controlled by the solubility of a solid phase, such as $\mathrm{Np}$ or $\mathrm{Pu}$, or not controlled by solubility, such as $\mathrm{Cs}$ or $\mathrm{Tc}$ are released congruently with the glass matrix. This approach is taken because the rate a radionuclide is released from the glass matrix cannot be distinguished from the effects of solubility control in most test results. The effects of solubility control are imposed in the TSPA-LA with a different model.

\subsubsection{Impact of Input Variable Uncertainty}

The uncertainty in the exposure conditions is provided through the input variables $\mathrm{pH}$, temperature, and relative humidity. Therefore, the sensitivity of the glass alteration rate is obtained through the variability in the individual input parameter. The assignment of constant values to the model parameters for the $\mathrm{pH}$ and temperature dependence provides a link between the uncertainty in the $\mathrm{pH}$ and temperature and the uncertainty in the rate that can be readily calculated. For example, the degradation rate calculated by the model increases by about a factor of 3.1 for every unit increase in $\mathrm{pH}$ in acidic or alkaline solutions. When the temperature increases, for example, from $35^{\circ} \mathrm{C}$ to $45^{\circ} \mathrm{C}$ in alkaline solutions, the alteration rate increases by a factor of 2.7 or decreases by a factor of 2.9 when the temperature decreases from $35^{\circ} \mathrm{C}$ to $25^{\circ} \mathrm{C}$ (Equations 50 and 51). Smaller temperature effects occur for acidic solutions. Uncertainty in the relative humidity impacts this model only with regard to whether the relative humidity is greater than or less than $44 \%$.

\subsubsection{Impacts of Uncertainty on Scientific Analysis Output}

Uncertainty in the individual effects of glass composition, solution composition, temperature, and $\mathrm{pH}$ on the glass degradation rate is not propagated into other models, such as In-Package Chemistry Abstraction (BSC 2004 [DIRS 167621]). This is because the glass dissolution model provides only the calculated glass degradation rate, not individual parameter values. The assignment of single values, rather than ranges of values, for the $\mathrm{pH}$ and temperature parameters and assigning the uncertainties in the parameter values to the ranges of $\mathrm{k}_{\mathrm{E}}$ for degradation in acidic and alkaline solutions reduce the uncertainty in the calculated glass dissolution rate. This approach avoids the possible calculation of unrealistically high or extremely low rates that would be calculated if unrealistic combinations of parameter values were selected. The range of rates 
calculated by the TSPA-LA model will accurately reflect the range of rates determined from experiments in which relevant glass compositions were exposed to repository-relevant conditions.

The glass surface area available for degradation cannot be validated, as well as the glass degradation rate. Both the limited data base available on the extent of fracturing of glass in the pour canister, the unknown accessibility of water to those fractures, and the difficulties in estimating the separate surface areas exposed to humid air, dripping water, and immersion during simulations lead to high uncertainty in the surface area parameter, $f_{\text {exposure. The use of the }}$ maximum value $f_{\text {exposure of }} 17$ (Section 6.5 .4 ) provides a highly conservative estimate. The use of the minimum value $\mathrm{f}_{\text {exposure }}=4$ (Section 6.5.4) provides a realistic and lower bound estimate.

\subsection{DESCRIPTION OF BARRIER CAPABILITY}

The DHLW glass waste forms provide a barrier to the release of radionuclides because the glass must degrade before radionuclides are made available for transport. The glass dissolution model developed here is used to calculate the rate at which radionuclides are made available for transport as either dissolved or colloidal species. The measured B release from glasses immersed in water or contacted by dripping water, and the alteration of glass specimens in contact with humid air were used to develop the glass dissolution model. The primary focus of this model is the development of a mathematical model to calculate the glass degradation rate for waste glass exposed to humid air, dripping water, or immersion conditions under the constraints of TSPA-LA. This section provides an analysis of how well the glass matrix degradation rate represents the resulting radionuclide release rate.

\subsubsection{Analysis of DHLW Glass Barrier Capability}

In the glass dissolution model, the release rate of radionuclides is bounded by the glass dissolution rate. Dissolution of glass in water results in the formation of a layer of physically and chemically altered glass on the surface and the release of some elements to solution. The amounts of glass dissolved and the thickness of the alteration layer depend on the water contact conditions. Contact with large amounts of water will result in more dissolved glass and thinner alteration layers than contact with smaller amounts of water. In the TSPA-LA model, radionuclides in both the glass that dissolves and the glass that is altered are considered to be available for transport. That is, no credit is taken for the capacity of the altered glass to retain radionuclides. This is because the layer on the surface of the altered glass may contain very soluble phases or the layer itself can spall from the surface thereby providing material that can be transported as colloids. Some experiments in which the release of radionuclides is compared to the release of boron under a range of test conditions are discussed below.

\subsubsection{Results from Immersion Tests}

The release of radionuclides from several doped glasses has been measured in tests in which the glass is immersed in demineralized water or groundwater. These tests have consistently shown the release rate of boron is nearly stoichiometric with the release of soluble radionuclides, including Tc. Thus, the B release provides a conservative upper bound to the release of less soluble radionuclides, such as $\mathrm{Np}$ and $\mathrm{Pu}$. Some examples are shown in Figure 6-11 for tests 
with different glasses at several $\mathrm{S} / \mathrm{V}$. These test results show the releases of B and Tc are nearly stoichiometric. Although the values of NL(B) do not always exceed the values of NL(Tc), they are within experimental error of being the same.

Figure 6-11a shows the releases of B and Tc in tests with ATM-8 conducted at $90^{\circ} \mathrm{C}$ and an S/V of about $39 \mathrm{~m}^{-1}$ in tuff groundwater in the presence of tuff and stainless steel (Bazan et al. 1987 [DIRS 104269]). The results of duplicate tests are shown. Although the results of the duplicate tests differ, the values of $\mathrm{NL}(\mathrm{B})$ and $\mathrm{NL}(\mathrm{Tc})$ are the same for individual tests, within experimental uncertainty, and both are significantly higher than the values of $\mathrm{NL}(\mathrm{Np}), \mathrm{NL}(\mathrm{Pu})$, and $\mathrm{NL}(\mathrm{Am})$ from all tests.

Figure $6-11 \mathrm{~b}$ shows the results of tests with a glass made with SRP 165 black frit and added $\mathrm{NH}_{4} \mathrm{TcO}_{4}$. Tests were conducted at $90^{\circ} \mathrm{C}$ in a simulated tuff groundwater at an $\mathrm{S} / \mathrm{V}$ of $100 \mathrm{~m}^{-1}$ (Bibler and Jurgensen 1988 [DIRS 128081]). The releases of B, Na, and Tc are nearly congruent in all tests.

Figure 6-11c and Figure 6-11d show the results of SRL 131A and SRL 202A glasses that were made with SRL 131 and SRL 202 frits, respectively, and added Tc, Np, Pu, and Am. Tests were conducted at $90^{\circ} \mathrm{C}$ in a simulated tuff groundwater at an $\mathrm{S} / \mathrm{V}$ of $2,000 \mathrm{~m}^{-1}$ (Ebert, Wolf, and Bates 1996 [DIRS 163249]). The averages of duplicate tests are plotted. The releases of B, Na, and $\mathrm{Tc}$ are seen to be significantly higher than the releases of $\mathrm{Np}, \mathrm{Pu}$, and $\mathrm{Am}$ in all tests.

Tests with a uranium and plutonium-bearing glass-ceramic waste form have shown the release of $\mathrm{B}$ bounds the release of $\mathrm{U}$ and $\mathrm{Pu}$, which were found to exist primarily as $(\mathrm{U}, \mathrm{Pu}) \mathrm{O}_{2}$ crystallite colloids (Morss et al. 2002 [DIRS 163273]). Figure 6-12 shows the values of NL(B), NL(Si), $\mathrm{NL}(\mathrm{U})$, and $\mathrm{NL}(\mathrm{Pu})$ for long-term PCTs conducted at $90^{\circ} \mathrm{C}$ and $1: 10$ ceramic waste form (CWF)-to-water mass ratio with four CWF materials made with different amounts of $\mathrm{U}$ and $\mathrm{Pu}$ (Morss et al. 2002 [DIRS 163273], Table 9). Even though the amounts of U and Pu in solution are not limited by solubility in these tests, their releases are bounded by the release of B. 
(a)

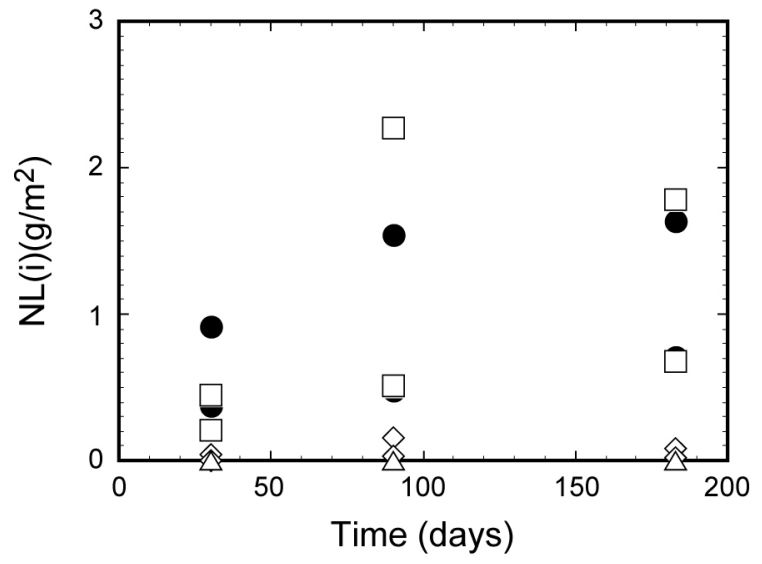

(c)

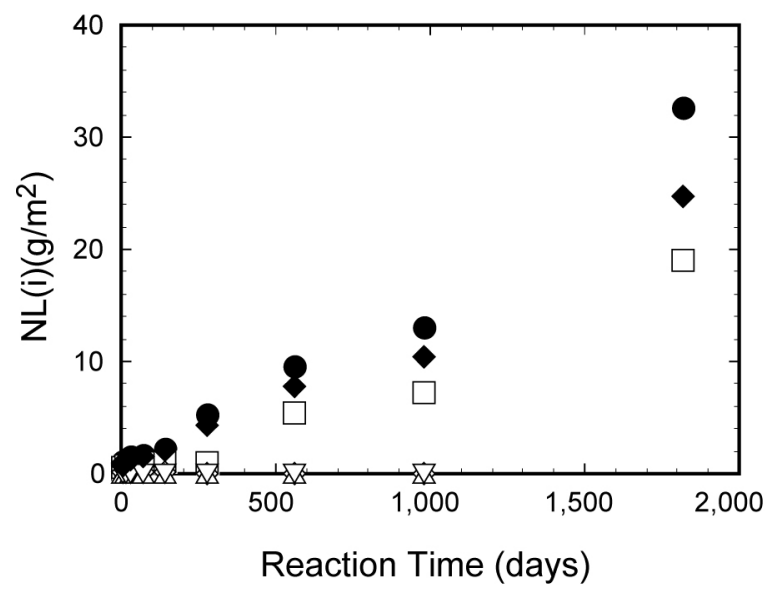

(b)

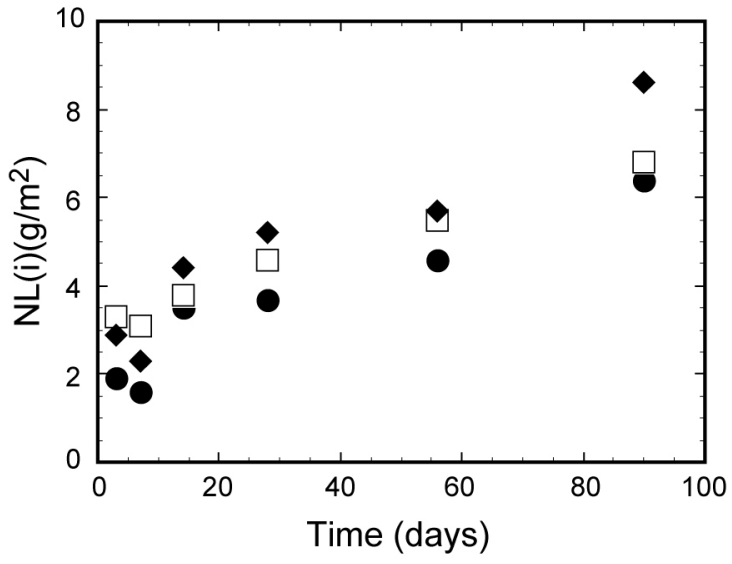

(d)

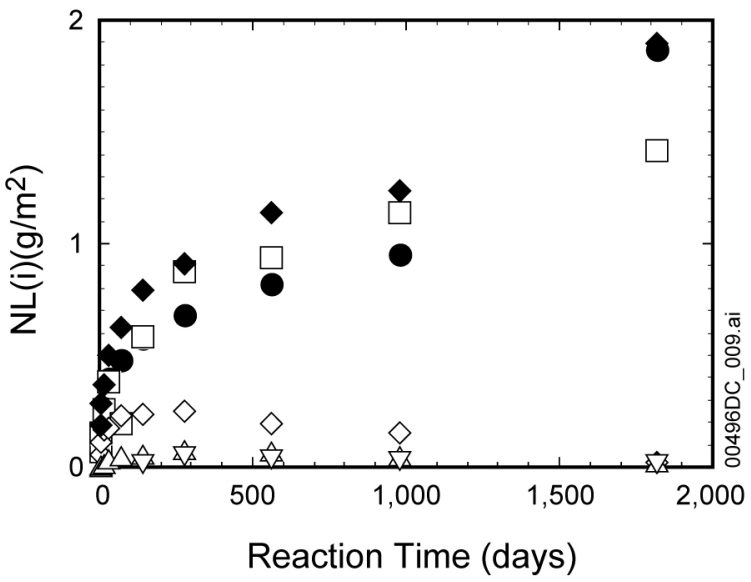

Sources: (a) Bazan et al. 1987 [DIRS 104269].

(b) Bibler and Jurgensen 1988 [DIRS 128081].

(c) Ebert et al. 1996 [DIRS 163249].

(d) Ebert et al. 1996 [DIRS 163249].

Figure 6-11. Comparison of Releases of $(\bullet) \mathrm{B},(\bullet) \mathrm{Na},(\square) \mathrm{Tc},(\diamond) \mathrm{Np},(\nabla) \mathrm{Pu}$, and $(\Delta)$ Am in Immersion Tests with (a) ATM-8 Glass, (b) an SRP Glass, (c) SRL 131A Glass, and (d) SRL 202A Glass

\subsubsection{Results from Unsaturated Tests}

The results of N2 tests with an actinide-doped reference glass for DWPF waste glasses that were discussed in Section 6.5.3.4.1 provide a measure of how well the release of boron represents the releases of $\mathrm{Tc}, \mathrm{Np}, \mathrm{Pu}$, and $\mathrm{Am}$ from the glass. Both the amounts released in each sampling interval and the cumulative amounts released over the entire test duration can be compared. The normalized mass losses of $\mathrm{B}, \mathrm{Tc}, \mathrm{Np}, \mathrm{Pu}$, and $\mathrm{Am}$ at each test interval are given in Table 1 of DTN: MO0407ANLGNN02.608 [DIRS 171277]. Figure 6-12 compares the normalized mass losses calculated for $\mathrm{Tc}, \mathrm{Np}, \mathrm{Pu}$, and $\mathrm{Am}$ with the normalized mass loss of boron for each sampling. Uncertainty bars are drawn at $40 \%$ of the $\mathrm{NL}(\mathrm{Tc})$ and $\mathrm{NL}(\mathrm{Pu})$ values, $50 \%$ of the NL(Np) values, $30 \%$ of the NL(Am) values, and at $15 \%$ of the NL(B) values in Figure 6-12a to represent the propagated uncertainties in measurements of solution volumes and concentrations, sample surface areas, and glass composition. The diagonal lines drawn in Figures 6-10a 
and 6-10b represent stoichiometric release of $\mathrm{B}, \mathrm{Tc}, \mathrm{Np}, \mathrm{Pu}$, and $\mathrm{Am}$ to show how well the release of boron represents the release of radionuclides. The values of NL(B) provide an upper bound to $\mathrm{NL}(\mathrm{Tc})$ and $\mathrm{NL}(\mathrm{Am})$ for all samplings and to $\mathrm{NL}(\mathrm{Np})$ and $\mathrm{NL}(\mathrm{Pu})$ for all but a few samplings.

In the configuration of the unsaturated test, elements released from the glass drip from the sample to the bottom of the test vessel. Soluble elements such as B and Tc will accumulate in the vessel bottom as solution periodically drips from the sample. Sparingly soluble elements that are transported by association with colloids or spalled alteration phases may drop to the vessel bottom sporatically. It is possible that elements released from the glass within the same test interval may not have been collected in the same sampling. The cumulative releases of the different elements can be compared as a better measure of the overall release. The cumulative amounts of $\mathrm{B}, \mathrm{Np}, \mathrm{Pu}$, and Am released in tests N2-9, N2-10, and N2-12 at each sampling are given in Table 2 of DTN: MO0407ANLGNN02.608 [DIRS 171277]. The values through the longest durations for which data are available for all elements are summarized in Table 6-15. The cumulative releases of Tc and B are compared separately for the later samplings that were analyzed for Tc. The cumulative amounts of $\mathrm{Np}$ released in are about $39 \%$ and $29 \%$ greater than the cumulative amounts of B released tests N2-10 and N2-12, respectively, and $16 \%$ lower than the cumulative amounts of B released test N2-9. These differences are well within the testing uncertainties of $50 \%$ for $\mathrm{NL}(\mathrm{Np})$ and $15 \%$ for $\mathrm{NL}(\mathrm{B})$. The release rate of $\mathrm{B}$ in the unsaturated tests is representative of the release rates of $\mathrm{Np}$ and bounds the release rates of $\mathrm{Tc}, \mathrm{Pu}$, and $\mathrm{Am}$ under these test conditions. Since the release rate of boron was used to determine the minimum value of $\mathrm{k}_{\mathrm{E}}$ used in the glass degradation rate for acidic solutions, the modeled rates will bound the release rates of these radionuclides.

(a)

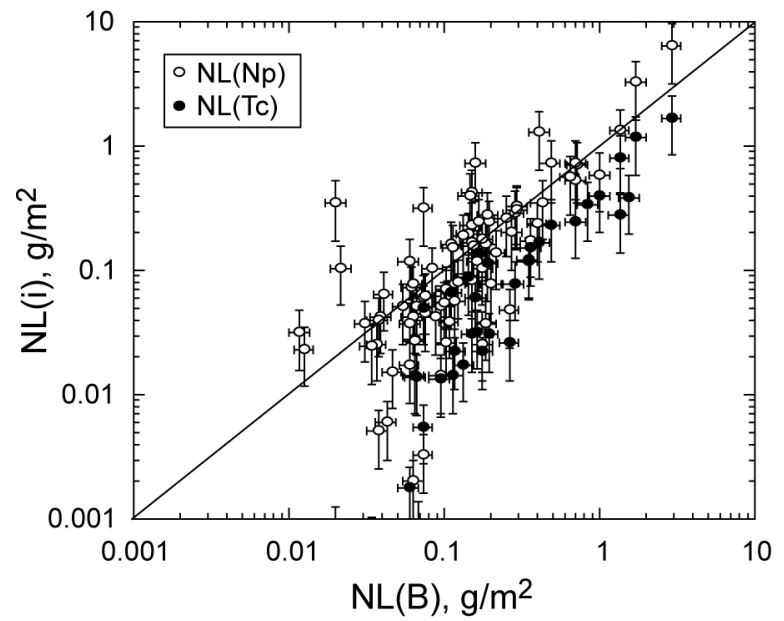

(b)

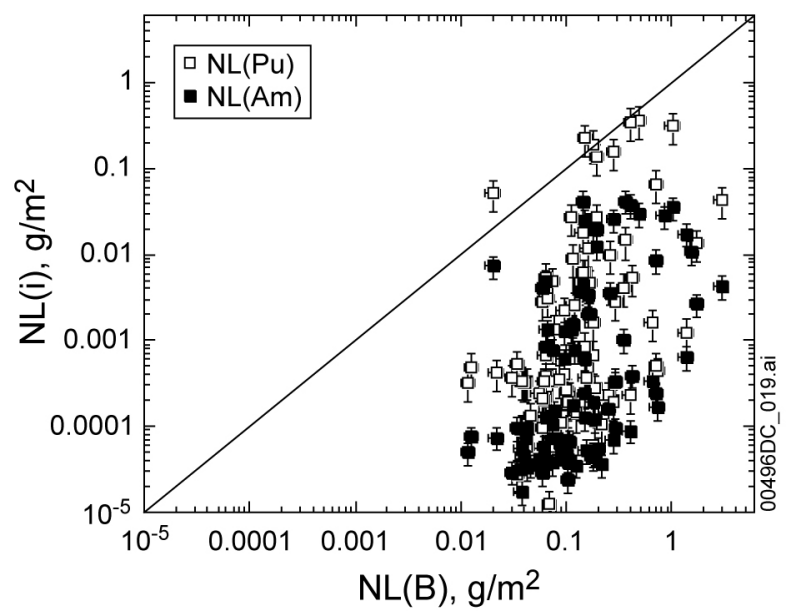

Source: DTN: MO0407ANLGNN02.608 [DIRS 171277], Table 1.

Figure 6-12. Normalized Mass Losses for (a) Tc and Np and (b) Pu and Am versus Normalized Mass Loss of Boron for Each Sample in Tests N2-9, N2-10, and N2-12 with SRL 165 Glass 
Table 6-15. Cumulative Releases of $\mathrm{B}, \mathrm{Np}, \mathrm{Pu}$, and Am in N2 Tests

\begin{tabular}{|c|c|c|c|}
\hline & $\mathbf{N 2 - 9}$ & $\mathbf{N 2 - 1 0}$ & N2-12 \\
\hline \multicolumn{3}{|c|}{ Release through $\mathbf{1 2 / 1 7 / 9 8}$} \\
\hline Total Duration, days & 4,700 & 4,700 & 4,608 \\
\hline $\mathbf{N L}(\mathbf{B}), \mathbf{g} / \mathbf{m}^{2}$ & 5.32 & 9.45 & 6.08 \\
\hline $\mathbf{N L}(\mathbf{N p}), \mathbf{g} / \mathbf{m}^{\mathbf{2}}$ & 4.46 & 13.1 & 7.85 \\
\hline $\mathbf{N L}(\mathbf{P u}), \mathbf{g} / \mathbf{m}^{\mathbf{2}}$ & 0.0641 & 1.93 & 0.127 \\
\hline $\mathbf{N L}(\mathbf{A m}), \mathbf{g} / \mathbf{m}^{\mathbf{2}}$ & 0.0615 & 0.226 & 0.0654 \\
\hline \multicolumn{3}{|c|}{ Release 05/03/90 through 12/17/98 } \\
\hline Total Duration, days & 3,150 & 3,150 & 3,150 \\
\hline $\mathbf{N L}(\mathbf{B}), \mathbf{g} / \mathbf{m}^{\mathbf{2}}$ & 2.50 & 6.55 & 3.40 \\
\hline $\mathbf{N L}(\mathbf{T c}), \mathbf{g} / \mathbf{m}^{\mathbf{2}}$ & 0.929 & 3.01 & 1.88 \\
\hline
\end{tabular}

Source: DTN: MO0407ANLGNN02.608 [DIRS 171277], Tables 2 and 3.

\subsubsection{Summary of Barrier Capability of DHLW Glass}

Waste glass will completely immobilize radionuclides until the glass is contacted by water and degrades. The degradation rate of waste glass limits the release rates of radionuclides. Even soluble radionuclides such as technetium cannot be transported away from the waste form until the glass degrades. Tests show the release of technetium is similar to the releases of alkali metals (e.g., Li and $\mathrm{Na}$ ) and boron as glass degrades when contacted by dripping water or immersed in water. Technetium is probably physically encapsulated within the glass structure rather than being chemically bonded, but cannot diffuse out of the solidified glass. The diffusion of water into the glass and alkali metal ions out of the glass opens percolation channels through which technetium can escape the glass. The release rate of technetium is similar to the release rates of alkali metals and boron. Alkali metals are readily exchanged with protons provided by water. The release of boron requires hydrolysis of a boron-oxygen bond and is usually observed to be slower than the release of alkali metals. Likewise, the release of most radionuclides (e.g., $\mathrm{Np}, \mathrm{Pu}$, and $\mathrm{Am}$ ) requires chemical bonds to be broken. The relative bond strengths of different elements in the glass will affect their release rates as glass degrades. Because radionuclides are present in the glass in relatively low concentrations, a significant amount of glass must degrade before radionuclides are exposed to water. Therefore, the durability of the glass matrix and the strength of the bonds between radionuclides and the glass matrix contribute to the barrier capability of DHLW glass. 


\section{VALIDATION}

The model developed in this report is designed to provide a realistic estimate of the radionuclide release from the dissolution of waste glasses that are immersed in groundwater, exposed to humid air, or contacted by dripping water in the repository. Validation of the model involves presenting technical evidence that the model adequately represents waste glass dissolution and radionuclide release in the repository. This is done by showing that the mathematical form and resultant range of degradation rates calculated with the model are consistent with data for borosilicate glasses and natural analogs in the peer-reviewed technical literature. A comparison of key parameters is made to literature data to provide additional confidence.

The technical work plan (BSC 2004 [DIRS 171583], Section 2.2) under which this model was developed states that the model developed herein shall be validated to the lowest acceptable level of confidence (Level 1); this is consistent with the criteria specified in AP-SIII.10Q. The models developed in this report must meet the criterion listed in the technical work plan, which states, the "corroborating data must match qualitatively and must be bounded by model predictions."

Confidence-Building During Model Development to Establish Scientific Basis and Accuracy for Intended Use-Section 2.2.1 of Technical Work Plan for: Regulatory Integration Modeling and Analyses of the Waste Form and Waste Package (BSC 2004 [DIRS 171583]) specifies the following steps for confidence building during model development:

- The model will contain documentation of decisions and activities implemented during the model development process to build confidence and verify a reasonable and credible technical approach using scientific and engineering principles.

- The development of the model should be documented in accordance with AP-SIII.10Q, Section 5.3.2(b) requirements.

The development of the HLW glass degradation model was conducted according to the following criteria:

(1) Selection of input parameters and/or input data, and a discussion of how the selection process builds confidence in the model. (AP-SIII.10Q 5.3.2(b)(1); AP-2.27Q, Attachment 3, Level I (a))

The bases for selecting the input data used to determine and develop the HLW glass degradation model are documented Section 4.1. Model assumptions have been described in Section 5. Detailed discussion about model concepts can be found in Sections 6.3 and 6.5. Thus, this requirement can be considered satisfied.

(2) Description of calibration activities, and/or initial boundary condition runs, and/or run convergences, simulation conditions set up to span the range of intended use and avoid inconsistent outputs, and a discussion of how the activity or activities build confidence in the model. Inclusion of a discussion of impacts of any non-convergence runs. ((AP-SIII.10Q 5.3.2(b)(2); AP-2.27Q, Attachment 3, Level I (e)). 
Model formulations for HLW glass degradation and radionuclide release rates under alkaline and acidic conditions are discussed in Section 6.5.2.1, and under glass compositions in Section 6.5.2.2. The HLW glass degradation and radionuclide release modes span the range of intended use conditions for temperature and $\mathrm{pH}$ that influence the rate of HLW glass degradation and radionuclide release process. Thus, this requirement can also be considered satisfied.

(3) Discussion of the impacts of uncertainties to the model results including how the model results represent the range of possible outcomes consistent with important uncertainties. ((AP-SIII.10Q 5.3.2(b)(3); AP-2.27Q, Attachment 3, Level 1 (d) and (f)).

Uncertainties associated with the data used to determine the model parameter values are discussed in Section 6.8. A summary discussion on uncertainties and their impact is provided in Section 8.2.

(4) Formulation of defensible assumptions and simplifications. (AP-2.27Q, Attachment 3, Level I (b)).

Discussion of assumptions and simplifications and their rationale are provided in Sections 5 and 6.3.2.

(5) Consistency with physical principles, such as conservation of mass, energy, and momentum. (AP-2.27Q, Attachment 3, Level I (c)).

Section 6.3.1 provides a summary of the pertinent physical phenomena and chemical reactions associated with the dissolution process that occurs when HLW glass is exposed to water, dripping water, and humid air. These sections specifically address pertinent observations as to how HLW glass degrades under humid air and infiltrating groundwater conditions relevant to the repository and the factors that influence the rate.

\section{Confidence-Building After Model Development to Establish Scientific Basis and Accuracy for Intended Use}

According to Table 2-1 of Technical Work Plan for: Regulatory Integration Modeling and Analysis of the Waste Form and Waste Package (BSC 2004 [DIRS 171583]), this report is to be validated by answering one of two questions: Is the glass degradation rate consistent with experimental data (VA 1) and literature data (VA 3)? However, since this is a Level 1 model, only one validation activity is required. The model validation deviates from the technical work plan and only uses validation activity 3 (AP-SIII.10Q, Section 5.3.2(c)(3)).

- Validation Activity 3 is used to show that the required level of confidence has been satisfied per Section 5.3.2(C)(3) of AP-SIII.10Q: "Corroboration with information published in refereed journals or literature."

The mathematical form and the resultant degradation rates calculated with the glass dissolution model reported here are consistent with other models and borosilicate glass release rates reported in the literature and discussed in Sections 7.1 and 7.2. 
Validation of the glass dissolution rate model developed in this report is accomplished by comparison with laboratory test results and relevant observations in studies with simulated HLW and natural analog glasses that were not used to develop the model, determine model parameter values, or calibrate the model. Information used to validate the model or provide confidence in the parameter values is listed in Table $7-1$.

Table 7-1. Information Used to Validate the Model and Provide Confidence in the Parameters

\begin{tabular}{|c|c|c|}
\hline Issue & Information & Source \\
\hline $\begin{array}{l}\text { General form of glass } \\
\text { degradation rate expression } \\
\text { (Section } 7.1 \text { ) }\end{array}$ & Rate expression commonly used & $\begin{array}{l}\text { Advocat et al. } 1999 \text { [DIRS 163199] } \\
\text { CRWMS M\&O } 1998 \text { [DIRS 100362] } \\
\text { Grambow et al. } 1986 \text { [DIRS 163258] } \\
\text { Knauss et al. } 1990 \text { [DIRS 101701] } \\
\text { McGrail et al. } 1998 \text { [DIRS 153974] }\end{array}$ \\
\hline $\begin{array}{l}\text { Final form of glass degradation } \\
\text { rate expression (Section } 7.2 \text { ) }\end{array}$ & $\begin{array}{l}\text { Degradation rates calculated with } \\
\text { model bound degradation rates of } \\
\text { borosilicate glasses and naturally } \\
\text { occurring glasses not used for } \\
\text { model development. }\end{array}$ & $\begin{array}{l}\text { Grambow et al. } 1986 \text { [DIRS 163258] } \\
\text { Crovisier et al. } 1986 \text { [DIRS 163211] }\end{array}$ \\
\hline $\begin{array}{l}\text { Model parameter values } \\
\text { (Section } 7.3 \text { ) }\end{array}$ & $\begin{array}{l}\text { Parameter values selected for } \\
\text { model are representative of range } \\
\text { of borosilicate waste glasses to be } \\
\text { disposed in Yucca Mountain }\end{array}$ & $\begin{array}{l}\text { Knauss et al. } 1990 \text { [DIRS 101701] } \\
\text { McGrail, Ebert, et al. 1997 [DIRS 111039] } \\
\text { (reference was used in Section 6, but no data } \\
\text { were used) } \\
\text { Delage and Dussossoy } 1991 \text { [DIRS 111014] } \\
\text { Advocat et al. } 1991 \text { [DIRS 111000] } \\
\text { Gin et al. } 1994 \text { [DIRS 163254] } \\
\text { Abraitis et al. } 2000 \text { [DIRS 163195] } \\
\text { Fanning et al. } 2003 \text { [DIRS 163252] } \\
\text { White 1986 [DIRS 111049] }\end{array}$ \\
\hline $\begin{array}{l}\text { Exposed glass surface area } \\
\text { model (Section } 7.4 \text { ) }\end{array}$ & $\begin{array}{l}\text { Parameter bounds measured } \\
\text { increases of surface area due to } \\
\text { fracturing }\end{array}$ & $\begin{array}{l}\text { Bickford and Pellarin } 1987 \text { [DIRS 163207] } \\
\text { Sené et al. } 1999 \text { [DIRS 163283] }\end{array}$ \\
\hline
\end{tabular}

\subsection{VALIDATION OF THE FORM OF THE GENERAL GLASS DEGRADATION RATE EXPRESSION}

Literature data are evaluated in this section to validate the form of the rate expression for glass dissolution used in the TSPA-LA. First, the common use of the mechanistic rate expression on which the model developed here is used as validation of its mathematical form. The range of rates from the model is then compared with rates measured in long-term tests in which secondary alteration products formed that increased the glass dissolution rate.

The rate expression for glass dissolution (e.g., as expressed in Equation 5) was developed based primarily on the results of tests conducted with minerals and glass immersed in water (Bourcier 1994 [DIRS 101563], pp. 4 to 12). The general algebraic form of the model (Equation 6) is widely accepted and used in the literature of waste glass corrosion (Advocat et al. 1999 [DIRS 163199]; CRWMS M\&O 1998 [DIRS 100362]; Grambow et al. 1986 [DIRS 163258]; Knauss et al. 1990 [DIRS 101701]; McGrail et al. 1998 [DIRS 153974]) and is derived from the same model used at Hanford (Mann et al. 1998 [DIRS 171176]). In addition to waste glasses, the rate expression has been used to describe the alteration of basaltic glass on the seabed (Grambow et al. 1986 [DIRS 163258], p. 2,710); basaltic glass is used as a natural analog for waste glass. This wide acceptance substantially validates the basic algebraic form of the model, 
namely, an intrinsic rate constant that depends only on the glass composition, dependence on the solution $\mathrm{pH}$, Arrhenius temperature dependence, and dependence on the $\mathrm{H}_{4} \mathrm{SiO}_{4}$ concentration as representative of the rate-limiting step in the dissolution kinetic mechanism. Therefore, based upon the use of the glass degradation rate model form by other researchers and projects in refereed journals and literature, the model is validated per validation activity 3 .

\subsection{VALIDATION OF THE FINAL DEGRADATION RATE EXPRESSION}

The mathematical form of the model is found in Equation 13. Equation 13 is a simplification of Equation 6 obtained by combining the terms ' $\vec{k}_{0} \times[1-\mathrm{Q} / \mathrm{K}]$ ' in Equation 6 into one parameter ' $\mathrm{k}_{\mathrm{E}}$ ' in Equation 13. This section demonstrates that this simplification and the resultant mathematical form is valid based upon comparison of the model results with literature data (validation activity 3). The current understanding of waste glass degradation indicates that the predominant uncertainties in the long-term term dissolution rate are associated with the value of the effective rate constant, $\mathrm{k}_{\mathrm{E}}$, in the model. The value of $\mathrm{k}_{\mathrm{E}}$ is mathematically constrained to the range $\mathrm{k}_{0}>\mathrm{k}_{\mathrm{E}}>0$. The appropriate value to use for $\mathrm{k}_{\mathrm{E}}$ to represent glass degradation over long durations and changing environmental conditions is uncertain. The available data show that the dissolution rate decreases monotonically over time in static or nearly static systems from values on the order of $1 \mathrm{~g} /\left(\mathrm{m}^{2} \cdot \mathrm{d}\right)$ to values on the order of $1 \times 10^{-4} \mathrm{~g} /\left(\mathrm{m}^{2} \cdot \mathrm{d}\right)$. However, for some compositions, after initially decreasing, the dissolution rate has been observed to increase to a value nearly equal to the forward rate at the temperature and $\mathrm{pH}$ of the test solution. Because the conditions in the repository are open, both unlimited amounts of $\mathrm{CO}_{2}$ gas at ambient $p \mathrm{CO}_{2}$ and slowly flowing water, the secondary phases that could cause the acceleration will not form.

Also, the fact that the value of $\mathrm{k}_{\mathrm{E}}$ selected for the model is close to the estimated values of $\vec{k}_{0}$ (i.e., the intrinsic dissolution rate in the absence of solution feed-back effects) for a range of reference waste glass compositions (Table 6-5), and the conservative values selected for the other model parameters $\left(\eta\right.$ and $E_{a}$ ) in Section 6.5.2.1, support the contention that the upper bound of the model provides a conservative estimate of the long-term dissolution rate of waste glasses in the repository.

To show that the model provides a conservative representation of the long-term rate in alkaline solutions, the rates measured with long-term PCT that are shown in Table 7-2 are compared with the range of rates calculated with Equation 51 at the minimum, mean, and maximum values of $\mathrm{k}_{\mathrm{E}}$ and the same $\mathrm{pH}$ measured in the tests. The calculation is shown in Appendix B, Table B-3. The calculated rates are summarized in Table 7-2. The calculated mean rates for all $\mathrm{pH}$ values lie above the measured rates. This provides confidence that the base case model conservatively bounds the degradation rate of disposed waste glass. This validates the model per validation activity 3 .

Table 7-2. Comparison of Measured and Calculated Corrosion Rates of Various Glasses

\begin{tabular}{|l|l|l|l|l|l|}
\hline & \multirow{2}{*}{ Glass } & \multirow{2}{*}{$\begin{array}{c}\text { Measured Rate } \\
\mathbf{g} /\left(\mathbf{m}^{2} \cdot \mathbf{d}\right)\end{array}$} & \multirow{2}{*}{$\begin{array}{c}\text { Measured } \mathbf{p H} \\
\text { (at room temp.) }\end{array}$} & \multicolumn{3}{c|}{ Calculated Rate, $\mathbf{g} /\left(\mathbf{m}^{2} \cdot \mathbf{d}\right)$} \\
\cline { 4 - 6 } & 0.070 & 12.3 & 1.46 & 4.35 & 0.00353 \\
\hline EA & 0.070 & 12.1 & 1.16 & 3.47 & 0.00282 \\
\hline SRL 131A & 0.037 & 12.0 & 1.04 & 3.10 & 0.00252 \\
\hline SRL 202A & 0.032 &
\end{tabular}




\begin{tabular}{|l|l|l|l|l|l|}
\hline SRL 200S & 0.87 & 12.2 & 1.30 & 3.88 & 0.00316 \\
\hline SAN60 & 0.074 & 9.8 & 0.09 & 0.259 & 0.00021 \\
\hline LD6-5412 & 0.40 & 12.0 & 1.04 & 3.10 & 0.00252 \\
\hline
\end{tabular}

Source: Appendix B, Section B-3, Table B-3.

The model is further validated by comparison with literature data on basaltic glasses, which are used as natural analogs for waste glasses. The calculated dissolution rates (Equation 51) with the minimum and maximum value of $\mathrm{k}_{\mathrm{E}}$ can be compared directly with the dissolution rates of basaltic glasses recovered from the seabed. The dissolution rates of several basaltic glass samples were calculated based on the thickness of the layer of palagonite (alteration product(s) from glass reaction) that forms as an alteration phase and the age of the basaltic glass (Grambow et al. 1986 [DIRS 163258], pp. 268 and 269, Table 2, Figure 3). The dissolution rates for basaltic glasses covered in sediment and exposed to $\mathrm{Si}$-saturated seawater at about $3{ }^{\circ} \mathrm{C}$ are about $0.1 \mu \mathrm{m} / 1,000 \mathrm{yr}$, which is equivalent to $6 \times 10^{-7} \mathrm{~g} /\left(\mathrm{m}^{2} \cdot \mathrm{d}\right)$. The typical $\mathrm{pH}$ range for seawater is 7 to 9 . The respective minimum and maximum dissolution rates calculated with Equation 51 at $3^{\circ} \mathrm{C}$ are $6.62 \times 10^{-9}$ and $1.16 \times 10^{-5} \mathrm{~g} /\left(\mathrm{m}^{2} \cdot \mathrm{d}\right)$ at $\mathrm{pH} 7$, and $6.33 \times 10^{-8}$ and $1.11 \times 10^{-4} \mathrm{~g} /\left(\mathrm{m}^{2} \cdot \mathrm{d}\right)$ at $\mathrm{pH} 9$ (Appendix B, Table B-4). Thus, the rate expression in this report bounds the long-term dissolution rate of basaltic glasses.

The forward dissolution rate of a synthetic basaltic glass in synthetic seawater $\left(\mathrm{pH}\right.$ at $25^{\circ} \mathrm{C}$ was 8.8) was measured by Crovisier et al. (1986 [DIRS 163211]) at several temperatures. Crovisier et al. (1987 [DIRS 163212]) reported the dissolution rate to be $1 \times 10^{-3} \mathrm{~g} /\left(\mathrm{m}^{2} \cdot \mathrm{d}\right)$ at $3^{\circ} \mathrm{C}$. This is more than a factor of 1000 greater than the rate determined by Grambow et al. (1986 [DIRS 163258) for a natural basaltic glass and shows the important effect of the affinity term on the degradation rate. Crovisier et al. (1987 [DIRS 163212]) conducted their tests under conditions where the affinity term retained a value near one, whereas Grambow et al. (1986 DIRS 163258]) conducted their tests under conditions where the value of the affinity term was much less than one. The activation energy was determined to be $65 \mathrm{~kJ} / \mathrm{mol}$ (Crovisier et al. 1986 [DIRS 163211], p. 275). This is in excellent agreement with the activation energy for alkaline solutions used in the base case model $(69 \mathrm{~kJ} / \mathrm{mol}$, Section 6.5.2.1). Crovisier et al. (1987 [DIRS 163212]) noted that "the dissolution rate of the glass is probably lower in the natural environment than it is in laboratory experiments; this favors a kinetic control of the reaction by glass network dissolution (surface reaction) rather than by diffusion in the palagonite layer (p. 2,987)...there is no natural evidence for growth rate control of palagonite layers by diffusional transport and, hence, the empirical formula $\mathrm{S}=(\mathrm{C} \times \mathrm{t})^{1 / 2}$ must not be used (p. 2,988)...it appears that the kinetics is mainly controlled by the affinity of the dissolution reaction (i.e., the $\mathrm{pH}$ and the saturation of the solution with respect to the glass itself) (p. 2,989)."

These results show the degradation rate calculated by the TSPA-LA glass degradation model provides confidence that the model gives a realistic estimate of basaltic glass dissolution over long reaction times. They also show the activation energy used in the model for dissolution in alkaline solutions is applicable to basaltic glasses. This further validates the form of the model and the range of calculated rates per validation activity 3 . 


\subsection{COMPARISON OF PARAMETER VALUES FOR DEGRADATION MODEL WITH VALUES FOR OTHER GLASSES}

Literature data are evaluated in this section to provide confidence in the model parameter values of $\mathrm{pH}(\eta)$ and temperature $\left(\mathrm{E}_{\mathrm{a}}\right)$ in the glass degradation model. This is done by comparing the coefficients for the $\mathrm{pH}$ and temperature dependencies that were determined in Section 6.5.2 from tests with SRL 202G glass with the $\mathrm{pH}$ and temperature dependencies that were either determined previously for the dissolution rates of other alkali borosilicate glasses or determined from published test results. The forward dissolution rates of other borosilicate glasses have been measured to determine values of $\eta$ and $E_{a}$. The comparison of the results to the model is provided in Section 7.3.1 and the details regarding each particular glass are described thereafter.

\subsubsection{Dependence on $\mathrm{pH}$ and Temperature}

The values of $\eta$ and $E_{a}$ determined from tests with several glasses are compared with the values measured in tests with other glasses and with the values used in the base model. The values of $\eta$ and $E_{a}$ determined for various borosilicate glasses are summarized in Table 7-3. The $\mathrm{pH}$ dependence in acidic solutions varies significantly for the different glasses, ranging from -0.36 to -0.70. The value of $\eta=-0.49$ that is used in the base model (Section 6.5.2.1) is in the middle of that range. The range of $\mathrm{pH}$ dependencies in alkaline solutions is from 0.40 to 0.64 . The value of $\eta=0.49$ that is used in the base model (Section 6.5.2.1) is near the middle of that range and is therfore appropriate.

It has been reported that "the activation energies for a very large number of [borosilicate glass] compositions cluster between 60 and $90 \mathrm{~kJ} / \mathrm{mol}$ " (White 1986 [DIRS 111049], p. 439). The values given in Table 7-3 for dissolution in alkaline solutions are consistent with this range. The activation energy of $69 \mathrm{~kJ} / \mathrm{mol}$ that is used in the base case model (Section 6.5.3.1) for alkaline solutions is near the middle of the range and is therefore appropriate.

The activation energy of $31 \mathrm{~kJ} / \mathrm{mol}$ that is used for acidic solutions in the base case model (Section 6.5.3.1) is at the lower end of the range of values measured for other glasses. Higher values were determined for the CSG and binder glasses. Because the values of $\mathrm{k}_{\mathrm{E}}$ were determined from tests conducted at $90^{\circ} \mathrm{C}$, the use of an activation energy at the lower end of the range for different glass compositions ensures that the rates calculated at temperatures less than $90^{\circ} \mathrm{C}$ will not underestimate the dissolution rates. In the model, a $\mathrm{pH}$ of 10 is assigned to the solution in contact with glass when the temperature rises above $100^{\circ} \mathrm{C}$, meaning that the value of $\mathrm{E}_{\mathrm{a}}$ for alkaline solutions is used in most situations for temperatures above $90^{\circ} \mathrm{C}$.

These data show the $\mathrm{pH}$ and temperature dependence parameter values used in the TSPA-LA glass degradation model are either representative of a wide range of borosilicate waste glass compositions or provide a conservative upper bound. 
Table 7-3. Values of $\eta$ and $E_{a}$ Extracted from Literature Data

\begin{tabular}{|c|c|c|c|c|c|}
\hline Glass & Element & $\begin{array}{c}\text { Temperature } \\
\left({ }^{\circ} \mathrm{C}\right)\end{array}$ & $\eta$ & $\begin{array}{c}E_{a} \\
(\mathrm{~kJ} / \mathrm{mol})\end{array}$ & Literature Reference \\
\hline \multicolumn{6}{|c|}{ Acidic Solutions } \\
\hline CSG & $\mathrm{Si}$ & $25,50,70$ & -0.70 & 60 & Knauss et al. 1990 [DIRS 101701] \\
\hline MW & $\mathrm{Si}$ & $30,50,70,90$ & -0.39 & 32 & Abraitis et al. 2000 [DIRS 163195] \\
\hline Binder Glass & $\mathrm{Si}$ & $40,70,90$ & -0.36 & 72 & Fanning et al. 2003 [DIRS 163252] \\
\hline \multicolumn{6}{|c|}{ Alkaline Solutions } \\
\hline CSG & $\mathrm{Si}$ & $40,70,90$ & 0.49 & 85 & Knauss et al. 1990 [DIRS 101701] \\
\hline MW & $\mathrm{Si}$ & $30,50,70,90$ & 0.43 & 56 & Abraitis et al. 2000 [DIRS 163195] \\
\hline LD6-5412 & $\mathrm{Si}$ & $20,40,70,90$ & 0.40 & 75 & McGrail et al. 1997 [DIRS 111040] \\
\hline R7T7 & B & 90 & - & 59 & $\begin{array}{l}\text { Delage and Dussossoy } 1991 \\
\text { [DIRS 111014], p. } 47\end{array}$ \\
\hline R7T7 & $\mathrm{B}$ & 90 & 0.41 & - & Advocat et al. 1991 [DIRS 111000] \\
\hline Binder Glass & $\mathrm{Si}$ & $40,70,90$ & 0.64 & 83 & Fanning et al. 2003 [DIRS 163252] \\
\hline
\end{tabular}

NOTE: $\quad$ a See Appendix V.

\subsubsection{Tests with CSG Glass}

A simple 5-component glass referred to as "Celia's Simple Glass" (CSG; Knauss et al. 1990 [DIRS 101701]) was formulated as surrogate for DWPF waste glasses to measure glass dissolution parameter values. The glass contains $\mathrm{Al}_{2} \mathrm{O}_{3}, \mathrm{~B}_{2} \mathrm{O}_{3}, \mathrm{CaO}, \mathrm{Na}_{2} \mathrm{O}$, and $\mathrm{SiO}_{2}$. Redox sensitive elements were excluded to facilitate subsequent analyses of the reacted solids. Single-pass flow-through (SPFT) tests were conducted with CSG glass to measure the dissolution rate as a function of temperature and $\mathrm{pH}$ (Knauss et al. 1990 [DIRS 101701], p. 372). Tests were conducted at $25^{\circ} \mathrm{C}, 50^{\circ} \mathrm{C}$, and $70^{\circ} \mathrm{C}$ in $\mathrm{pH}$ buffer solutions spanning the range from $\mathrm{pH} 1$ to $\mathrm{pH}$ 13. Knauss et al. (1990 [DIRS 101701]) quantified the glass dissolution rate based on the release of silicon. Knauss et al. (1990 [DIRS 101701]) presented the rate constants without separating the intrinsic and temperature-dependent components. They reported rates as $\log _{10}(\kappa)$, where $\log _{10}(\kappa)=\log _{10}\left(\mathrm{k}_{0}\right)+\log _{10}\left\{\exp \left(-\mathrm{E}_{\mathrm{a}} / \mathrm{RT}\right)\right\}$. Separate values of $\eta$ were reported for each temperature.

The results reported by Knauss et al. (1990 [DIRS 101701], Figure 1) were reanalyzed here to provide single values for the $\mathrm{pH}$ dependence in acidic and alkaline solutions at all temperatures. The reanalysis was done as follows (Appendix V): the results of tests at $50^{\circ} \mathrm{C}$ and $70^{\circ} \mathrm{C}$ were regressed together to determine values for acidic and alkaline solutions. Those values are $\eta_{\text {acid }}=-0.698$ and $\eta_{\text {alkaline }}=0.486$. Lines with these slopes were then regressed manually with Microsoft Excel to the results of tests at $25^{\circ} \mathrm{C}, 50^{\circ} \mathrm{C}$, and $70^{\circ} \mathrm{C}$. The equations of these lines had the form $\log _{10}($ rate $)=\log _{10}(\kappa)+\eta \times p H$ and were used to determine the values of $\log _{10}(\kappa)$ at each temperature for acidic and alkaline solutions. The resulting lines are shown in Figure 7-1a with the test results determined from Figure 1 the report by Knauss et al. (1990 [DIRS 101701]). The equations were then used to calculate the rates at $\mathrm{pH} 0$ and at $\mathrm{pH} 14$. These rates were used to determine the activation energies for the acidic and alkaline solutions, as shown in the Arrhenius plot in Figure 7-1. The activation energies are $60 \mathrm{~kJ} / \mathrm{mol}$ for acids and $85 \mathrm{~kJ} / \mathrm{mol}$ for bases. 
(a)

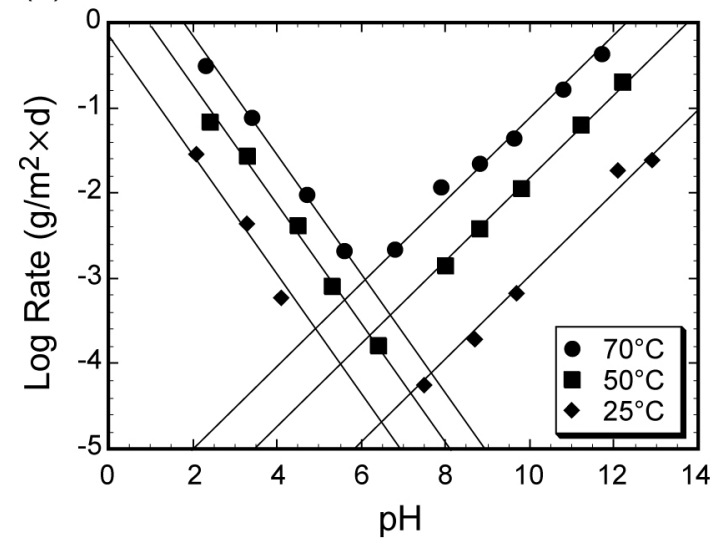

(b)

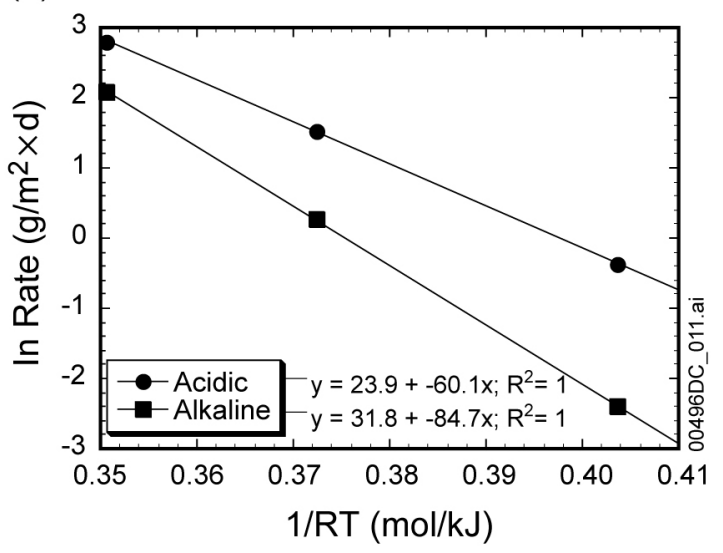

NOTES: (a) Acidic solutions fitted with $\eta=-0.698$ and alkaline solutions fitted with $\eta=0.486$; data points from Knauss et al. (1990 [DIRS 101701]), lines from reanalysis done for this report (Appendix V) (b) Arrhenius plot for calculated rates at $\mathrm{pH} 0$ and $\mathrm{pH} 14$.

Figure 7-1. Measured NR(Si) from Single-Pass Flow-Through Tests with CSG Glass

\subsubsection{Tests with LD6-5412 Glass}

The LD6-5412 glass was developed as a reference test glass for Hanford low-activity waste glasses. An extensive series of SPFT tests have been conducted with LD6-5412 glass at $20^{\circ} \mathrm{C}$, $40^{\circ} \mathrm{C}, 70^{\circ} \mathrm{C}$, and $90^{\circ} \mathrm{C}$ and at $\mathrm{pH}$ values as low as 6 (McGrail et al. 1997 [DIRS 111039], p. 186, Figure 12; reproduced here as Figure 7-2). The regressed parameter values based on the release of $\mathrm{Si}$ are reported to be $\eta_{\text {alkaline }}=0.40 \pm 0.03, \mathrm{E}_{\mathrm{a}}=74.8 \pm 1.0 \mathrm{~kJ} / \mathrm{mol}$, and $\log _{10}\left(\mathrm{k}_{0}\right)\left[\mathrm{g} /\left(\mathrm{m}^{2} \cdot \mathrm{s}\right)\right]=$ $2.05 \pm 0.16\left\{\log _{10}\left(\mathrm{k}_{0}\right)\left[\mathrm{g} /\left(\mathrm{m}^{2} \cdot \mathrm{d}\right)\right]=6.99\right\}$. The value of $\log _{10}\left(\mathrm{k}_{0}\right)$ given by McGrail et al. (1997 [DIRS 111039]) for LD6-5412 glass differs from the value of $\log _{10}\left(\mathrm{k}_{0}\right)=5.14$ reported in Table 6-8, because different values of $\eta$ and $E_{a}$ were used to extract the value of $\log _{10}\left(k_{0}\right)$.

The intrinsic rate constant of LD6-5412 glass that was measured with MCC-1 tests can be compared with the value measured with SPFT tests by McGrail et al. (1997 [DIRS 111039]) if the same activation energy and value of $\eta$ are used to separate the temperature and $\mathrm{pH}$ effects from the measured rates. The value of $\log _{10}\left(\mathrm{k}_{0}\right)$ extracted from the MCC-1 test results $\left[\mathrm{NR}(\mathrm{B})=0.47 \mathrm{~g} /\left(\mathrm{m}^{2} \cdot \mathrm{d}\right)\right.$ from Table 6-5], with Equation 13 and the values $\eta=0.40$ and $\mathrm{E}_{\mathrm{a}}=75 \mathrm{~kJ} / \mathrm{mol}$, is $\log _{10}\left(\mathrm{k}_{0}\right)\left[\mathrm{g} /\left(\mathrm{m}^{2} \cdot \mathrm{d}\right)\right]=7.00$. This is in excellent agreement with the value of $\log _{10}\left(\mathrm{k}_{0}\right)\left[\mathrm{g} /\left(\mathrm{m}^{2} \cdot \mathrm{s}\right)\right]=2.05$ reported by McGrail et al. (1997 [DIRS 111039]), which is equivalent to $\log _{10}\left(\mathrm{k}_{0}\right)\left[\mathrm{g} /\left(\mathrm{m}^{2} \cdot \mathrm{d}\right)\right]=6.99 \pm 0.55$. This comparison shows that the MCC-1 test method and single-pass flow-through tests provide the same estimate the value of $\log _{10}\left(\mathrm{k}_{0}\right)$. 


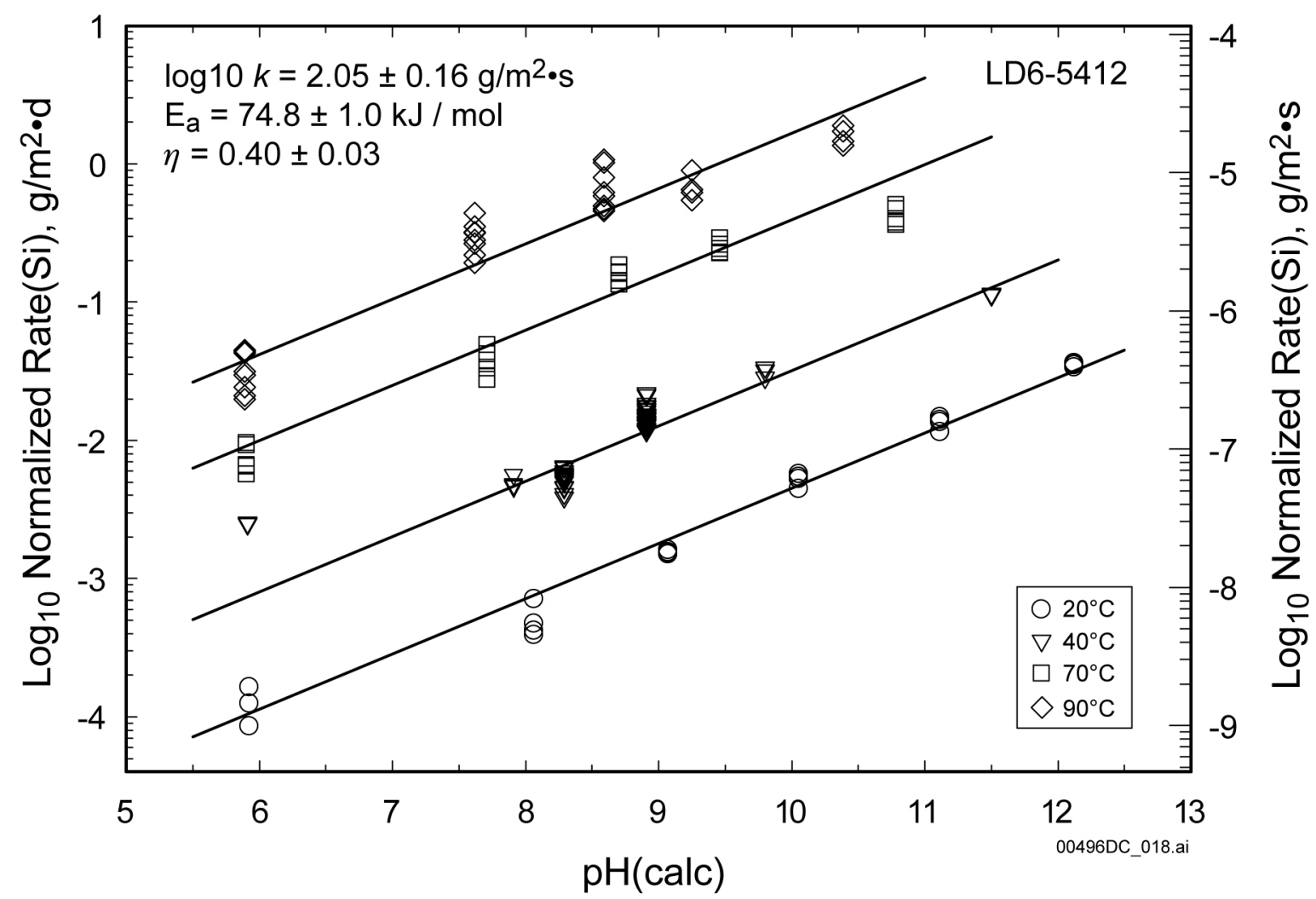

Source: McGrail et al. 1997 [DIRS 111039].

Figure 7-2. Results of Single-Pass Flow-Through Tests with LD6-5412 Glass

\subsubsection{Tests with R7T7 Glass}

The R7T7 glass is a nonradioactive reference glass for the French R7 vitrification facility at La Hague that has been tested extensively. Soxhlet tests were used to measure the temperature dependence of R7T7 dissolution rate (Delage and Dussossoy (1991 [DIRS 111014], p. 41). Results reported by Delage and Dussossoy (1991 [DIRS 111014], Table IV) are shown in Figure 7-3. The slope of the regression line is the negative of the activation energy, which is $59.7 \mathrm{~kJ} / \mathrm{mol}$. A value of $59 \pm 2 \mathrm{~kJ} / \mathrm{mol}$ was reported by Delage and Dussossoy (1991 [DIRS 111014]). 


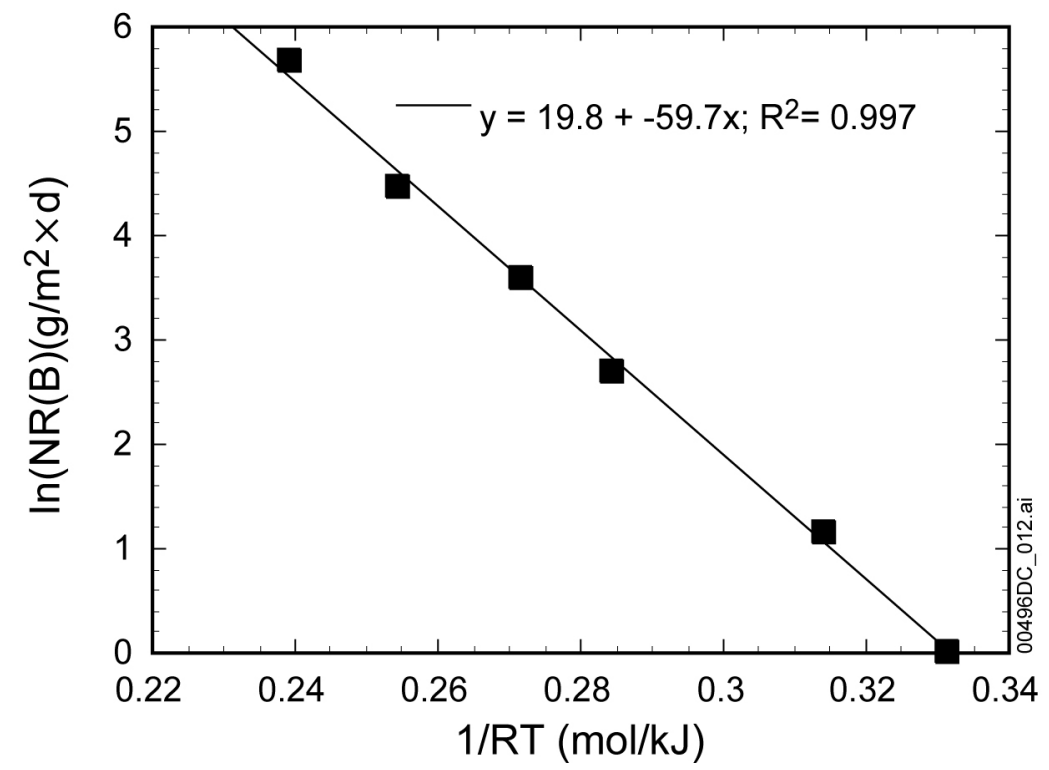

Source: Delage and Dussossoy 1991 [DIRS 111014].

Figure 7-3. Arrhenius Plot for Dissolution of R7T7 Glass

Short-term MCC-1 tests in solutions with various imposed $\mathrm{pH}$ values were used to measure the $\mathrm{pH}$ dependence of the R7T7 dissolution rate (Advocat et al. 1991 [DIRS 111000], p. 57). Results are shown in Figure 7-4. Neither a minimum rate nor an increase in the rate with decreasing $\mathrm{pH}$ was observed in tests conducted at $90^{\circ} \mathrm{C}$ and at $\mathrm{pH}$ values as low as 4.5 (Advocat et al. 1991 [DIRS 111000], p. 63, Figure 4). The relative releases of B, Na, and $\mathrm{Si}$ in mildly acidic solutions mimics that seen by Knauss et al. (1990 [DIRS 101701]) in tests at $70^{\circ} \mathrm{C}$ over the range $\mathrm{pH} 3$ to $\mathrm{pH}$ 7. The slope of the line drawn between $\mathrm{pH} 7$ and $\mathrm{pH} 10$ in Figure 7-4 is reported as 0.41 .

The dissolution rate of R7T7 glass (based on the release of B) was measured to be $5.41 \mathrm{~g} /\left(\mathrm{m}^{2} \cdot \mathrm{d}\right.$ ) at $90^{\circ} \mathrm{C}$ in a pH 2.5 solution (Gin et al. 1994 [DIRS 163254], p. 258). For comparison with the data in Figure 7-3, this is equivalent to $9.04 \times 10^{-11} \mathrm{~mol} /\left(\mathrm{cm}^{2} \cdot \mathrm{s}\right)\left(\log _{10}(\right.$ rate $\left.)=-10.0\right)$ when the molecular weight of $69.39 \mathrm{~g}$ glass $/ \mathrm{mol}$ is used (Advocat et al. 1990 [DIRS 110996]). This indicates that the dissolution rate of R7T7 glass does increase at low $\mathrm{pH}$ values and may indeed have a $\mathrm{V}$-shaped $\mathrm{pH}$ dependence. A bounding value of the degradation rate can be determined from the values $\log _{10}($ rate $)=-10.0$ at $\mathrm{pH} 2.5$ and $\log _{10}($ rate $)=-11.2$ at $\mathrm{pH} 4.5$ (Figure 7-3). If the rate begins to increase at $\mathrm{pH}$ values less than 4.5 , the value of $\eta$ will be -0.6 . 


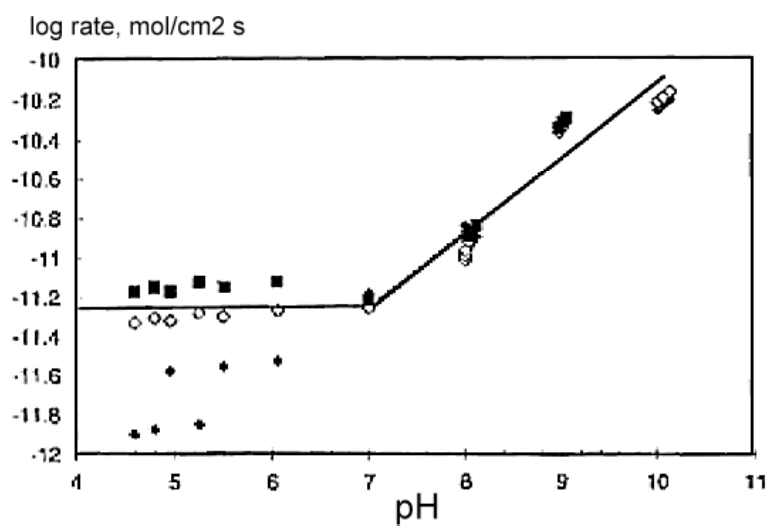

Source: Advocat et al. 1990 [DIRS 110996].

Figure 7-4. Results of MCC-1 Tests with R7T7 Glass for $(\diamond) \mathrm{B},(\boldsymbol{\square}) \mathrm{Na}$, and $(\bullet) \mathrm{Si}$

\subsubsection{Tests with Magnox Glass}

A borosilicate glass is used to immobilize solutions from Magnox reprocessing operations in Britain (referred to as MW glass). Tests have been conducted to study the dissolution mechanism and kinetics to support modeling. Figure 7-5 shows the dissolution rates measured for MW glass in short-term static leach tests (up to 28 days) conducted in various $\mathrm{pH}$-buffered solutions at $60^{\circ} \mathrm{C}$ and $90^{\circ} \mathrm{C}$ (Abraitis et al. 2000 [DIRS 163195], Figure 1). Because of the limited data, the rates measured in acidic solutions are fit to the four data points for NR(B) at $90^{\circ} \mathrm{C}$ and the rates in alkaline solutions are fit to the four data points for $\mathrm{NR}(\mathrm{B})$ at $60^{\circ} \mathrm{C}$. The values are $\eta_{\text {acid }}=-0.37$ and $\eta_{\text {alkaline }}=0.37$. The other data are consistent with these $\mathrm{pH}$ dependencies. Abraitis et al. (2000 [DIRS 163195]) report values of $\eta_{\text {acid }}=-0.39$ and $\eta_{\text {alkaline }}=0.43$ based on boron release rates in tests conducted at $18^{\circ} \mathrm{C}$. The activation energies are reported by Abraitis et al. (2000 [DIRS 163195]) to be $32 \mathrm{~kJ} / \mathrm{mol}$ for acidic and $56 \mathrm{~kJ} / \mathrm{mol}$ alkaline solutions based on the release of $\mathrm{Si}$ at $\mathrm{pH} 2.3$ and $\mathrm{pH} 12.1$. 


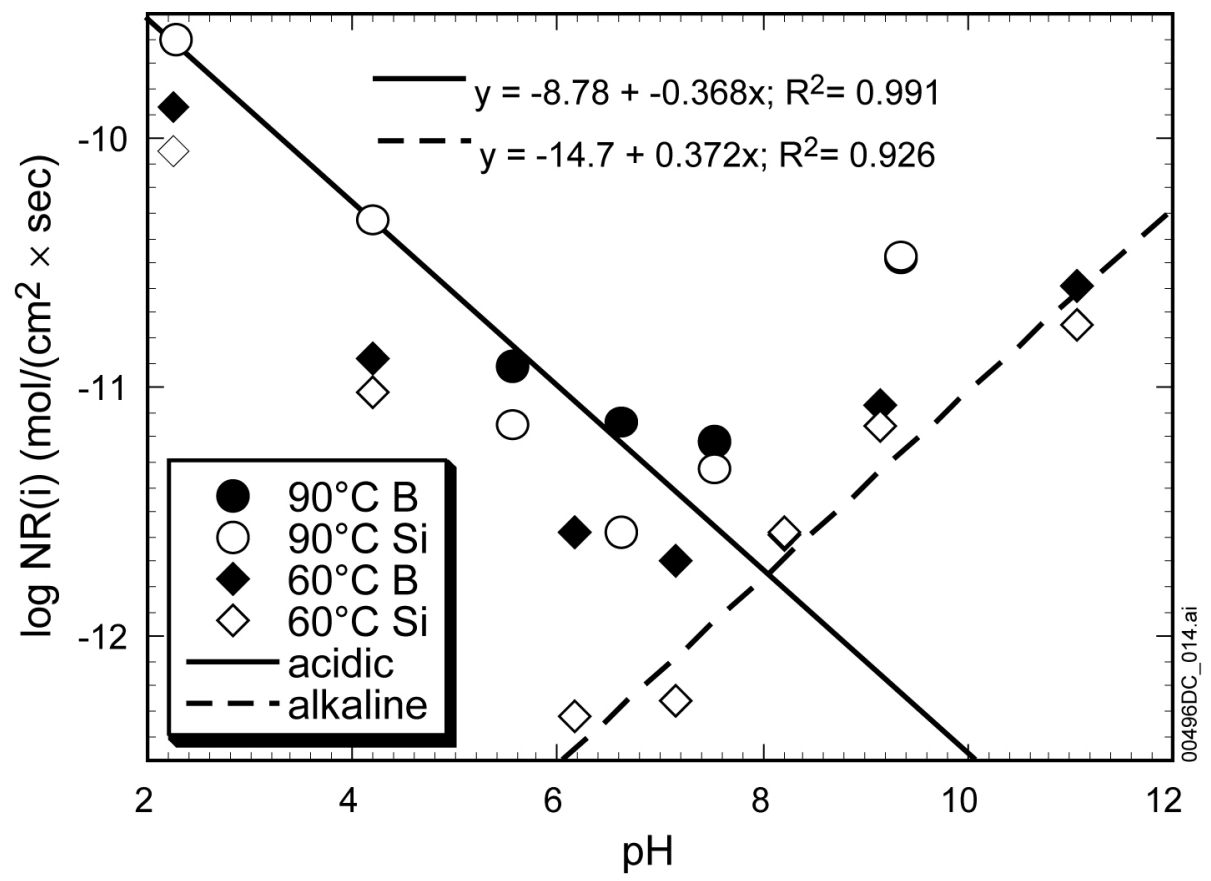

Source: Abraitis et al. 2000 [DIRS 163195].

Figure 7-5. Results of Tests with MW Glass at $60^{\circ} \mathrm{C}$ and $90^{\circ} \mathrm{C}$

\subsubsection{Tests with Binder Glass}

A borosilicate binder glass is used to immobilize salt wastes from electrochemically treated spent sodium bonded nuclear fuel. Because of the low solubility of $\mathrm{Cl}$ in borosilicate glasses, the salt is first occluded in zeolite $5 \mathrm{~A}$, and then the salt-loaded zeolite is encapsulated in the binder glass. Series of MCC-1 tests were conducted to measure the temperature and $\mathrm{pH}$ dependence of the binder glass dissolution rate. The release of silicon was used to monitor the dissolution rate. The results are shown in Figure 7-6. The temperature and $\mathrm{pH}$ dependencies were determined based on the results of tests at $40^{\circ} \mathrm{C}, 70^{\circ} \mathrm{C}$, and $90^{\circ} \mathrm{C}$ (Fanning et al. 2003 [DIRS 163252]). The regression gives values of $\eta_{\text {acid }}=-0.36$ and $\mathrm{E}_{\mathrm{a}}=72 \mathrm{~kJ} / \mathrm{mol}$ and $\eta_{\text {alkaline }}=0.64$ and $\mathrm{E}_{\mathrm{a}}=83 \mathrm{~kJ} / \mathrm{mol}$. Also shown in Figure 7-6 is a comparison of the results of tests conducted at $20^{\circ} \mathrm{C}$ and the predicted rates (dashed lines) (Jeong et al. 2002 [DIRS 163261]). Although the absolute differences between the measured and predicted rates are only on the order of $0.001 \mathrm{~g} /\left(\mathrm{m}^{2} \cdot \mathrm{d}\right)$, the measured rates are almost all greater than the predicted rates. 


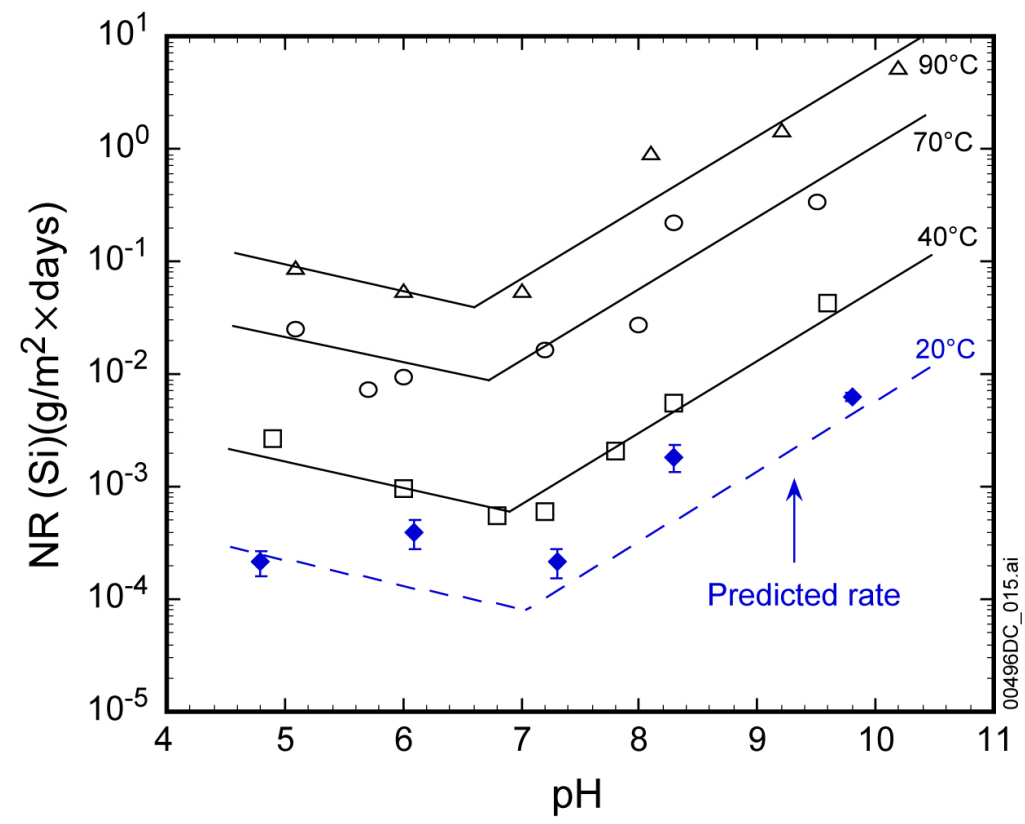

Source: Jeong et al. 2002 [DIRS 163261].

Figure 7-6. Results of MCC-1 Tests with Binder Glass

\subsection{COMPARISON OF THE EXPOSED SURFACE AREA PARAMETER RANGE TO LITERATURE DATA}

Literature data are evaluated in this section to provide confidence in the appropriateness for the calculation of the exposed glass surface area in the TSPA-LA glass dissolution model. Tests with approximately $0.3-\mathrm{m}$-long and $0.6-\mathrm{m}$-diameter sections cut from a nonradioactive glass (SRL 165 glass) were conducted as scaled-up MCC-1 static leach tests (Bickford and Pellarin 1987 [DIRS 163207]). The authors estimated a 25- to 35-fold increase in the surface area from cracking. The results of the scaled-up tests were within a factor of 3 of the typical laboratory tests results with 1-cm-diameter and 2-mm-thick samples when normalized to the surface area. The authors attributed much of the difference to the greater roughness (surface finish) of the large samples. The factor of 3 is slightly less than the lower end of the range of exposure used in the base model (i.e., 4 to 17 ).

A study of the fracturing of full-scale samples of nonradioactive R7T7 glass was conducted under the auspices of the European Commission on Nuclear Science and Technology (Sené et al. 1999 [DIRS 163283]). Two full-size glass samples had a mass of about $400 \mathrm{~kg}$ each, compared to the masses of U.S. HLW glasses, which are about 3,200 kg for long canisters and $1,700 \mathrm{~kg}$ for short canisters. While the size of the canister will affect the cooling rate of the glass, the primary cause of fracturing is from the hoop stresses incurred by the difference in thermal expansion of the glass and the steel canister. The degree of fracturing measured with the smaller R7T7 glass provides validation of the degree of fracturing calculated for U.S. glasses in this report. Analyses were conducted with two samples and two different methods: the extent of fracturing was measured with tomography and the accessible surface area was evaluated by conducting large-scale Soxhlet tests (Sené et al. 1999 [DIRS 163283]). The accessible surface area was assessed from Soxhlet results by comparing the measured release rates of glass components from full-sized glass with the rates measured with small samples that were not 
fractured. The difference is attributed to a different surface area. To minimize the amount of fracturing incurred by removing the sample from the pour canister, Sample 1 was made in a perforated inner container and Sample 2 was made in a four-sided container. The perforated inner container was retained for the Soxhlet tests; the four-sided container was removed, which resulted in additional fracturing and fragmenting of Sample 2. It was expected that results from Sample 1 would underestimate the degree of fracturing because of the perforated container and results from Sample 2 would overestimate the degree of fracturing. Both sets of results are summarized in Table 7-4 (Sené et al. 1999 [DIRS 163283], Table 13). The fracture ratio was calculated as the measured surface area divided by the geometric surface area. The high uncertainty in the value from the Soxhlet test with Sample 2 gives a range of 13 to 61. This was due to Sample 2 breaking into loose fragments and a "more complete exposure of all the fractured glass surfaces to the leaching solution" (Sené et al. 1999 [DIRS 163283], Section 5.5.2). Small pieces of glass that were not detected with tomography were probably exposed in the Soxhlet test. The Soxhlet results for Sample 2 are not representative of a canistered waste glass. The fracture ratios for the other analyses are within the range of 4 to 17 that is used in the base model.

Table 7-4. Measured Surface Areas for Full-Scale Glass of R7T7 Glass

\begin{tabular}{|l|c|c|}
\hline & Sample 1 & Sample 2 \\
\hline Volume, $\mathrm{m}^{3}$ & 0.140 & 0.147 \\
\hline Geometric Surface Area, $\mathrm{m}^{2}$ & 1.88 & 1.88 \\
\hline \multicolumn{2}{|c|}{ Results Using Tomography Method } \\
\hline Total Surface Area, $\mathrm{m}^{2}$ & $13 \pm 3$ & $26 \pm 6$ \\
\hline Fracture Ratio & $7 \pm 2$ & $15 \pm 4$ \\
\hline \multicolumn{3}{|c|}{ Results Using Soxhlet Method } \\
\hline Total Surface Area, $\mathrm{m}^{2}$ & $7 \pm 3$ & $64 \pm 42$ \\
\hline Fracture Ratio & $3 \pm 2$ & $37 \pm 24$ \\
\hline
\end{tabular}

Source: Sené et al. 1999 [DIRS 163283].

This comparison provides confidence that the range of surface areas calculated in the TSPA-LA glass degradation model provides a conservative but realistic representation of the reactive surface area of a fractured waste glass, compared to available literature information.

\subsection{SUMMARY OF MODEL VALIDATION}

The glass degradation model is validated in the preceding Sections 7.1 through 7.4 by comparison with literature data that were not used to develop or calibrate the model (Criterion for validation per BSC 2004 [DIRS 171583]). The form of the rate expression is validated by comparison with rate expressions used in other waste disposal programs. The range of calculated rates for dissolution in alkaline solutions is validated by comparison with increased rates after zeolite formation and rates measured for basalt glass. While not validated per se, model parameter values for the temperature and $\mathrm{pH}$ dependence are compared with parameters measured for other glasses to provide additional confidence. These comparisons demonstrate that an appropriate level of confidence in the glass degradation model exists and the requirements of the technical work plan (BSC 2004 [DIRS 171583], Table 2-1) are satisfied. The level of confidence for the results from the model is consistent with the level of importance 
and the criteria listed in the technical work plan under which the model was developed (BSC 2004 [DIRS 171583], Table 2-1).

No further activities are needed to complete this model validation for its intended use. The basecase model developed in this report is adequately validated for HLW borosilicate glass waste forms that meet current acceptance requirements (DOE 2002 [DIRS 158873]; DOE 1996 [DIRS 102589]), the most important of which is the requirement that HLW glasses be more durable than the EA glass as measured using PCT-A. 


\section{INTENTIONALLY LEFT BLANK}




\section{CONCLUSIONS}

The models developed in this report provide a rate expression to calculate the release of radionuclides as the HLW glass dissolves when contacted by water. The radionuclide release rate is calculated as the product of three terms: the surface area of glass contacted by water; the glass dissolution rate; and the mass fraction of the radionuclide in the glass. Mathematical expressions and parameter values for the first two terms are developed output of this report and are summarized in the following subsections. The mass fractions of radionuclides in the glass are obtained from the inventory abstraction.

The modeling activities documented in this report include:

- Simplifying a well-accepted mechanistic model for the dissolution of borosilicate waste glasses

- Determining model parameter values that represent the behavior of the range of glass compositions expected to be disposed, based on current DOE waste form acceptance criteria (DOE 2002 [DIRS 158873])

- Determining model parameter values for the anticipated range of environmental conditions in the repository

- Developing an expression for the glass surface area exposed to water in a breached waste package

- Validating the model for its intended use in TSPA calculations for License Application.

Constant parameter values were determined from the results of tests conducted specifically to provide data to determine the dependence of the glass dissolution rate on $\mathrm{pH}$, temperature, and composition. The results of other tests were used to determine ranges of parameter values to take into account variability in glass composition and water exposure conditions. The output developed in this report are mathematical expressions for calculating the glass dissolution rate and surface area of glass available for corrosion and model parameter values. These are summarized in the following sections and in output DTN: MO0409ANLGAMR1.016. The Microsoft Excel spreadsheets used to perform the calculations are also provided in output DTN: MO0307ANLGAMR3.016.

\subsection{DEVELOPED OUTPUT}

The output developed in this report includes the exposed surface area of glass, the rate expression for glass degradation, and model parameter values. The computational parameter values are summarized in Table $8-1$. 
The expression developed to model the surface area of glass that reacts is:

$$
\mathrm{S}=\mathrm{f}_{\text {exposure }} \times 2.70 \times 10^{-3} \mathrm{~m}^{2} / \mathrm{kg} \times\left(2,710 \mathrm{~kg}-\Sigma \mathrm{M}_{\mathrm{t}} \mathrm{kg}\right)
$$

where:

$\mathrm{S} \quad$ is the surface area $\left(\mathrm{m}^{2}\right)$ available during the current time step

$\mathrm{f}_{\text {exposure }}$ is an empirical factor that accounts for the effects of cracking, the extent to which water can penetrate cracks, and the lower reactivity of glass in cracks relative to free surfaces

$\Sigma \mathrm{M}_{\mathrm{t}} \quad$ is the total mass of glass that has been dissolved through time $\mathrm{t}$ (the value of $\Sigma \mathrm{M}_{\mathrm{t}}$ is incremented after each time step).

The surface area available at each time step is calculated from the mass of glass that has not been dissolved or altered in all previous time steps. The mass dissolved in each time step is tracked in the simulation. A constant value is used for the specific surface area based on the geometric surface area and mass of glass in a canister. The nominal dimensions and mass of the glass form represent a weighted average of anticipated waste glasses in short and long canisters. The exposure factor accounts of the thermal cracking anticipated for all glass and impact cracking anticipated for about $1 \%$ of the glass. A range of values is used for the exposure factor. The upper limit of the range $\left(f_{\text {exposure }}=17\right)$ represents the case where glass in cracks has the same reactivity as glass at free surfaces. The lower limit of the range $\left(f_{\text {exposure }}=4\right)$ accounts for the limited access of water to glass in interior cracks and the lower reactivity of glass in the cracks. The most probable value of $f_{\text {exposure }}=4$.

The mass of glass degraded at the end of the current time step is calculated with Equation 52:

$$
\mathrm{M}(\mathrm{t})=\operatorname{rate}_{\mathrm{G}} \times \mathrm{t} \times \mathrm{S}
$$

where $\mathrm{M}(\mathrm{t})$ and $\mathrm{S}$ are the mass dissolved or altered and surface area available in the current time step, and $t$ is the duration of the time step in the same time units as the rate. The mass of glass that remains at the end of the current time step $\Sigma \mathrm{M}_{\mathrm{t}}$ is calculated using Equation 53:

$$
\Sigma \mathrm{M}_{\mathrm{t}}=\Sigma \mathrm{M}_{\mathrm{t}-1}-\mathrm{M}(\mathrm{t})
$$

where $\Sigma \mathrm{M}_{\mathrm{t}-1}$ is the mass of glass remaining prior to the current time step. The surface area available for the next time step is calculated by substituting the value of $\Sigma \mathrm{M}_{\mathrm{t}}$ into Equation 49 . 
Table 8-1. Computational Model Parameter Values Developed in This Report ${ }^{\mathrm{a}}$

\begin{tabular}{|c|c|c|c|c|}
\hline $\begin{array}{l}\text { Output } \\
\text { Name }\end{array}$ & $\begin{array}{c}\text { Output } \\
\text { Description }\end{array}$ & Value & Distribution & $\begin{array}{c}\text { Type of } \\
\text { Uncertainty }\end{array}$ \\
\hline$f_{\text {exposure }}$ & $\begin{array}{l}\text { glass exposure } \\
\text { factor }\end{array}$ & $\begin{array}{ll}\text { minimum: } & 4 \text { (no units) } \\
\text { maximum: } & 17 \text { (no units) } \\
\text { most probable: } & 4 \text { (no units) }\end{array}$ & Triangular & Aleatory \\
\hline $\mathrm{S}_{\mathrm{sp}}$ & $\begin{array}{l}\text { glass specific } \\
\text { surface area }\end{array}$ & $2.70 \times 10^{-3} \mathrm{~m}^{2} / \mathrm{kg}$ & Single Value & Epistemic \\
\hline $\mathrm{M}_{0}$ & $\begin{array}{l}\text { initial mass of } \\
\text { glass }\end{array}$ & $2,710 \mathrm{~kg}$ & Single Value & Epistemic \\
\hline$\eta_{\text {acidic }}$ & $\begin{array}{l}\text { pH coefficient for } \\
\text { acidic solutions }\end{array}$ & -0.49 (no units) & Single Value & Epistemic \\
\hline$\eta_{\text {alkaline }}$ & $\begin{array}{l}\text { pH coefficient for } \\
\text { alkaline solutions }\end{array}$ & 0.49 (no units) & Single Value & Epistemic \\
\hline $\mathrm{E}_{\mathrm{a}_{-} \text {acidic }}$ & $\begin{array}{l}\text { temperature } \\
\text { coefficient for } \\
\text { acidic solutions }\end{array}$ & $31 \mathrm{~kJ} / \mathrm{mol}$ & Single Value & Epistemic \\
\hline$E_{\text {a_alkaline }}$ & $\begin{array}{l}\text { temperature } \\
\text { coefficient for } \\
\text { alkaline solutions }\end{array}$ & $69 \mathrm{~kJ} / \mathrm{mol}$ & Single Value & Epistemic \\
\hline $\mathrm{K}_{\mathrm{E} \_ \text {acidic }}$ & $\begin{array}{l}\text { glass degradation } \\
\text { rate coefficient for } \\
\text { acidic solutions }\end{array}$ & $\begin{array}{ll}\text { minimum: } & 8.41 \times 10^{3} \mathrm{~g} /\left(\mathrm{m}^{2} \cdot \mathrm{d}\right) \\
\text { maximum: } & 1.15 \times 10^{7} \mathrm{~g} /\left(\mathrm{m}^{2} \cdot \mathrm{d}\right) \\
\text { most probable: } & 8.41 \times 10^{3} \mathrm{~g} /\left(\mathrm{m}^{2} \cdot \mathrm{d}\right) \\
\end{array}$ & Triangular & Epistemic \\
\hline $\mathrm{k}_{\mathrm{E}_{-} \text {alkaline }}$ & $\begin{array}{l}\text { glass degradation } \\
\text { rate coefficient for } \\
\text { alkaline solutions }\end{array}$ & $\begin{array}{ll}\text { minimum: } & 2.82 \times 10^{1} \mathrm{~g} /\left(\mathrm{m}^{2} \cdot \mathrm{d}\right) \\
\text { maximum: } & 3.47 \times 10^{4} \mathrm{~g} /\left(\mathrm{m}^{2} \cdot \mathrm{d}\right) \\
\text { most probable: } & 2.82 \times 10^{1} \mathrm{~g} /\left(\mathrm{m}^{2} \cdot \mathrm{d}\right) \\
\end{array}$ & Triangular & Epistemic \\
\hline$\rho_{G}$ & $\begin{array}{l}\text { representative } \\
\text { density of HLW } \\
\text { glass and dry rind }\end{array}$ & $2,700 \mathrm{~kg} / \mathrm{m}^{3}$ & Single Value & Epistemic \\
\hline$\phi$ & $\begin{array}{l}\text { porosity of rind } \\
\text { (alteration layer) }\end{array}$ & $17 \%$ & Single Value & Epistemic \\
\hline$r_{0}$ & $\begin{array}{l}\text { initial radius of } \\
\text { glass log }\end{array}$ & $0.30 \mathrm{~m}$ & Single Value & Epistemic \\
\hline $\mathrm{L}_{0}$ & $\begin{array}{l}\text { initial length of } \\
\text { average glass log }\end{array}$ & $3.9 \mathrm{~m}$ & Single Value & Epistemic \\
\hline
\end{tabular}

NOTE: $\quad{ }^{a}$ Some of the numbers in this table are reported as logarithms or other derived numbers. During calculation, additional significant figures were used that were later rounded to a lower number of significant figures. Therefore, variations in the last digit should be expected when trying to reproduce these calculations.

Glass degradation does not occur if the relative humidity is less than $44 \%$. If the relative humidity is greater than or equal to $44 \%$, the same rate expression is used to calculate the degradation rate when HLW glass is exposed to humid air, dripping water, or immersed. At temperatures between $100^{\circ} \mathrm{C}(100 \%$ relative humidity for water at $0.1 \mathrm{MPa}$ total pressure) and $125^{\circ} \mathrm{C}$ (44\% relative humidity), Equation 13 is used with a $\mathrm{pH}$ fixed at 10 . The relative humidity is obtained from the appropriate model. 
The rate expression developed for glass alteration is given by Equation 13 from Section 6.5.1:

$$
\text { rate }_{\text {glass }}=k_{E} \times 10^{\eta \cdot p H} \times \exp \left(\frac{-E_{a}}{R T}\right)
$$

Separate sets of parameter values are used for degradation in acidic and alkaline solutions. Constant values of $\eta=-0.49$ and $E_{a}=31 \mathrm{~kJ} / \mathrm{mol}$ are used for acidic solutions, and constant values of $\eta=0.49$ and $E_{a}=69 \mathrm{~kJ} / \mathrm{mol}$ are used for alkaline solutions. Substituting these constant values into Equation 13 yields:

$$
\begin{aligned}
& \text { rate }_{G}=k_{E \_ \text {acidic }} \times 10^{-0.49 \cdot \mathrm{pH}} \times \exp (-31 / \mathrm{RT}) \\
& \text { rate }_{G}=k_{E_{-} \text {alkaline }} \times 10^{0.49 \cdot \mathrm{pH}} \times \exp (-69 / \mathrm{RT})
\end{aligned}
$$

Different bounding values are used for $\mathrm{k}_{\mathrm{E}}$ in acidic and alkaline solutions. Values for $\mathrm{k}_{\mathrm{E}_{-} \text {acidic }}$ and $\mathrm{k}_{\mathrm{E}_{-} a \mathrm{lkaline}}$ to be used for any time step in a realization are selected from the following:

- The maximum value of $k_{E_{-} \text {acidic }}$ is $1.15 \times 10^{7} \mathrm{~g} /\left(\mathrm{m}^{2} \cdot \mathrm{d}\right)$

- The minimum and most probable value of $k_{E}$ acidic is $8.41 \times 10^{3} \mathrm{~g} /\left(\mathrm{m}^{2} \cdot \mathrm{d}\right)$

- The maximum value of $k_{E \text { alkaline }}$ is $3.47 \times 10^{4} \mathrm{~g} /\left(\mathrm{m}^{2} \cdot \mathrm{d}\right)$

- The minimum and most probable value of $k_{E_{-} \text {alkaline }}$ is $2.82 \times 10^{1} \mathrm{~g} /\left(\mathrm{m}^{2} \cdot \mathrm{d}\right)$.

The greater of the two calculated rates calculated with Equations 50 and 51 is used as the degradation rate for all time steps in a calculation. The $\mathrm{pH}$ and temperature are variables in the glass dissolution model. Values of the $\mathrm{pH}$ and temperature must be obtained from another model. The glass dissolution model is valid over the $\mathrm{pH}$ range 1 to 14 , over the temperature range $20^{\circ} \mathrm{C}$ to $300^{\circ} \mathrm{C}$, and over the relative humidity range 0 to $100 \% \mathrm{RH}$.

The release rate of radionuclides from HLW glass dissolution can be calculated from Equation 9 from Section 6.5:

$$
R_{R N}=S \times \text { rate }_{G} \times I_{R N}
$$

where $R_{R N}$ is the rate at which a radionuclide $R N$ is released from the glass matrix (in units of curies/time), $\mathrm{S}$ is the surface area of glass available for reaction (in units of area) calculated with Equation 48, rate $_{\mathrm{G}}$ is the specific degradation rate of the glass (in units mass glass/(area.time)), which is the sum of the rates calculated with Equations 50 and 51, and $\mathrm{I}_{\mathrm{RN}}$ is the mass fraction of a radionuclide $\mathrm{RN}$ in the glass (in units curies/mass glass) that must be obtained from another model. Expressions to calculate $\mathrm{S}$ and rate $_{\mathrm{G}}$ are given in this report. The value calculated with Equation 9 represents release from a single canister.

A description of the alteration layer is given in Appendix D, including equations to calculate the volume, thickness, and water content of the layer, in terms of the mass of HLW glass that dissolves in a canister. The volume of the alteration layer is calculated as:

$$
V_{R}\left(\text { in } \mathrm{m}^{3}\right)=3.7 \times 10^{-4} \times \Sigma M_{t}(\text { in } \mathrm{kg})
$$


The volume of pore water in the alteration layer is calculated as:

$$
V_{w}\left(\text { in } \mathrm{m}^{3}\right)=6.3 \times 10^{-5} \times \Sigma M_{t}(\text { in } \mathrm{kg})
$$

The thickness of the layer, $T_{R}$, is calculated as:

$$
T_{R}(\text { in meters })=0.30-\left[0.090-\left(3.0 \times 10^{-5}\right) \times \Sigma M_{t}\right]^{1 / 2}
$$

\subsection{OUTPUT UNCERTAINTY AND DISTRIBUTIONS}

Uncertainties are associated with both the mathematical expressions for surface area and glass dissolution rate and the model parameter values. The glass dissolution rate and the radionuclide release rate are also affected by uncertainty in the input variables relative humidity, $\mathrm{pH}$, and temperature. These uncertainties are described below.

\subsubsection{Exposed Surface Area}

Uncertainty in the surface area is represented by the range of values assigned to the exposure factor, $f_{\text {exposure. }}$ The maximum value represents a conservative estimate of the increase in surface area based on measurements of the extents of thermal and impact cracking combined with a conservative estimate of the fraction of glass that will be affected. The minimum value represents a subjective estimate of the accessibility of water to tight cracks within the glass and the reduced reactivity of glass within cracks due to transport limits both for water entering cracks and radionuclides exiting cracks. Estimates of water accessibility and glass reactivity are based on qualitative experimental evidence. The range of values is based on experimental evidence that the dissolution of large samples with cracking representative of full-sized glass samples increased by less than a factor of 4 compared to laboratory-sized samples without cracks.

The constant values, used for the specific surface area of a glass and the initial mass, are based on the expected number of long and short canisters and the estimated geometric surface area and mass of the glass in the canisters. These values are intended to reflect the probability of whether a long or short waste package is breached in the simulation.

\subsubsection{Glass Degradation Rate}

The uncertainty in the glass degradation rate is represented by the range of values and distributions assigned to the dissolution rate coefficients, $\mathrm{k}_{\mathrm{E}}$, for contact by acidic and alkaline solutions. The ranges represent the combined uncertainties of the water contact mode (humid air, dripping water, and immersion), the glass composition, and the chemical affinity term. The ranges of values for degradation in acidic and alkaline solutions are based on the rates measured in laboratory tests with a range of water contact modes, glass compositions, and chemical affinities. The effects of glass composition on the degradation rate are small compared with the effect of the affinity term. The impact of the water contact mode is primarily through its effect on the affinity term. The maximum value of $\mathrm{k}_{\mathrm{E}}$ for acidic solutions represents dissolution under immersion conditions with a chemical affinity near 1 . The minimum value of $\mathrm{k}_{\mathrm{E}}$ for acidic solutions represents dissolution under dripping water conditions under which the chemical affinity is significantly less than 1 , perhaps as low as $10^{-4}$. The maximum value of $\mathrm{k}_{\mathrm{E}}$ for alkaline solutions represents dissolution under immersion conditions with a chemical affinity 
established by secondary alteration phases (e.g., zeolites). The minimum value of $\mathrm{k}_{\mathrm{E}}$ for alkaline solutions represents degradation upon exposure to humid air with a chemical affinity significantly less than 1 .

Because the values of $\mathrm{k}_{\mathrm{E}}$ were extracted from measured degradation rates with the same values for the $\mathrm{pH}$ and temperature dependence used in the mathematical rate expressions, the uncertainty in how well those parameter values represent that glass is also contained in the value of $\mathrm{k}_{\mathrm{E}}$. That is, the sets of parameter values $\mathrm{k}_{\mathrm{E}}, \eta$, and $\mathrm{E}_{\mathrm{a}}$ are not independent. By using the rates measured in laboratory tests that simulated likely environmental and water contact conditions, the effects of processes not explicitly taken into account in the mathematical rate expression are captured in the rates calculated with the model.

\subsubsection{Radionuclide Release Rates}

Another source of uncertainty is the relative release rates of radionuclides and $\mathrm{B}$. The dissolution rates of glasses reacted in dripping water and immersed in water are determined from the release of $\mathrm{B}$ in dissolution tests. The thickness of alteration layer was used to determine the alteration rates of glasses exposed to humid air. Boron is taken to be the most rapidly released structural element of a borosilicate waste glass and provides a conservative upper limit to the release of radionuclides in the glass. The release of B is used to represent the glass dissolution or alteration rate, and thereby represents the maximum release rates of all radionuclides. This is, in part, a simplification of the model in that a factor could be included in Equation 9 to scale the release of individual radionuclides to the release of B. Experiments show B and Tc are released nearly congruently; boron is released faster than Tc in some tests and slower in others. This probably reflects uncertainty in measuring the release of Tc, which is present in waste glasses at much lower concentrations than B and is often not homogeneously distributed in the glass. The use of a scaling factor for the release of individual radionuclides was not implemented in the model because (1) data are not available to reliably quantify the relative releases of all radionuclides, and (2) the relative impacts of reactions to break bonds between the radionuclides and the glass cannot be distinguished from the effects of the solubility limits of the radionuclide species in the tests. Solubility limitations are imposed on key radionuclides by other models in TSPA-LA.

\subsubsection{Impact of Input Uncertainties on Output}

Implementation of the glass dissolution model for performance assessment calculations requires specification of values for three variables: relative humidity, in-package solution $\mathrm{pH}$, and in-package temperature. Relative humidity, temperature, $\mathrm{pH}$, and radionuclide inventories do not affect the models developed in this report. No degradation can occur if the relative humidity is less than 44\%. Degradation is calculated with Equations 50 and 51 if the relative humidity is greater than or equal to $44 \%$. The solution $\mathrm{pH}$ and the glass temperature are variables in Equations 50 and 51. The uncertainty in those variables can be used to determine their impact on the glass dissolution rate with standard propagation of errors methods. 


\subsection{CONFIDENCE IN THE MODEL}

The rate expressions developed in this report provide a mathematically simplified model of a generally accepted mechanistic model for borosilicate waste glass dissolution. The computational model parameters were selected to represent the effects of environmental variables tracked in TSPA-LA on glass dissolution and radionuclide release, and the range of those variables over the service life of the disposal system modeled in TSPA-LA calculations. The form of the model and the values of model parameters have been validated by comparison with the best available data for current waste glass compositions. This model is valid over the relative humidity range of $0 \%$ to $100 \%$, the temperature range of $20^{\circ} \mathrm{C}$ to $300^{\circ} \mathrm{C}$, the $\mathrm{pH}$ range 1 to 14, and for glasses with compositions similar to those shown in Table 6-5. Although the maximum temperature at which the experiments have been performed with the glasses discussed in this report is $200^{\circ} \mathrm{C}$, the relative humidity at 1 atmosphere total pressure falls below $44 \%$ at $125^{\circ} \mathrm{C}$. Hence, glass does not react at temperatures exceeding $125^{\circ} \mathrm{C}$ at 1 atmosphere total pressure and the maximum range of applicability can be extended to $300^{\circ} \mathrm{C}$ without impact. This temperature is well below the glass transition temperature, which is in the range of $600^{\circ} \mathrm{C}$ to $700^{\circ} \mathrm{C}$ for proposed HLW glasses. At temperatures approaching or exceeding the glass transition temperature, glasses could crystallize with a possible impact on the degradation rate in water.

\subsection{NRC ACCEPTANCE CRITERIA}

The following acceptance criteria, provided by the NRC in Section 2.2.1.3.4.3 of Yucca Mountain Review Plan, Final Report (NRC 2003 [DIRS 163274]), are relevant to the glass degradation model developed in this report (BSC 2004 [DIRS 171583, Table 3-1). These acceptance criteria are listed with statements summarizing how each criterion is addressed.

\section{Acceptance Criterion 1-System Description and Model Integration are Adequate}

(1) Total system performance assessment adequately incorporates important design features, physical phenomena, and couplings, and uses consistent and appropriate assumptions throughout the radionuclide release rates and solubility abstraction processes.

The glass degradation model developed in this report is consistent with the design features relevant to models from which input is taken and models to which output is provided. The values (or ranges of values) of parameters used in the glass degradation model are either developed within the model (Section 6.5) or obtained from project sources of technical information (e.g., information regarding the dimensions and number of glass canisters and nominal masses of canistered glass). Implementation of the glass degradation model requires definition of variables for relative humidity, solution $\mathrm{pH}$, and temperature that will be obtained from other TSPA-LA or in-package chemistry.

(2) The abstraction of radionuclide release rates uses assumptions, technical bases, data, and models that are appropriate and consistent with other related U.S. Department of Energy abstractions. The descriptions and technical bases 
provide transparent and traceable support for the abstraction of radionuclide release rates and solubility limits.

The glass degradation model is valid for the range of temperatures, $\mathrm{pH}$ values, and relative humidities (Section 6.5) that are consistent with other models implemented with the glass degradation model.

(3) The abstraction of radionuclide release rates and solubility limits provides sufficient, consistent design information on waste packages and engineered barrier systems.

The glass degradation model provides values for the surface area of glass contacted by water (Section 6.5.4), the glass degradation rate (Section 6.5.2), and an expression to calculate the radionuclide release rates (Section 6.7). The rate expression accounts for the anticipated range of glass compositions and water contact scenarios in the disposal system. The surface area calculation accounts for the relative amounts of short and long canisters of HLW glass.

(4) The U.S. Department of Energy reasonably accounts for the range of environmental conditions expected inside breached waste packages and in the engineered barrier environment surrounding the waste package.

The glass degradation model is applicable over the range of anticipated environmental conditions in a breached waste package, including the relative humidity, $\mathrm{pH}$, temperature, and the amount of water. Conditions within the waste package and external to the waste package, as developed in other reports, are used as input to the model developed herein.

(5) The description of process-level conceptual and mathematical models is sufficiently complete with respect to thermal-hydrologic processes affecting radionuclide release from the emplacement drifts.

The release rates of radionuclides are sensitive to changes in the temperature and solution $\mathrm{pH}$. Hydrologic effects are accounted for in the range of values used for the exposure factor and the dissolution rate coefficient. Minimum values for these parameters represent contact by humid air (Section 6.5.3) and maximum values represent immersion (Section 6.5.2).

(6) Technical bases for inclusion of any thermal-hydrologic-mechanical-chemical couplings and features, events, and processes in the radionuclide release rates and solubility limits model abstraction are adequate.

Bounding parameter values were selected to provide calculated radionuclide release rates equal to rates measured in experiments under humid air, dripping water, and immersion conditions.

\section{Acceptance Criterion 2-Data are Sufficient for Model Justification}

(1) Geological, hydrological, and geochemical values used in the safety case are adequately justified. Adequate description of how the data were used, interpreted, and appropriately synthesized into the parameters is provided. 
Justification for the values used in the developed model and descriptions of how the data are used, interpreted, and appropriately synthesized into the parameters is provided in Section 6 .

(2) Sufficient data have been collected on the characteristics of the natural system and engineered materials to establish initial and boundary conditions for conceptual models and simulations of thermal-hydrologic-chemical coupled processes.

The characteristics of the natural system and engineered materials are not addressed in this report.

(4) The corrosion and radionuclide release testing program for high-level radioactive waste forms intended for disposal provides consistent, sufficient, and suitable data for the in-package and in-drift chemistry used in the abstraction of radionuclide release rates and solubility limits. For expected environmental conditions, U.S. Department of Energy provides sufficient justification for the use of test results, not specifically collected from the YM site, for engineered barrier components such as high-level radioactive waste forms, drip shield, and backfill.

Corrosion tests with borosilicate HLW glasses conducted over the past 30 years show the dissolution rate depends on the temperature, $\mathrm{pH}$, and orthosilicic acid activity in solution (Section 6.3). Test results from a number of laboratories on glasses with different compositions provide consistent information on the dissolution and alteration (corrosion) of HLW glasses and the radionuclides they release.

\section{Acceptance Criterion 3-Data Uncertainty is Characterized and Propagated Through the Model Abstraction}

(1) Models use parameter values, assumed ranges, probability distributions, and bounding assumptions that are technically defensible and reasonably account for uncertainties and variabilities, and do not result in an under-representation of the risk estimate.

The uncertainty in specific parameter values is accounted for in the range of the rate coefficients for the modeled glass degradation rate and in the range of exposure factors for the modeled surface area (Section 6.8).

(2) Parameter values, assumed ranges, probability distributions, and bounding assumptions used in the abstractions of radionuclide release rates in the total system performance assessment are technically defensible and reasonable based on data from the YM region, laboratory tests, and natural analogs.

Parameter values, assumed ranges, probability distributions, and bounding assumptions adequately reflect the range of environmental conditions expected inside breached waste packages (Section 8.1, Table 8-1). The lower bounding values of the ranges of the dissolution rate and exposed surface area are based on measured values that are expected to be the most representative of the disposal system. The upper bounding values provide conservative estimates 
of the highest practical rates and surface areas. Sufficient bases exist for selection of maximum and minimum model parameter values and distributions for calculation of both the exposed surface area and the glass degradation rate. Parameter values were determined based on the dissolution rates for several reference waste glasses measured under extreme exposure conditions of humid air, dripping water, and immersion. The experimental conditions were representative of bounding conditions in a breached waste package. The parameter values used in the model were validated by comparison to parameter values determined from dissolution rates for a range of glass compositions reported in the technical literature.

(4) Uncertainty is adequately represented in parameter development for conceptual models, process models, and alternative conceptual models considered in developing the abstraction of radionuclide release rates and solubility limits either through sensitivity analysis or use of bounding analyses.

Parameter development for the conceptual model is developed in Section 6.5; alternative conceptual models have been adequately considered in Section 6.4.

(8) U.S. Department of Energy adequately considers the uncertainties in the characteristics of the natural system and engineered materials, such as the type, quantity, and reactivity of material, in establishing initial and boundary conditions for conceptual models and simulations of thermal-hydrologic-chemical coupled processes that affect radionuclide release.

The key variables affecting the glass degradation rate that are tracked in TSPA-LA calculations are $\mathrm{pH}$, temperature, and relative humidity. The effects of $\mathrm{pH}$ and temperature are modeled explicitly and the glass degradation rate is directly responsive to the uncertainty in those variables (Section 8.1). A minimum relative humidity is required for glass degradation to occur (Section 8.1). Since the range of effects of $\mathrm{pH}$, temperature, and relative humidity span the range of these characteristics of the natural system and engineered materials, these effects have been considered.

(9) Where sufficient data do not exist, the definition of parameter values and conceptual models is based on a appropriate other sources.

The lack of sufficient data for effects of some conditions on glass dissolution and radionuclide release is referred to as "bounding" in this report. For example, data are not available to evaluate glass degradation rates in acidic solutions containing dissolved glass components (Section 6.5). The potential slowing effects of dissolved aluminum or silicon in acidic solutions are neglected in the model.

\section{Acceptance Criterion 4-Model Uncertainty in Characterized and Propagated Through the Model Abstraction}

(1) Alternative modeling approaches of features, events, and processes are considered and are consistent with available data and current scientific understanding, and the results and limitations appropriately considered in the abstraction. 
The full range of glass compositions (Section 6.5.2), exposed glass surface areas (Section 6.5.4), and possible water contact scenarios that can occur in a breached waste package cannot be modeled directly. Instead, the impact of these variables is represented by the range and distribution of parameter values.

(2) In considering alternative conceptual models for radionuclide release rates and solubility limits, the U.S. Department of Energy uses appropriate models, tests, and analyses that are sensitive to the processes modeled for both natural and engineering systems. Conceptual model uncertainties are adequately defined and documented, and effects on conclusions regarding performance are properly assessed.

The mechanistic model for borosilicate glass dissolution is well established (Section 6.3.1). Uncertainty remains only with regard to the process controlling glass dissolution rate in highly concentrated solutions, which is usually too slow to measure. Selection of the minimum rate is affected by this uncertainty, but this has no significant impact on the dose calculation.

(4) The effects of thermal-hydrologic-chemical coupled processes that may occur in the natural setting due to interactions with engineered materials or their alteration products on radionuclide release are appropriately considered.

The effect of steel corrosion on the glass degradation rate was measured experimentally (Section 6.5.2). It was determined that the effects of dissolved iron (III) are negligible relative to the $\mathrm{pH}$ dependence and the effects of sorption to colloidal and solid iron corrosion products are bounded by the upper limit parameter values.

\section{Acceptance Criterion 5-Model Abstraction Output is Supported by Objective Comparisons}

(1) The models implemented in this total system performance assessment abstraction provide results consistent with output from detailed process level models and/or empirical observations (laboratory tests and filed testing and/or natural analogs).

Validation of the glass degradation model was done by comparison to dissolution rates measured for waste glasses in laboratory tests and for basaltic glass reacted at the sea floor (Sections 7.1 through 7.6). 


\section{INTENTIONALLY LEFT BLANK}




\section{INPUTS AND REFERENCES}

\subsection{DOCUMENTS CITED}

101530 Aagaard, P. and Helgeson, H.C. 1982. "Thermodynamic and Kinetic Constraints on Reaction Rates Among Minerals and Aqueous Solutions. I. Theoretical Considerations." American Journal of Science, 282, (3), 237-285. New Haven, Connecticut: Yale University. TIC: 225516.

163195 Abraitis, P.K.; Livens, F.R.; Monteith, J.E.; Small, J.S.; Trivedi, D.P.; Vaughan, D.J.; and Wogelius, R.A. 2000. "The Kinetics and Mechanisms of Simulated British Magnox Waste Glass Dissolution as a Function of pH, Silicic Acid Activity, and Time in Low Temperature Aqueous Systems." Applied Geochemistry, 15, (9), 13991416. New York, New York: Pergamon. TIC: 254333.

110990 Abrajano, T.A., Jr.; Bates, J.K.; and Byers, C.D. 1986. “Aqueous Corrosion of Natural and Nuclear Waste Glasses, I. Comparative Rates of Hydration in Liquid and Vapor Environments at Elevated Temperatures." Journal of Non-Crystalline Solids, 84, 251-257. Amsterdam, The Netherlands: Elsevier. TIC: 246077.

110996 Advocat, T.; Crovisier, J.L.; Fritz, B.; and Vernaz, E. 1990. “Thermokinetic Model of Borosilicate Glass Dissolution: Contextual Affinity." Scientific Basis for Nuclear Waste Management XIII, Symposium held November 27-30, 1989, Boston, Massachusetts. Oversby, V.M. and Brown, P.W., eds. 176, 241-248. Pittsburgh, Pennsylvania: Materials Research Society. TIC: 203658.

111000 Advocat, T.; Crovisier, J.L.; Vernaz, E.; Ehret, G.; and Charpentier, H. 1991. "Hydrolysis of R7T7 Nuclear Waste Glass in Dilute Media: Mechanisms and Rate as a Function of pH." Scientific Basis for Nuclear Waste Management XIV, Symposium held November 26-29, 1990, Boston, Massachusetts. Abrajano, T., Jr. and Johnson, L.H., eds. 212, 57-64. Pittsburgh, Pennsylvania: Materials Research Society. TIC: 203656.

163199 Advocat, T.; Jollivet, P.; Minet, Y.; Luckscheiter, B.; Grambow, B.; Gens, R.; Lemmens, K.; Van Iseghem, P.; Aertsens, M.; Pirlet, V.; and Curti, E. 1999. Experimental and Modelling Studies to Formulate a Nuclear Waste Glass Source Term in Representative Geological Disposal Conditions. EUR 19120 EN. Luxembourg, Luxembourg: Commission of the European Communities. TIC: 254312.

104318 Aines, R.D.; Weed, H.C.; and Bates, J.K. 1987. "Hydrogen Speciation in Hydrated Layers on Nuclear Waste Glass." Scientific Basis for Nuclear Waste Management X, Symposium held December 1-4, 1986, Boston, Massachusetts. Bates, J.K. and Seefeldt, W.B., eds. 84, 547-558. Pittsburgh, Pennsylvania: Materials Research Society. TIC: 203663

104261 Bates, J.K. and Steindler, M.J. 1983. "Alteration of Nuclear Waste Glass by Hydration.” Scientific Basis for Nuclear Waste Management VI, Symposium held 
November 1-4, 1982, Boston, Massachusetts. Brookins, D.G., ed. 15, 83-90. New York, New York: Elsevier. TIC: 204396.

111002 Bates, J.K.; Ebert, W.L.; and Gerding, T.J. 1990. "Vapor Hydration and Subsequent Leaching of Transuranic-Containing SRL and WV Glasses." High Level Radioactive Waste Management, Proceedings of the International Topical Meeting, Las Vegas, Nevada, April 8-12, 1990. 2, 1095-1102. La Grange Park, Illinois: American Nuclear Society. TIC: 202058.

164407 Bates, J.K.; Ebert, W.L.; Mazer, J.J.; Bradley, J.P.; Bradley, C.R.; and Dietz, N.L. 1991. "The Role of Surface Layers in Glass Leaching Performance." Scientific Basis for Nuclear Waste Management XIV, Symposium held November 26-29, 1990, Boston, Massachusetts. Abrajano, T., Jr. and Johnson, L.H., eds. 212, 77-87. Pittsburgh, Pennsylvania: Materials Research Society. TIC: 203656.

104269 Bazan, F.; Rego, J.; and Aines, R.D. 1987. "Leaching of Actinide-Doped Nuclear Waste Glass in a Tuff-Dominated System." Scientific Basis for Nuclear Waste Management X, Symposium held December 1-4, 1986, Boston, Massachusetts. Bates, J.K. and Seefeldt, W.B., eds. 84, 447-458. Pittsburgh, Pennsylvania: Materials Research Society. TIC: 203663.

128081 Bibler, N.E. and Jurgensen, A.R. 1988. "Leaching Tc-99 from SRP Glass in Simulated Tuff and Salt Groundwaters." Scientific Basis for Nuclear Waste Management XI, Symposium held November 30-December 3, 1987, Boston, Massachusetts. Apted, M.J. and Westerman, R.E., eds. 112, 585-593. Pittsburgh, Pennsylvania: Materials Research Society. TIC: 203662.

163206 Bickford, D.F. and Jantzen, C.M. 1984. "Devitrification Behavior of SRL Defense Waste Glass." Scientific Basis for Nuclear Waste Management VII, Symposium held November 14-17, 1983, Boston, Massachusetts. McVay, G.L., ed. 26, 557-566. New York, New York: Elsevier. TIC: 204393.

163207 Bickford, D.F. and Pellarin, D.H. 1987. "Large Scale Leach Testing of DWPF Canister Sections.” Scientific Basis for Nuclear Waste Management X, Symposium held December 1-4, 1986, Boston, Massachusetts. Bates, J.K. and Seefeldt, W.B., eds. 84, 509-518. Pittsburgh, Pennsylvania: Materials Research Society. TIC: 203663.

164408 Biwer, B.M.; Bates, J.K.; Abrajano, T.A., Jr.; and Bradley, J.P. 1990. "Comparison of the Layer Structure of Vapor Phase and Leached SRL Glass by Use of AEM." Scientific Basis for Nuclear Waste Management XIII, Symposium held November 2730, 1989, Boston, Massachusetts. Oversby, V.M. and Brown, P.W., eds. 176, 255263. Pittsburgh, Pennsylvania: Materials Research Society. TIC: 203658.

119110 Bourcier, W.L. 1991. "Overview of Chemical Modeling of Nuclear Waste Glass Dissolution." Scientific Basis for Nuclear Waste Management XIV, Symposium held November 26-29, 1990, Boston, Massachusetts. Abrajano, T., Jr. and Johnson, L.H., eds. 212, 3-18. Pittsburgh, Pennsylvania: Materials Research Society. TIC: 203656. 
101563 Bourcier, W.L. 1994. Critical Review of Glass Performance Modeling. ANL-94/17. Argonne, Illinois: Argonne National Laboratory. TIC: 211862.

110748 Brady, P.V. and Walther, J.V. 1989. "Controls on Silicate Dissolution Rates in Neutral and Basic pH Solutions at $25^{\circ} \mathrm{C}$." Geochimica et Cosmochimica Acta, 53, 2823-2830. New York, New York: Pergamon Press. TIC: 235216.

164401 BSC (Bechtel SAIC Company) 2002. Test Plan for Long-Term Studies of the Degradation and Radionuclide Release from Defense High-Level Waste (DHLW) Glass. SITP-02-WF-002, Rev. 00. Las Vegas, Nevada: Bechtel SAIC Company. ACC: MOL.20020402.0444.

169860 BSC 2004. Engineered Barrier System: Physical and Chemical Environment Model. ANL-EBS-MD-000033, Rev. 03. Las Vegas, Nevada: Bechtel SAIC Company.

167621 BSC 2004. In-Package Chemistry Abstraction. ANL-EBS-MD-000037, Rev. 03. Las Vegas, Nevada: Bechtel SAIC Company.

170022 BSC 2004. Initial Radionuclide Inventories. ANL-WIS-MD-000020 REV 01. Las Vegas, Nevada: Bechtel SAIC Company. ACC: DOC.20040921.0003.

168361 BSC 2004. Q-List. 000-30R-MGR0-00500-000-000 REV 00. Las Vegas, Nevada: Bechtel SAIC Company. ACC: ENG.20040721.0007.

171583 BSC 2004. Technical Work Plan For: Regulatory Integration Modeling and Analysis of the Waste Form and Waste Package. TWP-WIS-MD-000009 REV 00 ICN 01. Las Vegas, Nevada: Bechtel SAIC Company. ACC: DOC.20040910.0001.

170020 BSC 2004. Waste-Form Features, Events, and Processes. ANL-WIS-MD-000009, Rev. 02. Las Vegas, Nevada: Bechtel SAIC Company.

163209 Byers, C.D.; Jercinovic, M.J.; Ewing, R.C.; and Keil, K. 1985. "Basalt Glass: An Analogue for the Evaluation of the Long-Term Stability of Nuclear Waste Form Borosilicate Glasses." Scientific Basis for Nuclear Waste Management VIII, Symposium held November 26-29, 1984, Boston, Massachusetts. Jantzen, C.M.; Stone, J.A.; and Ewing, R.C., eds. 44, 583-590. Pittsburgh, Pennsylvania: Materials Research Society. TIC: 203665.

166275 Canori, G.F. and Leitner, M.M. 2003. Project Requirements Document. TER-MGRMD-000001 REV 02. Las Vegas, Nevada: Bechtel SAIC Company. ACC: DOC.20031222.0006.

111011 Carroll, S.A.; Bourcier, W.L.; and Phillips, B.L. 1994. "Surface Chemistry and Durability of Borosilicate Glass." Scientific Basis for Nuclear Waste Management XVII, Symposium held November 29-December 3, 1993, Boston, Massachusetts. Barkatt, A. and Van Konynenburg, R.A., eds. 333, 533-540. Pittsburgh, Pennsylvania: Materials Research Society. TIC: 213541. 
163211 Crovisier, J.L.; Fritz, B.; Grambow, B.; and Eberhart, J.P. 1986. "Dissolution of Basaltic Glass in Seawater: Experiments and Thermodynamic Modelling." Scientific Basis for Nuclear Waste Management IX, Symposium held September 9-11, 1985, Stockholm, Sweden. Werme, L.O., ed. 50, 273-280. Pittsburgh, Pennsylvania: Materials Research Society. TIC: 203664.

163212 Crovisier, J.L.; Honnorez, J.; and Eberhart, J.P. 1987. "Dissolution of Basaltic Glass in Seawater: Mechanism and Rate." Geochimica et Cosmochimica Acta, 51, (11), 2977-2990. Elmsford, New York: Pergamon. TIC: 254331.

100362 CRWMS M\&O 1998. "Waste Form Degradation, Radionuclide Mobilization, and Transport Through the Engineered Barrier System." Chapter 6 of Total System Performance Assessment-Viability Assessment (TSPA-VA) Analyses Technical Basis Document. B00000000-01717-4301-00006 REV 01. Las Vegas, Nevada: CRWMS M\&O. ACC: MOL.19981008.0006.

101589 Cunnane, J.C.; Bates, J.K.; Bradley, C.R.; Buck, E.C.; Ebert, W.L.; Feng, X.; Mazer, J.J.; Wronkiewicz, D.J.; Sproull, J.; Bourcier, W.L.; McGrail, B.P.; and Altenhofen, M.K., eds. 1994. High-Level Waste Borosilicate Glass: A Compendium of Corrosion Characteristics. DOE-EM-0177. Volume 1. Washington, D.C.: U.S. Department of Energy. TIC: 242675.

164410 Curti, E. and Smith, P.A. 1991. "Enhancement of Borosilicate Glass Dissolution by Silica Sorption and Diffusion in Compacted Bentonite: A Model Study." Scientific Basis for Nuclear Waste Management XIV, Symposium held November 26-29, 1990, Boston Massachusetts. Abrajano, T.A., Jr. and Johnson, L.H., eds. 212, 31-39. Pittsburgh, Pennsylvania: Materials Research Society. TIC: 203656.

102773 Deer, W.A.; Howie, R.A.; and Zussman, J. 1966. An Introduction to the RockForming Minerals. New York, New York: John Wiley \& Sons. TIC: 245492.

111014 Delage, F. and Dussossoy, J.L. 1991. "R7T7 Glass Initial Dissolution Rate Measurements Using a High-Temperature Soxhlet Device." Scientific Basis for Nuclear Waste Management XIV, Symposium held November 26-29, 1990, Boston, Massachusetts. Abrajano, T., Jr. and Johnson, L.H., eds. 212, 41-47. Pittsburgh, Pennsylvania: Materials Research Society. TIC: 203656.

102812 DOE (U.S. Department of Energy) 1992. Characteristics of Potential Repository Wastes. DOE/RW-0184-R1. Volume 1. Washington, D.C.: U.S. Department of Energy, Office of Civilian Radioactive Waste Management. ACC: HQO.19920827.0001.

102589 DOE 1996. Waste Acceptance Product Specifications for Vitrified High-Level Waste Forms. DOE/EM-WAPS, Rev. 02. Washington, D.C.: U.S. Department of Energy. TIC: 234751. 
155622 DOE 2001. Integrated Safety Management Quality Assurance Program. Addendum 1, DOE/RW-0333P, Rev. 1. Washington, D.C.: U.S. Department of Energy, Office of Civilian Radioactive Waste Management. ACC: MOL.20010530.0147.

158398 DOE 2002. U.S. Department of Energy Spent Nuclear Fuel and High-Level Radioactive Waste to the Monitored Geologic Repository. Volume 1 of Integrated Interface Control Document. DOE/RW-0511 Rev. 01. Las Vegas, Nevada: U.S. Department of Energy. ACC: MOL.20020614.0342.

158873 DOE 2002. Waste Acceptance System Requirements Document. DOE/RW-0351, Rev. 4. Washington, D.C.: U.S. Department of Energy, Office of Civilian Radioactive Waste Management. ACC: MOL.20020326.0056.

171539 DOE 2004. Quality Assurance Requirements and Description. DOE/RW-0333P, Rev. 16. Washington, D.C.: U.S. Department of Energy, Office of Civilian Radioactive Waste Management. ACC: DOC.20040907.0002.

170920 Doremus, R.H. 1975. "Interdiffusion of Hydrogen and Alkali Ions in a Glass Surface." Journal of Non-Crystalline Solids, 19, 137-144. Amsterdam, The Netherlands: North-Holland. TIC: 256314.

171004 Durham, R.W. 1957. "Fission Product Disposal in Glass.” Report of Working Meeting on Fixation of Radioactivity in Stable, Solid Media at the Johns Hopkins University, June 19-21, 1957. TID-7550. 8-9. Oak Ridge, Tennessee: U.S. Atomic Energy Commission. ACC: MOL.20040804.0190.

145950 Ebert, W. 2000. "Interpretation/Analysis of Data in Ebert et al. 1998 in Support of ANL-EBS-MD-000016.” Memorandum from W. Ebert to File, February 18, 2000, with attachment. ACC: MOL.20000221.0326.

145944 Ebert, W. 2000. "Interpretation/Analysis of Data in McGrail and Peeler 1995 in Support of ANL-EBS-MD-000016.” Memorandum from W. Ebert to File, February 18, 2000, with attachment. ACC: MOL.20000221.0708.

164517 Ebert, W.L. 2003. "Data Report for MCC-1 Tests and PCTs with SRL 202G Glass." Memo from W.L. Ebert to File, July 24, 2003, with attachment.

ACC: MOL.20030728.0214; MOL.20030728.0215.

164518 Ebert, W.L. 2003. "Vapor Hydration Tests with DWPF Reference Glasses.” Memo from W.L. Ebert to File, July 24, 2003, with attachment. ACC: MOL.20030728.0211; MOL.20030728.0212.

164411 Ebert, W.L. and Bates, J.K. 1995. "The Corrosion Behavior of DWPF Glasses." Environmental Issues and Waste Management Technologies in the Ceramic and Nuclear Industries, Proceedings of the International Symposium on Environmental Issues and Waste Management Technologies in the Ceramic and Nuclear Industries, Presented at the 97th Annual Meeting of the American Ceramic Society, held in Cincinnati, May 1-3, 1995. Jain, V. and Palmer, R., eds. Ceramic Transactions 
Volume 61. Pages 479-488. Westerville, Ohio: American Ceramic Society. TIC: 254578.

113264 Ebert, W.L. and Bates, J.K. 1993. "A Comparison of Glass Reaction at High and Low Glass Surface/Solution Volume.” Nuclear Technology, 104, 372-384. Hinsdale, Illinois: American Nuclear Society. TIC: 246461.

171327 Ebert, W.L. and Mazer, J.J. 1994. "Laboratory Testing of Waste Glass Aqueous Corrosion: Effects of Experimental Parameters." Scientific Basis for Nuclear Waste Management XVII, Symposium Held November 29-December 3, 1993, Boston, Massachusetts. Barkatt, A, and Van Konynenburg, R.; eds. 333, 27-40. Pittsburgh, Pennsylvania: Materials Research Society. TIC: 213541.

111029 Ebert, W.L. and Tam, S.W. 1997. "Dissolution Rates of DWPF Glasses from LongTerm PCT." Scientific Basis for Nuclear Waste Management XX, Symposium held December 2-6, 1996, Boston, Massachusetts. Gray, W.J. and Triay, I.R., eds. 465, 149-156. Pittsburgh, Pennsylvania: Materials Research Society. TIC: 238884.

111023 Ebert, W.L.; Bakel, A.J.; and Brown, N.R. 1996. "Measurement of the Glass Dissolution Rate in the Presence of Alteration Phases." Proceedings of the International Topical Meeting on Nuclear and Hazardous Waste Management, Spectrum '96, August 18-23, 1996, Seattle, Washington. Pages 569-575. La Grange Park, Illinois: American Nuclear Society. TIC: 246748.

111026 Ebert, W.L.; Bates, J.K.; and Bourcier, W.L. 1991. "The Hydration of Borosilicate Waste Glass in Liquid Water and Steam at $200^{\circ}$ C." Waste Management, 11, 205-221. New York, New York: Pergamon Press. TIC: 246081.

111052 Ebert, W.L.; Bates, J.K.; Buck, E.C.; and Bradley, C.R. 1993. "Accelerated Glass Reaction Under PCT Conditions.” Scientific Basis for Nuclear Waste Management XVI, Symposium held November 30-December 4, 1992, Boston, Massachusetts. Interrante, C.G. and Pabalan, R.T., eds. 294, 569-576. Pittsburgh, Pennsylvania: Materials Research Society. TIC: 208880.

163248 Ebert, W.L.; Bates, J.K.; Gerding, T.J.; and Van Konynenburg, R.A. 1987. "The Effects of Gamma Radiation on Groundwater Chemistry and Glass Reaction in a Saturated Tuff Environment." Scientific Basis for Nuclear Waste Management X, Symposium held December 1-4, 1986, Boston, Massachusetts. Bates, J.K and Seefeldt, W.B., eds. 84, 613-622. Pittsburgh, Pennsylvania: Materials Research Society. TIC: 203663.

111027 Ebert, W.L.; Buck, E.C.; Luo, J.S.; Tam, S.W.; and Bates, J.K. 1998. Corrosion Behavior of Environmental Assessment Glass in Product Consistency Tests of Extended Duration. ANL-98/27. Argonne, Illinois: Argonne National Laboratory. TIC: 243543. 
111028 Ebert, W.L.; Hoburg, R.F.; and Bates, J.K. 1991. "The Sorption of Water on Obsidian and a Nuclear Waste Glass." Physics and Chemistry of Glasses, 32, (4), 133-137.

Sheffield, England: Society of Glass Technology. TIC: 246078.

163250 Ebert, W.L.; Lewis, M.A.; and Johnson, S.G. 2002. "The Precision of Product Consistency Tests Conducted with a Glass-Bonded Ceramic Waste Form.” Journal of Nuclear Materials, 305, (1), 37-51. New York, New York: North-Holland. TIC: 254330.

163249 Ebert, W.L.; Wolf, S.F.; and Bates, J.K. 1996. "The Release of Technetium from Defense Waste Processing Facility Glasses." Scientific Basis for Nuclear Waste Management XIX, Symposium held November 27-December 1, 1995, Boston, Massachusetts. Murphy, W.M. and Knecht, D.A., eds. 412, 221-227. Pittsburgh, Pennsylvania: Materials Research Society. TIC: 233877.

111030 Ellison, A.J.G.; Mazer, J.J.; and Ebert, W.L. 1994. Effect of Glass Composition on Waste Form Durability: A Critical Review. ANL-94/28. Argonne, Illinois: Argonne National Laboratory. TIC: 214163.

112115 Evans, M.; Hastings, N.; and Peacock, B. 1993. Statistical Distributions. 2nd Edition. New York, New York: John Wiley \& Sons. TIC: 246114.

163252 Fanning, T.H.; Ebert, W.L.; Frank, S.M.; Hash, M.C.; Morris, E.E.; Morss, L.R.; O'Holleran, T.P.; and Wigeland, R.A. 2003. Status of Ceramic Waste Form Degradation and Radionuclide Release Modeling. ANL-03/8. Argonne, Illinois: Argonne National Laboratory. TIC: 254324.

111031 Feng, X.; Bates, J.K.; Buck, E.C.; Bradley, C.R.; and Gong, M. 1993. "Long-Term Comparison of Dissolution Behavior Between Fully Radioactive and Simulated Nuclear Waste Glasses." Nuclear Technology, 104, 193-206. Chicago, Illinois: American Nuclear Society. TIC: 246075.

111033 Fortner, J.A. and Bates, J.K. 1996. "Long-Term Results from Unsaturated Durability Testing of Actinide-Doped DWPF and WVDP Waste Glasses." Scientific Basis for Nuclear Waste Management XIX, Symposium held November 27-December 1, 1995, Boston, Massachusetts. Murphy, W.M. and Knecht, D.A., eds. 412, 205-211. Pittsburgh, Pennsylvania: Materials Research Society. TIC: 233877.

163253 Friedman, I. and Long, W. 1976. "Hydration Rate of Obsidian.” Science, 191, 347352. Washington, D.C.: American Association for the Advancement of Science. TIC: 254343.

171328 Gin, S. and Frugier, P. 2003. "SON68 Glass Dissolution Kinetics at High Reaction Progress: Experimental Evidence of the Residual Rate." Scientific Basis for Nuclear Waste Management XXVI, Symposium held December 2-5, 2002, Boston, Massachusetts. Finch, R. and Bullen, D.; eds. 757, 175-182. Warrendale, Pennsylvania: Materials Research Society. TIC: 254940. 
171170 Gin, S. and Mestre, J.P. 2001. "SON 68 Nuclear Glass Alteration Kinetics Between pH 7 and pH 11.5." Journal of Nuclear Materials, 295, 83-96. New York, New York: Elsevier. TIC: 256395.

163254 Gin, S.; Godon, N.; Mestre, J.P.; Vernaz, E.Y.; and Beaufort, D. 1994. "Experimental Investigation of Aqueous Corrosion of R7T7 Nuclear Glass at $90^{\circ} \mathrm{C}$ in the Presence of Organic Species.” Applied Geochemistry, 9, (3), 255-269. New York, New York: Pergamon. TIC: 254470.

163256 Gin, S.; Jollivet, P.; Mestre, J.P.; Jullien, M.; and Pozo, C. 2001. "French SON 68 Nuclear Glass Alteration Mechanisms on Contact with Clay Media." Applied Geochemistry, 16, (7-8), 861-881. New York, New York: Pergamon. TIC: 254342.

163255 Gin, S.; Ribet, I.; and Couillard, M. 2001. "Role and Properties of the Gel Formed During Nuclear Glass Alteration: Importance of Gel Formation Conditions.” Journal of Nuclear Materials, 298, (1-2), 1-10. New York, New York: North-Holland. TIC: 254320.

171003 Goldman, M.I.; Servizi, J.A.; Lauderdale, R.A.; and Eliassen, R. 1957. "Fixation of Fission Products in Ceramic Glazes." Report of Working Meeting on Fixation of Radioactivity in Stable, Solid Media at the Johns Hopkins University, June 19-21, 1957. TID-7550. 6-8. Oak Ridge, Tennessee: U.S. Atomic Energy Commission. ACC: MOL.20040804.0190.

158976 Gong, W.L.; Wang, L.M.; Ewing, R.C.; Vernaz, E.; Bates, J.K.; and Ebert, W.L. 1998. "Analytical Electron Microscopy Study of Surface Layers Formed on the French SON68 Nuclear Waste Glass During Vapor Hydration at 200 C." Journal of Nuclear Materials, 254, (2-3), 249-265. New York, New York: Elsevier.

TIC: 252351.

163257 Grambow, B. 1985. "A General Rate Equation for Nuclear Waste Glass Corrosion." Scientific Basis for Nuclear Waste Management VIII, Symposium held November 2629, 1984, Boston, Massachusetts. Jantzen, C.M.; Stone, J.A.; and Ewing, R.C., eds. 44, 15-27. Pittsburgh, Pennsylvania: Materials Research Society. TIC: 203665.

118987 Grambow, B. 1984. Ein Physikalisch-Chemisches Modell fur den Mechanismus der Glaskorrosion-Unter Besonderer Berucksichtigung Simulierter Radioaktiver Abfallglaser. Doctorate in Chemistry. Berlin, Germany: Freien Universitat Berlin. TIC: 225985.

171412 Grambow, B. and Müller, R. 2001. "First-Order Dissolution Rate Law and the Role of Surface Layers in Glass Performance Assessment." Journal of Nuclear Materials, 298, 112-124. New York, New York: Elsevier. TIC: 256444.

163258 Grambow, B.; Jercinovic, M.J.; Ewing, R.C.; and Byers, C.D. 1986. "Weathered Basalt Glass: A Natural Analogue for the Effects of Reaction Progress on Nuclear Waste Glass Alteration.” Scientific Basis for Nuclear Waste Management IX, 
Symposium held September 9-11, 1985, Stockholm, Sweden. Werme, L.O., ed. 50, 263-272. Pittsburgh, Pennsylvania: Materials Research Society. TIC: 203664.

119131 Grambow, B.; Lutze, W.; and Muller, R. 1992. "Empirical Dissolution Rate law for the Glass R7T7 Contacting Halite- and Silica-Saturated Brines." Scientific Basis for Nuclear Waste Management XV, Symposium held November 4-7, 1991, Strasbourg, France. Sombret, C.G., ed. 257, 143-150. Pittsburgh, Pennsylvania: Materials Research Society. TIC: 204618.

104945 Greenspan, L. 1977. "Humidity Fixed Points of Binary Saturated Aqueous Solutions." Journal of Research of the National Bureau of Standards, 81A, (1), 89-96. Washington, D.C.: U.S. Department of Commerce. TIC: 241138.

111034 Hagymassy, J., Jr.; Brunauer, S.; and Mikhail, R.Sh. 1969. "Pore Structure Analysis by Water Vapour Absorption. Part 1. T-Curves for Water Vapour." Journal of Colloid and Interface Science, 29, (3), 485-491. New York, New York: Academic Press. TIC: 246076.

163259 Jantzen, C.M. and Bickford, D.F. 1985. "Leaching of Devitrified Glass Containing Simulated SRP Nuclear Waste.” Scientific Basis for Nuclear Waste Management VIII, Symposium held November 26-29, 1984, Boston, Massachusetts. Jantzen, C.M.; Stone, J.A.; and Ewing, R.C., eds. 44, 135-146. Pittsburgh, Pennsylvania: Materials Research Society. TIC: 203665.

163260 Jégou, C.; Gin, S.; and Larché, F. 2000. “Alteration Kinetics of a Simplified Nuclear Glass in an Aqueous Medium: Effects of Solution Chemistry and of Protective Gel Properties on Diminishing the Alteration Rate." Journal of Nuclear Materials, 280, (2), 216-229. New York, New York: North-Holland. TIC: 254325.

163261 Jeong, S.-Y.; Fanning, T.H.; Morss, L.R.; and Ebert, W.L. 2002. Corrosion Tests to Determine Temperature and $\mathrm{pH}$ Dependencies of the Dissolution Rates of Sodalite, Binder Glass, and Ceramic Waste Form. ANL-02/32. Argonne, Illinois: Argonne National Laboratory. TIC: 254323.

163262 Jiricka, A.; Vienna, J.D.; Hrma, P.; and Strachan, D.M. 2001. "The Effect of Experimental Conditions and Evaluation Techniques on the Alteration of Low Activity Glasses by Vapor Hydration.” Journal of Non-Crystalline Solids, 292, (1-3), 25-43. New York, New York: North-Holland. TIC: 254327.

101701 Knauss, K.G.; Bourcier, W.L.; McKeegan, K.D.; Merzbacher, C.I.; Nguyen, S.N.; Ryerson, F.J.; Smith, D.K.; Weed, H.C.; and Newton, L. 1990. "Dissolution Kinetics of a Simple Analogue Nuclear Waste Glass as a Function of $\mathrm{pH}$, Time and Temperature." Scientific Basis for Nuclear Waste Management XIII, Symposium held November 27-30, 1989, Boston, Massachusetts. Oversby, V.M. and Brown, P.W., eds. 176, 371-381. Pittsburgh, Pennsylvania: Materials Research Society. TIC: 203658. 
141616 Lasaga, A.C. 1983. "Rate Laws of Chemical Reactions." Chapter 1 of Kinetics of Geochemical Processes. Lasaga, A.C. and Kirkpatrick, R.J., eds. Reviews in Mineralogy Volume 8. Washington, D.C.: Mineralogical Society of America. TIC: 239318.

163265 Lasaga, A.C. and Gibbs, G.V. 1990. “Ab-Initio Quantum Mechanical Calculations of Water-Rock Interactions: Adsorption and Hydrolysis Reactions." American Journal of Science, 290, (3), 263-295. New Haven, Connecticut: Yale University, Kline Geology Laboratory. TIC: 236214.

171169 Lemmens, K.; Aertsens, M.; Pirlet, V.; Maes, N.; Moors, H.; and Van Iseghem, P. 2003. "Measurement of Glass Corrosion in Boom Clay Disposal Conditions: First Results of the Experimental Programme 2000-2003 of SCK.CEN." Proceeding of ICEM'03: The 9th International Conference on Environmental Remediation and Radioactive Waste Management, September 21-25, 2003, Examination Schools, Oxford England. ICEM03-4774, 1-8. New York, New York: American Society of Mechanical Engineers. TIC: 256387.

163267 Lewis, M.A.; Hash, M.C.; Hebden, A.S.; and Ebert, W.L. 2002. Tests with Ceramic Waste Form Materials Made by Pressureless Consolidation. ANL-02/10. Argonne, Illinois: Argonne National Laboratory. TIC: 254322.

163268 Li, H.; Darab, J.G.; Matson, D.W.; Smith, P.A.; Hrma, P.; Chen, Y.; and Liu, J. 1996. "Phosphate-Sulfate Interaction in Simulated Low-Level Radioactive Waste Glasses." Scientific Basis for Nuclear Waste Management XIX, Symposium held November 27December 1, 1995, Boston, Massachusetts. Murphy, W.M. and Knecht, D.A., eds. 412, 141-148. Pittsburgh, Pennsylvania: Materials Research Society. TIC: 233877.

171167 Li, H.; Hrma, P.; Vienna, J.D.; Qian, M.; Su, Y.; and Smith, D.E. 2003. "Effects of $\mathrm{Al}_{2} \mathrm{O}_{3}, \mathrm{~B}_{2} \mathrm{O}_{3}, \mathrm{Na}_{2} \mathrm{O}$, and $\mathrm{SiO}_{2}$ on Nepheline Formation in Borosilicate Glasses: Chemical and Physical Correlations." Journal of Non-Crystalline Solids, 331, 202216. New York, New York: Elsevier. TIC: 256394.

163269 Li, H.; Vienna, J.D.; Hrma, P.; Smith, D.E.; and Schweiger, M.J. 1997. "Nepheline Precipitation in High-Level Waste Glasses: Compositional Effects and Impact on the Waste Form Acceptability." Scientific Basis for Nuclear Waste Management XX, Symposium held December 2-6, 1996, Boston, Massachusetts. Gray, W.J. and Triay, I.R., eds. 465, 261-268. Pittsburgh, Pennsylvania: Materials Research Society. TIC: 238884.

163271 Luo, J.S.; Ebert, W.L.; Mazer, J.J.; and Bates, J.K. 1997. "Simulation of Natural Corrosion by Vapor Hydration Test: Seven-Year Results." Scientific Basis for Nuclear Waste Management XX, Symposium held December 2-6, 1996, Boston, Massachusetts. Gray, W.J. and Triay, I.R., eds. 465, 157-163. Pittsburgh, Pennsylvania: Materials Research Society. TIC: 238884.

171176 Mann, F.M.; Puigh, R.J.; Rittmann, P.D.; Kline, N.W.; Voogd, J.A.; Chen, Y.; Eiholzer, C.R.; Kincaid, C.T.; McGrail, B.P.; Lu, A.H.; Williamson, G.F.; Brown, 
N.R.; and LaMont, P.E. 1998. Hanford Immobilized Low-Activity Tank Waste Performance Assessment. DOE/RL-97-69. Richland, Washington: U.S. Department of Energy. ACC: MOL.20040811.0165.

153974 McGrail, B.P.; Ebert, W.L.; Bacon, D.H.; and Strachan, D.M. 1998. A Strategy to Conduct an Analysis of the Long-Term Performance of Low-Activity Waste Glass in a Shallow Subsurface Disposal System at Hanford. PNNL-11834. Richland, Washington: Pacific Northwest National Laboratory. TIC: 249433.

111039 McGrail, B.P.; Ebert, W.L.; Bakel, A.J.; and Peeler, D.K. 1997. "Measurement of Kinetic Rate Law Parameters on a Na-Ca-Al Borosilicate Glass for Low-Activity Waste." Journal of Nuclear Materials, 249, 175-189. Amsterdam, The Netherlands: Elsevier. TIC: 246080.

163272 McGrail, B.P.; Icenhower, J.P.; and Rodriguez, E.A. 2002. "Origins of Discrepancies Between Kinetic Rate Law Theory and Experiments in the $\mathrm{Na}_{2} \mathrm{O}-\mathrm{B}_{2} \mathrm{O}_{3}-\mathrm{SiO}_{2}$ System." Scientific Basis for Nuclear Waste Management XXV, Symposium held November 2629, 2001, Boston, Massachusetts. McGrail, B.P. and Cragnolino, G.A., eds. 713, 537546. Warrendale, Pennsylvania: Materials Research Society. TIC: 248663.

171165 McGrail, B.P.; Icenhower, J.P.; Shuh, D.K.; Liu, P.; Darab, J.G.; Baer, D.R.; Thevuthasen, S.; Shutthanandan, V.; Engelhard, M.H.; Booth, C.H.; and Nachimuthu, P. 2001. "The Structure of $\mathrm{Na}_{2} \mathrm{O}-\mathrm{Al}_{2} \mathrm{O}_{3}-\mathrm{SiO}_{2}$ Glass: Impact on Sodium Ion Exchange in $\mathrm{H}_{2} \mathrm{O}$ and $\mathrm{D}_{2} \mathrm{O}$." Journal of Non-Crystalline Solids, 296, 10-26. New York, New York: Elsevier. TIC: 256393.

111040 McGrail, B.P.; Martin, P.F.; and Lindenmeier, C.W. 1997. "Accelerated Testing of Waste Forms Using a Novel Pressurized Unsaturated Flow (PUF) Method." Scientific Basis for Nuclear Waste Management XX, Symposium held December 2-6, 1996, Boston, Massachusetts. Gray, W.J. and Triay, I.R., eds. 465, 253-260. Pittsburgh, Pennsylvania: Materials Research Society. TIC: 238884.

171174 McGrail, B.P.; Pederson, L.R.; Strachan, D.M.; Ewing, R.C.; and Cordell, L.S. 1988. "Obsidian Hydration Dating - Field, Laboratory, and Modeling Results." Scientific Basis for Nuclear Waste Management. 122, 263-269. Pittsburgh, Pennsylvania: Materials Research Society. TIC: 256448.

101728 McVay, G.L. and Buckwalter, C.Q. 1983. "Effect of Iron on Waste-Glass Leaching." Journal of the American Ceramic Society, 66, (3), 170-174. Westerville, Ohio: American Ceramic Society. TIC: 238912.

163273 Morss, L.R.; Johnson, S.G.; Ebert, W.L.; DiSanto, T.; Frank, S.M.; Holly, J.L.; Kropf, A.J.; Mertz, C.J.; Noy, M.; O'Holleran, T.P.; Richmann, M.K.; Sinkler, W.; Tsai, Y.; and Warren, A.R. 2002. Corrosion Tests with Uranium- and PlutoniumLoaded Ceramic Waste Forms. ANL-02/9. Argonne, Illinois: Argonne National Laboratory. TIC: 254321. 
163274 NRC (U.S. Nuclear Regulatory Commission) 2003. Yucca Mountain Review Plan, Final Report. NUREG-1804, Rev. 2. Washington, D.C.: U.S. Nuclear Regulatory Commission, Office of Nuclear Material Safety and Safeguards. TIC: 254568.

163276 Oversby, V.M. 1982. Leach Testing of Waste Forms--Interrelationship of ISO and MCC - Type Tests. UCRL-87621 (Preprint). Livermore, California: Lawrence Livermore National Laboratory. TIC: 230301.

111042 Patyn, J.; Van Iseghem, P.; and Timmermans, W. 1990. "The Long-Term Corrosion and Modeling of Two Simulated Belgian Reference High-Level Waste Glasses-Part II." Scientific Basis for Nuclear Waste Management XIII, Symposium held November 27-30, 1989, Boston, Massachusetts. Oversby, V.M. and Brown, P.W., eds. 176, 299307. Pittsburgh, Pennsylvania: Materials Research Society. TIC: 203658.

118927 Pederson, L.R.; Buckwalter, C.Q.; and McVay, G.L. 1983. "The Effects of Surface Area to Solution Volume on Waste Glass Leaching." Nuclear Technology, 62, 151158. Washington, D.C.: American Nuclear Society. TIC: 246083.

111044 Perez, J.M., Jr. and Westsik, J.H., Jr. 1981. "Effects of Cracks on Glass Leaching." Nuclear and Chemical Waste Management, 2, 165-168. New York, New York: Pergamon Press. TIC: 246072.

163280 Reynolds, J.G. and Hrma, P. 1997. "The Kinetics of Spinel Crystallization from a High-Level Waste Glass.” Scientific Basis for Nuclear Waste Management XX, Symposium held December 2-6, 1996, Boston, Massachusetts. Gray, W.J. and Triay, I.R., eds. 465, 65-69. Pittsburgh, Pennsylvania: Materials Research Society. TIC: 238884.

170919 Schneider, K.J. 1971. "Solidification and Disposal of High-Level Radioactive Wastes in the United States." Reactor Technology, 13, (4), 387-415. Washington, D.C.: Atomic Energy Commission. TIC: 256351.

163283 Sené, M.R.; Baily, M.; Illerhaus, B.; Goebbels, J.; Haase, O.; Kulish, A.; Godon, N.; and Choucan, J.L. 1999. Characterisation of Accessible Surface Area of HLW Glass Monoliths by High Energy Accelerator Tomography and Comparison with Conventional Techniques. EUR 19119 EN. Luxembourg, Luxembourg: Commission of the European Communities. TIC: 254444.

163284 Smith, G.L. and Marschman, S.C. 1994. "Nuclear Waste Analytical Round Robins 16 Summary Report." Scientific Basis for Nuclear Waste Management XVII, Symposium held November 29-December 3, 1993, Boston, Massachusetts. Barkatt, A. and Van Konynenberg, R.A., eds. 333, 461-472. Pittsburgh, Pennsylvania: Materials Research Society. TIC: 213541.

102089 Smith, P.K. and Baxter, C.A. 1981. Fracture During Cooling of Cast Borosilicate Glass Containing Nuclear Wastes. DP-1602. Aiken, South Carolina: E.I. Du Pont de Nemours \& Company, Savannah River Laboratory. TIC: 238536. 
102088 Smith, T.H. and Ross, W.A. 1975. Impact Testing of Vitreous Simulated High-Level Waste in Canisters. BNWL-1903. Richland, Washington: Battelle Pacific Northwest Laboratories. TIC: 238924.

111047 Stout, R.B. and Leider, H.R. 1998. Waste Form Characteristics Report, CD-ROM Version. UCRL-ID-132375. Livermore, California: Lawrence Livermore National Laboratory. TIC: 246106.

163327 Strachan, D.M. and Croak, T.L. 2000. "Compositional Effects on Long-Term Dissolution of Borosilicate Glass." Journal of Non-Crystalline Solids, 272, (1), 22-33. New York, New York: North-Holland. TIC: 254326.

100829 Stumm, W. and Morgan, J.J. 1981. Aquatic Chemistry, An Introduction Emphasizing Chemical Equilibria in Natural Waters. 2nd Edition. New York, New York: John Wiley \& Sons. TIC: 208448.

171283 Swedish Nuclear Fuel and Waste Management 1999. Deep Repository for Spent Nuclear Fuel, SR 97 - Post-Closure Safety. Main Report Summary. SKB TR-99-06. Stockholm, Sweden: Swedish Nuclear Fuel and Waste Management. TIC: 246421.

171005 Thomas, R.G. and Christenson, C.W. 1957. "Leaching Studies on Fired Clays Containing Radionuclides." Report of Working Meeting on Fixation of Radioactivity in Stable, Solid Media at the Johns Hopkins University, June 19-21, 1957. TID-7550. 10-14. Oak Ridge, Tennessee: U.S. Atomic Energy Commission. ACC: MOL.20040804.0190.

164412 Tomozawa, H. and Tomozawa, M. 1989. "Diffusion of Water into a Borosilicate Glass.” Journal of Non-Crystalline Solids, 109, (2-3), 311-317. New York, New York: North-Holland. TIC: 254577.

111048 Van Iseghem, P. and Grambow, B. 1988. "The Long-Term Corrosion and Modeling of Two Simulated Belgian Reference High-Level Waste Glasses.” Scientific Basis for Nuclear Waste Management XI, Symposium held November 30-December 3, 1987, Boston, Massachusetts. Apted, M.J. and Westerman, R.E., eds. 112, 631-639. Pittsburgh, Pennsylvania: Materials Research Society. TIC: 203662.

163328 Vernaz, E.; Gin, S.; Jégou, C.; and Ribet, I. 2001. "Present Understanding of R7T7 Glass Alteration Kinetics and Their Impact on Long-Term Behavior Modeling." Journal of Nuclear Materials, 298, (1-2), 27-36. New York, New York: NorthHolland. TIC: 254328.

100942 Vernon, W.H.J. 1933. "The Role of the Corrosion Product in the Atmospheric Corrosion of Iron." Transactions of the Electrochemical Society. Volume LXIV. Pages 31-41. New York, New York: Electrochemical Society. TIC: 237703.

163330 Vienna, J.D.; Hrma, P.; and Smith, D.E. 1997. "Isothermal Crystallization Kinetics in Simulated High-Level Nuclear Waste Glass." Scientific Basis for Nuclear Waste Management XX, Symposium held December 2-6, 1996, Boston, Massachusetts. 
Gray, W.J. and Triay, I.R., eds. 465, 17-24. Pittsburgh, Pennsylvania: Materials Research Society. TIC: 238884.

163331 Vienna, J.D.; Hrma, P.; Crum, J.V.; and Mika, M. 2001. "Liquidus TemperatureComposition Model for Multi-Component Glasses in the Fe, Cr, Ni, and Mn Spinel Primary Phase Field.” Journal of Non-Crystalline Solids, 292, (1-3), 1-24. New York, New York: North-Holland. TIC: 254329.

171276 Wallace, R.M. and Wicks, G.G. 1983. "Leaching Chemistry of Defense Borosilicate Glass." Scientific Basis for Nuclear Waste Management VI, Symposium held November 1-4, 1982, Boston, Massachusetts. Brookins, D.G., ed. 15, 23-28. New York, New York: Elsevier. TIC: 204396.

106266 Weast, R.C., ed. 1977. CRC Handbook of Chemistry and Physics. 58th Edition. Cleveland, Ohio: CRC Press. TIC: 242376.

163346 Werme, L.; Björner, I.K.; Bart, G.; Zwicky, H.U.; Grambow, B.; Lutze, W.; Ewing, R.C.; and Magrabi, C. 1990. "Chemical Corrosion of Highly Radioactive Borosilicate Nuclear Waste Glass Under Simulated Repository Conditions.” Journal of Material Research, 5, (5), 1130-1146. Warrendale, Pennsylvania: Materials Research Society. TIC: 254313.

111049 White, W.B. 1986. Dissolution Mechanisms of Nuclear Waste Glasses: A Critical Review. Volume 20 of Nuclear Waste Management II. Westerville, Ohio: American Ceramic Society. TIC: 246079.

163349 Wicks, G.G. 1992. "Nuclear Waste Glasses: Corrosion Behavior and Field Tests." Chapter 7 of Corrosion of Glass, Ceramics and Ceramic Superconductors, Principles, Testing, Characterization and Applications. Clark, D.E. and Zoitos, B.K., eds. Park Ridge, New Jersey: Noyes Publications. TIC: 229453.

163350 Wronkiewicz, D.J.; Bates, J.K.; Buck, E.C.; Hoh, J.C.; Emery, J.W.; and Wang, L.M. 1997. Radiation Effects in Moist-Air Systems and the Influence of Radiolytic Product Formation on Nuclear Waste Glass Corrosion. ANL-97/15. Argonne, Illinois:

Argonne National Laboratory. TIC: 234821.

163351 Zoitos, B.K.; Clark, D.E.; Lodding, A.R.; and Wicks, G.G. 1989. "Correlation of Laboratory and Stripa Field Leaching Studies." Scientific Basis for Nuclear Waste Management XII, Symposium held October 10-13, 1988, Berlin, Germany. Lutze, W. and Ewing, R.C., eds. 127, 145-151. Pittsburgh, Pennsylvania: Materials Research Society. TIC: 203660.

\subsection{CODES, STANDARDS, REGULATIONS, AND PROCEDURES}

10354010 CFR 60. Energy: Disposal of High-Level Radioactive Wastes in Geologic Repositories. Readily available. 
15660510 CFR 63. Energy: Disposal of High-Level Radioactive Wastes in a Geologic Repository at Yucca Mountain, Nevada. Readily available.

AP-2.27Q, Rev. 1, ICN 4. Planning for Science Activities. Washington, D.C.: U.S. Department of Energy, Office of Civilian Radioactive Waste Management. ACC: DOC.20040610.0006.

AP-3.15Q, Rev. 4, ICN 5. Managing Technical Product Inputs. Washington, D.C.: U.S. Department of Energy, Office of Civilian Radioactive Waste Management. ACC: DOC.20040812.0004.

AP-SIII.2Q, Rev. 1, ICN 2. Qualification of Unqualified Data. Washington, D.C.: U.S. Department of Energy, Office of Civilian Radioactive Waste Management. ACC: DOC.20040127.0008.

AP-SIII.10Q, Rev. 2, ICN 7. Models. Washington, D.C.: U.S. Department of Energy, Office of Civilian Radioactive Waste Management. ACC: DOC.20040920.0002.

105725 ASTM C 1174-97. 1998. Standard Practice for Prediction of the Long-Term Behavior of Materials, Including Waste Forms, Used in Engineered Barrier Systems (EBS) for Geological Disposal of High-Level Radioactive Waste. West Conshohocken, Pennsylvania: American Society for Testing and Materials. TIC: 246015.

119321 ASTM C 1220-98. 1998. Standard Test Method for Static Leaching of Monolithic Waste Forms for Disposal of Radioactive Waste. West Conshohocken, Pennsylvania: American Society for Testing and Materials. TIC: 247005.

163205 ASTM C 1285-02. 2002. Standard Test Methods for Determining Chemical Durability of Nuclear, Hazardous, and Mixed Waste Glasses and Multiphase Glass Ceramics: The Product Consistency Test (PCT). West Conshohocken, Pennsylvania: American Society for Testing and Materials. TIC: 254461.

LP-SI.11Q-BSC, Rev. 00, ICN 01. Software Management. Washington, D.C.: U.S. Department of Energy, Office of Civilian Radioactive Waste Management. ACC: DOC.20041005.0008.

\subsection{SOURCE DATA, LISTED BY DATA TRACKING NUMBER}

164329 MO0306ANLGIM01.525. Glass Immersion Test Results (BSC Test Plan: SITP-02WF-002); Concentrations and pH. Submittal date: 06/12/2003.

164330 MO0306ANLGIM02.525. Glass Immersion Test Results (BSC Test Plan: SITP-02WF-002); Normalized Mass Losses. Submittal date: 06/12/2003.

164331 MO0306ANLGVH01.526. Glass Vapor Hydration Test Results (BSC Test Plan: SITP-02-WF-002). Submittal date: 06/12/2003. 
164790 MO0308ANLGPC01.528. Immersion Tests for Glass Composition Dependence. Submittal date: 08/15/2003.

171277 MO0407ANLGNN02.608. Normalized Mass Losses of Radionuclides In N2 Tests. Submittal date: 07/27/2004.

170760 MO0407SEPFEPLA.000. LA FEP List. Submittal date: 07/20/2004.

171574 MO0408ANLGNN01.527. Glass Unsaturated (Drip) Test Results (BSC Test Plan: SITP-02-WF-002): Boron Release. Submittal date: 08/26/2004.

\subsection{OUTPUT DATA, LISTED BY DATA TRACKING NUMBER}

MO0409ANLGAMR1.016. HLW Glass Degradation Model. Submittal date: 09/10/2004.

MO0307ANLGAMR3.016. Excel Spreadsheets for Calculations in HLW Glass Degradation Model. Submittal date: 07/25/2003. 


\section{APPENDIX A \\ pH AND TEMPERATURE DEPENDENCE OF THE FORWARD DISSOLUTION RATE OF SRL 202G GLASS}




\section{INTENTIONALLY LEFT BLANK}




\section{A. pH AND TEMPERATURE DEPENDENCE OF THE FORWARD DISSOLUTION RATE OF SRL 202G GLASS}

Tests were conducted specifically to measure the effect of $\mathrm{pH}$ and temperature on the forward dissolution rate of a glass having a composition within the composition envelope for DWPF glasses. The glass is referred to as SRL $202 \mathrm{G}$ and the composition is given in Table A-1 (DTN: MO0306ANLGIM02.525 [DIRS 164330], Table 1). The glass contains depleted uranium, but no other radionuclides. The tests are described in detail in (Ebert 2003 [DIRS 164517]). A modified static leach test method standardized by the American Society for Testing and Materials (ASTM) as standard test method C1220-98 was used to conduct the tests. In this method, a monolithic glass sample of known geometric surface area is immersed in a test solution in a sealed vessel for a predetermined duration. At the end of the test duration, the solution is analyzed for dissolved glass components, which are used as a measure of the extent of dissolution. Tests were conducted at $70^{\circ} \mathrm{C}$ and $90^{\circ} \mathrm{C}$. The modification to the ASTM method C1220-98 was that tests were conducted in leachant solutions having $\mathrm{pH}$ values imposed by added salts (Table A-2). Some leachant solutions were made with added $\mathrm{FeCl}_{3}, \mathrm{FeOOH}, \mathrm{Fe}_{2} \mathrm{O}_{3}$, or $\mathrm{Fe}_{3} \mathrm{O}_{4}$ to measure the effect of dissolved iron and the presence of iron corrosion products on the forward dissolution rate. The mass of each iron compound needed to make a 0.1 molal solution was added to the leachant, although only the $\mathrm{FeCl}_{3}$ completely dissolved. Undissolved $\mathrm{FeOOH}, \mathrm{Fe}_{2} \mathrm{O}_{3}$, or $\mathrm{Fe}_{3} \mathrm{O}_{4}$ particles were included in the tests to ensure the solutions remained saturated with respect to these oxides.

Monolithic samples were in shape of disks nominally $1 \mathrm{~cm}$ in diameter and $1.5-\mathrm{mm}$ thick. The faces of the disks were polished with silicon carbide paper and water lubrication to a 600-grit final finish. All tests were conducted in Teflon ${ }^{\circledR}$ vessels with sample-support stands made of Teflon mesh. Because it was expected that glass dissolution would be faster at very low and very high $\mathrm{pH}$ values, tests at $\mathrm{pH} 1$ and $\mathrm{pH} 11.9$ were conducted at a surface area-to-solution volume ratio $(\mathrm{S} / \mathrm{V})$ of $2.0 \mathrm{~m}^{-1}$ in $120 \mathrm{~mL}$ Teflon vessels. Tests at other $\mathrm{pH}$ values were conducted at an $\mathrm{S} / \mathrm{V}$ of $10 \mathrm{~m}^{-1}$ in $22 \mathrm{~mL}$ vessels. Blank tests were conducted in 22-mL Teflon vessels for 10 and 21 days at $90^{\circ} \mathrm{C}$ and for 7 days at $70^{\circ} \mathrm{C}$. Short test durations and low glass $\mathrm{S} / \mathrm{V}$ were used to maintain low concentrations of dissolved silica in the tests. At the end of the scheduled test duration, an aliquot of the test solution was taken for $\mathrm{pH}$ measurement. The $\mathrm{pH}$ of this aliquot was measured at room temperature with a combination electrode. The remaining test solution was passed through a $0.45 \mu \mathrm{m}$ pore-size filter and then acidified with ultrapure nitric acid. Solutions were analyzed for concentrations of $\mathrm{Al}, \mathrm{B}, \mathrm{Fe}, \mathrm{Na}, \mathrm{Si}$, and $\mathrm{U}$ with inductively coupled plasma-mass spectrometry (ICP-MS).

Table A-3 gives the concentrations measured in blank tests in units of parts per billion (ppb), which is equivalent to micrograms/liter solution (DTN: MO0306ANLGIM01.525 [DIRS 164329], Table 4). These results show that, except for tests B1Fe-10, B1Fe-21, and B7Fe-10 (nominal pH 1.0 and pH 3.7 solutions), only a small amount of the added iron actually dissolved. For tests in which $\mathrm{pH}$ was greater than 3.7, the primary effect was the inclusion of iron precipitates in the test.

The test results are summarized in Tables A-4, A-5, and A-6 (DTN: MO0306ANLGIM01.525 [DIRS 164329], Tables 1-3). The results are grouped by the nominal solution $\mathrm{pH}$. As mentioned above, an amount of the iron compound needed to make a 0.1 molal solution was added to the 
leachant solution. Whereas the $\mathrm{FeCl}_{3}$ almost completely dissolved, very little of the oxides dissolved. When leachant solutions were added to the test vessels, small amounts of the finely divided iron compound solids were added to the test vessels. This was done to provide a source to maintain saturated iron concentrations during the tests. The test solutions were filtered when the tests were terminated to exclude this iron from the aliquot submitted for analyses.

The 1-day tests at $70^{\circ} \mathrm{C}$ were conducted at $\mathrm{S} / \mathrm{V}$ of about $8 \mathrm{~m}^{-1}$ for durations that would allow direct comparison with tests conducted at $10 \mathrm{~m}^{-1}$. The 1 -day tests at $70^{\circ} \mathrm{C}$ and $\mathrm{pH}$ values of 1.3 and 11.9 were conducted for about 6 hours $(0.25$ days $)$. Solutions generated in these tests are equivalent to 1-day tests at $2 \mathrm{~m}^{-1}$, since the product of $\mathrm{S} / \mathrm{V}$ and reaction time is $2 \mathrm{~d} / \mathrm{m}$ for both conditions. Likewise, the tests at other $\mathrm{pH}$ values were conducted for 30 hours (1.25 days) at $\mathrm{S} / \mathrm{V}$ of about $8 \mathrm{~m}^{-1}$, so the product of $\mathrm{S} / \mathrm{V}$ and reaction time is about $10 \mathrm{~d} / \mathrm{m}$. The results of tests at all $\mathrm{pH}$ values are treated as 1-day tests at $10 \mathrm{~m}^{-1}$ and directly compared with longer duration tests at $10 \mathrm{~m}^{-1}$ for data analysis.

The normalized boron mass loss, NL(B), was calculated from the measured concentrations from the following equation:

$$
\mathrm{NL}(\mathrm{B})=\left[\mathrm{C}(\mathrm{B})-\mathrm{C}^{\circ}(\mathrm{B})\right] \times 1,000 /(\mathrm{S} / \mathrm{V}) \times \mathrm{f}(\mathrm{B})
$$

Where $\mathrm{C}(\mathrm{B})$ is the $\mathrm{B}$ concentration $(\mu \mathrm{g} / \mathrm{L}[\mathrm{ppb}])$ in the leachate, $\mathrm{C}^{\circ}(\mathrm{B})$ is the boron concentration $(\mu \mathrm{g} / \mathrm{L})$ in the blank at the same temperature and for the same or longer duration, and $f(B)$ is the mass fraction of $\mathrm{B}$ in the glass (see Table A-1). The factor of 1,000 is the conversion factor $1 \times 10^{3}\left(\mathrm{~g} / \mathrm{m}^{3}\right) /(\mu \mathrm{g} / \mathrm{L})$. The values of $N \mathrm{~L}(\mathrm{~B})$ for tests at $70^{\circ} \mathrm{C}, 90^{\circ} \mathrm{C}$, and $90^{\circ} \mathrm{C}$ with added iron are summarized in Table A-7 (DTN: MO0306ANLGIM02.525 [DIRS 164329], Tables 2 to 4). The values of NL(B) are plotted against the test duration in Figures A-1, A-2, and A-3 for tests at $70^{\circ} \mathrm{C}, 90^{\circ} \mathrm{C}$, and $90^{\circ} \mathrm{C}$ with added iron, respectively. Results from the short-term tests were fit to a line to estimate the dissolution rate before the buildup of dissolved silica became significant. The origin was not included in the regression. This is because rapid dissolution of high-energy sites on the as-prepared surfaces results in a nonrepresentative rate early in the test. Longer-term results that deviated negatively from the line were excluded from the regression; those results were affected by the buildup of silica in the test solutions. The rate-limiting step in the mechanism for the dissolution of silicate glasses involves the neutral species $\mathrm{H}_{4} \mathrm{SiO}_{4}$ (see discussion in Section 6.3). Because the mono- and then double-negatively charged silicic acid species become dominant at $\mathrm{pH}$ values above about $\mathrm{pH} 9.7\left(\right.$ at $\left.90^{\circ} \mathrm{C}\right)$, a higher total silica concentration must be present to have the same $\mathrm{H}_{4} \mathrm{SiO}_{4}$ concentration as at lower $\mathrm{pH}$ values. This is seen in the results of tests conducted at $70^{\circ} \mathrm{C}$ and $90^{\circ} \mathrm{C}$ with and without added $\mathrm{FeOOH}$ (Figures A-2f and A-3f). The slope of the fit line gives the normalized B-release rate, NR(B), which is defined as:

$$
\mathrm{NR}(\mathrm{B})=\Delta \mathrm{NL}(\mathrm{B}) / \Delta \mathrm{t}
$$

where $\mathrm{t}$ is the test duration in days.

The values of $\mathrm{NR}(\mathrm{B})$ were used as the forward glass dissolution rate $\left(\mathrm{k}_{\mathrm{f}}\right.$ in Equation 11) at each temperature and $\mathrm{pH}$. The rates determined from the plots are summarized in Table A-8. The glass dissolution rate at $70^{\circ} \mathrm{C}$ and $\mathrm{pH} 11.9$ was also determined with the result of test GB6-70-1 
included in the regression. The equation of the regression line including the result for test GB6-70-1 is $\mathrm{y}=1.47+8.33 \mathrm{x}$, with $\mathrm{R}^{2}=0.980$.

The rates in Table A-8 are used to determine the $\mathrm{pH}$ and temperature dependence for acidic and alkaline solutions (Section 6.5.2). One step in determining the temperature dependence is a manual regression of lines with set $\mathrm{pH}$ dependence to the test results to determine the temperature dependence. Results from acidic solutions were regressed to lines with slopes of -0.49 and results from alkaline solutions were regressed to lines with slopes 0.49 . This was done by minimizing the difference between the logarithm of the measured rates and the values of $\log _{10}$ (rate) calculated from Equations A-3 and A-4 with various values of $A_{\text {acid }}$ and $A_{\text {alkaline: }}$ :

$$
\begin{gathered}
\log _{10}(\text { rate })=\mathrm{A}_{\text {acid }}-0.49 \times \mathrm{pH} \\
\log _{10}(\text { rate })=\mathrm{A}_{\text {alkaline }}+0.49 \times \mathrm{pH} .
\end{gathered}
$$

A Microsoft Excel spreadsheet, "A-9," in the workbook, EXCELglasscalc (DTN: MO0307ANLGAMR3.016) was used. Trial values of $\mathrm{A}_{\text {acid }}$ and $\mathrm{A}_{\text {alkaline }}$ and values $\mathrm{A}_{\text {acid }} \pm 0.01$ and $\mathrm{A}_{\text {alkaline }} \pm 0.01$ were used to calculate values of $\log _{10}$ (rate) for each $\mathrm{pH}$ and temperature at which the rate was measured. The differences between the calculated and measured rates at each $\mathrm{pH}$ were summed for both temperatures. The values of $\mathrm{A}_{\text {acid }}$ and $\mathrm{A}_{\text {alkaline }}$ were increased or decreased to minimize the sum of the residuals at both temperatures. Table A-9 shows the spreadsheet results for the best fits for acidic and alkaline solutions in tests at $70^{\circ} \mathrm{C}$ and $90^{\circ} \mathrm{C}$ (to the nearest 0.01 ). The best-fit equations for acidic solutions at $70^{\circ} \mathrm{C}$ and $90^{\circ} \mathrm{C}$ and for alkaline solutions at $70^{\circ} \mathrm{C}$ and $90^{\circ} \mathrm{C}$ are:

$$
\begin{aligned}
& \log _{10}\left(\operatorname{rate}_{\mathrm{G}}\right)=2.34-0.49 \times \mathrm{pH} \text { for acidic solutions at } 70^{\circ} \mathrm{C} \\
& \log _{10}\left(\operatorname{rate}_{\mathrm{G}}\right)=2.60-0.49 \times \mathrm{pH} \text { for acidic solutions at } 90^{\circ} \mathrm{C} \\
& \log _{10}\left(\operatorname{rate}_{\mathrm{G}}\right)=-5.12+0.49 \times \mathrm{pH} \text { for alkaline solutions at } 70^{\circ} \mathrm{C} \\
& \log _{10}\left(\text { rate }_{\mathrm{G}}\right)=-4.54+0.49 \times \mathrm{pH} \text { for alkaline solutions at } 90^{\circ} \mathrm{C}
\end{aligned}
$$

These equations are used in Section 6.5.2.1 as Equations 23 through 26, respectively, to determine the temperature dependence for the dissolution of SRL $202 \mathrm{G}$ glass. 
Table A-1. Composition of SRL 202G Glass

\begin{tabular}{|c|c|c|c|c|c|}
\hline Element & $\begin{array}{l}\text { Element } \\
\text { Mass \% }\end{array}$ & Mass Fraction & Element & $\begin{array}{l}\text { Element } \\
\text { Mass \% }\end{array}$ & Mass Fraction \\
\hline $\mathrm{Al}$ & 3.07 & 0.0307 & Mo & 0.0072 & 0.000072 \\
\hline B & 3.21 & 0.0321 & $\mathrm{Na}$ & 11.36 & 0.1136 \\
\hline $\mathrm{Ba}$ & 0.03 & 0.0003 & $\mathrm{Nd}$ & 0.0107 & 0.000107 \\
\hline $\mathrm{Ca}$ & 0.768 & 0.00768 & $\mathrm{Ni}$ & 0.75 & 0.0075 \\
\hline $\mathrm{Cr}$ & 0.28 & 0.0028 & $\mathrm{P}$ & 0.14 & 0.0014 \\
\hline $\mathrm{Cu}$ & 0.096 & 0.00096 & $\mathrm{~Pb}$ & 0.037 & 0.00037 \\
\hline $\mathrm{Fe}$ & 6.48 & 0.0648 & $\mathrm{Si}$ & 20.77 & 0.2077 \\
\hline $\mathrm{K}$ & 2.74 & 0.0274 & $\mathrm{Sr}$ & 0.014 & 0.00014 \\
\hline La & 0.014 & 0.00014 & $\mathrm{Ti}$ & 0.076 & 0.00076 \\
\hline $\mathrm{Li}$ & 1.60 & 0.0160 & $\mathrm{U}$ & 1.34 & 0.0134 \\
\hline $\mathrm{Mg}$ & 1.02 & 0.0102 & $\mathrm{Zn}$ & 0.011 & 0.00011 \\
\hline $\mathrm{Mn}$ & 0.977 & 0.00977 & $\mathrm{Zr}$ & 0.060 & 0.00060 \\
\hline
\end{tabular}

Source: DTN: MO0306ANLGIM02.525 [DIRS 164329], Table 1.

Table A-2. Composition of Leachant Solutions

\begin{tabular}{|c|c|c|c|}
\hline Composition & $\begin{array}{l}\text { Solution } \\
\text { Identifier }\end{array}$ & $\begin{array}{l}\mathrm{pH} \text { at } \\
25^{\circ} \mathrm{C}\end{array}$ & $\mathrm{Fe}(\mu \mathrm{g} / \mathrm{L})$ \\
\hline $0.025 \mathrm{~m} \mathrm{KCl}+0.205 \mathrm{~m} \mathrm{HCl}$ & B1 & 1.29 & 76.4 \\
\hline $0.025 \mathrm{~m} \mathrm{KCl}+0.025 \mathrm{~m} \mathrm{HCl}+16.3 \mathrm{~g} \mathrm{FeCl}_{3} / \mathrm{kg}$ solution $^{\mathrm{a}}$ & $\mathrm{B} 1 \mathrm{Fe}$ & 1.21 & $3.61 \times 10^{6}$ \\
\hline $0.05 \mathrm{~m} \mathrm{KHph}^{\mathrm{b}}+0.005 \mathrm{~m} \mathrm{HCl}$ & B7 & 3.68 & 80.0 \\
\hline $0.05 \mathrm{~m} \mathrm{KHph}+0.005 \mathrm{~m} \mathrm{HCl}+0.406 \mathrm{~g} \mathrm{FeCl}_{3} / \mathrm{kg}$ solution $^{\mathrm{a}}$ & $\mathrm{B} 7 \mathrm{Fe}$ & 3.66 & $1.89 \times 10^{4}$ \\
\hline $0.0095 \mathrm{~m} \mathrm{KHph}+0.00266 \mathrm{~m} \mathrm{LiOH} \times \mathrm{H}_{2} \mathrm{O}$ & B2 & 4.86 & 50.1 \\
\hline $0.008 \mathrm{~m} \mathrm{HNO}_{3}+0.025 \mathrm{~m} \mathrm{TRIS}{ }^{\mathrm{c}}$ & B3 & 8.49 & 76.6 \\
\hline $0.008 \mathrm{~m} \mathrm{HNO}_{3}+0.025 \mathrm{~m}$ TRIS $+16.0 \mathrm{~g} \mathrm{Fe}_{2} \mathrm{O}_{3} / \mathrm{kg}_{\text {solution }}{ }^{\mathrm{a}}$ & $\mathrm{B} 3 \mathrm{Fe}$ & 8.48 & 65.3 \\
\hline $0.0038 \mathrm{~m} \mathrm{HNO}_{3}+0.05 \mathrm{~m}$ TRIS & B4 & 9.24 & 71.5 \\
\hline $0.0038 \mathrm{~m} \mathrm{HNO}_{3}+0.05 \mathrm{~m}$ TRIS $+23.2 \mathrm{~g} \mathrm{Fe}_{3} \mathrm{O}_{4} / \mathrm{kg}$ solution $^{\mathrm{a}}$ & $\mathrm{B} 4 \mathrm{Fe}$ & 9.24 & 83.3 \\
\hline $0.00117 \mathrm{~m} \mathrm{HNO}_{3}+0.00144 \mathrm{~m} \mathrm{LiOH} \times \mathrm{H}_{2} \mathrm{O}$ & B5 & 9.80 & 68.6 \\
\hline $0.00117 \mathrm{~m} \mathrm{HNO}_{3}+0.00144 \mathrm{~m} \mathrm{LiOH} \times \mathrm{H}_{2} \mathrm{O}+0.889 \mathrm{~g} \mathrm{FeOOH} / \mathrm{kg}$ solution ${ }^{\mathrm{a}}$ & $\mathrm{B} 5 \mathrm{Fe}$ & 9.92 & 52.0 \\
\hline $0.00505 \mathrm{~m} \mathrm{LiCl}+0.0107 \mathrm{~m} \mathrm{LiOH}$ & B6 & 11.97 & 30.7 \\
\hline $0.00505 \mathrm{~m} \mathrm{LiCl}+0.0107 \mathrm{~m} \mathrm{LiOH}+0.889 \mathrm{~g} \mathrm{FeOOH} / \mathrm{kg}$ solution $^{\mathrm{a}}$ & $\mathrm{B} 6 \mathrm{Fe}$ & 11.93 & 75.4 \\
\hline
\end{tabular}

Source: Ebert 2003 [DIRS 164517].

NOTE: ${ }^{a}$ Amount needed to make a $0.1 \mathrm{~m}$ solution, although not all of added Fe compound may be dissolved.

${ }^{\mathrm{b}} \mathrm{KHph}$ : Potassium hydrogen phthalate.

${ }^{c}$ TRIS: Tris(hydroxymethyl)aminomethane. 
Table A-3. Results of Blank Tests with SRL 202G Glass

\begin{tabular}{|c|c|c|c|c|c|c|}
\hline \multirow[b]{2}{*}{ Test Number } & \multirow{2}{*}{$\begin{array}{c}\text { Duration } \\
\text { (days) }\end{array}$} & \multirow[b]{2}{*}{$\mathrm{pH}^{\mathrm{a}}$} & \multicolumn{4}{|c|}{ Concentration ( $\mu \mathrm{g} / \mathrm{L})$} \\
\hline & & & B & $\mathrm{Fe}$ & Si & $\mathbf{U}$ \\
\hline \multicolumn{7}{|c|}{ Blank Tests at $70^{\circ} \mathrm{C}$} \\
\hline B1-70-7-blank & 7 & 1.34 & 59 & 100 & 35.6 & 0.061 \\
\hline B7-70-7-blank & 7 & 3.67 & 62.9 & 72.2 & 535 & $<0.06$ \\
\hline B2-70-7-blank & 7 & 4.95 & 51.7 & 61.8 & 177 & $<0.06$ \\
\hline B3-70-7-blank & 7 & 8.42 & 49.6 & 72.2 & 193 & $<0.06$ \\
\hline B4-70-7-blank & 7 & 9.21 & 49.8 & 74.3 & 375 & $<0.06$ \\
\hline B5-70-7-blank & 7 & 10.18 & 44.0 & 67.4 & $<7.82$ & $<0.06$ \\
\hline B6-70-7-blank & 7 & 11.90 & 48.8 & 74.8 & 53 & $<0.06$ \\
\hline \multicolumn{7}{|c|}{ Blank Tests at $90^{\circ} \mathrm{C}$} \\
\hline B1-10 & 10 & 1.31 & 175 & 76.4 & 65.5 & 0.186 \\
\hline $\mathrm{B} 1-21$ & 21 & 1.31 & 123 & 77.8 & 67.6 & 0.276 \\
\hline B7-10 & 10 & 3.78 & 143 & 80.0 & 479 & 1.89 \\
\hline B2-10 & 10 & 4.81 & 69.8 & 50.1 & 126 & 0.216 \\
\hline B2-21 & 21 & 5.12 & 39.6 & 71.1 & $<28.6$ & 0.196 \\
\hline B3-10 & 10 & 8.53 & 108 & 76.6 & 125 & 0.25 \\
\hline B3-21 & 21 & 8.51 & 73.2 & 71.4 & 140 & 0.231 \\
\hline B4-10 & 10 & 9.29 & 74.4 & 71.5 & 286 & $<0.142$ \\
\hline B4-21 & 21 & 9.23 & 66.4 & 78.4 & 260 & $<0.142$ \\
\hline B5-10 & 10 & 9.34 & 116 & 68.6 & $<18.16$ & $<0.142$ \\
\hline B5-21 & 21 & 9.38 & 89.9 & 101 & 29.5 & $<0.142$ \\
\hline B6-10 & 10 & 12.00 & 123 & 30.7 & 51.5 & 0.124 \\
\hline B6-21 & 21 & 11.96 & 98.7 & 51.3 & 49.0 & 0.122 \\
\hline \multicolumn{7}{|c|}{ Blank Tests at $90^{\circ} \mathrm{C}$ with Added Iron } \\
\hline $\mathrm{B} 1 \mathrm{Fe}-10$ & 10 & 0.86 & 629 & $3,610,000$ & 776 & 34.7 \\
\hline $\mathrm{B} 1 \mathrm{Fe}-21$ & 21 & 0.81 & 515 & $3,350,000$ & 390 & 1.11 \\
\hline B7Fe-10 & 10 & 3.70 & 71 & 18,900 & 492 & $<0.08$ \\
\hline B3Fe-10 & 10 & 8.45 & 103 & 65.3 & 358 & 0.199 \\
\hline B3Fe-21 & 21 & 8.39 & 74.6 & 75.4 & 330 & 0.205 \\
\hline $\mathrm{B} 4 \mathrm{Fe}-10$ & 10 & 9.26 & 100 & 83.3 & 1740 & $<0.14$ \\
\hline B4Fe-21 & 21 & 9.26 & 84.2 & 84.3 & 1900 & $<0.14$ \\
\hline B5Fe-10 & 10 & 10.22 & 296 & 52.0 & 48.9 & 0.127 \\
\hline B5Fe-21 & 21 & 10.24 & 273 & 56.5 & 69.8 & 0.098 \\
\hline B6Fe-10 & 10 & 11.99 & 124 & 75.4 & 85.2 & $<0.2$ \\
\hline
\end{tabular}

Source: DTN: MO0306ANLGIM01.525 [DIRS 164329], Table 4.

NOTE: ${ }^{a} \mathrm{pH}$ measured at room temperature. 
Table A-4. Solution Compositions for Tests with SRL 202G Glass at $70^{\circ} \mathrm{C}$

\begin{tabular}{|c|c|c|c|c|c|c|}
\hline \multirow[b]{2}{*}{ Test No. } & \multirow{2}{*}{$\begin{array}{l}\text { Time } \\
\text { (days) }\end{array}$} & \multirow[b]{2}{*}{$\mathrm{pH}^{\mathrm{a}}$} & \multicolumn{4}{|c|}{ Concentration $(\mu \mathrm{g} / \mathrm{L})$} \\
\hline & & & B & $\mathrm{Fe}$ & $\mathrm{Si}$ & U \\
\hline \multicolumn{7}{|c|}{ pH 1.3} \\
\hline GB1-70-1 & 0.25 & not analyzed & 27,900 & 62,800 & 182,000 & 14,100 \\
\hline GB1-70-2 & 2 & 1.31 & 11,200 & 25,500 & 63,400 & 5,610 \\
\hline GB1-70-3 & 3 & 1.30 & 13,600 & 29,900 & 73,900 & 6,090 \\
\hline GB1-70-5 & 5 & 1.29 & 16,000 & 35,200 & 78,900 & 7,250 \\
\hline GB1-70-7 & 7 & 1.34 & 16,400 & 35,800 & 79,700 & 7,370 \\
\hline \multicolumn{7}{|c|}{ pH 3.7} \\
\hline GB7-70-1 & 1.25 & not analyzed & 946 & 2,300 & 3,260 & 545 \\
\hline GB7-70-2 & 2 & 3.66 & 2,400 & 5,000 & 8,190 & 875 \\
\hline GB7-70-3 & 3 & 3.68 & 2,670 & 5,550 & 10,300 & 969 \\
\hline GB7-70-5 & 5 & 3.72 & 3,930 & 7,880 & 20,200 & 1,530 \\
\hline GB7-70-7 & 7 & 3.73 & 4,280 & 8,470 & 23,400 & 1,630 \\
\hline \multicolumn{7}{|c|}{ pH 5.0} \\
\hline GB2-70-1 & 1.25 & not analyzed & 341 & 128 & 1,190 & 170 \\
\hline GB2-70-2 & 2 & 4.96 & 972 & 181 & 2,580 & 264 \\
\hline GB2-70-3 & 3 & 4.94 & 1,100 & 177 & 3,140 & 292 \\
\hline GB2-70-5 & 5 & 4.98 & 1,500 & 136 & 5,340 & 447 \\
\hline GB2-70-7 & 7 & 5.01 & 1,840 & 137 & 6,350 & 581 \\
\hline \multicolumn{7}{|c|}{ pH 8.5} \\
\hline GB3-70-1 & 1.25 & not analyzed & 99.0 & $<40.8$ & 431 & 6.76 \\
\hline GB3-70-2 & 2 & 8.39 & 247 & 101 & 623 & 19.5 \\
\hline GB3-70-3 & 3 & 8.45 & 245 & 101 & 901 & 22.9 \\
\hline GB3-70-5 & 5 & 8.46 & 322 & 101 & 1,100 & 33.9 \\
\hline GB3-70-7 & 7 & 8.48 & 389 & 233 & 1,610 & 75.8 \\
\hline \multicolumn{7}{|c|}{ pH 9.3} \\
\hline GB4-70-1 & 1.25 & not analyzed & 96.6 & $<40.8$ & 1,030 & 18.1 \\
\hline GB4-70-2 & 2 & 9.23 & 239 & 101 & 2,020 & 57.0 \\
\hline GB4-70-3 & 3 & 9.26 & 268 & 101 & 2,370 & 71.9 \\
\hline GB4-70-5 & 5 & 9.27 & 345 & 101 & 3,100 & 95.1 \\
\hline GB4-70-7 & 7 & 9.27 & 387 & 109 & 3,650 & 123 \\
\hline \multicolumn{7}{|c|}{ pH 10.2} \\
\hline GB5-70-1 & 1.25 & not analyzed & 55.5 & $<40.8$ & 942 & 45.2 \\
\hline GB5-70-2 & 2 & 10.13 & 455 & 106 & 4,220 & 150 \\
\hline GB5-70-3 & 3 & 10.19 & 750 & 101 & 5,460 & 191 \\
\hline GB5-70-5 & 5 & 10.20 & 942 & 127 & 6,920 & 230 \\
\hline GB5-70-7 & 7 & 10.21 & 1,180 & 194 & 8,950 & 304 \\
\hline \multicolumn{7}{|c|}{ pH 11.9} \\
\hline GB6-70-1 & 0.25 & not analyzed & 361 & $<40.8$ & 4,160 & 230 \\
\hline GB6-70-2 & 2 & 11.89 & 1,380 & 288 & 10,500 & 695 \\
\hline GB6-70-3 & 3 & 11.93 & 1,810 & 242 & 13,200 & 800 \\
\hline GB6-70-5 & 5 & 11.90 & 2,690 & 235 & 19,200 & 1,130 \\
\hline GB6-70-7 & 7 & 11.89 & 3,030 & 209 & 22,600 & 1,260 \\
\hline
\end{tabular}

Source: DTN: MO0306ANLGIM01.525 [DIRS 164329], Table 1.

NOTE: ${ }^{a} \mathrm{pH}$ measured at room temperature. 
Table A-5. Solution Compositions for Tests with SRL 202G Glass at $90^{\circ} \mathrm{C}$

\begin{tabular}{|c|c|c|c|c|c|c|}
\hline \multirow[b]{2}{*}{ Test No. } & \multirow{2}{*}{$\begin{array}{c}\text { Time } \\
\text { (days) }\end{array}$} & \multirow[b]{2}{*}{$\mathrm{pH}^{\mathrm{a}}$} & \multicolumn{4}{|c|}{ Concentration $(\mu \mathrm{g} / \mathrm{L})$} \\
\hline & & & B & $\mathrm{Fe}$ & $\mathrm{Si}$ & U \\
\hline \multicolumn{7}{|c|}{ pH 1.3} \\
\hline GB1-1 & 1 & 1.32 & 9,540 & 23,200 & 47,500 & 4,810 \\
\hline GB1-1.3 & 1.3 & 1.31 & 12,000 & 27,700 & 58,900 & 5,980 \\
\hline GB1-2 & 2 & 1.36 & 15,600 & 34,300 & 68,500 & 6,600 \\
\hline GB1-3 & 3 & 1.34 & 19,800 & 41,800 & 97,300 & 8,140 \\
\hline GB1-5 & 5 & 1.40 & 21,300 & 44,300 & 98,100 & 8,730 \\
\hline GB1-7 & 7 & 1.42 & 26,200 & 57,500 & 121,000 & 11,200 \\
\hline GB1-10 & 10 & 1.44 & 33,200 & 71,000 & 139,000 & 14,200 \\
\hline GB1-21 & 21 & 1.53 & 41,900 & 92,300 & 142,000 & 18,100 \\
\hline \multicolumn{7}{|c|}{ pH 3.7} \\
\hline GB7-1 & 1 & 3.74 & 603 & 987 & 2,970 & 252 \\
\hline GB7-2 & 2 & 3.74 & 968 & 1,540 & 5,970 & 426 \\
\hline GB7-3 & 3 & 3.74 & 1,160 & 1,840 & 8,190 & 514 \\
\hline GB7-5 & 5 & 3.75 & 2,010 & 2,520 & 12,400 & 765 \\
\hline GB7-7 & 7 & 3.77 & 3,110 & 3,890 & 19,300 & 1,210 \\
\hline GB7-10 & 10 & 3.78 & 3,460 & 4,220 & 22,100 & 1,390 \\
\hline \multicolumn{7}{|c|}{ pH 5.0} \\
\hline GB2-2 & 2 & 4.97 & 1,990 & 79.0 & 5,630 & 407 \\
\hline GB2-3 & 3 & 4.95 & 2,570 & 82.3 & 8,340 & 560 \\
\hline GB2-5 & 5 & 5.03 & 3,250 & 91.6 & 10,900 & 751 \\
\hline GB2-7 & 7 & 5.07 & 4,060 & 74.2 & 14,300 & 929 \\
\hline GB2-10 & 10 & 5.06 & 4,830 & 64.0 & 16,100 & 976 \\
\hline GB2-21 & 21 & 5.20 & 7,150 & 66.8 & 26,500 & 1,390 \\
\hline \multicolumn{7}{|c|}{$\mathrm{pH} 8.5$} \\
\hline GB3-2 & 2 & 8.50 & 518 & 73.7 & 1490 & 25.1 \\
\hline GB3-3 & 3 & 8.50 & 609 & 68.7 & 1760 & 39.3 \\
\hline GB3-5 & 5 & 8.53 & 984 & 101 & 2480 & 29.8 \\
\hline GB3-7 & 7 & 8.53 & 1130 & 81.5 & 3160 & 34.5 \\
\hline GB3-10 & 10 & 8.52 & 1440 & 114 & 3730 & 39.3 \\
\hline GB3-21 & 21 & 8.52 & 1920 & 58.3 & 5440 & 51.3 \\
\hline \multicolumn{7}{|c|}{ pH 9.3} \\
\hline GB4-2 & 2 & 9.24 & 403 & 83.0 & 3,210 & 62.6 \\
\hline GB4-3 & 3 & 9.22 & 578 & 81.1 & 4,700 & 130 \\
\hline GB4-5 & 5 & 9.29 & 950 & 89.8 & 6,160 & 90.8 \\
\hline GB4-7 & 7 & 9.27 & 1,220 & 86.2 & 7,900 & 113 \\
\hline GB4-10 & 10 & 9.27 & 1,360 & 91.3 & 8,910 & 124 \\
\hline GB4-21 & 21 & 8.93 & 1,970 & 427 & 12,200 & 363 \\
\hline \multicolumn{7}{|c|}{ pH 9.8} \\
\hline GB5-2 & 2 & 9.72 & 456 & 98.2 & 3,750 & 91 \\
\hline GB5-3 & 3 & 9.76 & 609 & 98.4 & 5,040 & 110 \\
\hline GB5-5 & 5 & 9.89 & 1,090 & 248 & 7,220 & 119 \\
\hline GB5-7 & 7 & 9.87 & 1,350 & 85.5 & 8,880 & 120 \\
\hline GB5-10 & 10 & 9.96 & 2,050 & 87.6 & 12,300 & 135 \\
\hline
\end{tabular}


Table A-5. Solution Compositions for Tests with SRL 202G Glass at $90^{\circ} \mathrm{C}$ (Continued)

\begin{tabular}{|c|c|c|c|c|c|c|}
\hline \multirow[b]{2}{*}{ Test No. } & \multirow{2}{*}{$\begin{array}{c}\text { Time } \\
\text { (days) }\end{array}$} & \multirow[b]{2}{*}{$\mathrm{pH}^{\mathrm{a}}$} & \multicolumn{4}{|c|}{ Concentration $(\mu \mathrm{g} / \mathrm{L})$} \\
\hline & & & B & $\mathrm{Fe}$ & Si & U \\
\hline GB5-21 & 21 & 9.94 & 2,450 & 279 & 15,500 & 157 \\
\hline \multicolumn{7}{|c|}{ pH 11.9} \\
\hline GB6-2 & 2 & 11.94 & 2,450 & 244 & 16,500 & 817 \\
\hline GB6-3 & 3 & 11.91 & 3,440 & 239 & 22,900 & 1,080 \\
\hline GB6-5 & 5 & 12.00 & 4,390 & 216 & 28,200 & 1,160 \\
\hline GB6-7 & 7 & 12.00 & 4,870 & 247 & 29,200 & 1,260 \\
\hline GB6-10 & 10 & 11.91 & 5,910 & 220 & 36,000 & 1,240 \\
\hline GB6-21 & 21 & 11.90 & 8,950 & $<179$ & 51,400 & 2,130 \\
\hline
\end{tabular}

Source: DTN: MO0306ANLGIM01.525 [DIRS 164329], Table 2.

NOTE: ${ }^{a} \mathrm{pH}$ measured at room temperature.

Table A-6. Solution Compositions for Tests with SRL 202G Glass at $90^{\circ} \mathrm{C}$ with Added Iron Compounds

\begin{tabular}{|c|c|c|c|c|c|c|}
\hline \multirow[b]{2}{*}{ Test No. } & \multirow{2}{*}{$\begin{array}{c}\text { Time } \\
\text { (days) }\end{array}$} & \multirow[b]{2}{*}{$\mathrm{pH}^{\mathrm{a}}$} & \multicolumn{4}{|c|}{ Concentration $(\mu \mathrm{g} / \mathrm{L})$} \\
\hline & & & B & $\mathrm{Fe}$ & Si & U \\
\hline \multicolumn{7}{|c|}{ pH $1.0+0.1 \mathrm{~m} \mathrm{FeCl}_{3}{ }^{b}$} \\
\hline GB1Fe-1 & 1 & 1.02 & 12,700 & 4980000 & 68900 & 6180 \\
\hline GB1Fe-1.3 & 1.3 & 0.98 & 16,600 & $4,630,000$ & 86,100 & 8,150 \\
\hline GB1Fe-2 & 2 & 0.99 & 19,300 & $3,940,000$ & 92,100 & 8,010 \\
\hline GB1Fe-3 & 3 & 0.97 & 30,400 & $4,090,000$ & 122,000 & 13,100 \\
\hline GB1Fe-5 & 5 & 1.00 & 34,200 & $4,060,000$ & 127,000 & 14,700 \\
\hline GB1Fe-7 & 7 & 0.97 & 45,400 & $4,070,000$ & 132,000 & 19,700 \\
\hline GB1Fe-10 & 10 & 0.96 & 53,800 & $4,130,000$ & 146,000 & 24,000 \\
\hline GB1Fe-21 & 21 & 0.90 & 60,000 & $3,600,000$ & 143,000 & 26,900 \\
\hline \multicolumn{7}{|c|}{$\mathrm{pH} 3.7+0.1 \mathrm{~m} \mathrm{FeCl}_{3}{ }^{b}$} \\
\hline GB7Fe-1 & 1 & 3.72 & 496 & 20,800 & 2,970 & 188 \\
\hline GB7Fe-2 & 2 & 3.73 & 917 & 19,500 & 6,360 & 382 \\
\hline GB7Fe-3 & 3 & 3.73 & 1,410 & 18,300 & 9,050 & 507 \\
\hline GB7Fe-5 & 5 & 3.74 & 1,980 & 18,600 & 13,800 & 803 \\
\hline GB7Fe-7 & 7 & 3.75 & 2,700 & 18,600 & 19,400 & 1,040 \\
\hline GB7Fe-10 & 10 & 3.75 & 3,690 & 17,300 & 26,400 & 1,230 \\
\hline \multicolumn{7}{|c|}{$\mathrm{pH} 8.5+0.1 \mathrm{~m} \mathrm{Fe}_{2} \mathrm{O}_{3}{ }^{\mathrm{c}}$} \\
\hline GB3Fe-2 & 2 & 8.46 & 477 & 50.8 & 1820 & 9.10 \\
\hline GB3Fe-3 & 3 & 8.46 & 655 & 59.4 & 2450 & 12.6 \\
\hline GB3Fe-5 & 5 & 8.50 & 1180 & 53.3 & 4090 & 12.6 \\
\hline GB3Fe-7 & 7 & 8.46 & 1290 & 44.5 & 5910 & 14.5 \\
\hline GB3Fe-10 & 10 & 8.48 & 1420 & 44.2 & 6080 & 15.9 \\
\hline GB3Fe-21 & 21 & 8.46 & 2530 & 57.4 & 11500 & 31.0 \\
\hline \multicolumn{7}{|c|}{$\mathrm{pH} 9.3+0.1 \mathrm{~m} \mathrm{Fe}_{3} \mathrm{O}_{4}{ }^{d}$} \\
\hline GB4Fe-2 & 2 & 9.26 & 789 & 87.0 & 4,920 & 30.2 \\
\hline GB4Fe-3 & 3 & 9.24 & 988 & 84.1 & 6,140 & 54.0 \\
\hline GB4Fe-5 & 5 & 9.31 & 1,530 & 146 & 8,650 & 46.9 \\
\hline
\end{tabular}


Table A-6. Solution Compositions for Tests with SRL 202G Glass at $90^{\circ} \mathrm{C}$ with Added Iron Compounds (Continued)

\begin{tabular}{|c|c|c|c|c|c|c|}
\hline \multirow[b]{2}{*}{ Test No. } & \multirow{2}{*}{$\begin{array}{c}\text { Time } \\
\text { (days) }\end{array}$} & \multirow[b]{2}{*}{$\mathrm{pH}^{\mathrm{a}}$} & \multicolumn{4}{|c|}{ Concentration $(\mu \mathrm{g} / \mathrm{L})$} \\
\hline & & & B & $\mathrm{Fe}$ & Si & $\mathbf{U}$ \\
\hline GB4Fe-7 & 7 & 9.31 & 1,680 & 78.0 & 10,300 & 66.2 \\
\hline GB4Fe-10 & 10 & 9.30 & 1,950 & 93.3 & 10,900 & 69.7 \\
\hline GB4Fe-21 & 21 & 8.86 & 2,720 & 738 & 14,200 & 336 \\
\hline \multicolumn{7}{|c|}{$\mathrm{pH} 10.2+0.1 \mathrm{~m} \mathrm{FeOOH}^{\mathrm{e}}$} \\
\hline GB5Fe-2 & 2 & 9.91 & 900 & 77.2 & 905 & 24.6 \\
\hline GB5Fe-3 & 3 & 9.81 & 1,410 & 41.0 & 992 & 26.1 \\
\hline GB5Fe-5 & 5 & 10.23 & 2,080 & 32.2 & 1,330 & 28.7 \\
\hline GB5Fe-7 & 7 & 10.25 & 2,570 & 39.0 & 1,510 & 41.2 \\
\hline GB5Fe-10 & 10 & 10.22 & 3,340 & 46.1 & 2,170 & 29.3 \\
\hline GB5Fe-21 & 21 & 10.36 & 6,200 & 105 & 8,050 & 27.0 \\
\hline \multicolumn{7}{|c|}{ pH $11.9+0.1 \mathrm{~m} \mathrm{FeOOH}^{\mathrm{e}}$} \\
\hline GB6Fe-1 & 1 & 12.00 & 1,770 & 102 & 8,860 & 402 \\
\hline GB6Fe-2 & 2 & 11.98 & 2,870 & 109 & 14,900 & 568 \\
\hline GB6Fe-3 & 3 & 11.99 & 3,760 & 120 & 18,100 & 619 \\
\hline GB6Fe-5 & 5 & 11.98 & 4,590 & 113 & 23,500 & 724 \\
\hline GB6Fe-7 & 7 & 11.98 & 6,100 & 146 & 29,800 & 813 \\
\hline GB6Fe-10 & 10 & 11.99 & 7,010 & 112 & 34,100 & 846 \\
\hline
\end{tabular}

Source: DTN: MO0306ANLGIM01.525 [DIRS 164329], Table 3.

NOTES: ${ }^{a} \mathrm{pH}$ measured at room temperature.

${ }^{\mathrm{b}} \mathrm{FeCl}_{3}$ added to leachant make $0.1 \mathrm{~m} \mathrm{FeCl}_{3}$ solution.

${ }^{\mathrm{c}} \mathrm{Fe}_{2} \mathrm{O}_{3}$ added to leachant make $0.1 \mathrm{~m} \mathrm{Fe}_{2} \mathrm{O}_{3}$ solution.

${ }^{d} \mathrm{Fe}_{3} \mathrm{O}_{4}$ added to leachant make $0.1 \mathrm{~m} \mathrm{Fe}_{3} \mathrm{O}_{4}$ solution.

${ }^{\mathrm{e}} \mathrm{FeOOH}$ added to leachant make $0.1 \mathrm{~m}$ FeOOH solution.

Table A-7. Results of Tests with SRL 202G Glass: NL(B), $g / \mathrm{m}^{2}$

\begin{tabular}{|c|c|c|c|c|c|}
\hline \multicolumn{2}{|c|}{ Tests at $70^{\circ} \mathrm{C}$} & \multicolumn{2}{|c|}{ Tests at $90^{\circ} \mathrm{C}$} & \multicolumn{2}{|c|}{ Tests at $90^{\circ} \mathrm{C}$ with added Iron } \\
\hline Test No. & $\mathrm{NL}(\mathrm{B})$ & Test No. & $\mathrm{NL}(\mathrm{B})$ & Test No. & $N L(B)$ \\
\hline \multicolumn{2}{|c|}{$\mathrm{pH} 1.3^{\mathrm{a}}$} & \multicolumn{2}{|c|}{$\mathrm{pH} 1.3^{\mathrm{a}}$} & \multicolumn{2}{|c|}{$\mathrm{pH} 1.0^{\mathrm{a}}+0.1 \mathrm{~m} \mathrm{FeCl}_{3}$} \\
\hline GB1-70-1 & 102 & GB1-1 & 147 & GBFe1-1 & 189 \\
\hline GB1-70-2 & 174 & GB1-1.3 & 185 & GBFe1-1.3 & 250 \\
\hline GB1-70-3 & 213 & GB1-2 & 243 & GB1Fe-2 & 294 \\
\hline GB1-70-5 & 250 & GB1-3 & 309 & GB1Fe-3 & 468 \\
\hline \multirow[t]{4}{*}{ GB1-70-7 } & 258 & GB1-5 & 332 & GB1Fe-5 & 535 \\
\hline & & GB1-7 & 410 & GB1Fe-7 & 704 \\
\hline & & GB1-10 & 519 & GB1Fe-10 & 836 \\
\hline & & GB1-21 & 659 & GB1Fe-21 & 940 \\
\hline \multicolumn{2}{|c|}{ pH $3.7^{\mathrm{a}}$} & \multicolumn{2}{|c|}{$\mathrm{pH} 3.7^{\mathrm{a}}$} & \multicolumn{2}{|c|}{$\mathrm{pH} 3.7^{\mathrm{a}}+0.1 \mathrm{~m} \mathrm{FeCl}_{3}$} \\
\hline GB7-70-1 & 3.70 & GB7-1 & 7.21 & GB7Fe-1 & 6.67 \\
\hline GB7-70-2 & 7.36 & GB7-2 & 12.9 & GB7Fe-2 & 13.3 \\
\hline GB7-70-3 & 8.22 & GB7-3 & 16.0 & GB7Fe-3 & 21.0 \\
\hline
\end{tabular}


Table A-7. Results of Tests with SRL 202G Glass: NL(B), $\mathrm{g} / \mathrm{m}^{2}$ (Continued)

\begin{tabular}{|c|c|c|c|c|c|}
\hline \multicolumn{2}{|c|}{ Tests at $70^{\circ} \mathrm{C}$} & \multicolumn{2}{|c|}{ Tests at $90^{\circ} \mathrm{C}$} & \multicolumn{2}{|c|}{ Tests at $90^{\circ} \mathrm{C}$ with added Iron } \\
\hline Test No. & NL(B) & Test No. & NL(B) & Test No. & NL(B) \\
\hline \multicolumn{2}{|c|}{$\mathrm{pH} 1.3^{\mathrm{a}}$} & \multicolumn{2}{|c|}{$\mathrm{pH} 1.3^{\mathrm{a}}$} & \multicolumn{2}{|c|}{$\mathrm{pH} 1.0^{\mathrm{a}}+0.1 \mathrm{~m} \mathrm{FeCl}_{3}$} \\
\hline GB7-70-5 & 12.2 & GB7-5 & 29.3 & GB7Fe-5 & 29.6 \\
\hline \multirow[t]{2}{*}{ GB7-70-7 } & 13.3 & GB7-7 & 46.5 & GB7Fe-7 & 41.2 \\
\hline & & GB7-10 & 52.0 & GB7Fe-10 & 56.8 \\
\hline \multicolumn{2}{|c|}{$\mathrm{pH} 5.0^{\mathrm{a}}$} & \multicolumn{2}{|c|}{$\mathrm{pH} 5.0^{\mathrm{a}}$} & & \\
\hline GB2-70-1 & 1.25 & GB2-2 & 6.07 & & \\
\hline GB2-70-2 & 2.90 & GB2-3 & 7.85 & & \\
\hline GB2-70-3 & 3.31 & GB2-5 & 10.0 & & \\
\hline GB2-70-5 & 4.56 & GB2-7 & 12.6 & & \\
\hline \multirow[t]{2}{*}{ GB2-70-7 } & 5.62 & GB2-10 & 15.0 & & \\
\hline & & GB2-21 & 22.5 & & \\
\hline \multicolumn{2}{|c|}{$\mathrm{pH} 8.5^{\mathrm{a}}$} & \multicolumn{2}{|c|}{$\mathrm{pH} 8.5^{\mathrm{a}}$} & \multicolumn{2}{|c|}{$\mathrm{pH} 8.5^{\mathrm{a}}+0.1 \mathrm{~m} \mathrm{Fe}_{2} \mathrm{O}_{3}$} \\
\hline GB3-70-1 & 0.337 & GB3-2 & 1.30 & GB3Fe-2 & 1.19 \\
\hline GB3-70-2 & 0.621 & GB3-3 & 1.58 & GB3Fe-3 & 1.74 \\
\hline GB3-70-3 & 0.615 & GB3-5 & 2.76 & GB3Fe-5 & 3.40 \\
\hline GB3-70-5 & 0.857 & GB3-7 & 3.23 & GB3Fe-7 & 3.75 \\
\hline \multirow[t]{2}{*}{ GB3-70-7 } & 1.07 & GB3-10 & 4.20 & GB3Fe-10 & 4.16 \\
\hline & & GB3-21 & 5.86 & GB3Fe-21 & 7.78 \\
\hline \multicolumn{2}{|c|}{$\mathrm{pH} 9.3^{\mathrm{a}}$} & \multicolumn{2}{|c|}{$\mathrm{pH} 9.3^{\mathrm{a}}$} & \multicolumn{2}{|c|}{$\mathrm{pH} 9.3^{\mathrm{a}}+0.1 \mathrm{~m} \mathrm{Fe}_{3} \mathrm{O}_{4}$} \\
\hline GB4-70-1 & 0.295 & GB4-2 & 1.04 & GB4Fe-2 & 2.18 \\
\hline GB4-70-2 & 0.595 & GB4-3 & 1.59 & GB4Fe-3 & 2.80 \\
\hline GB4-70-3 & 0.688 & GB4-5 & 2.76 & GB4Fe-5 & 4.59 \\
\hline GB4-70-5 & 0.929 & GB4-7 & 3.62 & GB4Fe-7 & 5.02 \\
\hline \multirow[t]{2}{*}{ GB4-70-7 } & 1.06 & GB4-10 & 4.06 & GB4Fe-10 & 5.84 \\
\hline & & GB4-21 & 6.03 & GB4Fe-21 & 8.37 \\
\hline \multicolumn{2}{|c|}{$\mathrm{pH} 10.2^{\mathrm{a}}$} & \multicolumn{2}{|c|}{$\mathrm{pH} 9.8^{\mathrm{a}}$} & \multicolumn{2}{|c|}{$\mathrm{pH} 10.2^{\mathrm{a}}+0.1 \mathrm{~m} \mathrm{FeOOH}$} \\
\hline GB5-70-1 & 0.175 & GB5-2 & 5.36 & GB5Fe-2 & 9.52 \\
\hline GB5-70-2 & 1.29 & GB5-3 & 7.75 & GB5Fe-3 & 17.5 \\
\hline GB5-70-3 & 2.22 & GB5-5 & 15.3 & GB5Fe-5 & 28.1 \\
\hline GB5-70-5 & 2.83 & GB5-7 & 19.4 & GB5Fe-7 & 35.8 \\
\hline \multirow[t]{2}{*}{ GB5-70-7 } & 3.58 & GB5-10 & 30.4 & GB5Fe-10 & 47.9 \\
\hline & & GB5-21 & 37.2 & GB5Fe-21 & 93.5 \\
\hline \multicolumn{2}{|c|}{ Tests at $70^{\circ} \mathrm{C}$} & \multicolumn{2}{|c|}{ Tests at $90^{\circ} \mathrm{C}$} & \multicolumn{2}{|c|}{ Tests at $90^{\circ} \mathrm{C}$ with added Iron } \\
\hline Test No. & NL(B) & Test No. & NL(B) & Test No. & NL(B) \\
\hline & & & & pH 11.9 & $\mathrm{FeOOH}$ \\
\hline GB6-70-1 & 1.34 & GB6-2 & 36.7 & GB6Fe-1 & 25.8 \\
\hline GB6-70-2 & 20.8 & GB6-3 & 52.1 & GB6Fe-2 & 43.1 \\
\hline GB6-70-3 & 27.7 & GB6-5 & 67.1 & GB6Fe-3 & 57.0 \\
\hline GB6-70-5 & 41.4 & GB6-7 & 74.4 & GB6Fe-5 & 70.0 \\
\hline GB6-70-7 & 46.8 & GB6-10 & 91.0 & GB6Fe-7 & 93.8 \\
\hline & & GB6-21 & 140 & GB6Fe-10 & 108 \\
\hline
\end{tabular}

Source: DTN: MO0306ANLGIM02.525 [DIRS 164329], Tables 2, 3, and 4.

NOTE: ${ }^{a} \mathrm{pH}$ measured at room temperature. 
(a)

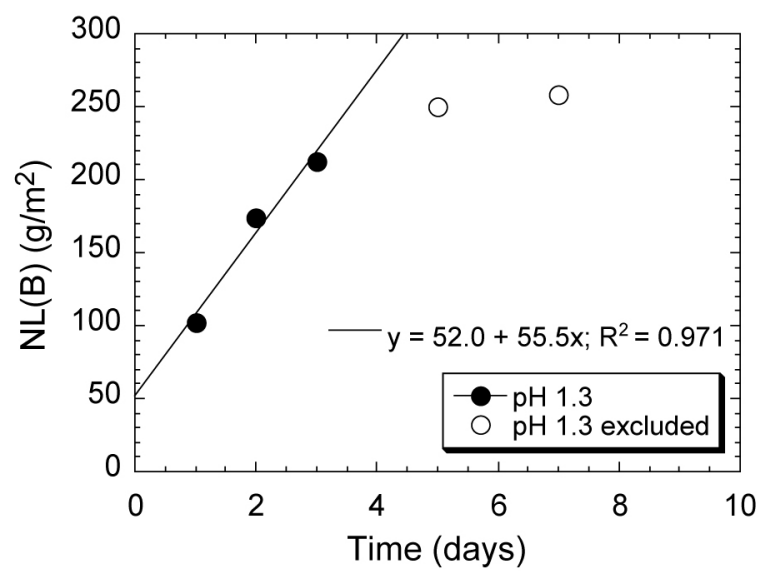

(c)

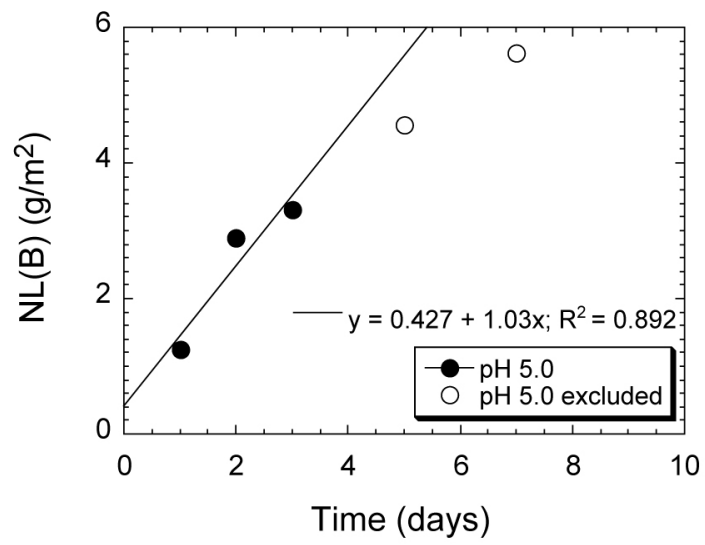

(e)

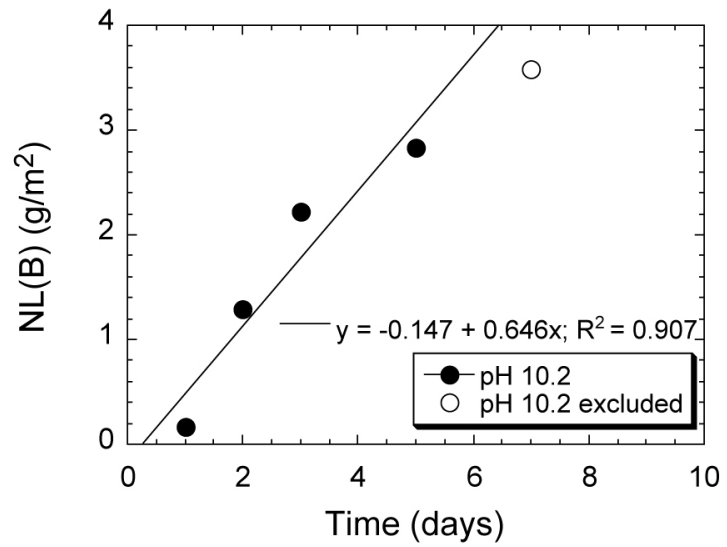

(b)

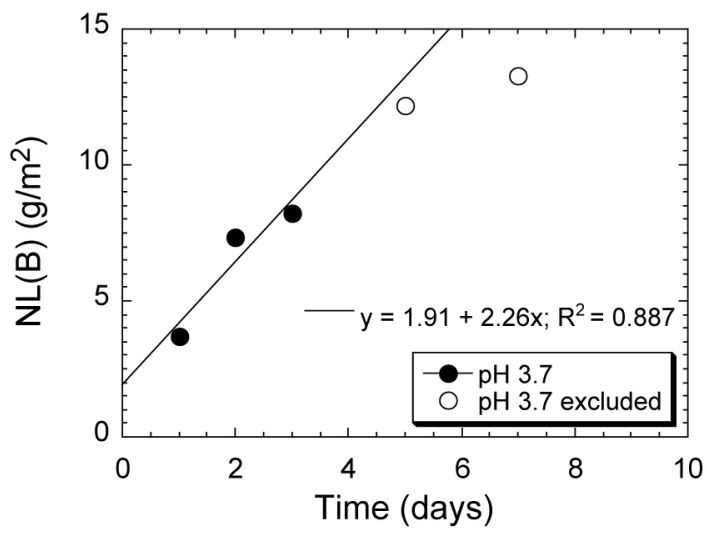

(d)

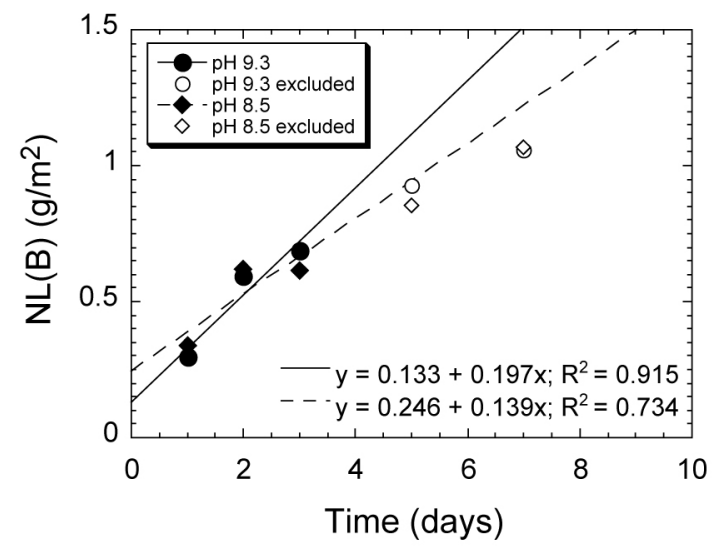

(f)

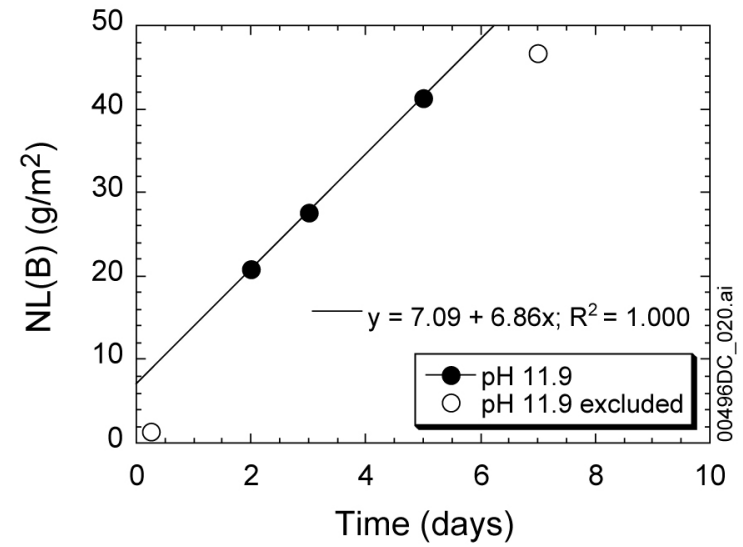

NOTE: Results shown by open symbols were excluded from the regression line (see text following Equation A-1).

Figure A-1. NL(B) vs. Test Duration for MCC-1 Tests at $70^{\circ} \mathrm{C}$ at (a) $\mathrm{pH} 1.3$, (b) $\mathrm{pH} 3.7$, (c) $\mathrm{pH} 5.0$, (d) $\mathrm{pH} 8.5$ and $\mathrm{pH} 9.3$, (e) $\mathrm{pH} 10.2$, and (f) $\mathrm{pH} 11.9$ 
(a)

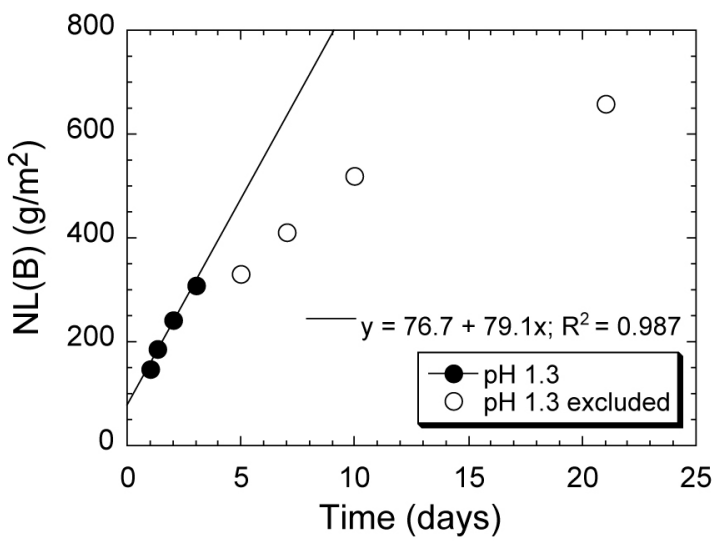

(c)

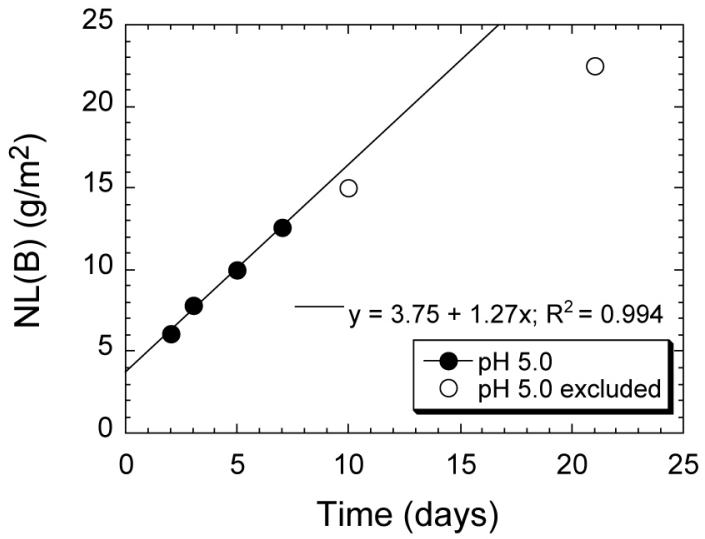

(e)

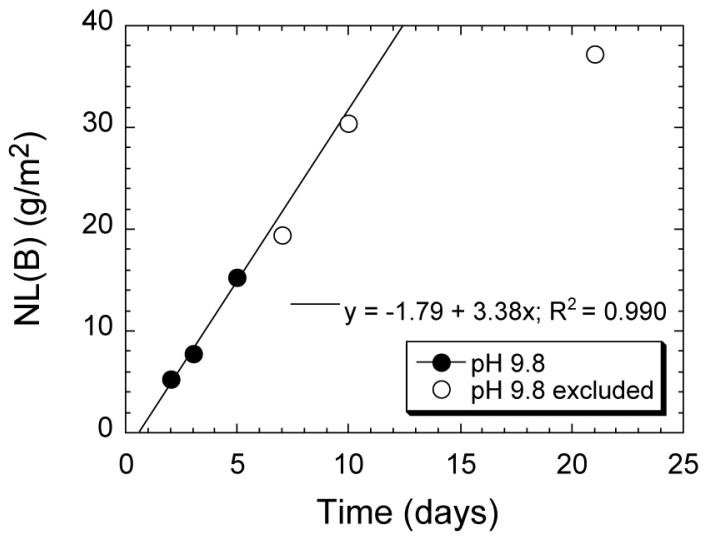

(b)

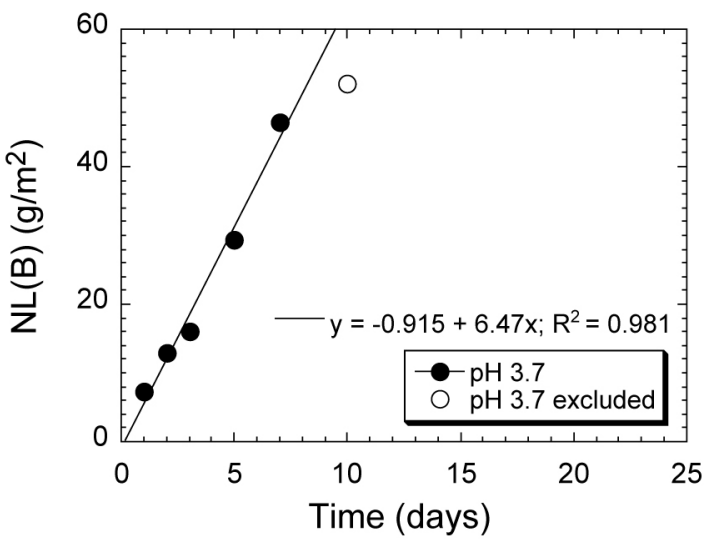

(d)

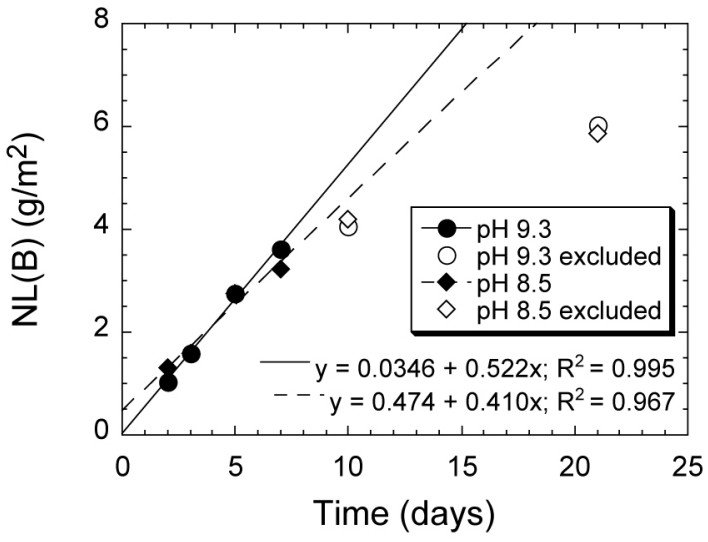

(f)

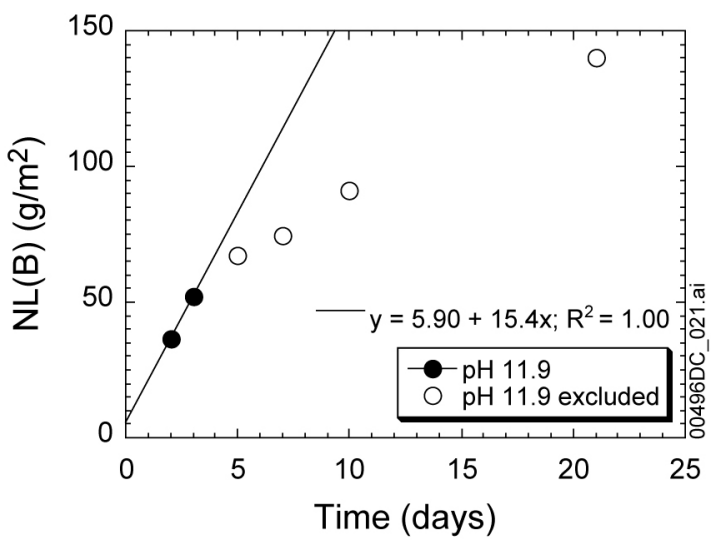

NOTE: Results shown by open symbols were excluded from the regression line (see text following Equation A-1).

Figure A-2. $\mathrm{NL}(\mathrm{B})$ vs. Test Duration for MCC-1 Tests at $90^{\circ} \mathrm{C}$ at (a) $\mathrm{pH} 1.3$, (b) $\mathrm{pH} 3.7$, (c) $\mathrm{pH} 5.0$, (d) $\mathrm{pH} 8.5$ and $\mathrm{pH} 9.3$, (e) $\mathrm{pH} 9.8$, and (f) $\mathrm{pH} 11.9$ 
(a)

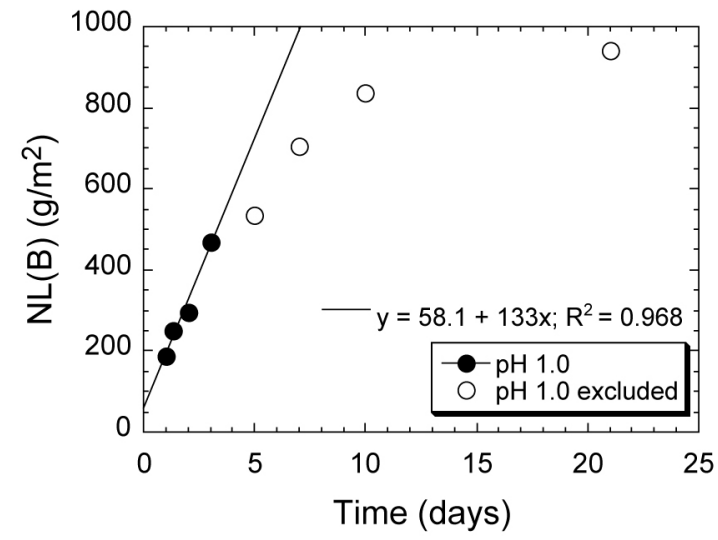

(c)

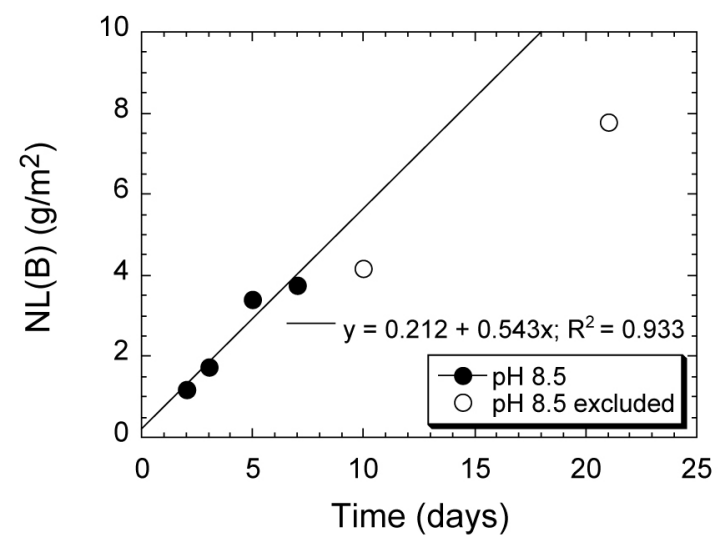

(e)

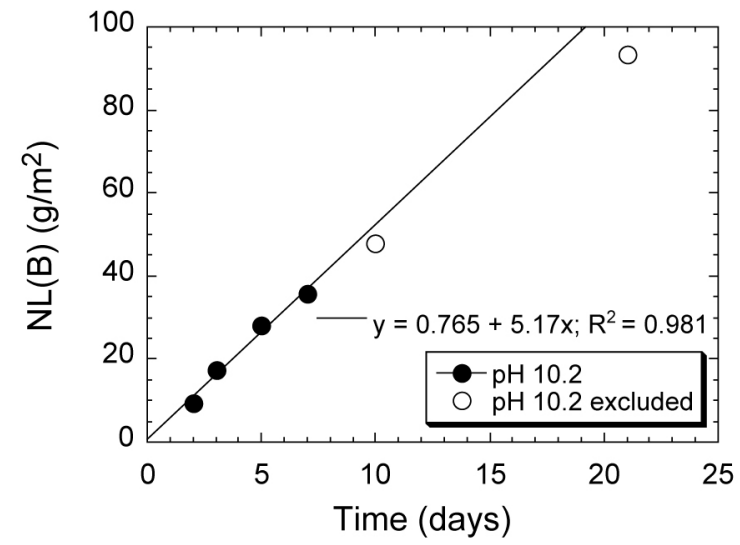

(b)

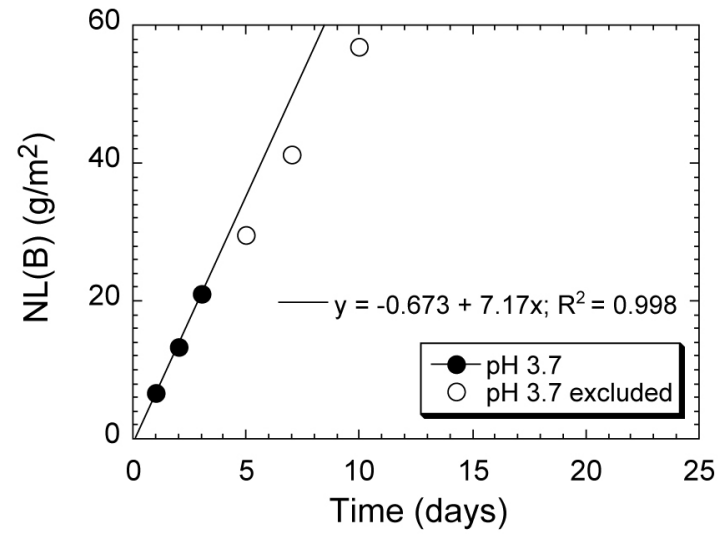

(d)

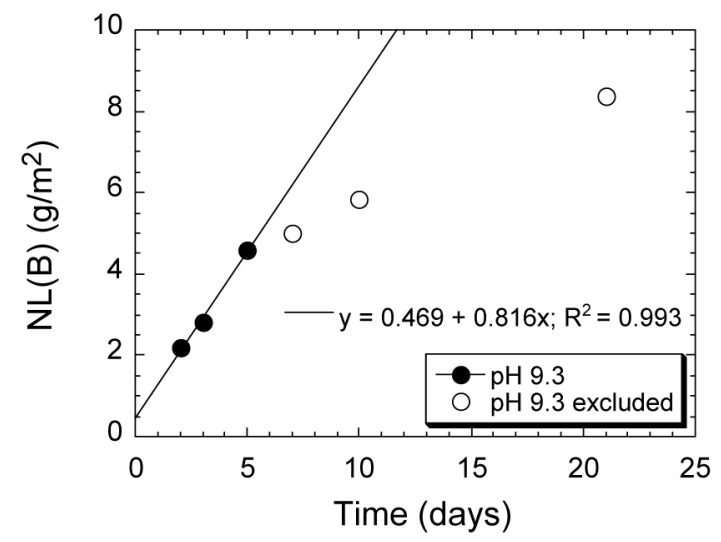

(f)

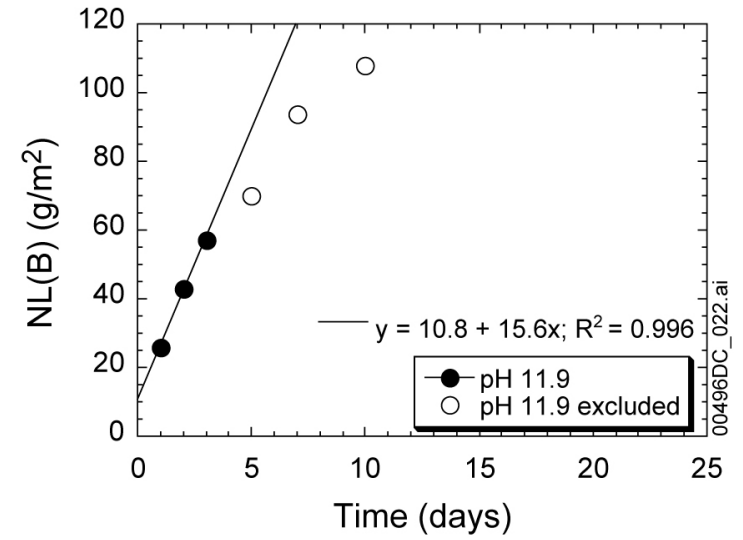

NOTE: Results shown by open symbols were excluded from the regression line (see text following Equation A-1).

Figure A-3. $\mathrm{NL}(\mathrm{B})$ vs. Test Duration for MCC-1 Tests at $90^{\circ} \mathrm{C}$ with Added Iron at (a) $\mathrm{pH} 1.0$ with $\mathrm{FeCl}_{3}$, (b) $\mathrm{pH} 3.7$ with $\mathrm{FeOOH}$, (c) pH 8.5 with $\mathrm{Fe}_{2} \mathrm{O}_{3}$, (d) $\mathrm{pH} 9.3$ with $\mathrm{Fe}_{3} \mathrm{O}_{4}$, (e) $\mathrm{pH} 10.2$ with $\mathrm{FeOOH}$, and (f) $\mathrm{pH} 11.9$ with $\mathrm{FeOOH}$ 
Table A-8. Results of Tests with SRL 202G glass: NR(B), $g /\left(m^{2} \cdot d\right)$

\begin{tabular}{|c|c|c|}
\hline Nominal $\mathrm{pH}^{\mathrm{a}}$ & $\begin{array}{c}N R(B) \\
g /\left(m^{2} \cdot d\right)\end{array}$ & $\mathbf{R}^{2, b}$ \\
\hline \multicolumn{3}{|c|}{ Tests at $70^{\circ} \mathrm{C}$} \\
\hline 1.3 & 55.5 & 0.971 \\
\hline 3.7 & 2.26 & 0.887 \\
\hline 5.0 & 1.03 & 0.892 \\
\hline 8.5 & 0.139 & 0.734 \\
\hline 9.3 & 0.197 & 0.915 \\
\hline 10.2 & 0.646 & 0.907 \\
\hline 11.9 & $6.86 \mathrm{c}$ & $1.000 \mathrm{c}$ \\
\hline 11.9 & $8.33 d$ & $0.980 d$ \\
\hline \multicolumn{3}{|c|}{ Tests at $90^{\circ} \mathrm{C}$} \\
\hline 1.3 & 79.1 & 0.987 \\
\hline 3.7 & 6.47 & 0.981 \\
\hline 5.0 & 1.27 & 0.994 \\
\hline 8.5 & 0.410 & 0.967 \\
\hline 9.3 & 0.522 & 0.995 \\
\hline 9.8 & 3.38 & 0.990 \\
\hline 11.9 & 15.4 & 1.000 \\
\hline \multicolumn{3}{|c|}{ Tests at $90^{\circ} \mathrm{C}$ with Iron } \\
\hline 1.0 & 133 & 0.968 \\
\hline 3.7 & 7.17 & 0.998 \\
\hline 8.5 & 0.543 & 0.933 \\
\hline 9.3 & 0.816 & 0.993 \\
\hline 10.2 & 5.17 & 0.981 \\
\hline 11.9 & 15.6 & 0.996 \\
\hline
\end{tabular}

NOTES: ${ }^{a} \mathrm{pH}$ measured at room temperature.

${ }^{b}$ Linear correlation coefficient squared.

${ }^{\mathrm{c}}$ Excluding result of test GB6-70-1.

d Including result of test GB6-70-1. 
Tests at $90^{\circ} \mathrm{C}$ in Acidic Solutions

\begin{tabular}{|c|c|c|c|c|c|c|c|c|c|c|}
\hline \multirow{2}{*}{$\underset{\mathrm{pH}}{\text { Nominal }}$} & \multirow{2}{*}{$\begin{array}{c}\text { Measured } \\
\text { Rate, } \\
\text { g/(m².d) }\end{array}$} & \multirow{2}{*}{$\log ($ rate) } & \multicolumn{4}{|c|}{$\log _{10}($ rate $)=-0.49 \mathrm{pH}+2.60+\varepsilon$} & \multicolumn{4}{|c|}{ Residuals } \\
\hline & & & $\varepsilon=0$ & $\varepsilon=0.01$ & $\varepsilon=-0.01$ & $\varepsilon=-0.00107$ & $\varepsilon=0$ & $\varepsilon=0.01$ & $\varepsilon=-0.01$ & $\varepsilon=-0.00107$ \\
\hline 1.3 & 79.1 & 1.90 & 1.963 & 1.973 & 1.953 & 1.962 & -0.065 & -0.075 & -0.055 & -0.0638 \\
\hline 3.7 & 6.47 & 0.811 & 0.787 & 0.797 & 0.777 & 0.786 & 0.024 & 0.014 & 0.034 & 0.0250 \\
\hline 5 & 1.27 & 0.104 & 0.150 & 0.160 & 0.140 & 0.149 & -0.046 & -0.056 & -0.036 & -0.0451 \\
\hline $1.0 \mathrm{w} / \mathrm{Fe}$ & 133 & 2.12 & 2.110 & 2.120 & 2.100 & 2.109 & 0.014 & 0.004 & 0.024 & 0.0149 \\
\hline $3.7 \mathrm{w} / \mathrm{Fe}$ & 7.17 & 0.856 & 0.787 & 0.797 & 0.777 & 0.786 & 0.069 & 0.059 & 0.079 & 0.0696 \\
\hline & & & & & & of Residuals: & -0.005 & -0.055 & 0.045 & 0.0006 \\
\hline
\end{tabular}

Tests at $90^{\circ} \mathrm{C}$ in Alkaline Solutions

\begin{tabular}{|c|c|c|c|c|c|c|c|c|c|c|}
\hline \multirow{2}{*}{$\underset{\mathrm{pH}}{\text { Nominal }}$} & \multirow{2}{*}{$\begin{array}{c}\text { Measured } \\
\text { Rate, } \\
\text { g/(m².d) }\end{array}$} & \multirow{2}{*}{$\log _{10}($ rate $)$} & \multicolumn{4}{|c|}{$\log _{10}($ rate $)=0.49 \mathrm{pH}-4.54+\varepsilon$} & \multicolumn{4}{|c|}{ Residuals } \\
\hline & & & $\varepsilon=0$ & $\varepsilon=0.01$ & $\varepsilon=-0.01$ & $\varepsilon=0.00175$ & $\varepsilon=0$ & $\varepsilon=0.01$ & $\varepsilon=-0.01$ & $\varepsilon=0.00175$ \\
\hline 8.5 & 0.41 & -0.387 & -0.375 & -0.365 & -0.385 & -0.373 & -0.012 & -0.022 & -0.002 & -0.0140 \\
\hline 9.3 & 0.522 & -0.282 & 0.017 & 0.027 & 0.007 & 0.019 & -0.299 & -0.309 & -0.289 & -0.3011 \\
\hline 9.8 & 3.38 & 0.529 & 0.262 & 0.272 & 0.252 & 0.264 & 0.267 & 0.257 & 0.277 & 0.2652 \\
\hline 11.9 & 15.4 & 1.19 & 1.291 & 1.301 & 1.281 & 1.293 & -0.103 & -0.113 & -0.093 & -0.1052 \\
\hline $8.5 \mathrm{w} / \mathrm{Fe}$ & 0.543 & -0.265 & -0.375 & -0.365 & -0.385 & -0.373 & 0.110 & 0.100 & 0.120 & 0.1080 \\
\hline $9.3 \mathrm{w} / \mathrm{Fe}$ & 0.816 & -0.0883 & 0.017 & 0.027 & 0.007 & 0.019 & -0.105 & -0.115 & -0.095 & -0.1071 \\
\hline $10.2 \mathrm{w} / \mathrm{Fe}$ & 5.17 & 0.713 & 0.458 & 0.468 & 0.448 & 0.460 & 0.255 & 0.245 & 0.265 & 0.2537 \\
\hline $11.9 \mathrm{w} / \mathrm{Fe}$ & 15.6 & 1.19 & 1.291 & 1.301 & 1.281 & 1.293 & -0.098 & -0.108 & -0.088 & -0.0996 \\
\hline \multicolumn{7}{|r|}{ f Residuals: } & 0.014 & -0.066 & 0.094 & 0.0000 \\
\hline
\end{tabular}


Table A-9. Results of Manual Regression of pH Dependence to Measured Rates (Continued)

Tests at $70^{\circ} \mathrm{C}$ in Acidic Solutions

\begin{tabular}{|c|c|c|c|c|c|c|c|c|c|c|}
\hline \multirow{2}{*}{$\begin{array}{c}\text { Nominal } \\
\mathrm{pH}\end{array}$} & \multirow{2}{*}{$\begin{array}{c}\text { Measured } \\
\text { Rate, } \\
\text { g/(m².d) }\end{array}$} & \multirow[b]{2}{*}{$\log _{10}($ rate $)$} & \multicolumn{4}{|c|}{$\log _{10}($ rate $)=-0.49 \mathrm{pH}+2.34+\varepsilon$} & \multicolumn{4}{|c|}{ Residuals } \\
\hline & & & $\varepsilon=0$ & $\varepsilon=0.01$ & $\varepsilon=-0.01$ & $\varepsilon=-0.00293$ & $\varepsilon=0$ & $\varepsilon=0.01$ & $\varepsilon=-0.01$ & $\varepsilon=-0.00293$ \\
\hline 1.3 & 55.5 & 1.74 & 1.703 & 1.713 & 1.693 & 1.700 & 0.041 & 0.031 & 0.051 & 0.0442 \\
\hline 3.7 & 2.26 & 0.354 & 0.527 & 0.537 & 0.517 & 0.524 & -0.173 & -0.183 & -0.163 & -0.1700 \\
\hline 5 & 1.03 & 0.0128 & -0.110 & -0.100 & -0.120 & -0.113 & 0.123 & 0.113 & 0.133 & 0.1258 \\
\hline \multicolumn{7}{|c|}{ Sum of Residuals: } & -0.009 & -0.039 & 0.021 & 0.0000 \\
\hline
\end{tabular}

Tests at $70^{\circ} \mathrm{C}$ in Alkaline Solutions

\begin{tabular}{|c|c|c|c|c|c|c|c|c|c|c|}
\hline \multirow{2}{*}{$\begin{array}{c}\text { Nominal } \\
\mathrm{pH}\end{array}$} & \multirow{2}{*}{$\begin{array}{c}\text { Measured } \\
\text { Rate, } \\
\mathrm{g} /\left(\mathrm{m}^{2} \cdot \mathrm{d}\right) \\
\end{array}$} & \multirow[b]{2}{*}{$\log _{10}$ (rate) } & \multicolumn{4}{|c|}{$\log _{10}($ rate $)=0.49 \mathrm{pH}-5.12+\varepsilon$} & \multicolumn{4}{|c|}{ Residuals } \\
\hline & & & $\varepsilon=0$ & $\varepsilon=0.01$ & $\varepsilon=-0.01$ & $\varepsilon=0.00325$ & $\varepsilon=0$ & $\varepsilon=0.01$ & $\varepsilon=-0.01$ & $\varepsilon=0.00325$ \\
\hline 8.5 & 0.139 & -0.86 & -0.955 & -0.945 & -0.965 & -0.952 & 0.098 & 0.088 & 0.108 & 0.0948 \\
\hline 9.3 & 0.197 & -0.71 & -0.563 & -0.553 & -0.573 & -0.560 & -0.143 & -0.153 & -0.133 & -0.1458 \\
\hline 10.2 & 0.646 & -0.19 & -0.122 & -0.112 & -0.132 & -0.119 & -0.068 & -0.078 & -0.058 & -0.0710 \\
\hline 11.9 & $6.86^{a}$ & 0.84 & 0.711 & 0.721 & 0.701 & 0.714 & 0.125 & 0.115 & 0.135 & 0.1221 \\
\hline \multicolumn{7}{|c|}{ Sum of Residuals: } & 0.013 & -0.027 & 0.053 & 0.0000 \\
\hline
\end{tabular}

Source: DTN: MO0307ANLGAMR3.016.

NOTE: $\quad$ a Rate when result of test GB6-70-1 is excluded. 
APPENDIX B

EXTRACTION OF $\log _{10}\left(k_{E}\right)$ FROM MEASURED DISSOLUTION RATES AND CALCULATION OF RATES 


\section{INTENTIONALLY LEFT BLANK}




\section{B. EXTRACTION OF $\log _{10}\left(k_{E}\right)$ FROM MEASURED DISSOLUTION RATES AND CALCULATION OF RATES}

The rate expression is:

$$
\text { rate }=\mathrm{k}_{\mathrm{E}} \times 10^{\eta} \times \mathrm{pH} \times \exp \left(-\mathrm{E}_{\mathrm{a}} / \mathrm{RT}\right)
$$

The logarithm form of the rate expression is:

$$
\begin{gathered}
\log _{10}(\text { rate })=\log _{10}\left(\mathrm{k}_{\mathrm{E}}\right)+\eta \times \mathrm{pH}+\log _{10}\left(\exp \left(-\mathrm{E}_{\mathrm{a}} / \mathrm{RT}\right)\right) \\
\log _{10}(\text { rate })=\log _{10}\left(\mathrm{k}_{\mathrm{E}}\right)+\eta \times \mathrm{pH}-\mathrm{E}_{\mathrm{a}} /(2.303 \mathrm{RT})
\end{gathered}
$$

The rate expression is rearranged to solve for the value of $\log _{10}\left(\mathrm{k}_{\mathrm{E}}\right)$ as:

$$
\log _{10}\left(k_{\mathrm{E}}\right)=\log _{10}(\text { rate })-\eta \times p H+E_{a} /(2.303 R T)
$$

The dissolution rate determined from the boron release rate is:

$$
\log _{10}\left(\mathrm{k}_{\mathrm{E}}\right)=\log _{10}(\mathrm{NR}(\mathrm{B}))-\eta \times \mathrm{pH}+\mathrm{E}_{\mathrm{a}} /(2.303 \mathrm{RT})
$$

If results are available for several durations, the normalized boron release rate can be determined as the slope of a plot of $\mathrm{NL}(\mathrm{B})$ versus duration and calculated as:

$$
\mathrm{NR}(\mathrm{B})=\Delta \mathrm{NL}(\mathrm{B}) / \Delta \mathrm{t}
$$

where $\mathrm{NL}(\mathrm{B})$ is the normalized boron mass loss and $t$ is the test duration. If tests are conducted for a single duration, the average normalized boron release rate can be calculated as:

$$
\mathrm{NR}(\mathrm{B})=\mathrm{NL}(\mathrm{B}) / \mathrm{t}
$$

\section{B.1 CALCULATION OF $\mathrm{k}_{\mathrm{E}}$ FROM THE FORWARD DISSOLUTION RATES}

For tests in which NR(B) gives the forward dissolution rate, the value of $\mathrm{k}_{\mathrm{E}}$ is expressed as $\mathrm{k}_{0}$. Equation B-5 was solved by substituting parameters determined from the dissolution in alkaline solutions. Table B-1 shows the determination of $\log _{10}\left(\mathrm{k}_{0}\right)$ from the values of $\mathrm{NR}(\mathrm{B})$ from MCC-1 tests (see Table 6-5 for references to measured rates and $\mathrm{pH}$ values) for $\eta=0.49$, $\mathrm{E}_{\mathrm{a}}=69 \mathrm{~kJ} / \mathrm{mol}, \mathrm{R}=0.008314 \mathrm{~kJ} / \mathrm{mol} \cdot \mathrm{K}$, and $\mathrm{T}=363 \mathrm{~K}\left(90^{\circ} \mathrm{C}\right)$. The value of the term giving the temperature dependence is $\mathrm{E}_{\mathrm{a}} /(2.303 \mathrm{RT})$ is 9.93 for all calculations. These results are shown in Table 6-5. 
Table B-1. Extraction of $\log _{10}\left(k_{0}\right)$ from Forward Dissolution Rates

\begin{tabular}{|c|c|c|c|c|c|}
\hline Glass & $\begin{array}{l}\mathrm{NR}(\mathrm{B}) \\
\mathrm{g} /\left(\mathrm{m}^{2} \cdot \mathrm{d}\right)\end{array}$ & $\log _{10}(N R(B))$ & pH & $0.49 \cdot \mathrm{pH}$ & $\log _{10}\left(k_{0},\right)$ \\
\hline \multicolumn{6}{|c|}{ HLW Glasses } \\
\hline SRL 51S & 0.66 & -0.1805 & 9.9 & 4.85 & 4.90 \\
\hline SRL 202U & 0.69 & -0.1612 & 9.8 & 4.80 & 4.97 \\
\hline SRL 165U & 1.0 & 0.0000 & 9.6 & 4.70 & 5.23 \\
\hline SRL 131U & 1.2 & 0.0792 & 9.8 & 4.80 & 5.21 \\
\hline WV6 & 0.69 & -0.1612 & 9.5 & 4.66 & 5.11 \\
\hline Hanford-D & 1.80 & 0.2553 & 10.5 & 5.15 & 5.04 \\
\hline \multicolumn{6}{|c|}{ Other Glasses } \\
\hline Hanford-L & 0.97 & -0.0132 & 9.5 & 4.66 & 5.26 \\
\hline LD6-5412 & 0.47 & -0.3279 & 9.3 & 4.56 & 5.04 \\
\hline PNL 7668 & 1.1 & 0.0414 & 9.2 & 4.51 & 5.46 \\
\hline \multirow{3}{*}{\multicolumn{2}{|c|}{ Average for All Glasses }} & \multicolumn{3}{|l|}{ Average: } & 5.14 \\
\hline & & \multicolumn{3}{|l|}{ Standard Deviation: } & 0.17 \\
\hline & & \multicolumn{3}{|c|}{ Percent Relative Standard Deviation: } & 3.31 \\
\hline \multirow{3}{*}{\multicolumn{2}{|c|}{$\begin{array}{l}\text { Average for } 6 \mathrm{HLW} \\
\text { Glasses }\end{array}$}} & \multicolumn{3}{|l|}{ Average: } & 5.07 \\
\hline & & \multicolumn{3}{|l|}{ Standard Deviation: } & 0.13 \\
\hline & & \multicolumn{3}{|c|}{ Percent Relative Standard Deviation: } & 2.56 \\
\hline
\end{tabular}

\section{B.2 EXTRACTION OF $k_{E}$ FROM PCT RATES}

For tests in which $\mathrm{NR}(\mathrm{B})$ gives the average dissolution rate in a 7-day PCT, the value of $\mathrm{k}_{\mathrm{E}}$ is expressed as $\mathrm{k}_{\text {РСT. }}$. Equation B-5 was solved by substituting parameters for dissolution in alkaline solutions in a Microsoft Excel spreadsheet. Table B-2 shows the determination of $\log _{10}\left(\mathrm{k}_{\mathrm{PCT}}\right.$ ) from the values of $\mathrm{NR}(\mathrm{B})$ from long-term PCT (see Table 6-6 for measured rates and $\mathrm{pH}$ values) for $\eta=0.49, \mathrm{E}_{\mathrm{a}}=69 \mathrm{~kJ} / \mathrm{mol}, \mathrm{R}=0.008314 \mathrm{~kJ} /(\mathrm{mol} \mathrm{K})$, and $\mathrm{T}=363 \mathrm{~K}\left(90^{\circ} \mathrm{C}\right)$. The value of the term giving the temperature dependence is $\mathrm{E}_{\mathrm{a}} /(2.303 \mathrm{RT})$ is 9.93 (unitless) for all calculations. These results are included in Table 6-6. 
Table B-2. Extraction of $\log 10(\mathrm{kPCT})$ from 7-day PCT Rates

\begin{tabular}{|c|c|c|c|c|c|c|}
\hline Glass & $\begin{array}{l}\mathrm{NL}(\mathrm{B}) \\
\left(\mathrm{g} / \mathrm{m}^{2}\right)\end{array}$ & $\begin{array}{c}N R(B) \\
\left(g /\left(m^{2} \cdot d\right)\right)\end{array}$ & $\log _{10}(N R(B))$ & $\mathrm{pH}$ & $0.49 \cdot \mathrm{pH}$ & $\begin{array}{l}\log _{10}\left(k_{P C T}\right) \\
\left(g /\left(m^{2} \cdot d\right)\right)\end{array}$ \\
\hline \multicolumn{7}{|c|}{ HLW Glasses } \\
\hline SRL 51Sa & 0.267 & 0.0381 & -1.419 & 10.66 & 5.223 & 3.29 \\
\hline SRL 51Sb & 0.247 & 0.0353 & -1.452 & 10.33 & 5.062 & 3.42 \\
\hline \multicolumn{6}{|l|}{ SRL 51S avg } & 3.35 \\
\hline SRL 165U & 0.308 & 0.0440 & -1.357 & 10.31 & 5.052 & 3.52 \\
\hline SRL 202U & 0.298 & 0.0426 & -1.371 & 10.42 & 5.106 & 3.45 \\
\hline SRL 131U & 4.81 & 0.6871 & -0.163 & 11.63 & 5.699 & 4.07 \\
\hline WV ref 6 & 0.270 & 0.0386 & -1.414 & 9.98 & 4.890 & 3.63 \\
\hline Hanford-D & 0.361 & 0.0516 & -1.288 & 10.67 & 5.228 & 3.41 \\
\hline Glass & $\begin{array}{l}\mathrm{NL}(\mathrm{B}) \\
\left(\mathrm{g} / \mathrm{m}^{2}\right)\end{array}$ & $\begin{array}{c}N R(B) \\
\left(g /\left(m^{2} \cdot d\right)\right)\end{array}$ & $\log _{10}(N R(B))$ & $\mathrm{pH}$ & $0.49 \cdot \mathrm{pH}$ & $\begin{array}{c}\log _{10}\left(\mathrm{~K}_{\mathrm{PCT}}\right) \\
\left(\mathrm{g} /\left(\mathrm{m}^{2} \cdot \mathrm{d}\right)\right)\end{array}$ \\
\hline \multicolumn{7}{|c|}{ HLW Glasses } \\
\hline SRL202G & 0.608 & 0.0869 & -1.061 & 11.11 & 5.444 & 3.42 \\
\hline SRL 200S & 0.700 & 0.100 & -1.000 & 10.65 & 5.219 & 3.71 \\
\hline \multicolumn{7}{|c|}{ Other Glasses } \\
\hline Hanford-L & 0.475 & 0.0679 & -1.168 & 10.96 & 5.370 & 3.39 \\
\hline PNL 76-68 & 1.23 & 0.176 & -0.755 & 9.43 & 4.621 & 4.55 \\
\hline LD6-5412 & 0.082 & 0.0117 & -1.931 & 11.20 & 5.488 & 2.51 \\
\hline SAN 60 & 0.385 & 0.0550 & -1.260 & 9.80 & 4.802 & 3.87 \\
\hline EA & 8.21 & 1.17 & 0.0682 & 11.87 & 5.816 & 4.18 \\
\hline \multirow{3}{*}{\multicolumn{3}{|c|}{ For All Glasses: }} & \multicolumn{3}{|l|}{\begin{tabular}{|l} 
Average: \\
\end{tabular}} & 3.58 \\
\hline & & & \multicolumn{3}{|c|}{ Standard deviation: } & 0.47 \\
\hline & & & \multicolumn{3}{|c|}{ Percent relative standard deviation: } & 13.13 \\
\hline \multirow{3}{*}{\multicolumn{3}{|c|}{ For All Glasses Except EA: }} & \multicolumn{3}{|l|}{ Average: } & 3.57 \\
\hline & & & \multicolumn{3}{|c|}{ Standard deviation: } & 0.48 \\
\hline & & & \multicolumn{3}{|c|}{ Percent relative standard deviation: } & 13.45 \\
\hline \multirow{3}{*}{\multicolumn{3}{|c|}{ For 8 HLW Glasses }} & \multicolumn{3}{|l|}{ Average: } & 3.57 \\
\hline & & & \multicolumn{3}{|c|}{ Standard deviation: } & 0.23 \\
\hline & & & \multicolumn{3}{|c|}{ Percent relative standard deviation: } & 6.44 \\
\hline \multicolumn{7}{|c|}{ Other Tests } \\
\hline Glass & $\begin{array}{l}N \mathrm{NL}(\mathrm{B}) \\
\left(\mathrm{g} / \mathrm{m}^{2}\right)\end{array}$ & $\begin{array}{c}N R(B) \\
\left(g /\left(m^{2} \cdot d\right)\right)\end{array}$ & $\begin{array}{c}\log _{10}(N R(B)) \\
\left(g /\left(m^{2} \cdot d\right)\right)\end{array}$ & pH & $0.49 \cdot \mathrm{pH}$ & $\begin{array}{c}\log _{10}\left(k_{P C T}\right) \\
\left(g /\left(m^{2} \cdot d\right)\right)\end{array}$ \\
\hline $\begin{array}{l}\text { EA in Tuff } \\
\text { Groundwater }\end{array}$ & 4.48 & 0.64 & 0.6513 & 11.61 & 5.689 & 4.05 \\
\hline CWF & 0.0675 & 0.00964 & -1.171 & 9.01 & 4.416 & 3.50 \\
\hline
\end{tabular}




\section{B.3 CALCULATION OF MODEL RATES FOR COMPARISON WITH MEASURED RATES AFTER SECONDARY ALTERATION PHASES FORM}

Equation B-3 was solved using the maximum and minimum values of $\mathrm{k}_{\mathrm{E}}$ for dissolution in alkaline solutions at $90^{\circ} \mathrm{C}$ and at the $\mathrm{pH}$ values attained by various glasses when zeolites precipitate and cause the dissolution rate to increase. The parameter values are:

$$
\begin{gathered}
\mathrm{k}_{\mathrm{E}_{-} \text {alkaline }} \operatorname{maximum}=3.47 \times 10^{4} \mathrm{~g} /\left(\mathrm{m}^{2} \cdot \mathrm{d}\right) ; \mathrm{k}_{\mathrm{E} \_ \text {alkaline }} \operatorname{minimum}=28.2 \mathrm{~g} /\left(\mathrm{m}^{2} \cdot \mathrm{d}\right) ; \\
\eta=0.49 ;-69 /(2.303 \mathrm{RT}) \text { at } 90^{\circ} \mathrm{C}=-9.927
\end{gathered}
$$

The rate expressions are:

$$
\begin{gathered}
\log _{10}(\text { maximum rate })=\log \left(3.47 \times 10^{4}\right)+0.49 \times \mathrm{pH}-9.927 \\
\log _{10}(\text { minimum rate })=\log (28.2)+0.49 \times \mathrm{pH}-9.927 \\
\log _{10}(\text { mean rate })=\log \left(1.16 \times 10^{4}\right)+0.49 \times \mathrm{pH}-9.927
\end{gathered}
$$

The mean rate is calculated from the maximum, minimum, and mode of the $\mathrm{k}_{\mathrm{E}}$ distribution (Evans et al. 1993 [DIRS 112115]). These expressions were solved in a Microsoft Excel spreadsheet. The results are summarized in Table B-3. The results are included in Table 7-2.

Table B-3. Calculation of Maximum and Minimum Rates from Tests in which Secondary Alteration Products formed on the Sample Surface

\begin{tabular}{|l|c|c|c|c|c|c|c|}
\hline \multirow{2}{*}{ Glass } & \multirow{2}{*}{$\mathbf{p H}$} & \multicolumn{2}{c|}{ Mean Rate $\left.\mathbf{g} / \mathbf{m}^{\mathbf{2}} \cdot \mathbf{d}\right)$} & \multicolumn{2}{c|}{ Maximum Rate $\left.\mathbf{g} / \mathbf{m}^{\mathbf{2}} \cdot \mathbf{d}\right)$} & \multicolumn{2}{c|}{ Minimum Rate $\left.\mathbf{g} / \mathbf{m}^{2} \cdot \mathbf{d}\right)$} \\
\cline { 3 - 8 } & & $\log _{10}($ Rate $)$ & Rate & $\log _{10}($ Rate $)$ & Rate & $\log _{10}($ Rate $)$ & Rate \\
\hline EA & 12.3 & 0.164 & 1.46 & 0.638 & 4.35 & -2.45 & 0.00353 \\
\hline SRL 131A & 12.1 & 0.066 & 1.16 & 0.540 & 3.47 & -2.55 & 0.00282 \\
\hline SRL 202A & 12.0 & 0.017 & 1.04 & 0.491 & 3.10 & -2.60 & 0.00252 \\
\hline SRL 200S & 12.2 & 0.115 & 1.30 & 0.589 & 3.88 & -2.50 & 0.00316 \\
\hline SAN60 & 9.8 & -1.061 & 0.09 & -0.587 & 0.259 & -3.68 & 0.000210 \\
\hline LD6-5412 & 12.0 & 0.017 & 1.04 & 0.491 & 3.10 & -2.60 & 0.00252 \\
\hline
\end{tabular}

\section{B.4 CALCULATION OF MODEL RATES FOR COMPARISON WITH MEASURED RATES FOR BASALTIC GLASS}

Equation B-3 was solved by substituting the maximum and minimum values of $\mathrm{k}_{\mathrm{E}}$ for dissolution in alkaline solutions at $3^{\circ} \mathrm{C}$. The parameter values are:

$$
\begin{gathered}
\mathrm{k}_{\mathrm{E}_{-} \text {alkaline }} \operatorname{maximum}=3.47 \times 10^{4} \mathrm{~g} /\left(\mathrm{m}^{2} \cdot \mathrm{d}\right) ; \mathrm{k}_{\mathrm{E}_{-} \text {alkaline }} \operatorname{minimum}=28.2 \mathrm{~g} /\left(\mathrm{m}^{2} \cdot \mathrm{d}\right) \\
\eta=0.49 ;-69 /(2.303 \mathrm{RT}) \text { at } 90^{\circ} \mathrm{C}=-13.057 \\
\mathrm{k}_{\mathrm{E}_{-} \text {alkaline }} \operatorname{maximum}=2.47 \times 10^{4} \mathrm{~g} /\left(\mathrm{m}^{2} \cdot \mathrm{d}\right) ; \mathrm{k}_{\mathrm{E}_{-} \text {alkaline }} \operatorname{minimum}=28.2 \mathrm{~g} /\left(\mathrm{m}^{2} \cdot \mathrm{d}\right) \\
\eta=0.49 ;-69 /(2.303 \mathrm{RT}) \text { at } 3^{\circ} \mathrm{C}=-13.057 \\
\log _{10}(\operatorname{maximum} \text { rate })=\log \left(3.47 \times 10^{4}\right)+0.49 \times \mathrm{pH}-13.057 \\
\log _{10}(\text { minimum rate })=\log (28.2)+0.49 \times \mathrm{pH}-13.057
\end{gathered}
$$


These expressions were solved using a Microsoft Excel spreadsheet. The results are given in Table B-4 and cited in Section 7.3.

Table B-4. Calculation of Maximum and Minimum Rates at $3^{\circ} \mathrm{C}$

\begin{tabular}{|c|c|c|c|c|c|}
\hline \multirow{2}{*}{ Glass } & \multirow{2}{*}{$\mathbf{p H}$} & \multicolumn{2}{c|}{ Maximum Rate $\mathbf{g} /\left(\mathbf{m}^{\mathbf{2}} \cdot \mathbf{d}\right)$} & \multicolumn{2}{c|}{ Minimum $\mathbf{R a t e} \mathbf{g}\left(\mathbf{m}^{2} \cdot \mathbf{d}\right)$} \\
\cline { 2 - 6 } & 7 & $\log _{\mathbf{1 0}}($ Rate $)$ & Rate & $\log _{\mathbf{1 0}}($ Rate $)$ & Rate \\
\hline Basalt & 7 & -4.93513 & $1.16 \mathrm{E}-05$ & -8.17888 & $6.62 \mathrm{E}-09$ \\
\hline Basalt & 8 & -4.44513 & $3.59 \mathrm{E}-05$ & -7.68888 & $2.05 \mathrm{E}-08$ \\
\hline Basalt & 9 & -3.95513 & $1.11 \mathrm{E}-04$ & -7.19888 & $6.33 \mathrm{E}-08$ \\
\hline
\end{tabular}




\section{INTENTIONALLY LEFT BLANK}


APPENDIX C

VAPOR HYDRATION TESTS 


\section{INTENTIONALLY LEFT BLANK}




\section{VAPOR HYDRATION TESTS}

A series of vapor hydration tests (VHTs) was conducted at ANL specifically to measure the degradation rates of three glasses at $70^{\circ} \mathrm{C}, 90^{\circ} \mathrm{C}, 125^{\circ} \mathrm{C}, 150^{\circ} \mathrm{C}, 175^{\circ} \mathrm{C}$, and $200^{\circ} \mathrm{C}$ (Ebert 2003 [DIRS 164518]). These test results are used to determine parameter values for the TSPA-LA glass degradation model that are applicable to glass degradation in humid air. The test results and analysis are described in this section.

The VHTs were conducted by suspending two monolithic glass samples in a sealed stainless steel vessel with a small amount of demineralized water, then heating at an elevated temperature for durations between a few hours and a few years. The extent of corrosion was quantified by measuring the thickness of a surface alteration layer. Tests were conducted at several relative humidities by varying the amount of water that was added, to the test vessel; the relative humidity was calculated from the vessel volume, the volume of water, the temperature, and the published vapor pressure of water at that temperature. Tests at relative humidities less than $100 \%$ were conducted by adding less water than the amount required to saturate the vapor phase, which was calculated steam table data. What will be referred to as standard VHTs were conducted by adding enough water to the $22 \mathrm{~mL}$ vessel to attain $100 \%$ relative humidity and provide enough water to condense on the samples and form a thin film in which corrosion occurs, but not enough water to cause the solution to drip from the sample during the test. Standard VHTs at $70^{\circ} \mathrm{C}, 90^{\circ} \mathrm{C}, 125^{\circ} \mathrm{C}, 150^{\circ} \mathrm{C}, 175^{\circ} \mathrm{C}$, and $200^{\circ} \mathrm{C}$ were conducted with about $0.10,0.11,0.13,0.15,0.20,0.25 \mathrm{~g}$ of water, respectively. Some tests were conducted with "seeded samples." Small crystals of various minerals were fixed to the surface of one of the samples (Sample B) used in a test; the other sample in the test vessel (Sample A) was not seeded. This was done to see if the presence of the seed crystal caused the alteration of that test sample to increase relative to the other, nonseeded sample. Tests were also conducted with excess water (e.g., with $7.5 \mathrm{~g}$ ) to cause a continuous reflux of water condensing on and dripping off the sample. A few tests were interrupted after a few hours to replace the water. This was done to determine if tests could be sampled periodically without affecting the reaction progress. Some tests were conducted with less than the "standard" amount of water. This was done to achieve less than $100 \%$ relative humidity.

Tests were conducted with three glasses representative of DWPF waste glasses: SRL 51S glass was made with SRL 202 frit and added chemicals, SRL 131 was made with SRL 131 frit and added chemicals (this glass is referred to as SRL 131-TDS in DTN: MO0306ANLGVH01.526 [DIRS 164331] and in some of the data source documents), and SRL 165S was made with SRL black frit II and added chemicals. The glass compositions are given in Table C-1 (DTN: MO0306ANLGIM01.525 [DIRS 164329], Table 4). Analytical results that show a mass balance of $95 \%$ to $105 \%$ are considered to be quantitative. Standard VHTs were conducted with SRL 51S glass at $70^{\circ} \mathrm{C}, 90^{\circ} \mathrm{C}, 125^{\circ} \mathrm{C}, 150^{\circ} \mathrm{C}, 175^{\circ} \mathrm{C}$, and $200^{\circ} \mathrm{C}$, with SRL 131 glass at $150^{\circ} \mathrm{C}$ and $200^{\circ} \mathrm{C}$, and with SRL $165 \mathrm{~S}$ glass at $90^{\circ} \mathrm{C}, 125^{\circ} \mathrm{C}$, and $200^{\circ} \mathrm{C}$. Tests at $<100 \%$ relative humidity and tests with excess water were conducted with the SRL 51S and SRL 131 glasses.

At the end of the test duration, vessels were removed from the oven and placed in a shallow water bath so that water vapor would rapidly condense to the bottom of the vessel. This also resulted in the evaporation of most of the water from the test samples, which remained hotter than the vessel bottom for about an hour (depending on the test temperature). The vessel was then opened and the $\mathrm{pH}$ of the condensed water was measured with $\mathrm{pH}$ paper and the $\mathrm{pH}$ 
recorded. If the water was alkaline (i.e., $\mathrm{pH}>8$ ), it was assumed that water had dripped from the sample either during the test or when the test vessel was removed from the oven and opened. The layers in tests in which water had dripped from the sample during the test are expected to be thinner than in tests in which water had not dripped. This is not used as a quantitative measure of the solution $\mathrm{pH}$ contacting the sample, and samples in tests with alkaline solutions were not rejected, but the layer thickness may be less than expected from other tests.

One or both of the reacted samples from a test were split in half in the direction they hung in the vessels then fixed in epoxy so that the range of layer thicknesses formed from top to bottom of the sample was analyzed. Jigs were used in the epoxy mounts to hold the samples perpendicular in the epoxy mounts to get an accurate measure of the layer thickness. Polishing of the sample cross sections was performed with carbide abrasive paper and water lubrication. The thickness of the alteration layer was measured with a Topcon AB60 scanning electron microscope. The average of 10 to 15 measurements for each sample was typically used as a measure of the extent of reaction.

The results are summarized in Tables C-2 through C-7 (DTN: MO0306ANLGVH01.526 [DIRS 164331]). Fewer significant figures are reported for the test duration and layer thicknesses in these tables than in DTN: MO0306ANLGVH01.526 [DIRS 164331] for some tests. Test durations less than 20 days are reported to the nearest tenth of a day. Layer thicknesses less than $99 \mu \mathrm{m}$ are reported to two significant figures.

Table C-1. Compositions of SRL 51S, SRL 165, and SRL 131 Glasses

\begin{tabular}{|c|c|c|c|c|c|c|c|}
\hline \multirow[b]{2}{*}{ Oxide } & \multicolumn{3}{|c|}{ Oxide mass \% } & \multirow[b]{2}{*}{ Oxide } & \multicolumn{3}{|c|}{ Oxide mass $\%$} \\
\hline & SRL 51S & SRL 131 & SRL 165S & & SRL 51S & SRL 131 & SRL 165S \\
\hline $\mathrm{Al}_{2} \mathrm{O}_{3}$ & 5.18 & 3.91 & 4.08 & $\mathrm{Na}_{2} \mathrm{O}$ & 9.19 & 13.4 & 10.9 \\
\hline $\mathrm{B}_{2} \mathrm{O}_{3}$ & 6.41 & 10.8 & 6.76 & $\mathrm{NiO}$ & 0.36 & 1.68 & 0.85 \\
\hline $\mathrm{BaO}$ & - & - & 0.06 & $\mathrm{P}_{2} \mathrm{O}_{5}$ & 0.573 & - & 0.02 \\
\hline $\mathrm{CaO}$ & 1.3 & 1.2 & 1.62 & $\mathrm{SiO}_{2}$ & 48.5 & 41.4 & 52.9 \\
\hline $\mathrm{Cr}_{2} \mathrm{O}_{3}$ & 0.53 & 0.1 & - & Sro & - & - & 0.1 \\
\hline $\mathrm{Fe}_{2} \mathrm{O}_{3}$ & 14.4 & 15.4 & 11.7 & $\mathrm{TiO}_{2}$ & 0.033 & 0.82 & 0.14 \\
\hline $\mathrm{K}_{2} \mathrm{O}$ & 1.64 & 0.048 & - & $\mathrm{ThO}_{2}$ & 0.034 & - & - \\
\hline $\mathrm{La}_{2} \mathrm{O}_{3}$ & 0.49 & 0.30 & - & $\mathrm{UO}_{2}$ & 0.644 & 0 & 0.92 \\
\hline $\mathrm{Li}_{2} \mathrm{O}$ & 4.69 & 4.19 & 4.18 & $\mathrm{ZnO}$ & 0.012 & 0.31 & 0.04 \\
\hline MgO & 1.97 & 1.5 & 0.70 & $\mathrm{ZrO}_{2}$ & 0.014 & 0.34 & 0.66 \\
\hline $\mathrm{MnO}_{2}$ & 1.6 & 3.90 & 2.79 & Total & 97.589 & 99.382 & 98.383 \\
\hline
\end{tabular}

Source: DTN: MO0306ANLGVH01.526 [DIRS 164331], Table 3.

NOTE: "-" = Not measured or not detected.

Table C-2. Test Matrix and Layer Thickness on the Test Specimen for VHTs with SRL 51S Glass

\begin{tabular}{|c|c|c|c|c|c|c|}
\hline \multirow[b]{2}{*}{ Test No. } & \multirow{2}{*}{$\begin{array}{c}\text { Temperature } \\
\left({ }^{\circ} \mathrm{C}\right)\end{array}$} & \multirow{2}{*}{$\begin{array}{c}\text { Time } \\
\text { (days) }\end{array}$} & \multirow[b]{2}{*}{ Water (g) } & \multirow[b]{2}{*}{$\mathrm{pH}^{\mathrm{a}}$} & \multicolumn{2}{|c|}{ Layer Thickness $(\mu \mathrm{m})$} \\
\hline & & & & & Sample A & Sample B \\
\hline \multicolumn{7}{|c|}{ Standard VHTs } \\
\hline $\mathrm{VHT}(70)-1$ & 70 & 182 & 0.1017 & 6 & not measured & not measured \\
\hline VHT(70)-2 & 70 & 471 & 0.1014 & 7 & 0 & not measured \\
\hline VHT(70)-3 & 70 & 838 & 0.1044 & 6 to 7 & 0 & 0 \\
\hline VHT(70)-4 & 70 & 1,084 & 0.1008 & 7 & 0 & not measured \\
\hline
\end{tabular}


Table C-2. Test Matrix and Layer Thickness on the Test Specimen for VHTs with SRL 51S Glass

(Continued)

\begin{tabular}{|c|c|c|c|c|c|c|}
\hline \multirow[b]{2}{*}{ Test No. } & \multirow{2}{*}{$\begin{array}{c}\text { Temperature } \\
\left({ }^{\circ} \mathrm{C}\right)\end{array}$} & \multirow{2}{*}{$\begin{array}{l}\text { Time } \\
\text { (days) }\end{array}$} & \multirow[b]{2}{*}{ Water $(g)$} & \multirow[b]{2}{*}{$\mathrm{pH}^{\mathrm{a}}$} & \multicolumn{2}{|c|}{ Layer Thickness $(\mu \mathrm{m})$} \\
\hline & & & & & Sample A & Sample B \\
\hline VHT(70)-5 & 70 & 1,361 & 0.1010 & 7 & 0 & 0 \\
\hline VHT(70)-6 & 70 & 1,361 & 0.1017 & 6 & 0 & 0 \\
\hline VHT(70)-7 & 70 & 1,361 & 0.1017 & 7 & 0 & 0 \\
\hline VHT(70)-8 & 70 & 1,045 & 0.1018 & 6 & 0 & not measured \\
\hline VHT(70)-9 & 70 & 1,322 & 0.0973 & 6 & 0 & not measured \\
\hline VHT(70)-10 & 70 & 1,322 & 0.0990 & 7 & 0 & not measured \\
\hline VHT(90)-1 & 90 & 91 & 0.1083 & 8 & $0.64 \pm 0.15$ & $0.75 \pm 0.13$ \\
\hline VHT(90)-2 & 90 & 182 & 0.1084 & 6 & not measured & not measured \\
\hline VHT(90)-3 & 90 & 418 & 0.1086 & 8 & 0 & 0 \\
\hline VHT(90)-4 & 90 & 836 & 0.1081 & 6 to 7 & 0 & 0 \\
\hline VHT(90)-5 & 90 & 1,360 & 0.1099 & 6 & 0 & 0 \\
\hline VHT(90)-6 & 90 & 1,360 & 0.1064 & 7 & 0 & 0 \\
\hline VHT(90)-7 & 90 & 279 & 0.1073 & 7 & 0 & 0 \\
\hline VHT(90)-8 & 90 & 1,037 & 0.1091 & 6 & 0 & 0 \\
\hline VHT(90)-9 & 90 & 1,285 & 0.1096 & 7 & 0 & 0 \\
\hline VHT(90)-10 & 90 & 1,285 & 0.1090 & 6 & 0 & 0 \\
\hline VHT(125)-1 & 125 & 56 & 0.1280 & 8 & $1.7 \pm 0.3$ & $3.2 \pm 0.9$ \\
\hline VHT(125)-2 & 125 & 91 & 0.1289 & 9 & $5.9 \pm 0.9$ & $8.8 \pm 1.5$ \\
\hline VHT(125)-3 & 125 & 182 & 0.1307 & 9 & $7.8 \pm 0.9$ & $15 \pm 2$ \\
\hline VHT(125)-4 & 125 & 414 & 0.1285 & 9 & $14 \pm 2$ & $19 \pm 1$ \\
\hline VHT(125)-5 & 125 & 832 & 0.1277 & 10 to 11 & $38 \pm 2$ & $41 \pm 14$ \\
\hline VHT(125)-6 & 125 & 245 & 0.1288 & 12 & 14 & 2.0 \\
\hline $\mathrm{VHT}(125)-7$ & 125 & 1,326 & 0.1291 & 9 & $32 \pm 7$ & $33 \pm 2$ \\
\hline VHT(125)-8 & 125 & 591 & 0.1306 & 8 & $43 \pm 2$ & not measured \\
\hline VHT(125)-9 & 125 & 591 & 0.1324 & 9 & $18 \pm 3$ & $15 \pm 3$ \\
\hline $\mathrm{VHT}(125)-10$ & 125 & 1,039 & 0.1311 & 10 & $24 \pm 3$ & $29 \pm 9$ \\
\hline VHT(150)-1 & 150 & 28 & 0.1480 & 8 & 0 & not measured \\
\hline VHT(150)-2 & 150 & 56 & 0.1503 & 7 & $0.93 \pm 0.15$ & $0.86 \pm 0.28$ \\
\hline VHT(150)-3 & 150 & 91 & 0.1510 & 9 & $13 \pm 2.6$ & $21 \pm 2.9$ \\
\hline VHT(150)-4 & 150 & 182 & 0.1503 & 9 & $41 \pm 1.7$ & $36 \pm 2.6$ \\
\hline VHT(150)-5 & 150 & 420 & 0.1516 & 10 & not measured & not measured \\
\hline VHT(150)-6 & 150 & 281 & 0.1470 & 12 & 50 & 43 \\
\hline $\mathrm{VHT}(150)-7$ & 150 & 443 & 0.1508 & 9 & $51 \pm 3$ & $51 \pm 9$ \\
\hline VHT(150)-8 & 150 & 597 & 0.1515 & 9 & $18 \pm 4$ & $17 \pm 2$ \\
\hline VHT(150)-9 & 150 & 351 & 0.1498 & 7 to 8 & $25 \pm 5$ & $28 \pm 5$ \\
\hline VHT(150)-10 & 150 & 351 & 0.1502 & 9 & $27 \pm 1$ & $35 \pm 2$ \\
\hline VHT(175)-1 & 175 & 17.8 & 0.1992 & 10 & $6.0 \pm 0.5$ & $5.6 \pm 0.9$ \\
\hline VHT(175)-2 & 175 & 28 & 0.2016 & 7 & $1.5 \pm 0.2$ & $1.9 \pm 0.2$ \\
\hline VHT(175)-3 & 175 & 41 & 0.1997 & 9 & $7.3 \pm 1.1$ & $11 \pm 2$ \\
\hline VHT(175)-4 & 175 & 61 & 0.1983 & 10 & $18 \pm 3$ & $22 \pm 4$ \\
\hline VHT(175)-5 & 175 & 102 & 0.2013 & 11 & $30 \pm 2$ & $59 \pm 4$ \\
\hline VHT(175)-6 & 175 & 151 & 0.1980 & 9 & $84 \pm 4$ & $79 \pm 3$ \\
\hline $\mathrm{VHT}(175)-7$ & 175 & 196 & 0.2001 & 9 & $188 \pm 7$ & $223 \pm 17$ \\
\hline $\mathrm{VHT}(200)-1$ & 200 & 2.8 & 0.2489 & 9 & $2.7 \pm 0.4$ & $4.4 \pm 0.3$ \\
\hline
\end{tabular}


Table C-2. Test Matrix and Layer Thickness on the Test Specimen for VHTs with SRL 51S Glass

(Continued)

\begin{tabular}{|c|c|c|c|c|c|c|}
\hline \multirow[b]{2}{*}{ Test No. } & \multirow{2}{*}{$\begin{array}{c}\text { Temperature } \\
\left({ }^{\circ} \mathrm{C}\right)\end{array}$} & \multirow{2}{*}{$\begin{array}{c}\text { Time } \\
\text { (days) }\end{array}$} & \multirow[b]{2}{*}{ Water (g) } & \multirow[b]{2}{*}{$\mathrm{pH}^{\mathrm{a}}$} & \multicolumn{2}{|c|}{ Layer Thickness $(\mu \mathrm{m})$} \\
\hline & & & & & Sample A & Sample B \\
\hline VHT(200)-2 & 200 & 6.8 & 0.2467 & 9 & $4.7 \pm 0.3$ & $4.3 \pm 0.4$ \\
\hline VHT(200)-3 & 200 & 9.8 & 0.2512 & 8 & $12 \pm 3$ & $8.9 \pm 0.9$ \\
\hline VHT(200)-4 & 200 & 13.9 & 0.2508 & 10 & $33 \pm 1$ & $37 \pm 2$ \\
\hline VHT(200)-5 & 200 & 16.9 & 0.2501 & 9 & $27 \pm 1$ & not measured \\
\hline VHT(200)-6 & 200 & 21 & 0.2485 & 8 & $66 \pm 3$ & not measured \\
\hline VHT(200)-7 & 200 & 35 & 0.2508 & 9 & $79 \pm 5$ & $77 \pm 4$ \\
\hline VHT(200)-8 & 200 & 28 & 0.2492 & 9 & $80 \pm 2$ & $89 \pm 2$ \\
\hline VHT(200)-9 & 200 & 45 & 0.2492 & 9 & $204 \pm 7$ & $167 \pm 17$ \\
\hline VHT(200)-10 & 200 & 57 & 0.2517 & 8 & $345 \pm 13$ & $357 \pm 41$ \\
\hline VHT(200)-11 & 200 & 70 & 0.2501 & 8 & $514 \pm 27$ & $510 \pm 48$ \\
\hline VHT(200)-12 & 200 & 87 & 0.2496 & 10 & $420 \pm 31$ & $528 \pm 13$ \\
\hline VHT(200)-13 & 200 & 49 & 0.2513 & 10 & $55 \pm 2$ & $61 \pm 7$ \\
\hline \multicolumn{7}{|c|}{ Standard VHT with and without Seeded Samples ${ }^{\mathrm{b}}$} \\
\hline $51 S 1-1$ & 200 & 2.8 & 0.2525 & & $1.7 \pm 0.2$ & $1.7 \pm 0.3$ \\
\hline $51 \mathrm{~S} 1-1 \mathrm{~A}$ & 200 & 13.8 & 0.2502 & & $12 \pm 1$ & $17 \pm 5$ \\
\hline 51S1-1S & 200 & 13.8 & 0.2495 & & $136 \pm 8$ & not measured \\
\hline $51 \mathrm{~S} 1-2$ & 200 & 21 & 0.2529 & & $24 \pm 1$ & $24 \pm 1$ \\
\hline $51 \mathrm{~S} 1-2 \mathrm{~A}$ & 200 & 6.8 & 0.2509 & & $3.6 \pm 0.6$ & $11 \pm 3$ \\
\hline $51 \mathrm{S1}-2 \mathrm{~S}$ & 200 & 2.6 & 0.2518 & & $15 \pm 1$ & $17 \pm 1$ \\
\hline $51 S 1-3$ & 200 & 9.7 & 0.2501 & & $14 \pm 1$ & $13 \pm 1$ \\
\hline 51S1-3T & 200 & 9.9 & 0.2511 & & $7.7 \pm 0.3$ & $9.4 \pm 0.7$ \\
\hline $51 \mathrm{S1-4}$ & 200 & 0.9 & 0.2522 & & $1.5 \pm 0.1$ & not measured \\
\hline 51S1-4T & 200 & 2.9 & 0.2516 & & $1.3 \pm 0.2$ & $1.6 \pm 0.2$ \\
\hline $51 S 1-5$ & 200 & 35 & 0.2501 & & $68 \pm 3$ & $69 \pm 4$ \\
\hline $51 S 1-5 A$ & 200 & 21 & 0.2514 & & $19 \pm 1$ & $24 \pm 2$ \\
\hline 51S1-6 & 200 & 60 & 0.2509 & & $409 \pm 28$ & $649 \pm 79$ \\
\hline $51 \mathrm{~S} 1-6 \mathrm{~A}$ & 200 & 9.9 & 0.2505 & & $8.5 \pm 0.4$ & $8.6 \pm 1.6$ \\
\hline $51 S 1-7$ & 200 & 6.8 & 0.2585 & & $2.8 \pm 0.3$ & $7.9 \pm 1.4$ \\
\hline $51 \mathrm{~S} 1-7 \mathrm{~A}$ & 200 & 2.6 & 0.2491 & & $2.8 \pm 0.5$ & $2.5 \pm 0.4$ \\
\hline $51 S 1-8$ & 200 & 13.8 & 0.2500 & & $15 \pm 1$ & $15 \pm 1$ \\
\hline 51S1-8A & 200 & 16.8 & 0.2516 & & $32 \pm 1$ & $32 \pm 2$ \\
\hline $51 S 1-9$ & 200 & 49 & 0.2512 & & $180 \pm 12$ & $145 \pm 22$ \\
\hline $51 S 1-10$ & 200 & 16.8 & 0.2507 & & $18 \pm 1$ & $15 \pm 1$ \\
\hline $51 \mathrm{~S} 2-11$ & 200 & 4.9 & 0.2543 & & $2.6 \pm 0.2$ & not measured \\
\hline $51 S 2-12$ & 200 & 35 & 0.2530 & & $69 \pm 2$ & $67 \pm 2$ \\
\hline $51 S 2-13$ & 200 & 28 & 0.2498 & & not measured & not measured \\
\hline $51 S 2-14$ & 200 & 49 & 0.2475 & & $225 \pm 10$ & $277 \pm 17$ \\
\hline 51S2-15 & 200 & 28 & 0.2492 & & $44 \pm 2$ & $43 \pm 4$ \\
\hline $51 \mathrm{~S}-1.5 \mathrm{~mL}-1$ & 200 & 21 & 1.4900 & 10 & $36 \pm 2$ & $38 \pm 6$ \\
\hline $51 \mathrm{~S}-1.5 \mathrm{~mL}-2$ & 200 & 6.7 & 1.4977 & 10 & $6.8 \pm 0.6$ & not measured \\
\hline $51 \mathrm{~S}-1.5 \mathrm{~mL}-3$ & 200 & 35 & 1.5113 & 11 & $38 \pm 1$ & $44 \pm 4$ \\
\hline 51S-7.5-901 & 90 & 61 & 7.5089 & 8.60 & $0.41 \pm 0.16$ & $0.75 \pm 0.53$ \\
\hline 51S-7.5-902 & 90 & 458 & 7.5292 & 7 & 0 & 0 \\
\hline 51S-7.5-1251 & 125 & 61 & 7.5034 & 8.21 & $0.97 \pm 0.26$ & not measured \\
\hline $51 S-7.5-1252$ & 125 & 458 & 7.4990 & 8 & $3.8 \pm 0.2$ & $7.7 \pm 3.0$ \\
\hline
\end{tabular}


Table C-2. Test Matrix and Layer Thickness on the Test Specimen for VHTs with SRL 51S Glass (Continued)

\begin{tabular}{|c|c|c|c|c|c|c|}
\hline \multirow[b]{2}{*}{ Test No. } & \multirow{2}{*}{$\begin{array}{c}\text { Temperature } \\
\left({ }^{\circ} \mathrm{C}\right)\end{array}$} & \multirow{2}{*}{$\begin{array}{c}\text { Time } \\
\text { (days) }\end{array}$} & \multirow[b]{2}{*}{ Water (g) } & \multirow[b]{2}{*}{$\mathrm{pH}^{\mathrm{a}}$} & \multicolumn{2}{|c|}{ Layer Thickness $(\mu \mathrm{m})$} \\
\hline & & & & & Sample A & Sample B \\
\hline \multicolumn{7}{|c|}{ Excess Water $\mathrm{VHT}^{\mathrm{c}}$} \\
\hline 51S-7.5-1501 & 150 & 61 & 7.5090 & 7.22 & $0.98 \pm 0.07$ & 0 \\
\hline 51S-7.5-1502 & 150 & 458 & 7.5059 & 7 & 0 & $2.7 \pm 0.7$ \\
\hline 51S-7.5-1751 & 175 & 49 & 7.4984 & 10.16 & 0 & $22 \pm 2$ \\
\hline 51S-7.5-1752 & 175 & 458 & 7.5035 & 10.50 & not measured & not measured \\
\hline 51S-7.5-2001 & 200 & 13.8 & 7.5091 & 9 & $7.6 \pm 6.3$ & $2.7 \pm 3.2$ \\
\hline 51S-7.5-2002 & 200 & 28 & 7.5008 & 9 & $54 \pm 6$ & $60 \pm 9$ \\
\hline 51S-7.5-2003 & 200 & 56 & 7.5085 & 10.28 & not measured & $77 \pm 5.4$ \\
\hline 51S-7.5-2004 & 200 & 73 & 7.5012 & 10.34 & not measured & not measured \\
\hline 51S-7.5-2005 & 200 & 215 & 7.5083 & 10 & not measured & not measured \\
\hline 51S-7.5-2006 & 200 & 458 & 7.5065 & dry & not measured & $133 \pm 49$ \\
\hline 51S-7.5-2007 & 200 & 6.8 & 7.5050 & 8 & $8.3 \pm 1.9$ & $0.91 \pm 0.26$ \\
\hline \multicolumn{7}{|c|}{ Interrupted Standard VHT } \\
\hline 51S-OP1 & 200 & 0.3 & 0.2497 & & & \\
\hline 51S-OP1R & 200 & 13.5 & 0.2502 & 7 & $23 \pm 2$ & $20 \pm 1$ \\
\hline 51S-OP2 & 200 & 0.3 & 0.2514 & & & \\
\hline 51S-OP2R & 200 & 28 & 0.2514 & 9 & $79 \pm 3$ & $76 \pm 3$ \\
\hline 51S-OP3 & 200 & 0.3 & 0.2498 & & & \\
\hline 51S-OP3R & 200 & 35 & 0.2509 & 9 & $105 \pm 4$ & $102 \pm 3$ \\
\hline \multicolumn{7}{|c|}{ Undersaturated $\mathrm{VHT}^{\mathrm{d}}$} \\
\hline 51S-20RH-1 & 200 & 182 & 0.0340 & 7 & not measured & not measured \\
\hline 51S-20RH-2 & 200 & 312 & 0.0301 & dry & not measured & not measured \\
\hline 51S-20RH-3 & 200 & 312 & 0.0340 & dry & not measured & not measured \\
\hline $51 \mathrm{~S}-45 \mathrm{RH}-1$ & 200 & 182 & 0.0725 & 7 & not measured & not measured \\
\hline 51S-45RH-2 & 200 & 90 & 0.0742 & 7 & $1.4 \pm 0.2$ & not measured \\
\hline $51 \mathrm{~S}-45 \mathrm{RH}-3$ & 200 & 93 & 0.0757 & dry & not measured & not measured \\
\hline 51S-64RH-1 & 200 & 12.9 & 0.0997 & dry & not measured & not measured \\
\hline 51S-64RH-2 & 200 & 91 & 0.1019 & dry & not measured & not measured \\
\hline 51S-80RH-1 & 200 & 35 & 0.1218 & dry & not measured & not measured \\
\hline 51S-80RH-2 & 200 & 35 & 0.1215 & dry & not measured & not measured \\
\hline 51S-80RH-3 & 200 & 31 & 0.1214 & dry & not measured & not measured \\
\hline 51S-80RH-4 & 200 & 14.5 & 0.1243 & dry & not measured & not measured \\
\hline 51S-80RH-5 & 200 & 90 & 0.1292 & 7 & $5.7 \pm 0.5$ & $5.1 \pm 0.8$ \\
\hline 51S-80RH-6 & 200 & 182 & 0.1229 & 7 & $3.9 \pm 0.8$ & $3.1 \pm 0.5$ \\
\hline 51S-80RH-7 & 200 & 49 & 0.1243 & 7 & $4.6 \pm 0.8$ & $4.6 \pm 1.5$ \\
\hline 51S-90RH-1 & 200 & 49 & 0.1397 & 7 & $33 \pm 10$ & not measured \\
\hline 51S-90RH-2 & 200 & 49 & 0.1425 & 7 & $33 \pm 5$ & $41 \pm 7$ \\
\hline
\end{tabular}

Source: DTN: MO0306ANLGVH01.526 [DIRS 164331], Table 1.

NOTES: ${ }^{a} \mathrm{pH}$ of solution in bottom of test vessel at end of test; $\mathrm{pH}$ measured at room temperature. Integer values measured with $\mathrm{pH}$ paper (values reported as $\mathrm{X}-\mathrm{Y}$ reported by experimentalist as between integer values $\mathrm{X}$ and $\mathrm{Y}$ ). Values given to hundredth of $\mathrm{pH}$ unit measured quantitatively with $\mathrm{pH}$ electrode. "Dry" indicates not enough solution to measure $\mathrm{pH}$.

${ }^{b}$ Appended letters denote test contained one sample seeded with: $A=$ analcime; $N=$ sodium silicate; $\mathrm{T}=$ tobermorite. Thickness of alteration layer on seeded Sample B is given in bold font.

${ }^{c}$ The second group of numbers in the Test No. is the approximate mass of water added, in $\mathrm{g}$.

${ }^{d}$ The second group of numbers in the Test No. is the approximate \% relative humidity at $200^{\circ} \mathrm{C}$. 
Table C-3. Test Matrix and Layer Thickness on the Test Specimen for VHTs with SRL 131 Glass

\begin{tabular}{|c|c|c|c|c|c|c|}
\hline \multirow[b]{2}{*}{ Test No. } & \multirow{2}{*}{$\begin{array}{c}\text { Temperature } \\
\left({ }^{\circ} \mathrm{C}\right)\end{array}$} & \multirow{2}{*}{$\begin{array}{c}\text { Time } \\
\text { (days) }\end{array}$} & \multirow{2}{*}{$\begin{array}{c}\text { Water } \\
\text { (g) }\end{array}$} & \multirow[b]{2}{*}{$\mathrm{pH}^{\mathrm{a}}$} & \multicolumn{2}{|c|}{ Layer thickness $(\mu \mathrm{m})$} \\
\hline & & & & & Sample A & Sample B \\
\hline \multicolumn{7}{|c|}{ Standard VHT } \\
\hline 131-VHT(150)-1 & 150 & 28 & 0.1495 & 8 & $11 \pm 1$ & $10 \pm 1$ \\
\hline 131-VHT(150)-2 & 150 & 56 & 0.1490 & 10 & $17 \pm 1$ & $18 \pm 1$ \\
\hline 131-VHT(150)-3 & 150 & 91 & 0.1540 & 10 & $20 \pm 1$ & $23 \pm 1$ \\
\hline 131-VHT(150)-4 & 150 & 182 & 0.1501 & 9 & $29 \pm 1$ & $30 \pm 1$ \\
\hline 131-VHT(150)-5 & 150 & 241 & 0.1475 & 9 & 43 & 50 \\
\hline \multicolumn{7}{|c|}{ Undersaturated $\mathrm{VHT}^{\mathrm{d}}$} \\
\hline 131-48RH-1 & 200 & 182 & 0.0765 & 7 & $4.5 \pm 0.3$ & 0 \\
\hline $131-48 \mathrm{RH}-2^{\mathrm{d}}$ & 200 & 90 & 0.0764 & 7 & $0.82 \pm 0.16$ & not measured \\
\hline $131-48 \mathrm{RH}-3^{\mathrm{d}}$ & 200 & 21 & 0.0770 & 8 & 0 & 0 \\
\hline $131-80 R \mathrm{RH}-1^{\mathrm{d}}$ & 200 & 12.7 & 0.1224 & 7 & $15 \pm 3$ & $15 \pm 1$ \\
\hline $131-80 R H-2^{d}$ & 200 & 20.7 & 0.1224 & dry & not measured & not measured \\
\hline 131-80RH-3 & 200 & 31 & 0.1218 & 7 & $56 \pm 5$ & $55 \pm 5$ \\
\hline $131-80 \mathrm{RH}-4^{\mathrm{d}}$ & 200 & 21 & 0.1270 & 7 & $98 \pm 6$ & $91 \pm 2$ \\
\hline $131-90 \mathrm{RH}-1^{\mathrm{d}}$ & 200 & 21 & 0.1404 & 7 & $190 \pm 8$ & $186 \pm 14$ \\
\hline \multicolumn{7}{|c|}{ Excess Water VHT ${ }^{c}$} \\
\hline $131-0.5 \mathrm{~mL}-1^{\mathrm{d}}$ & 200 & 21 & 0.4999 & 10.20 & $32 \pm 1$ & $30 \pm 5$ \\
\hline $131-1 \mathrm{~mL}-1^{\mathrm{d}}$ & 200 & 21 & 1.0032 & 9.65 & $26 \pm 3$ & $26 \pm 2$ \\
\hline $131-1.5 \mathrm{~mL}-1^{\mathrm{d}}$ & 200 & 21 & 1.5028 & 12 & $28 \pm 3$ & $21 \pm 8$ \\
\hline $131-1.5 \mathrm{~mL}-2$ & 200 & 5.7 & 1.4984 & 12 & $10 \pm 2$ & $27 \pm 1$ \\
\hline $131-1.5 \mathrm{~mL}-3$ & 200 & 2.7 & 1.4982 & 12 & $5.6 \pm 1$ & $5.7 \pm 0.5$ \\
\hline $131-1.5 \mathrm{~mL}-4^{\mathrm{d}}$ & 200 & 31 & 1.5000 & 10.14 & $35 \pm 2$ & $35 \pm 3$ \\
\hline $131-4 m L-1^{d}$ & 200 & 21 & 3.9950 & 10.23 & $20 \pm 1$ & $26 \pm 2$ \\
\hline $131-7.5 \mathrm{~mL}-1^{\mathrm{d}}$ & 200 & 21 & 7.5245 & 10 & $45 \pm 5$ & $41 \pm 2$ \\
\hline $131-7.5 \mathrm{~mL}-2$ & 200 & 2.7 & 7.4912 & 9 & $8.2 \pm 0.8$ & $8.7 \pm 0.5$ \\
\hline $131-7.5 \mathrm{~mL}-3$ & 200 & 31 & 7.5143 & 9.94 & $28 \pm 6$ & $48 \pm 5$ \\
\hline $131-7.5 \mathrm{~mL}-4^{\mathrm{d}}$ & 200 & 21 & 7.5015 & 9 & $17 \pm 1$ & $18 \pm 1$ \\
\hline $131-7.5 \mathrm{~mL}-5$ & 200 & 48 & 7.5284 & 10 & $56 \pm 13$ & $66 \pm 4$ \\
\hline $131-7.5 \mathrm{~mL}-6$ & 200 & 87 & 7.5229 & 10.11 & $130 \pm 10$ & $126 \pm 5$ \\
\hline $131-7.5-901$ & 90 & 116 & 7.4992 & 9 & $7.7 \pm 1.8$ & $18 \pm 12$ \\
\hline 131-7.5-902 & 90 & 399 & 7.4990 & 9 & $8.0 \pm 0.7$ & $14 \pm 2$ \\
\hline $131-7.5-1251$ & 125 & 116 & 7.4817 & 10 & $29 \pm 1$ & $34 \pm 2$ \\
\hline $131-7.5-1252$ & 125 & 399 & 7.5451 & $10-11$ & $34 \pm 19$ & $46 \pm 12$ \\
\hline $131-7.5-1501$ & 150 & 116 & 7.5321 & $9-10$ & $36 \pm 10$ & $29 \pm 12$ \\
\hline $131-7.5-1502$ & 150 & 399 & 7.4609 & $10-11$ & $27 \pm 7$ & $33 \pm 3$ \\
\hline \multicolumn{7}{|c|}{ Standard VHTs With and Without Seeded Samples ${ }^{\text {b }}$} \\
\hline $131-1$ & 200 & 12.0 & 0.2533 & 12 & $41 \pm 1$ & not measured \\
\hline $131-1 \mathrm{~K}$ & 200 & 2.7 & 0.2546 & 10 & $11 \pm 1$ & $9.5 \pm 0.3$ \\
\hline $131-1 \mathrm{~A}$ & 200 & 0.9 & 0.2502 & 10 & $4.4 \pm 0.5$ & $5.4 \pm 0.9$ \\
\hline $131-1 \mathrm{~N}$ & 200 & 2.7 & 0.2546 & 11 & not measured & $30 \pm 5$ \\
\hline $131-1 T$ & 200 & 1.0 & 0.2510 & 9 & $18 \pm 1$ & $31 \pm 2$ \\
\hline $131-1 \mathrm{~A}$ & 200 & 2.7 & 0.2530 & 9 & $15 \pm 1$ & $11 \pm 1$ \\
\hline $131-2$ & 200 & 3.0 & 0.2522 & dry & not measured & not measured \\
\hline
\end{tabular}


Table C-3. Test Matrix and Layer Thickness on the Test Specimen for VHTs with SRL 131 Glass

(Continued)

\begin{tabular}{|c|c|c|c|c|c|c|}
\hline \multirow[b]{2}{*}{ Test No. } & \multirow{2}{*}{$\begin{array}{c}\text { Temperature } \\
\left({ }^{\circ} \mathrm{C}\right)\end{array}$} & \multirow{2}{*}{$\begin{array}{c}\text { Time } \\
\text { (days) }\end{array}$} & \multirow{2}{*}{$\begin{array}{l}\text { Water } \\
\text { (g) }\end{array}$} & \multirow[b]{2}{*}{$\mathrm{pH}^{\mathrm{a}}$} & \multicolumn{2}{|c|}{ Layer thickness $(\mu \mathrm{m})$} \\
\hline & & & & & Sample A & Sample B \\
\hline $131-2 \mathrm{~A}$ & 200 & 5.8 & 0.2535 & 10 & $28 \pm 1$ & $26 \pm 2$ \\
\hline $131-2 \mathrm{~N}$ & 200 & 5.7 & 0.2518 & 10 & $32 \pm 3$ & $26 \pm 1$ \\
\hline $131-2 \mathrm{~T}$ & 200 & 2.8 & 0.2518 & 10 & $13 \pm 1$ & $14 \pm 1$ \\
\hline $131-3$ & 200 & 5.9 & 0.2516 & 10 & $24 \pm 1$ & $22 \pm 1$ \\
\hline $131-3 N$ & 200 & 0.7 & 0.2500 & 11 & not measured & $12 \pm 2$ \\
\hline $131-4$ & 200 & 3.0 & 0.2516 & 10 & $13 \pm 1$ & $14 \pm 1$ \\
\hline $1312-4 \mathrm{~N}$ & 200 & 13.8 & 0.2495 & 10 & $69 \pm 5$ & $60 \pm 6$ \\
\hline $1312-5$ & 200 & 1.0 & 0.2484 & dry & not measured & not measured \\
\hline $1312-5 \mathrm{~N}$ & 200 & 31 & 0.2499 & dry & not measured & not measured \\
\hline $131-6$ & 200 & 1.0 & 0.2500 & 10 & $5.5 \pm 0.3$ & $4.4 \pm 0.3$ \\
\hline $131-7$ & 200 & 12.8 & 0.2500 & 10 & $46 \pm 4$ & not measured \\
\hline $131-8$ & 200 & 0.3 & 0.2527 & dry & not measured & not measured \\
\hline $131-9$ & 200 & 28 & 0.2567 & 7 & not measured & not measured \\
\hline $131-10$ & 200 & 1.9 & 0.2529 & 10 & $5.2 \pm 0.6$ & $6.1 \pm 0.3$ \\
\hline $131-11$ & 200 & 28 & 0.2529 & 12 & not measured & not measured \\
\hline $131-12$ & 200 & 0.2 & 0.2492 & 7 & $1.4 \pm 0.2$ & not measured \\
\hline $131-13$ & 200 & 0.3 & 0.2504 & 10 & $3.5 \pm 0.3$ & $2.3 \pm 0.2$ \\
\hline $1312-14$ & 200 & 31 & 0.2502 & 12 & $273 \pm 14$ & $310 \pm 13$ \\
\hline $131-14-1$ & 200 & 21 & 0.1414 & dry & not measured & not measured \\
\hline $131-14-2$ & 200 & 21 & 0.1405 & 9 & $182 \pm 15$ & $172 \pm 8$ \\
\hline $131-14-3$ & 200 & 21 & 0.1390 & 8 & $138 \pm 9$ & $149 \pm 8$ \\
\hline $1312-15$ & 200 & 31 & 0.2494 & 12 & $422 \pm 10$ & $428 \pm 8$ \\
\hline $1312-16$ & 200 & 21 & 0.2488 & 10 & $110 \pm 16$ & $137 \pm 14$ \\
\hline $131-16-1$ & 200 & 21 & 0.1599 & 12 & $351 \pm 27$ & $341 \pm 28$ \\
\hline $131-17$ & 200 & 40 & 0.2489 & 12 & $990 \pm 39$ & $1050 \pm 20$ \\
\hline $131-18$ & 200 & 42 & 0.2490 & 12 & $584 \pm 13$ & $711 \pm 225$ \\
\hline $131-18-1$ & 200 & 21 & 0.1804 & 8 & not measured & $349 \pm 13$ \\
\hline $131-20-1$ & 200 & 21 & 0.2005 & 7 & $446 \pm 22$ & $378 \pm 11$ \\
\hline $131-22-1$ & 200 & 21 & 0.2200 & 8 & completely reacted & completely reacted \\
\hline $131-24-1$ & 200 & 210.8 & 0.2414 & 8 & completely reacted & completely reacted \\
\hline
\end{tabular}

Source: DTN: MO0306ANLGVH01.526 [DIRS 164331], Table 1.

NOTE: ${ }^{a} \mathrm{pH}$ of solution in bottom of test vessel at end of test; $\mathrm{pH}$ measured at room temperature. Integer values measured with $\mathrm{pH}$ paper (values reported as $\mathrm{X}-\mathrm{Y}$ reported by experimentalist as between integer values $\mathrm{X}$ and $\mathrm{Y}$ ). "Dry" indicates not enough solution to measure $\mathrm{pH}$.

${ }^{\mathrm{b}}$ Appended letters denote test contained one sample seeded with: $\mathrm{A}=$ analcime; $\mathrm{K}=$ kaolin clay; $\mathrm{N}$ = sodium silicate; $\mathrm{T}$ = tobermorite; Thickness of alteration layer on seeded Sample B is shown in bold.

${ }^{c}$ The second group of numbers in the Test No. is the approximate mass of water added, in $\mathrm{g}$.

${ }^{d}$ The second group of numbers in the Test No. is the approximate $\%$ relative humidity at $200^{\circ} \mathrm{C}$. 
Table C-4. Test Matrix and Layer Thickness on the Test Specimen for VHTs with SRL 165S Glass

\begin{tabular}{|c|c|c|c|c|c|c|}
\hline \multirow[b]{2}{*}{ Test No. } & \multirow{2}{*}{$\begin{array}{c}\text { Temperature } \\
\left({ }^{\circ} \mathrm{C}\right)\end{array}$} & \multirow{2}{*}{$\begin{array}{c}\text { Time } \\
\text { (days) }\end{array}$} & \multirow[b]{2}{*}{ Water $(g)$} & \multirow[b]{2}{*}{$\mathrm{pH}^{\mathrm{a}}$} & \multicolumn{2}{|c|}{ Layer thickness $(\mu \mathrm{m})$} \\
\hline & & & & & Sample A & Sample B \\
\hline 165S-VHT(90)-2 & 90 & 265 & 0.1079 & 7 & 0 & 0 \\
\hline 165S-VHT(90)-3 & 90 & 511 & 0.1135 & 7 & not measured & not measured \\
\hline 165S-VHT(90)-4 & 90 & 959 & 0.1120 & 10 & $8.0 \pm 1.4$ & not measured \\
\hline 165S-VHT(90)-5 & 90 & 1,237 & 0.1103 & 6 & 0 & 0 \\
\hline 165S-VHT(90)-6 & 90 & 1,237 & 0.1118 & 6 & 0 & 0 \\
\hline 165S-VHT(90)-7 & 90 & 1,237 & 0.1079 & 7 & 0 & 0 \\
\hline 165S-VHT(125)-2 & 125 & 91 & 0.1292 & 7 & $2.2 \pm 0.3$ & $5.1 \pm 0.7$ \\
\hline 165S-VHT(125)-3 & 125 & 265 & 0.1305 & 8 & $3.8 \pm 1.6$ & $7.4 \pm 0.8$ \\
\hline 165S-VHT(125)-4 & 125 & 511 & 0.1312 & 9 & $9.0 \pm 1.4$ & $23 \pm 2$ \\
\hline 165S-VHT(125)-5 & 125 & 959 & 0.1305 & 10 & $78 \pm 8$ & 20 \\
\hline 165S-VHT(125)-6 & 125 & 1,237 & 0.1305 & 7 & $71 \pm 19$ & $45 \pm 11$ \\
\hline 165S-VHT(125)-7 & 125 & 1,237 & 0.1314 & 9 & $111 \pm 10$ & $85 \pm 23$ \\
\hline 165S-VHT(200)-2 & 200 & 6.8 & 0.2507 & 11 & $21 \pm 2$ & $23 \pm 0.9$ \\
\hline 165S-VHT(200)-4 & 200 & 13.0 & 0.2530 & dry & not measured & not measured \\
\hline 165S-VHT(200)-5 & 200 & 16.8 & 0.2537 & 12 & $69 \pm 4$ & $95 \pm 27$ \\
\hline 165S-VHT(200)-6 & 200 & 21 & 0.2508 & 12 & $125 \pm 15$ & $148 \pm 8$ \\
\hline 165S-VHT(200)-7 & 200 & 35 & 0.2505 & 10 & $46 \pm 7$ & $57 \pm 4$ \\
\hline 165S-VHT(200)-8 & 200 & 5.0 & 0.2486 & 11 & $20 \pm 1$ & $23 \pm 3$ \\
\hline 165S-VHT(200)-9 & 200 & 26 & 0.2499 & 12 & not measured & not measured \\
\hline 165S-VHT(200)-10 & 200 & 1.9 & 0.2494 & 8 & $3.0 \pm 1.0$ & $1.7 \pm 0.4$ \\
\hline
\end{tabular}

Source: DTN: MO0306ANLGVH01.526 [DIRS 164331], Table 1.

NOTE: ${ }^{a} \mathrm{pH}$ of solution in bottom of test vessel at end of test; $\mathrm{pH}$ measured at room temperature. Integer values measured with $\mathrm{pH}$ paper. "Dry" indicates not enough solution to measure $\mathrm{pH}$. 
Table C-5. Test Results Plotted in Figure 6-5

\begin{tabular}{|c|c|c|c|c|}
\hline \multirow[b]{2}{*}{ Test Number } & \multirow{2}{*}{$\begin{array}{c}\text { Duration } \\
\text { (days) }\end{array}$} & \multirow{2}{*}{$\begin{array}{c}\text { Mass Water } \\
(\mathrm{g})\end{array}$} & \multicolumn{2}{|c|}{ Thickness $(\mu \mathrm{m})$} \\
\hline & & & Sample A & Sample B \\
\hline 131-48RH-2 & 90 & 0.0764 & 0.82 & \\
\hline 131-80RH-3 & 31 & 0.1218 & 56 & 55 \\
\hline 131-80RH-4 & 21 & 0.1270 & 98 & 91 \\
\hline 131-90RH-1 & 21 & 0.1404 & 190 & 186 \\
\hline $131-0.5 \mathrm{~mL}-1$ & 21 & 0.4999 & 32 & 30 \\
\hline $131-1 \mathrm{~mL}-1$ & 21 & 1.0032 & 26 & 26 \\
\hline $131-1.5 \mathrm{~mL}-1$ & 21 & 1.5028 & 28 & 21 \\
\hline $131-1.5 \mathrm{~mL}-4$ & 31 & 1.5000 & 35 & 35 \\
\hline $131-4 \mathrm{~mL}-1$ & 21 & 3.9950 & 20 & 26 \\
\hline $131-7.5 \mathrm{~mL}-1$ & 21 & 7.5245 & 45 & 41 \\
\hline $131-7.5 \mathrm{~mL}-3$ & 31 & 7.5143 & 28 & 47 \\
\hline $131-7.5 \mathrm{~mL} 4$ & 21 & 7.5015 & 17 & 18 \\
\hline $131-7.5 \mathrm{~mL}-6$ & 21 & 7.5229 & 130 & 126 \\
\hline $131-14-2$ & 21 & 0.1405 & 182 & 172 \\
\hline $131-14-3$ & 21 & 0.1390 & 138 & 149 \\
\hline $131-15$ & 31 & 0.2494 & 422 & 428 \\
\hline $1312-16$ & 21 & 0.2488 & 110 & 137 \\
\hline $131-16-1$ & 21 & 0.1599 & 351 & 341 \\
\hline $131-18-1$ & 21 & 0.1804 & & 349 \\
\hline $131-20-1$ & 21 & 0.2005 & 446 & 378 \\
\hline $131-22-1$ & 21 & 0.2200 & $750^{a}$ & $750^{a}$ \\
\hline $131-24-1$ & 21 & 0.2414 & $750^{a}$ & $750^{a}$ \\
\hline $131-7.5 \mathrm{~mL}-4$ & 21 & 7.5015 & 17 & 18 \\
\hline $131-7.5 \mathrm{~mL}-6$ & 87 & 7.5229 & 130 & 126 \\
\hline
\end{tabular}

Source: DTN: MO0306ANLGVH01.526 [DIRS 164331].

NOTE: ${ }^{a}$ Sample was completely reacted. 
Table C-6. Test Results Plotted in Figure 6-6a

\begin{tabular}{|c|c|c|c|c|c|}
\hline Test Number & $\begin{array}{c}\text { Duration } \\
\text { (days) }\end{array}$ & $\begin{array}{c}\text { Thickness } \\
(\mu \mathrm{m})\end{array}$ & Test Number & $\begin{array}{c}\text { Duration } \\
\text { (days) }\end{array}$ & $\begin{array}{c}\text { Thickness } \\
(\mu \mathrm{m})\end{array}$ \\
\hline \multicolumn{6}{|c|}{ Tests with SRL 51S Glass at $125^{\circ} \mathrm{C}$} \\
\hline $\mathrm{VHT}(125)-1^{\mathrm{b}}$ & 55.8 & 3.2 & $\mathrm{VHT}(125)-6^{\mathrm{b}}$ & 245 & 14 \\
\hline $\mathrm{VHT}(125)-2^{\mathrm{b}}$ & 90.8 & 8.8 & $\mathrm{VHT}(125)-7^{\mathrm{b}}$ & 1,326 & 33 \\
\hline $\mathrm{VHT}(125)-3^{\mathrm{b}}$ & 182 & 15 & $\mathrm{VHT}(125)-8^{\mathrm{a}}$ & 591 & 43 \\
\hline $\mathrm{VHT}(125)-4^{\mathrm{b}}$ & 414 & 19 & $\mathrm{VHT}(125)-9^{\mathrm{a}}$ & 591 & 18 \\
\hline $\mathrm{VHT}(125)-5^{\mathrm{b}}$ & 832 & 41 & $\mathrm{VHT}(125)-10^{\mathrm{b}}$ & 1,039 & 29 \\
\hline \multicolumn{6}{|c|}{ Tests with SRL $51 \mathrm{~S}$ Glass at $150^{\circ} \mathrm{C}$} \\
\hline $\mathrm{VHT}(150)-1^{\mathrm{a}}$ & 28 & 0 & VHT(150)-4 $4^{\mathrm{a}}$ & 182 & 41 \\
\hline $\operatorname{VHT}(150)-2^{a}$ & 56 & 0.93 & $\mathrm{VHT}(150)-6^{\mathrm{a}}$ & 281 & 50 \\
\hline $\operatorname{VHT}(150)-3^{b}$ & 91 & 21 & VHT(150)-7 $7^{\mathrm{b}}$ & 433 & 51 \\
\hline \multicolumn{6}{|c|}{ Tests with SRL $51 \mathrm{~S}$ Glass at $175^{\circ} \mathrm{C}$} \\
\hline $\mathrm{VHT}(175)-1^{\mathrm{a}}$ & 17.8 & 6.0 & $\mathrm{VHT}(175)-5^{\mathrm{b}}$ & 102 & 59 \\
\hline $\mathrm{VHT}(175)-2^{\mathrm{b}}$ & 28 & 1.9 & $\mathrm{VHT}(175)-6^{\mathrm{a}}$ & 151 & 84 \\
\hline $\mathrm{VHT}(175)-3^{\mathrm{b}}$ & 41 & 11 & $\mathrm{VHT}(175)-7^{\mathrm{b}}$ & 196 & 223 \\
\hline $\mathrm{VHT}(175)-4^{\mathrm{b}}$ & 61 & 22 & & & \\
\hline \multicolumn{6}{|c|}{ Tests with SRL $51 \mathrm{~S}$ Glass at $200^{\circ} \mathrm{C}$} \\
\hline $\mathrm{VHT}(200)-1^{\mathrm{b}}$ & 2.8 & 4.4 & $\mathrm{VHT}(200)-7^{\mathrm{a}}$ & 35 & 79 \\
\hline VHT(200)-2 $2^{a}$ & 6.8 & 4.7 & VHT(200)-8 ${ }^{\mathrm{b}}$ & 28 & 89 \\
\hline $\operatorname{VHT}(200)-3^{a}$ & 9.8 & 12 & VHT(200)-9a & 45 & 204 \\
\hline VHT(200)-4 ${ }^{\mathrm{b}}$ & 13.9 & 37 & $\mathrm{VHT}(200)-10^{\mathrm{b}}$ & 57 & 357 \\
\hline $\operatorname{VHT}(200)-5^{a}$ & 16.9 & 27 & $\mathrm{VHT}(200)-11^{\mathrm{b}}$ & 70 & 514 \\
\hline $\operatorname{VHT}(200)-6^{a}$ & 21 & 66 & VHT(200)-12 & 87 & 528 \\
\hline
\end{tabular}

Source: DTN: MO0306ANLGVH01.526 [DIRS 164331].

NOTE: ${ }^{a}$ Thickness for Sample A plotted.

${ }^{\mathrm{b}}$ Thickness for Sample B plotted. 
Table C-7. Test Results Plotted in Figure 6-6b

\begin{tabular}{|c|c|c|c|c|c|}
\hline Test Number & $\begin{array}{c}\text { Duration } \\
\text { (days) }\end{array}$ & $\begin{array}{c}\text { Thickness } \\
(\mu \mathrm{m})\end{array}$ & Test Number & $\begin{array}{c}\text { Duration } \\
\text { (days) }\end{array}$ & $\begin{array}{c}\text { Thickness } \\
(\mu \mathrm{m})\end{array}$ \\
\hline \multicolumn{6}{|c|}{ Tests with SRL 165 Glass at $125^{\circ} \mathrm{C}$} \\
\hline 165S-VHT(125)-2 & 91 & 5.1 & 165S-VHT(125)-5 & 959 & 78 \\
\hline 165S-VHT(125)-3 & 265 & 7.4 & 165S-VHT(125)-6 & 1,237 & 71 \\
\hline 165S-VHT(125)-4 & 511 & 23 & 165S-VHT(125)-7 & 1,237 & 111 \\
\hline \multicolumn{6}{|c|}{ Tests with SRL 131 Glass at $150^{\circ} \mathrm{C}$} \\
\hline 131-VHT(150)-1 & 28 & 11 & 131-VHT(150)-4 & 182 & 30 \\
\hline 131-VHT(150)-2 & 56 & 18 & 131-VHT(150)-5 & 241 & 50 \\
\hline 131-VHT(150)-3 & 91 & 23 & & & \\
\hline \multicolumn{6}{|c|}{ Tests with SRL 165 Glass at $200^{\circ} \mathrm{C}$} \\
\hline 165S-VHT(200)-2 & 6.8 & 23 & 165S-VHT(200)-8 & 5.0 & 23 \\
\hline 165S-VHT(200)-5 & 16.8 & 95 & 165S-VHT(200)-10 & 1.9 & 3.0 \\
\hline 165S-VHT(200)-6 & 21 & 148 & & & \\
\hline \multicolumn{6}{|c|}{ Tests with SRL 131 Glass at $200^{\circ} \mathrm{C}$} \\
\hline $131-1$ & 12.0 & 41 & $1312-15$ & 31 & 428 \\
\hline $131-3$ & 5.9 & 24 & $1312-16$ & 21 & 137 \\
\hline $131-4$ & 3.0 & 14 & $131-17$ & 40 & 1,050 \\
\hline $131-7$ & 12.8 & 46 & $131-18$ & 42 & 711 \\
\hline $1312-14$ & 31 & 310 & & & \\
\hline
\end{tabular}

Source: DTN: MO0306ANLGVH01.526 [DIRS 164331]. 


\section{INTENTIONALLY LEFT BLANK}




\section{APPENDIX D}

HIGH-LEVEL RADIOACTIVE WASTE GLASS ALTERATION LAYER MODEL 


\section{INTENTIONALLY LEFT BLANK}




\section{HIGH-LEVEL RADIOACTIVE WASTE GLASS ALTERATION LAYER MODEL}

The degradation of glass contacted by water (by immersion or exposure to dripping water or humid air at relative humidities $\geq 44 \%$ ) will result in transformation of glass into an alteration layer consisting of fine-grained clays (Biwer et al. 1990 [DIRS 164408]; Bates et al. 1991 [DIRS 164407]; Ebert and Bates 1995 [DIRS 164411]; Gong et al. 1998 [DIRS 158976]) and other alteration products such as ferrihydrite (Grambow 1984 [DIRS 118987]. Under VHT conditions, the small volume of solution condensed on the glass surface is saturated with respect to many mineral phases after only a little glass has reacted. Continued glass alteration results in a nearly isovolumetric replacement of glass with clay, as illustrated by the vapor-hydrated glass shown in Figure 6-4. The alteration layer overlays the remaining unreacted glass and is overlain by discrete precipitated phases (secondary phases). Precipitated phases are usually observed on the outer surface of the alteration layer, which indicates nucleation occurs preferentially at the outer surface of the alteration layer. The reaction between the glass and water proceeds as water diffuses into the glass and alteration and diffusion are mediated by the presence of water. The actual processes by which the glass is altered in the presence of water vapor or a thin layer of water are largely uncertain. However, because the structure is similar to that seen in glasses altered in the presence of liquid water, similar mechanisms are likely operating.

In borosilicate glasses, it appears that, at least at the elevated temperatures of the VHT, alteration and diffusion happen at the same time or alteration much more rapidly than water can diffuse. An expression to calculate the diffusion coefficient, D, for the diffusion of water into a commercial borosilicate glass as a function of temperature was determined by Tomozawa and Tomozawa (1989 [DIRS 164412]) from experiments conducted between $200^{\circ} \mathrm{C}$ and $500^{\circ} \mathrm{C}$ to be:

$$
\mathrm{D}=2.8 \times 10^{-7} \exp [-52(\mathrm{~kJ} / \mathrm{mol}) / \mathrm{RT}]\left(\mathrm{cm}^{2} / \mathrm{s}\right)
$$

Extrapolating Equation D-1 to $20^{\circ} \mathrm{C}$ and $100^{\circ} \mathrm{C}(293$ and $373 \mathrm{~K})$, the diffusion coefficients are calculated to be $1.5 \times 10^{-16}$ and $1.5 \times 10^{-14} \mathrm{~cm}^{2} / \mathrm{s}$, respectively. These low values indicate glass is a nonporous material. Molecular water has not been detected in analyses of reacted glasses (Aines et al. 1987 [DIRS 104318]).

Diffusion of water into glass is complicated by the fact that water is consumed in reactions with alkali metal (M), boron, and silica bonds as:

$$
\begin{gathered}
\text { glass } \equiv \mathrm{Si}-\mathrm{OM}+\mathrm{H}_{2} \mathrm{O} \rightarrow \text { glass } \equiv \mathrm{Si}-\mathrm{OH}+\mathrm{M}^{+} \mathrm{OH}^{-} \\
\text {glass } \equiv \mathrm{Si}-\mathrm{OB}(\mathrm{OH})_{2}+\mathrm{H}_{2} \mathrm{O} \rightarrow \text { glass } \equiv \mathrm{Si}-\mathrm{OH}+\mathrm{B}(\mathrm{OH})_{3} \\
\text { glass } \equiv \mathrm{Si}-\mathrm{O}-\mathrm{Si} \equiv \text { glass }+\mathrm{H}_{2} \mathrm{O} \rightarrow \text { glass } \equiv \mathrm{Si}-\mathrm{OH}+\mathrm{HO}-\mathrm{Si} \equiv \text { glass }
\end{gathered}
$$

All three reactions are reversible, and reaction in Equation D-2c provides a means for water to penetrate into the glass. Alteration of the glass continues at the layer-glass interface while the phase assemblage in the layer changes in response to the changes in the solution chemistry.

Gel layers have not been detected at the glass surface beneath the alteration layer (Ebert and Bates 1995 [DIRS 164411]). Instead, elements that are released from the glass enter solution or 
are sequestered into the clay to form the alteration layer, depending on the controlling solubility limits. Secondary alteration phases often form on the surface of the original alteration layer, as shown in Figure 6-4. In an open system, particularly in flowing or dripping water, solutes are carried away from the glass, thereby changing the chemistry and, ultimately, the phase assemblage that forms on the glass surface. In the model presented here, the alteration layer is modeled to remain in the canister and replace the degraded glass isovolumetrically.

Equations are derived to calculate the volume of pore water in the alteration layer and to calculate the average diffusion length for radionuclides leaving the glass. Both are calculated from the mass of glass that has altered at the time of interest.

\section{D.1 ALTERATION LAYER VOLUME}

If $\Sigma \mathrm{M}_{\mathrm{t}}$ is the total mass of glass that has degraded up to time, $t$, (Equation 53) and $\rho_{\mathrm{G}}$ is the density of the glass, then the volume of glass that has degraded, $\mathrm{V}_{\mathrm{G}}$, is calculated as:

$$
\mathrm{V}_{\mathrm{G}}=\Sigma \mathrm{M}_{\mathrm{t}} / \rho_{\mathrm{G}}
$$

Degradation of this volume of glass generates an equal volume of clay as the alteration layer, $V_{R}$, which can be expressed as:

$$
\mathrm{V}_{\mathrm{R}}=\Sigma \mathrm{M}_{\mathrm{t}} / \rho_{\mathrm{G}}
$$

A typical HLW glass density of $2,700 \mathrm{~kg} / \mathrm{m}^{3}$ gives:

$$
\mathrm{V}_{\mathrm{R}}\left(\text { in } \mathrm{m}^{3}\right)=3.7 \times 10^{-4} \times \Sigma \mathrm{M}_{\mathrm{t}}(\text { in } \mathrm{kg})
$$

\section{D.2 ALTERATION LAYER POROSITY AND PORE WATER VOLUME}

The alteration layer is composed of a dense matrix of coarse-grained and fine-grained clay crystals, usually smectite clays (Biwer et al. 1990 [DIRS 164408]; Ebert and Bates 1995 [DIRS 164411]; Gong et al. 1998 [DIRS 158976]). What is referred to as pore water here includes both the interlayer water in the clay sheet structures and the water between crystals (nonstructural water). Both the structural and nonstructural water will affect the diffusion of cations released from the glass, which can be absorbed in the clay sheet structure to form interlayer complexes or sorbed on the edges of the clay crystals. All of the pore water in the alteration layer is included in the alteration layer volume model.

The amount of water in the alteration layers formed on vapor-hydrated SRL 131 glass samples was measured to be up to 7 mass \% (Aines et al. 1987 [DIRS 104318]). A value of 7 mass \% is used to represent the pore water contents of alteration layers formed on all HLW glasses exposed to water or humid air (at $\mathrm{RH} \geq 44 \%$ ). The total volume of water in the alteration layer is simply the product of the alteration layer volume and pore water content. 
The porosity of the alteration layer is:

$$
\phi=X_{\mathrm{W}} \times \rho_{\mathrm{R}} / \rho_{\mathrm{W}}
$$

where

$$
\begin{aligned}
& \phi \quad=\text { porosity of the alteration layer } \\
& X_{W}=\text { mass fraction of water in the alteration layer } \\
& \rho_{\mathrm{R}}=\text { density of the alteration layer } \\
& \rho_{\mathrm{W}}=\text { density of the pore water. }
\end{aligned}
$$

The bulk density of the alteration layer is not known specifically, but can be expressed in terms of the densities of the clay minerals and the amount of pore water. Typical values of dehydrated clay minerals are $2,630 \mathrm{~kg} / \mathrm{m}^{3}$ for kaolinite, $2,550 \mathrm{~kg} / \mathrm{m}^{3}$ for halloysites, and 2,600 kg/m for dickite and nacrite (Deer et al. 1966 [DIRS 102773], p. 258). Curti and Smith (1991 [DIRS 164410]) used a value of $2,760 \mathrm{~kg} / \mathrm{m}^{3}$ for the density of bentonite clay. These are sufficiently similar to the densities of HLW glasses $\left(2,600\right.$ to $2,800 \mathrm{~kg} / \mathrm{m}^{3}$; Section 6.5.4) that the grain densities of the clay crystals and the glass density are considered equal. A density of $2,700 \mathrm{~kg} / \mathrm{m}^{3}$ is used for both the unreacted glass and the clay crystals. The bulk density of the alteration layer differs from that of the glass due to the presence of pore water. The bulk density of the alteration layer, $\rho_{\mathrm{R}}$, can be expressed in terms of the densities of the clay crystals, $\rho_{\mathrm{C}}$, and pore water, $\rho_{\mathrm{W}}$, at $100 \%$ saturation of pore water as given in Equation D-5:

$$
\rho_{\mathrm{R}}=\rho_{\mathrm{W}} \times \phi+(1-\phi) \times \rho_{\mathrm{C}}
$$

which is combined with Equation D-4 and expressed in terms of the porosity as:

$$
\phi=\left\{1+\left(\rho_{\mathrm{W}} / \rho_{\mathrm{C}}\right) \times\left[\left(1 / \mathrm{X}_{\mathrm{W}}\right)-1\right]\right\}^{-1}
$$

Solving Equation D-6 with the values $\rho_{\mathrm{W}}=1,000 \mathrm{~kg} / \mathrm{m}^{3}, \rho_{\mathrm{C}}=2,700 \mathrm{~kg} / \mathrm{m}^{3}$, and $X_{\mathrm{W}}=0.07$ gives $\phi=0.17$. The porosity of the alteration layer is $17 \%$. A porosity of $17 \%$ is consistent with the mass \%-soluble elements that are not incorporated into the clay alteration layer when glass degrades. For example, Table D-1 gives the elemental mass \% of soluble elements in 10 glasses used to determine model parameter values. The average total mass $\%$ of these soluble elements for the 10 glasses is $15.78 \%$. 
Table D-1. Soluble Elements in Glasses, in Elemental Mass \%

\begin{tabular}{|c|c|c|c|c|c|}
\hline Glass & B & $\mathrm{K}$ & $\mathrm{Li}$ & $\mathrm{Na}$ & Total \\
\hline SRL 202G ${ }^{a}$ & 3.21 & 2.74 & 1.60 & 11.36 & 18.91 \\
\hline SRL $51 S^{b}$ & 2.30 & 1.16 & 2.11 & 7.11 & 12.68 \\
\hline SRL 202U & 2.48 & 3.09 & 1.97 & 6.61 & 14.47 \\
\hline SRL 165U & 2.10 & 0 & 1.94 & 8.04 & 12.08 \\
\hline SRL $131 U^{b}$ & 3.00 & 3.22 & 1.40 & 8.95 & 16.57 \\
\hline WV ref $6^{b}$ & 4.00 & 4.17 & 1.73 & 5.93 & 15.83 \\
\hline Hanford-D ${ }^{b}$ & 2.17 & 0.72 & 1.40 & 11.7 & 15.99 \\
\hline Hanford- $\mathrm{L}^{\mathrm{b}}$ & 2.75 & 2.58 & 0 & 14.8 & 20.13 \\
\hline LD6-5412 ${ }^{b}$ & 1.66 & 1.14 & 0 & 15.0 & 17.80 \\
\hline PNL $76-68^{b}$ & 2.79 & 0 & 0 & 10.5 & 13.29 \\
\hline Average & 2.65 & 1.88 & 1.22 & 10.00 & 15.78 \\
\hline
\end{tabular}

Sources: ${ }^{a}$ DTN: MO0306ANLGIM01.525 [DIRS 164329], Table 1.

b DTN: MO0308ANLGPC01.528 [DIRS 164790], Table 1.

The volume of pore water in the alteration layer $\mathrm{V}_{\mathrm{W}}$ can be calculated as the product of the porosity $(\phi)$ and the volume of the alteration layer $\mathrm{V}_{\mathrm{R}}$ as:

$$
\mathrm{V}_{\mathrm{w}}=\mathrm{V}_{\mathrm{R}} \times \phi
$$

Substituting Equation D-3b into Equation D-7 for $V_{R}$ gives:

$$
\mathrm{V}_{\mathrm{w}}=\left(\Sigma \mathrm{M}_{\mathrm{t}} / \rho_{\mathrm{G}}\right) \times \phi
$$

Substituting $\rho_{\mathrm{G}}=2,700 \mathrm{~kg} / \mathrm{m}^{3}$ and $\phi=17 \%$ into Equation D-8 gives the relationship:

$$
\mathrm{V}_{\mathrm{w}}\left(\text { in } \mathrm{m}^{3}\right)=6.3 \times 10^{-5} \times \Sigma \mathrm{M}_{\mathrm{t}}(\text { in } \mathrm{kg})
$$

Equation D-9 can be used to calculate the volume of water in the alteration layer as a function of the total mass of glass that has degraded.

\section{D.3 ALTERATION LAYER THICKNESS}

Radionuclides that are freed from the glass matrix as the glass degrades must diffuse through the alteration layer to become available for transport away from a breached canister. An average alteration layer thickness can be determined by the geometry of the canistered glass waste form. The geometry shown in Figure D-1 is used to calculate the volume of alteration layer. In this geometry, the inner diameter of the glass pour canister is the same as the original outer surface of the glass. As glass is replaced by the alteration layer; the outer surface of the alteration layer remains the same as the inner diameter of the pour canister. The inner diameter of the alteration layer is determined from the calculated volume of the alteration layer. The pour canister does not, in this model, present a diffusion barrier to the movement of water or dissolved constituents As discussed in Section 6.5.4, it is expected that about two-thirds of the HLW glass will be in canisters that are $4.5-\mathrm{m}$ long, and about one-third in canisters $3.0-\mathrm{m}$ long. The weighted average of the overall canister heights is $4.0 \mathrm{~m}[(4.5 \times 2+3) / 3]$. Typically, the producer will attempt to put as much glass in the canister as possible. Over filling the canister must also be avoided. The 
typical canister has a neck that is about $0.2 \mathrm{~m}$ high (DOE 1992 [DIRS 102812]), which means that the average canister could only be filled to just over $3.8 \mathrm{~m}[((4.5-0.2) \times 2+$ $(3.0-0.2)) / 3]$. This does not account for the bottom thickness and stress relief bow. To accommodate these remaining uncertainties, the average between the two maximum fill heights $(3.9 \mathrm{~m})$ is used hereinafter to give conservative estimates of the volume and, hence, the thickness of the rind and water contained therein. The thickness of the alteration layer is determined from the initial glass volume and the volume of glass that has not reacted. These are represented by concentric cylinders with radii, $r_{o}$ and $r_{i}$ (see Figure D-1). The initial radius of the glass is $0.30 \mathrm{~m}$ (Section 6.5.4) and the initial glass volume is:

$$
\mathrm{V}_{\text {initial }}=\pi \times \mathrm{r}_{\mathrm{o}}^{2} \times \mathrm{L}_{\mathrm{o}}
$$

where

$$
\begin{array}{ll}
\mathrm{V}_{\text {initial }} & =\text { initial volume of glass }\left(\mathrm{m}^{3}\right) \\
\mathrm{r}_{\mathrm{o}} & =\text { initial radius of glass }(0.30 \mathrm{~m}) \\
\mathrm{L}_{\mathrm{o}} & =\text { length of glass }(3.9 \mathrm{~m})
\end{array}
$$

The volume of unreacted glass is:

$$
\mathrm{V}_{\text {inner }}=\pi \times \mathrm{r}_{\mathrm{i}}^{2} \times \mathrm{L}_{\mathrm{o}}
$$

where

$$
\begin{array}{ll}
\mathrm{V}_{\text {inner }} & =\text { volume of the inner cylinder }\left(\mathrm{m}^{3}\right) \\
\mathrm{r}_{\mathrm{i}} & =\text { outer radius of the inner cylinder } \\
\mathrm{L}_{\mathrm{o}} & =\text { length of the glass }(3.9 \mathrm{~m})
\end{array}
$$

The bulk volume of the alteration layer, $V_{R}$, is equal to $V_{\text {initial }}-V_{\text {inner }}$ and can be expressed as:

$$
\mathrm{V}_{\mathrm{R}}=\pi \times \mathrm{L}_{\mathrm{o}} \times\left(\mathrm{r}_{\mathrm{o}}{ }^{2}-\mathrm{r}_{\mathrm{i}}^{2}\right)
$$

The ends of the glass provide only about $7 \%$ of the initial surface area and their contribution decreases as the glass is altered. Equation D-9 can be solved for $\mathrm{r}_{\mathrm{i}}$ :

$$
\mathrm{r}_{\mathrm{i}}=\left[\mathrm{r}_{\mathrm{o}}{ }^{2}-\mathrm{V}_{\mathrm{R}} /\left(\pi \times \mathrm{L}_{\mathrm{o}}\right)\right]^{1 / 2}
$$

The thickness of the alteration layer is $T_{R}=r_{0}-r_{i}$. Substituting Equation D-13 for $r_{i}$ gives:

$$
\mathrm{T}_{\mathrm{R}}=\mathrm{r}_{\mathrm{o}}-\mathrm{r}_{\mathrm{i}}=\mathrm{r}_{\mathrm{o}}-\left[\mathrm{r}_{\mathrm{o}}{ }^{2}-\mathrm{V}_{\mathrm{R}} /\left(\pi \times \mathrm{L}_{\mathrm{o}}\right)\right]^{1 / 2}
$$

Substituting the values $r_{o}=0.30 \mathrm{~m}$ and $\mathrm{L}_{\mathrm{o}}=3.9 \mathrm{~m}$ into Equation $\mathrm{D}-14$ gives:

$$
\mathrm{T}_{\mathrm{R}}(\text { in meters })=0.30-\left[0.090-\left(8.2 \times 10^{-2} \times \mathrm{V}_{\mathrm{R}}\right)\right]^{1 / 2}
$$

Substituting Equation D-3b in Equation D-15 gives:

$$
\mathrm{T}_{\mathrm{R}}=(\text { in meters })=0.30-\left[0.090-\left(8.2 \times 10^{-2} \times\left(\Sigma \mathrm{M}_{\mathrm{t}} / \rho_{\mathrm{G}}\right)\right]^{1 / 2}\right.
$$


Equation D-16 is the average alteration layer thickness in terms of the mass of glass (in $\mathrm{kg}$ ) altered. Substituting $\rho_{\mathrm{G}}=2700 \mathrm{~kg} / \mathrm{m}^{3}$ for the density of a typical HLW glass gives the alteration layer thickness:

$$
\mathrm{T}_{\mathrm{R}}(\text { in meters })=\mathrm{r}_{\mathrm{o}}-\mathrm{r}_{\mathrm{i}}=0.30-\left[0.090-\left(3.0 \times 10^{-5}\right) \times \Sigma \mathrm{M}_{\mathrm{t}}\right]^{1 / 2}
$$

Equation D-17 gives the relationship between the average alteration layer thickness (in meters) and the mass of altered glass (in $\mathrm{kg}$ ) that is calculated with the glass alteration rate equation developed in this report.

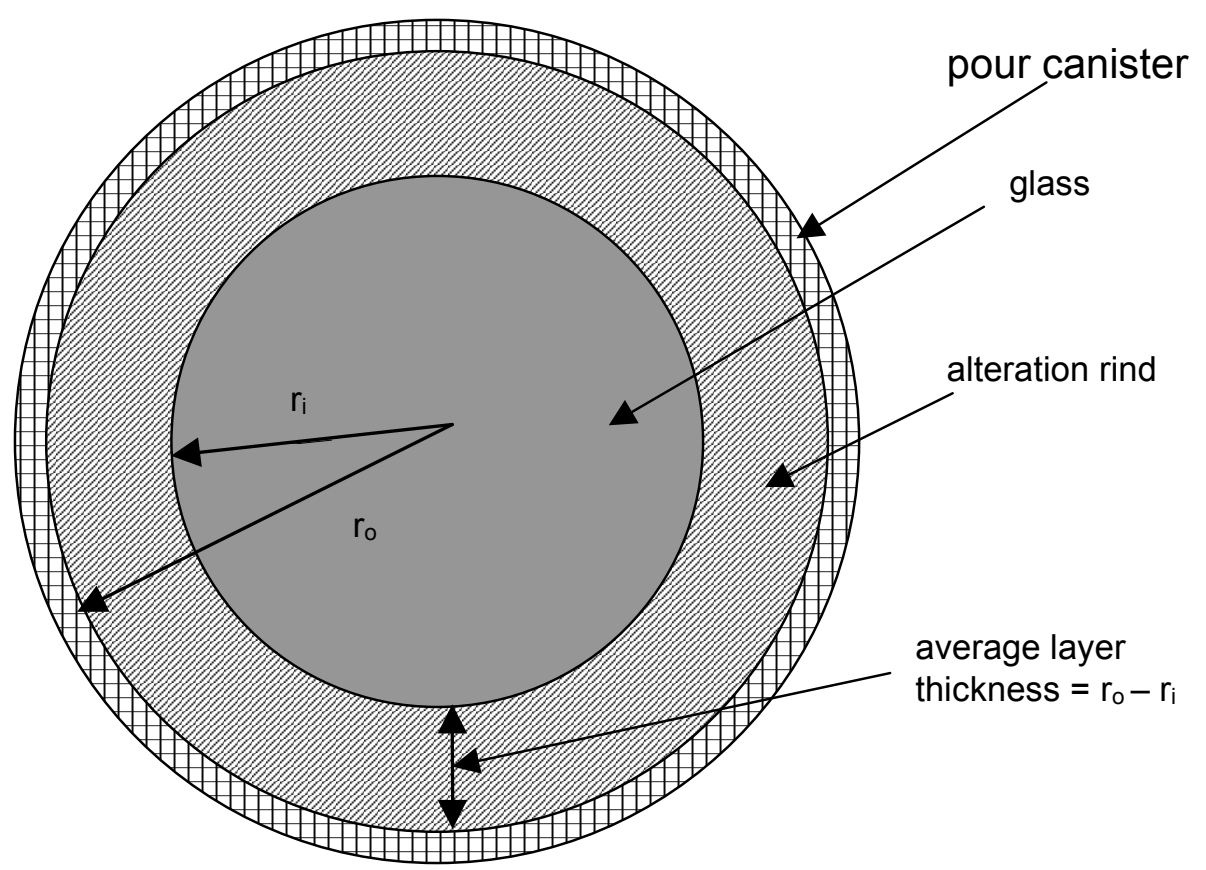

Figure D-1. Schematic Drawing of Canister Cross Section Used to Calculate Alteration Layer Thickness 
APPENDIX E

EVALUATION OF DATA IN KNAUSS ET AL. 1990 [DIRS 101701] 


\section{INTENTIONALLY LEFT BLANK}




\section{E. EVALUATION OF DATA IN KNAUSS ET AL. 1990 [DIRS 101701]}

The analysis in this appendix was conducted to extract model parameter values from the results of single-pass flow-through tests conducted at various temperatures and solution $\mathrm{pH}$ values presented in:

Knauss, K.G.; Bourcier, W.L.; McKeegan, K.D.; Merzbacher, C.I.; Nguyen, S.N.; Ryerson, F.J.; Smith, D.K.; Weed, H.C.; and Newton, L. 1990. "Dissolution Kinetics of a Simple Analogue Nuclear Waste Glass as a Function of $\mathrm{pH}$, Time and Temperature." Scientific Basis for Nuclear Waste Management XIII, Symposium held November 27-30, 1989, Boston, Massachusetts. Oversby, V.M. and Brown, P.W., eds. 176, 371-381. Pittsburgh, Pennsylvania: Materials Research Society. TIC: 203658.

In the cited publication, the authors extracted parameter values based on the release of Si. Separate parameter values for the $\mathrm{pH}$ dependence were extracted for each temperature. In the following analysis, a single set of model parameter values are extracted for acidic and alkaline solutions.

The rate expression for the forward rate is given in Equation 13. The logarithm of Equation 13 is used to determine parameters from test results:

$$
\log _{10}(\text { rate })=\log _{10}\left(\mathrm{k}_{0}\right)+\eta \times \mathrm{pH}+\log _{10}\left(\exp \left(-\mathrm{E}_{\mathrm{a}} / \mathrm{RT}\right)\right)
$$

where $\log _{10}$ (rate) is the measured rate. Values of $\eta$ were determined through regression of $\log _{10}$ (rate) and $\mathrm{pH}$ data obtained from experiments performed at $40^{\circ} \mathrm{C}$ and $70^{\circ} \mathrm{C}$. Lines having the slopes for acidic and alkaline solutions determined from those plots were then fit to the results at $25^{\circ} \mathrm{C}, 50^{\circ} \mathrm{C}$, and $70^{\circ} \mathrm{C}$ to determine the values of the sum of the terms $\log _{10}\left(\mathrm{k}_{0}\right)+$ $\log _{10}\left(\exp \left(-\mathrm{E}_{\mathrm{a}} / \mathrm{RT}\right)\right)$ at each temperature. The rates were then calculated at $\mathrm{pH} 0$ and at $\mathrm{pH} 14$ at each temperature. These rates were used in a plot of $\ln ($ rate $)$ vs. $1 /$ RT for acidic and alkaline solutions. From Equation E-1, the slopes of those plots give the values of $-E_{a}$.

\section{E.1 EXTRACTION OF DATA FROM KNAUSS ET AL. (1990 [DIRS 101701]) FIGURE 2}

Figure 2 from the report by Knauss et al. (1990 [DIRS 101701]) is reproduced in Figure E-1. The values of $\mathrm{pH}$ and $\log ($ rate $)$ for $\mathrm{Si}$ data at the three temperatures were read from enlarged photocopies of the graphs in this figure. An architect's scale (with 50 divisions per inch) was used measure the distance of each data point on the $\mathrm{pH}$ and $\log ($ rate $)$ scales. The relationship between distance and scale was determined by measuring distances between tick marks on the plots. The extracted data are shown in Table E-1. 


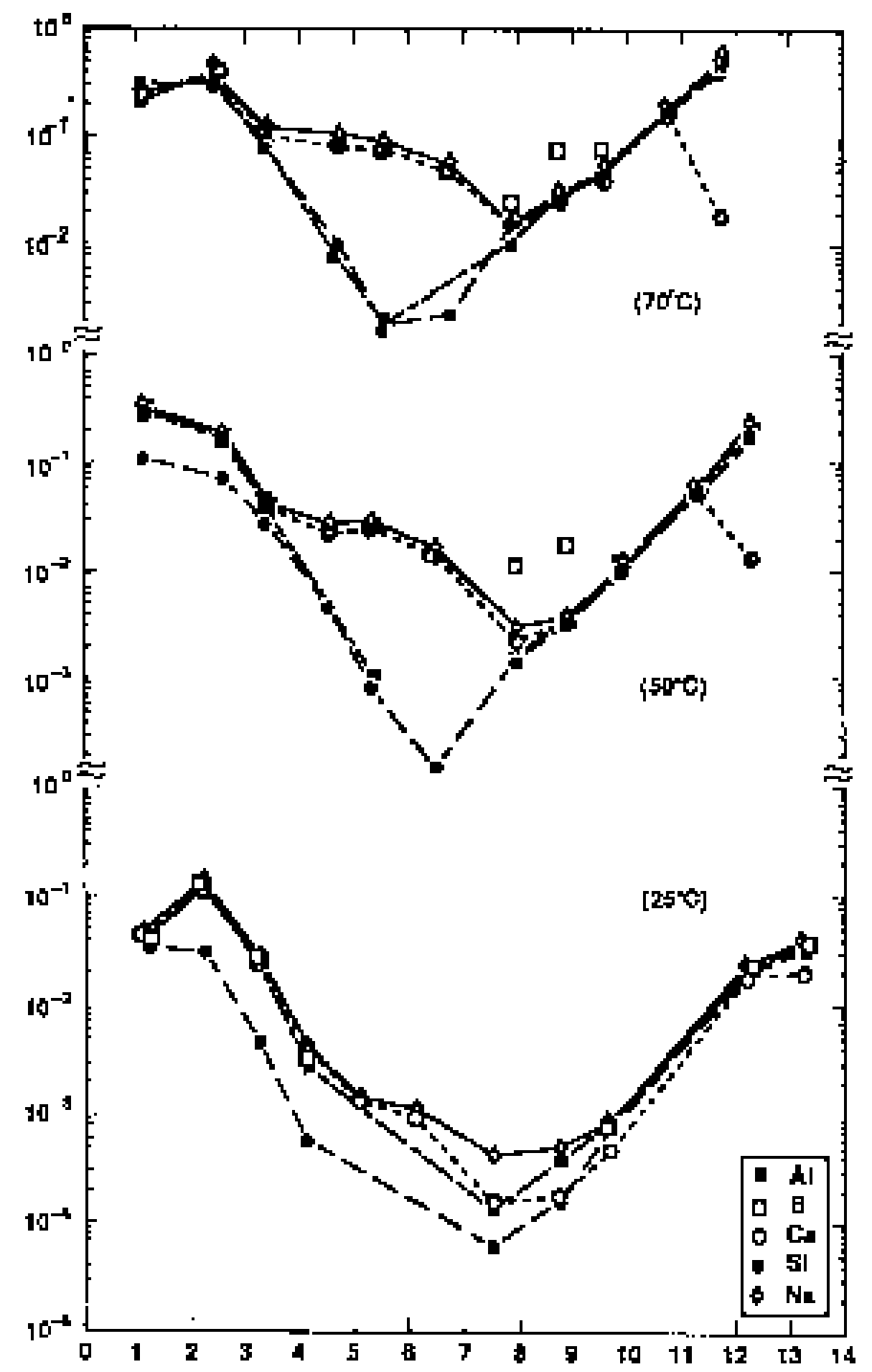

NOTE: The $x$-axis gives the solution $\mathrm{pH}$ and the $y$-axis gives the dissolution rate, $g /\left(\mathrm{m}^{2} \cdot d\right)$.

Figure E-1. Reproduction of Figure 2 from Knauss et al. (1990 DIRS 101701]) 
Table E-1. Values of $\mathrm{pH}$ and $\log _{10}($ Rate $)$

\begin{tabular}{|c|c|c|c|c|c|c|c|}
\hline \multicolumn{4}{|c|}{ Acidic Solutions } & \multicolumn{4}{|c|}{ Alkaline Solutions } \\
\hline pH & $70^{\circ} \mathrm{C}$ & $50^{\circ} \mathrm{C}$ & $25^{\circ} \mathrm{C}$ & pH & $70^{\circ} \mathrm{C}$ & $50^{\circ} \mathrm{C}$ & $25^{\circ} \mathrm{C}$ \\
\hline 2.1 & - & - & -1.54 & 6.8 & -2.65 & - & - \\
\hline 2.3 & -0.51 & - & - & 7.5 & - & - & -4.25 \\
\hline 2.4 & - & -1.17 & - & 7.9 & -1.93 & - & - \\
\hline 3.3 & - & -1.56 & -2.36 & 8.0 & - & -2.85 & - \\
\hline 3.4 & -1.11 & - & - & 8.7 & - & - & -3.71 \\
\hline 4.1 & - & - & -3.22 & 8.8 & -1.64 & -2.42 & - \\
\hline 4.5 & - & -2.38 & - & 9.6 & -1.35 & - & - \\
\hline 4.7 & -2.01 & - & - & 9.7 & - & - & -3.18 \\
\hline 5.3 & - & -3.08 & - & 9.8 & - & -1.95 & - \\
\hline 5.6 & -2.67 & - & - & 10.8 & -0.78 & - & - \\
\hline 6.4 & - & -3.79 & - & 11.2 & - & -1.19 & - \\
\hline 6.8 & -2.65 & - & - & 11.7 & -0.37 & - & - \\
\hline & & & & 12.1 & - & - & -1.74 \\
\hline & & & & 12.2 & - & -0.7 & - \\
\hline & & & & 12.9 & - & - & -1.62 \\
\hline
\end{tabular}

NOTE: Based on NR(Si). Extracted from Knauss et al. 1990 [DIRS 101701], Figure 2 (Figure E-1 in this document).

\section{E.2 DETERMINATION OF PH DEPENDENCE $(\eta)$}

The data for tests at $50^{\circ} \mathrm{C}$ and $70^{\circ} \mathrm{C}$ were regressed to determine the $\mathrm{pH}$ dependence. Results of tests in acidic and alkaline solutions were regressed separately. These are shown in Figure E-2. Results for tests at $50^{\circ} \mathrm{C}$ are included in the plot to show they follow the same $\mathrm{pH}$ dependence, but they were not used in the regression. The $\mathrm{pH}$ dependence for acid is $\eta=-0.698$ and the $\mathrm{pH}$ dependence for bases is $\eta=0.486$.

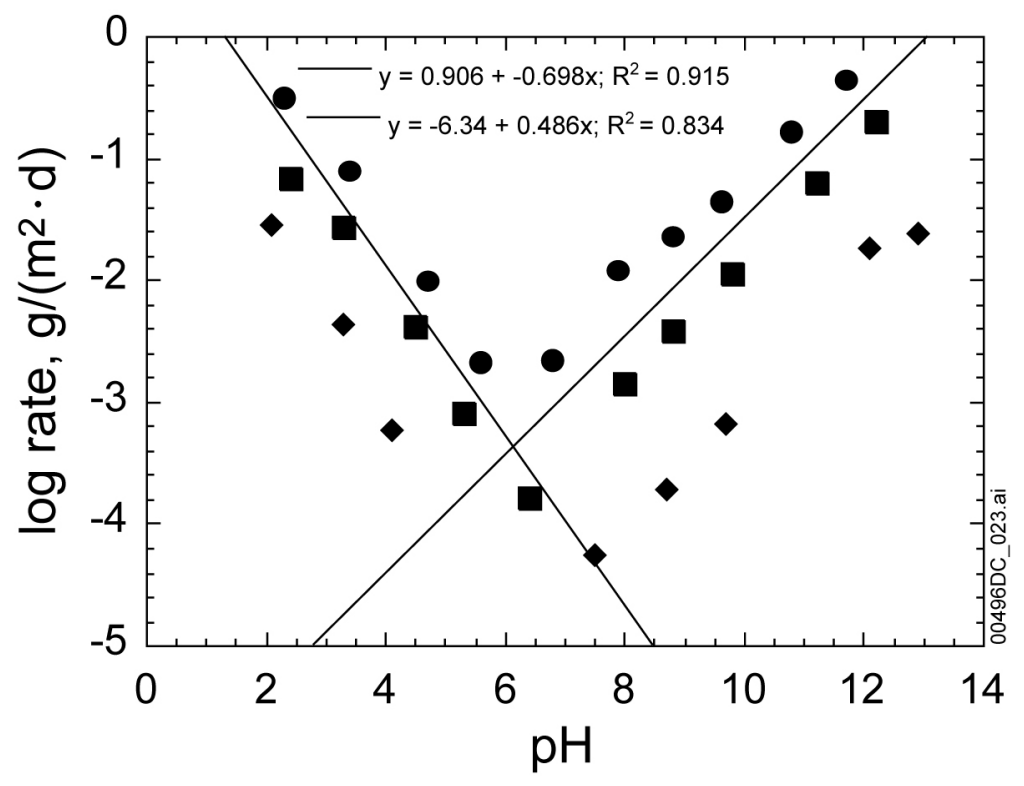

Figure E-2. Regression of Data (Table V-1) at $50^{\circ} \mathrm{C}$ and $70^{\circ} \mathrm{C}$ 
The rates measured by Knauss et al. (1990 [DIRS 101701]) at each temperature were fit with lines having slopes of -0.698 for acids and slopes 0.486 for bases. The general equation of the line was:

$$
\log _{10}(\text { rate })=A+\eta \times p H .
$$

The best value of $\mathrm{A}$ was determined by minimizing the residuals between the calculated and measured values of $\log ($ rate) at each temperature for both acids and bases. This was done in a Microsoft Excel spreadsheet. The results are shown in Table E-2. The equations of the fit lines are as follows:

Acidic Solutions

$$
\begin{array}{ll}
70^{\circ} \mathrm{C}: & \log (\text { rate })=1.217-0.698 \times \mathrm{pH} \\
50^{\circ} \mathrm{C}: & \log (\text { rate })=0.6613-0.698 \times \mathrm{pH} \\
25^{\circ} \mathrm{C}: & \log (\text { rate })=-0.1630-0.698 \times \mathrm{pH}
\end{array}
$$

Alkaline Solutions

$$
\begin{array}{ll}
70^{\circ} \mathrm{C}: & \log (\text { rate })=-5.9014+0.486 \times \mathrm{pH} \\
50^{\circ} \mathrm{C}: & \log (\text { rate })=-6.682+0.486 \times \mathrm{pH} \\
25^{\circ} \mathrm{C}: & \log (\text { rate })=-7.8475+0.486 \times \mathrm{pH}
\end{array}
$$

The fitted lines are shown with the measured rates in Figure E-3a. The $\mathrm{pH}$ dependencies determined by Knauss et al. (1990 [DIRS 101701) for each temperature are shown in Figure E-3b for comparison (visual comparison of Figures E-3a and $\mathrm{b}$ confirms the rate and $\mathrm{pH}$ values extracted from the report by Knauss et al. (1990 [DIRS 101701]) Figure 2 and shown in Table E-1.) The $\mathrm{pH}$ dependencies are $\eta=-0.698$ for the acidic leg and $\eta=0.486$ for the alkaline leg. These are used in Section 7.4.1.

(a)

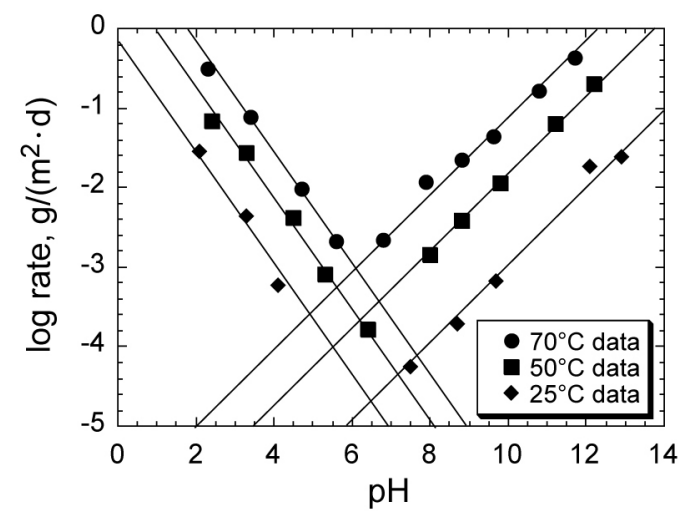

(b)

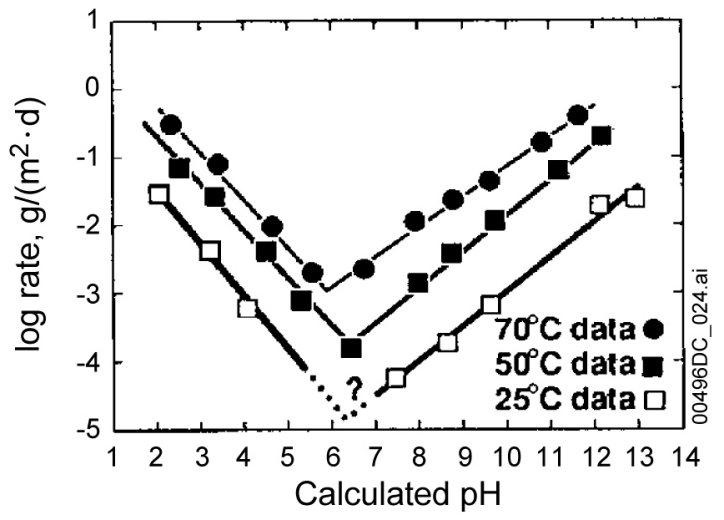

Figure E-3. Regression of Data provided by Knauss et al. (1990 [DIRS 101701]) (a) This Analysis and (b) as Presented in Figure 3 in a Report by Knauss et al. (1990 [DIRS 101701]) 
Table E-2. Regression of Lines with Constant Slopes to Data

\begin{tabular}{|c|c|c|c|c|c|c|c|}
\hline \multirow[b]{3}{*}{ pH } & \multirow{3}{*}{$\begin{array}{l}\text { Measured } \\
\text { log(Rate) }\end{array}$} & \multicolumn{3}{|c|}{ Calculated $\log _{10}($ Rate $)$} & \multicolumn{3}{|c|}{ Residual } \\
\hline & & \multicolumn{3}{|c|}{$\varepsilon$} & \multicolumn{3}{|c|}{$\varepsilon$} \\
\hline & & 0 & 0.01 & -0.01 & 0 & 0.01 & -0.01 \\
\hline \multicolumn{8}{|c|}{ Acids at $70^{\circ} \mathrm{C} \log _{10}($ Rate $)=1.217-0.698 \times \mathrm{pH}+\varepsilon$} \\
\hline 2.3 & -0.51 & -0.3884 & -0.3784 & -0.3984 & 0.1216 & 0.1316 & 0.1116 \\
\hline 3.4 & -1.11 & -1.1562 & -1.1462 & -1.1662 & -0.0462 & -0.0362 & -0.0562 \\
\hline 4.7 & -2.01 & -2.0636 & -2.0536 & -2.0736 & -0.0536 & -0.0436 & -0.0636 \\
\hline 5.6 & -2.67 & -2.6918 & -2.6818 & -2.7018 & -0.0218 & -0.0118 & -0.0318 \\
\hline \multicolumn{5}{|c|}{ Sum of Residuals: } & 1.5543E-15 & 0.04 & -0.04 \\
\hline \multicolumn{8}{|c|}{ Acids at $50^{\circ} \mathrm{C} \log _{10}($ Rate $)=0.6613-0.698 \times \mathrm{pH}+\varepsilon$} \\
\hline 2.4 & -1.17 & -1.0139 & -1.0039 & -1.0239 & 0.1561 & 0.1661 & 0.1461 \\
\hline 3.3 & -1.56 & -1.6421 & -1.6321 & -1.6521 & -0.0821 & -0.0721 & -0.0921 \\
\hline 4.5 & -2.38 & -2.4797 & -2.4697 & -2.4897 & -0.0997 & -0.0897 & -0.1097 \\
\hline 5.3 & -3.08 & -3.0381 & -3.0281 & -3.0481 & 0.0419 & 0.0519 & 0.0319 \\
\hline 6.4 & -3.79 & -3.8059 & -3.7959 & -3.8159 & -0.0159 & -0.0059 & -0.0259 \\
\hline \multicolumn{5}{|c|}{ Sum of Residuals: } & 0.0003 & 0.0503 & -0.0497 \\
\hline \multicolumn{8}{|c|}{ Acids at $25^{\circ} \mathrm{C} \log _{10}($ Rate $)=-0.163-0.698 \times \mathrm{pH}+\varepsilon$} \\
\hline 2.1 & -1.54 & -1.6288 & -1.6188 & -1.6388 & -0.0888 & -0.0788 & -0.0988 \\
\hline 3.3 & -2.36 & -2.4664 & -2.4564 & -2.4764 & -0.1064 & -0.0964 & -0.1164 \\
\hline 4.1 & -3.22 & -3.0248 & -3.0148 & v3.0348 & 0.1952 & 0.2052 & 0.1852 \\
\hline \multicolumn{5}{|c|}{ Sum of Residuals: } & $8.8818 \mathrm{E}-16$ & 0.03 & -0.03 \\
\hline \multicolumn{8}{|c|}{ Bases at $70^{\circ} \mathrm{C} \log _{10}($ Rate $)=-5.9014+0.486 \times \mathrm{pH}+\varepsilon$} \\
\hline 6.8 & -2.65 & -2.5966 & -2.5866 & -2.6066 & 0.0534 & 0.0634 & 0.0434 \\
\hline 7.9 & -1.93 & -2.062 & -2.052 & -2.072 & -0.132 & -0.122 & -0.142 \\
\hline 8.8 & -1.64 & -1.6246 & -1.6146 & -1.6346 & 0.0154 & 0.0254 & 0.0054 \\
\hline 9.6 & -1.35 & -1.2358 & -1.2258 & -1.2458 & 0.1142 & 0.1242 & 0.1042 \\
\hline 10.8 & -0.78 & -0.6526 & -0.6426 & -0.6626 & 0.1274 & 0.1374 & 0.1174 \\
\hline 11.7 & -0.037 & -0.2152 & -0.2052 & -0.2252 & -0.1782 & -0.1682 & -0.1882 \\
\hline \multicolumn{5}{|c|}{ Sum of Residuals: } & 0.0002 & 0.0602 & -0.0598 \\
\hline \multicolumn{8}{|c|}{ Bases at $50^{\circ} \mathrm{C} \log _{10}($ Rate $)=-6.682+0.486 \times \mathrm{pH}+\varepsilon$} \\
\hline 8 & -2.85 & -2.794 & -2.784 & -2.804 & 0.056 & 0.066 & 0.046 \\
\hline 8.8 & -2.42 & -2.4052 & -2.3952 & -2.4152 & 0.0148 & 0.0248 & 0.0048 \\
\hline 9.8 & -1.95 & -1.9192 & -1.9092 & -1.9292 & 0.0308 & 0.0408 & 0.0208 \\
\hline 11.2 & -1.19 & -1.2388 & -1.2288 & -1.2488 & -0.0488 & -0.0388 & -0.0588 \\
\hline 12.2 & -0.7 & -0.7528 & -0.7428 & -0.7628 & -0.0528 & -0.0428 & -0.0628 \\
\hline \multicolumn{5}{|c|}{ Sum of Residuals: } & $-2.22 \mathrm{E}-15$ & 0.05 & -0.05 \\
\hline \multicolumn{8}{|c|}{ Bases at $25^{\circ} \mathrm{C} \log _{10}($ Rate $)=-7.8475+0.486 \times \mathrm{pH}+\varepsilon$} \\
\hline 7.5 & -4.25 & -4.2025 & -4.1925 & -4.2125 & 0.0475 & 0.0575 & 0.0375 \\
\hline 8.7 & -3.71 & -3.6193 & -3.6093 & -3.6293 & 0.0907 & 0.1007 & 0.0807 \\
\hline 9.7 & -3.18 & -3.1333 & -3.1233 & -3.1433 & 0.0467 & 0.0567 & 0.0367 \\
\hline 12.1 & -1.74 & -1.9669 & -1.9569 & -1.9769 & -0.2269 & -0.2169 & -0.2369 \\
\hline 12.9 & -1.62 & -1.5781 & -1.5681 & -1.5881 & 0.0419 & 0.0519 & 0.0319 \\
\hline \multicolumn{5}{|c|}{ Sum of Residuals: } & -0.0001 & 0.0499 & -0.0501 \\
\hline
\end{tabular}

Source: DTN: MO0307ANLGAMR3.016. 


\section{E.3 DETERMINATION OF TEMPERATURE DEPENDENCE $\left(\mathrm{E}_{\mathrm{a}}\right)$}

From Table V-2, the equations for $\log _{10}$ (rate) were used to calculate the values of $\log _{10}$ (rate) were calculated at $\mathrm{pH} 0$ and at $\mathrm{pH} 14$. These were then converted to $\ln ($ rate $)$ and plotted against $1 / \mathrm{RT}$ to determine the activation energy $(\mathrm{R}=0.008314 \mathrm{~kJ} / \mathrm{mol} \times \mathrm{K})$. The data are tabulated in Table E-3 and plotted in Figure E-4. The equations from linear regression of the acidic and alkaline data are:

$$
\begin{array}{ll}
\text { Acid: } & \ln (\text { rate })=23.9-60.1 /(\mathrm{RT}) \\
\text { Base: } & \ln (\text { rate })=31.8-84.7 /(\mathrm{RT})
\end{array}
$$

The activation energies are $E_{a}=60.1 \mathrm{~kJ} / \mathrm{mol}$ for acids and $E_{a}=84.7 \mathrm{~kJ} / \mathrm{mol}$ for bases. The values of $\eta$ and $E_{a}$ rounded to two significant figures are reported in Table 7-3.

Table E-3. Data for Arrhenius plots

\begin{tabular}{|c|c|c|c|}
\hline \multirow{2}{*}{$\begin{array}{c}\text { Temperature } \\
\left({ }^{\circ} \mathbf{C}\right)\end{array}$} & 1/RT (mol/kJ) & Acids & Bases \\
\cline { 3 - 4 } & 0.35067 & 2.8022 & 2.0783 \\
\hline 70 & 0.37238 & 1.5226 & 0.28092 \\
\hline 50 & 0.40362 & -0.37532 & -2.4027 \\
\hline 25 &
\end{tabular}

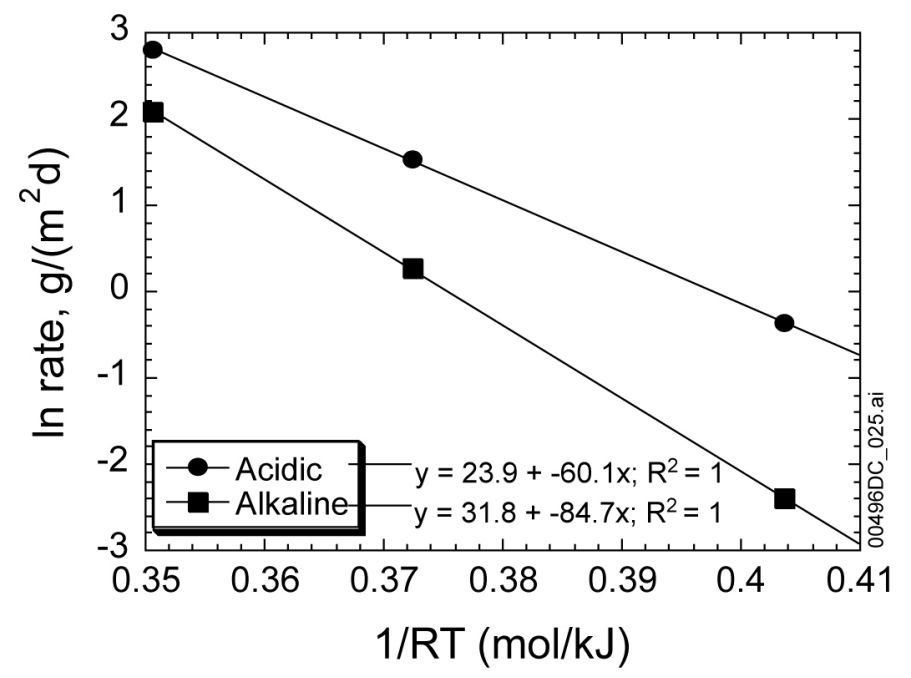

Figure E-4. Arrhenius Plot of Rates Calculated at pH 0 and pH 14 (Table V-3) 
APPENDIX F

DATA QUALIFICATION REPORT FOR DTN：MO0408ANLGNN01.527 


\section{INTENTIONALLY LEFT BLANK}




\section{F. DATA QUALIFICATION REPORT FOR DTN: MO0408ANLGNN01.527}

\section{F.1. PURPOSE}

The purpose of this Data Qualification Report is to qualify the data from DTN: MO0408ANLGNN01.527 [DIRS 171574], for use as direct input to Defense HLW Glass Degradation Model, ANL-EBS-MD-000016, Rev. 2. The data in the DTN are unqualified because some of the data were acquired prior to May 1989, when DOE established the Quality Assurance Requirements and Description (QARD) to meet 10 CFR Part 60 [DIRS 103540], Subpart G, and are required to be qualified in accordance with AP-SIII.2Q.

\section{F.2 QUALIFICATION METHOD}

The data from DTN: MO0408ANLGNN01.527 [DIRS 171574] are qualified in accordance with AP-SIII.2Q, Qualification of Unqualified Data. The qualification process used for these data involves the method of Corroborating Data (AP-SIII.2Q, Attachment 3). This qualification process is designed to provide the desired level of confidence for the data in their intended use for this model report.

This report documents the data qualification task conducted in accordance with the approved Data Qualification Plan (Appendix G). For the Corroborating Data qualification method, qualification process attributes 1 through 6 and 10 (AP-SIII.2Q, Attachment 4) were used as appropriate. The rationale for selecting the corroborating data method was to provide confidence that the test results are consistent with the test results acquired under the QARD. The qualification criterion is that the data collected before May 1989 must be consistent with the data collected after May 1989.

\section{F.3 CORROBORATING DATA}

The data for this DTN were acquired over the period from $02 / 18 / 86$ to $05 / 30 / 01$. The DOE adopted the QARD in May of 1989 and by the definition of qualified data, data acquired or developed under a Quality Assurance program which meets the requirements of the QARD, the data acquired prior to May of 1989 are unqualified and require qualification under AP-SIII.2Q.

The data are the results of unsaturated (drip) tests conducted to measure the degradation rates of SRL 165 (N2 series) and ATM-10 (N3 series) glasses contacted by dripping tuff groundwater $\left(\mathrm{J}-13\right.$ well water that had been pre-reacted with tuff at $90^{\circ} \mathrm{C}$ ) at $90^{\circ} \mathrm{C}$. The extent of degradation was monitored by release of boron into solution. This data was acquired by Argonne National Laboratory (ANL) under the technical direction of Lawrence Livermore National Laboratory (LLNL). All of this work has been done under contract to DOE (Yucca Mountain Project), which established the Quality Assurance program requirements.

\section{F.3.1 Data Acquired After May 1989}

ANL has maintained a quality assurance program throughout the period of this data acquisition. After May 1989, the data collection was completed under a QA program required by contract to DOE to meet the requirements of the QARD. All of the data were acquired using "The NNWSI Unsaturated Test Procedure," procedure number DP-05-174, for the ANL Unsaturated Glass 
Testing Program. This procedure, which defines the test method, was initially issued 01/15/86 and has been revised throughout the data acquisition period. It has been produced and revised under ANL's QA program. Additional procedures for the operation and calibration of measuring and test equipment, sample preparation and other activities necessary to support the testing were produced and maintained under ANL's QA program. Scientific notebooks, maintained under ANL's QA program, were used to document the data and its acquisition. Both LLNL and DOE (Yucca Mountain Project) have audited ANL's QA program on a scheduled basis. The audits determined that ANL was satisfactorily implementing the QA requirements established by the DOE contract.

The data acquired since May 1989 have been acquired under a QA program meeting the requirements of DOE (Yucca Mountain Project) QARD. These data are therefore qualified.

\section{F.3.2 Data Acquired Before May 1989}

From February 1986 to May 1989, ANL's QA program was maintained to meet contractual requirements set by DOE (Yucca Mountain Project) through the technical direction of LLNL. ANL's activities during this time period were audited by LLNL to confirm satisfactory implementation of the QA requirements. The data acquired during this period were acquired using an earlier revision of the same procedure (DP-05-174) for the ANL Unsaturated Glass Testing Program that was used for data acquisition after May 1989. This procedure identified the measuring and test equipment, and their calibration requirements, required to support the data acquisition under this procedure. The procedure also identified procedures for use in the calibration of the measuring and test equipment. This procedure and the others used to conduct the testing were produced and maintained under ANL's QA program at that time. The measuring and test equipment used in this testing was the same or equivalent to that used in data acquisition after May 1989. The procedure, DP-05-174, through its revision process maintained the same methodology and testing requirements throughout the testing period, $02 / 18 / 89$ to $05 / 30 / 01$.

\section{F.3.3 Data Comparison}

Two data sets are qualified in this appendix. The first set, N2-9 through N2-12, was collected between 03/20/86 and 05/01/89. The second set, N3-9 through N3-12, was collected from $08 / 24 / 87$ to $04 / 03 / 89$. These sets are qualified by comparison with later (qualified) test results from the same test series. The later data collection periods used the same test methods, procedures, equipment, and samples.

Two data sets are used as corroboration in this appendix. The first set, The first set, N2-9 through N2-12, was collected between 10/30/89 and 05/30/01. The second set, N3-9 through N3-12, was collected from 07/06/89 and 06/08/00. Results were compared for cumulative boron release into solution.

When the results are plotted for the entire period of testing for each test (e.g., Figure F-1) it is clear that the unqualified results are consistent with the qualified results and supportive of the overall test objective. The qualification criterion (the data collected before May 1989 must be consistent with the data collected after May 1989) is met. 
(a)

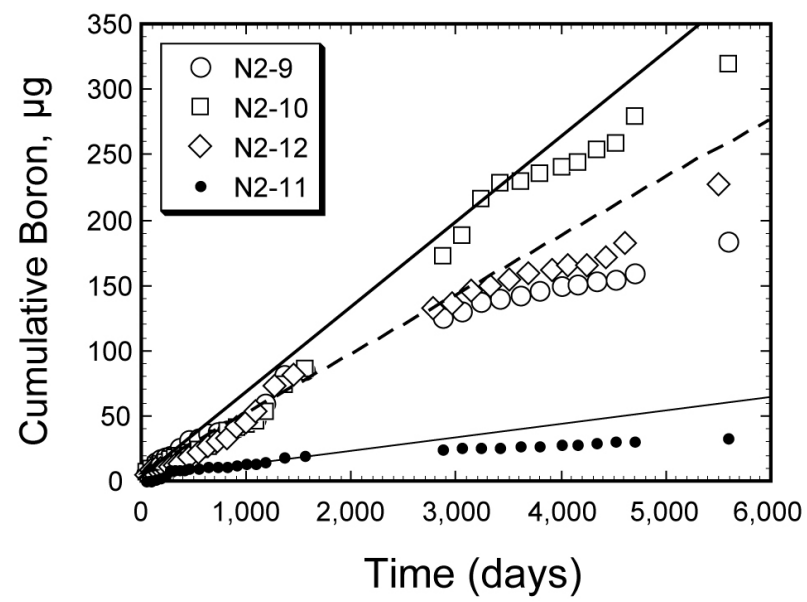

(b)

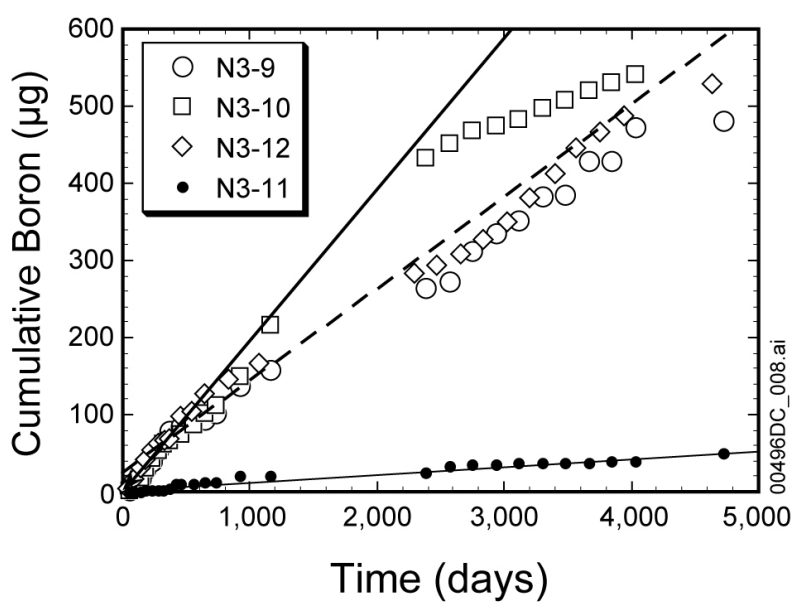

Source: Figure 6-8.

Figure F-1. Cumulative Boron Release in Tests with (a) SRL 165 Glass and (b) ATM-10 Glass

\section{F.4 CONCLUSION}

Based upon the evaluation of the attributes used in the qualification process and the comparison of the corroborating data meeting the qualification criteria, it is concluded that the desired level of confidence needed for this model has been obtained and that the data is qualified for its intended use in this model.

There was no data generated by this qualification report, and there are no limitations or caveats associated with the use of this data in the model. 


\section{INTENTIONALLY LEFT BLANK}


APPENDIX G

DATA QUALIFICATION PLAN 


\section{INTENTIONALLY LEFT BLANK}




\section{G. DATA QUALIFICATION PLAN}

\section{BSC \\ Data Qualification Plan}

QA: QA

\section{Section I. Organizational Information}

Qualification Title

Glass Unsaturated (Drip) Test Results: Boron Release DTN:MO0408ANLGNN01.527

Requesting Organization

Regulatory Integration Team

\section{Section II. Process Planning Requirements}

1. List of Unqualified Data to be Evaluated

DTN MO0408ANLGNN01.527, Glass Unsaturated (Drip) Test Results (BSC Test Plan: SITP-02-WF-002): Boron Release. These are the results of unsaturated (drip) tests conducted to measure the degradation rates of SRL 165 (N2 series) and ATM-10 (N3 series) glasses conducted by dripping tuff groundwater $\left(\mathrm{J}-13\right.$ that had been pre-reacted with tuff at $\left.90^{\circ} \mathrm{C}\right)$ at $90^{\circ} \mathrm{C}$. Extent of degradation monitored by release of boron into solution. Three replicate tests and one blank test in each series.

2. Type of Data Qualification Method(s) [Including rationale for selection of method(s) (Attachment 3) and qualification attributes (Attachment 4)] Corroborating Data:

Demonstration that a comparison of data can be shown to substantiate or confirm parameter values. Using available corroborating data to draw inferences that the qualification of unqualified data can be clearly identified, justified, and documented.

ACTION: Compare the pre-5/89 data with the post-5/89 data (QARD implementation) to demonstrate and document the technical consistency thereby justifying the qualification only for its intended use in Defense HLW Glass Degradation Model,ANL-EBS-MD000016 , Rev. 2

3. Data Qualification Team and Additional Support Staff Required

Qualification Chairperson: Denis Strachan

Data Qualification Team Member: James C. Cunnane

\section{Data Evaluation Criteria}

The Qualification criteria are based on AP-SIII.2Q, Rev. 1, ICN 2, Attributes 1 through 6 and 10 and that the pre-5/89 data must be consistent with the post-5/89 data. The data qualification report will be documented in the model report.

5. Identification of Procedures Used

AP-SIII.2Q, Rev. 01, ICN 02

AP-SIII.10Q, Rev 02, ICN 07

Section III. Approval

Qualification Chairperson Printed Name

Denis Strachan

Responsible Manager Printed Name

Neil Brown

\begin{tabular}{l|l} 
& Dualifigation_Chairpersensignature \\
& $10 / 9 / 04$ \\
\hline ResponsibleMagager signature & Date \\
& $10 / 9 / 04$
\end{tabular}




\section{INTENTIONALLY LEFT BLANK}

